\title{
The Upper Ocean Response to the Monsoon in the Arabian Sea
}

\author{
by \\ Albert Sok Fischer \\ S.M., MIT/WHOI Joint Program in Oceanography, 1997 \\ S.B., Massachusetts Institute of Technology, 1994 \\ Sumitted in partial fulfillment of the requirement for the degree of \\ Doctor of Philosophy \\ at the \\ MASSACHUSETTS INSTITUTE OF TECHNOLOGY \\ and the \\ WOODS HOLE OCEANOGRAPHIC INSTITUTION
}

September 2000

(C) 2000 Albert Sok Fischer. All rights reserved.

The author hereby grants MIT and WHOI permission to reproduce paper and electronic copies of this thesis in whole or in part and to distribute them publicly.

Signature of Author

Joint Program in Physical Oceanography Massachusetts Institute of Technology and Woods Hole Oceanographic Institution 4 August 2000

Certified by 


\title{
The Upper Ocean Response to the Monsoon in the Arabian Sea
}

\author{
by \\ Albert Sok Fischer \\ Submitted in partial fulfillment of the requirements for the degree of \\ Doctor of Philosophy at the Massachusetts Institute of Technology \\ and the Woods Hole Oceanographic Institution \\ 4 August 2000
}

\begin{abstract}
Estimation of the upper ocean heat budget from one year of observations at a moored array in the north central Arabian Sea shows a rough balance between the horizontal advection and time change in heat when the one-dimensional balance between the surface heat flux and oceanic heat content breaks down. The two major episodes of horizontal advection, during the early northeast (NE) and late southwest (SW) monsoon seasons, are both associated with the propagation of mesoscale eddies. During the NE monsoon, the heat fluxes within the mixed layer are not significantly different from zero, and the large heat flux comes from advected changes in the thermocline depth. During the SW monsoon a coastal filament exports recently upwelled water from the Omani coast to the site of the array, $600 \mathrm{~km}$ offshore. Altimetry shows mildly elevated levels of surface eddy kinetic energy along the Arabian coast during the SW monsoon, suggesting that such offshore transport may be an important component of the Arabian Sea heat budget.

The sea surface temperature (SST) and mixed layer depth are observed to respond to high frequency (HF, diurnal to atmospheric synoptic time scales) variability in the surface heat flux and wind stress. The rectified effect of this HF forcing is investigated in a three-dimensional reduced gravity thermodynamic model of the Arabian Sea and Indian Ocean. Both the HF heat and wind forcing act locally to increase vertical mixing in the model, reducing the SST. Interactions between the local response to the surface forcing, Ekman divergences, and remotely propagated signals in the model can reverse this, generating greater SSTs under HF forcing, particularly at low latitudes. The annual mean SST, however, is lowered under HF forcing, changing the balance between the net surface heat flux (which is dependent on the SST) and the meridional heat flux in the model.

A suite of experiments with one-dimensional upper ocean models with different representations of vertical mixing processes suggests that the rectified effect of the diurnal heating cycle is dependent on the model, and overstated in the formulation used in the three-dimensional model.
\end{abstract}

Thesis Supervisor: Robert A. Weller

Senior Scientist, Department of Physical Oceanography

Woods Hole Oceanographic Institution 


\section{Acknowledgements}

The work described in this thesis was funded by the Office of Naval Research (ONR), grant N00014-94-1-0161. In addition, I was supported by a National Defense Science and Engineering Graduate Fellowship and by ONR grant N00014-99-1-0090.

First a very special thanks to Bob Weller, who managed to give me the right balance of guidance and freedom over many years, great data to build from, and lots of cool toys to boot. Thanks also to my committee, who all had a hand in shaping the direction of my research: particularly Ken Brink for providing SeaSoar data, for detailed comments on drafts, and for both his encouragement and prodding, Jim Price for forever being the optimist, Paola Rizzoli for her resolute belief in me, and Mike Spall for his always sage counsel. Bruce Warren agreed to chair my defense, and let me tap into his vast knowledge of and love for the Indian Ocean. And thanks to Glenn Flierl for providing me a repeating and welcome opportunity to help teach. I am also much obliged to Tim Dowling and John Largier for first drawing me deeper into science and research.

Scientific research is at its best when it is collaborative, and many people have assisted me along the way. Dan Rudnick, Charlie Eriksen, Tommy Dickey, and John Marra graciously allowed me free reign with their moored data. Chad Fox and Bob Leben aided greatly by providing me with the altimetric data. Craig Lee helped with the SeaSoar data, and was a great sounding board for many ideas. Jay McCreary gave me not only his model, but a great deal of encouragement, while Ragu Murtugudde was ever amiable despite my abandonment of his model. The Upper Ocean Processes Group has been a great scientific home, and the efforts of Mark Baumgartner, Peter Furey, and Nan Galbraith were of particular assistance. The Pathfinder sea surface temperature data were obtained from the NASA Physical Oceanography Distributed Active Archive Center at the Jet Propulsion Laboratory, California Institute of Technology.

I am exceedingly indebted to my classmates Lou St. Laurent, Stephanie Harrington, and Brian Arbic, from whom I've learned quite a bit of oceanography, and who helped to keep me sane through the years by slowly going crazy alongside me. Also to the Joint Program student community, a thriving and indispensable entity. Particularly Mak Saito, Kirsten Laarkamp, Joe Warren, Brenda Jensen, and Nicole Poulton, my Thesis Support Group this past year; Payal Parekh, François Primeau, Helen Johnson, Patty Kassis, and 
Zan Stine for being excellent officemates and just plain mates; Bill Williams and Jay Austin for introducing me to kayaking; and Judith Wells, Sandra Werner, and Juan Botella for keeping their eyes out for me. And thanks also to my students at Macgregor through the years, who let me ground myself by becoming a part of their life.

I've had the love and support of some incredible friends through these yearsSameera Iyengar, Paulo Pereira, Richard Davis, Charles Armesto, Leanne and Ekrem Soylemez, Cleva Ow Yang. What can I say? Thank you. And a special thanks to Sarah Samuel for all she's brought into my life.

Finally, my thanks go to my family; to Philomena and Dietrich for letting me know I could find my way wherever and however I wished, to Heidi for her brightness and for her discovery of my inner comic, and to Max for sharing with me his sense of adventure. I dedicate this thesis to them. 


\section{Contents}

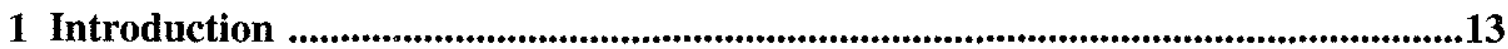

1.1 Outline 14

1.2 Surface forcing and the monsoon 15

1.3 Oceanic response 16

1.3.1 Basinwide response 17

1.3.2 Modeling efforts 19

1.3.3 Recent observations 19

2 Mesoscale eddies and the upper ocean heat budget in the Arabian Sea

2.1 Introduction 23

2.2 Heat budget from the moored array 26

2.2.1 Data 27

2.2.2 Method 30

2.2.3 Uncertainty 37

2.2.4 Results 40

2.2.5 Ekman pumping 47

2.2.6 Discussion 49

2.3 Remote Sensing of the Surface Evolution 50

2.3.1 Data 50

2.3.1.1 Altimetry 50

2.3.1.2 Sea Surface Temperature imagery 53

2.3.2 Northeast Monsoon 54

2.3.3 Southwest Monsoon 58

2.3.4 Wave propagation 63

2.3.5 Basinwide mean and seasonality 63

2.3.6 Discussion 68

2.4 Water mass properties and the mesoscale flow 68

2.4.1 Data 69 
2.4.2 Water mass changes during the SW monsoon 71

2.4.3 Water mass changes during the NE monsoon 75

2.4.4 Structure of the SW monsoon coastal filament 75

2.5 Summary and discussion 78

\section{Rectification of high-frequency heat and wind forcing in an Arabian Sea model 81}

3.1 Introduction 81

3.1.1 High-frequency surface forcing 81

3.1.2 Rectification of high-frequency surface forcing 83

3.1.2.1 One-dimensional model of the Arabian Sea upper ocean response 83

3.1.2.2 Rectification 87

3.1.2.3 Modeling background 89

3.1.3 Approach 90

3.2 The 4-1/2 layer model and surface forcing 91

3.2.1 The model equations 91

3.2.2 Numerical method 98

3.2.3 Surface forcing 100

3.3 Mean forced solution 102

3.3.1 SW monsoon 102

3.3.2 NE monsoon 108

3.3.3 Annual mean 111

3.3.4 Buoy site 112

3.3.5 Summary 115

3.4 Diurnally forced solution 115

3.4.1 SW monsoon 116

3.4.2 NE monsoon 124

3.4.3 Buoy site 130

3.4.4 Point heat budget 132

3.4.5 Annual mean fields 136

3.4.6 Basinwide mass, temperature, and heat budgets 138

3.4.7 Summary 147

3.5 ECMWF wind-forced solution 148

3.5.1 Differences introduced by the wind climatologies 151

3.5.2 SW monsoon 154

3.5.3 NE monsoon 161

3.5.4 Buoy site 166

3.5.5 Annual mean 170

3.5.6 Meridional mass and heat transport 172

3.5.7 Summary 176

3.6 High frequency wind and diurnal heating 176

3.6.1 Monsoon seasons and annual mean circulation differences 177 
3.6.2 Buoy site 177

3.6.3 Meridional mass and heat transport 184

3.7 Summary and discussion 185

4 Sub-mixed layer mixing in one-dimensional upper ocean models

4.1 Introduction 193

4.2 The models 194

4.2.1 McCreary KT layered formulation 195

4.2.2 PWP model 196

4.2.3 KPP model 197

4.3 The effect of the diurnal cycle under idealized wind and heat forcing 198

4.4 Variations in latitude 202

4.5 Seasonal cycle 204

4.6 Discussion 208

5 Conclusion

References 
I have bedimm'd

The noontide sun, call'd forth the mutinous winds, And 'twixt the green sea and the azur'd vault Set roaring war;

- Prospero, The Tempest William Shakespeare 


\section{Chapter 1}

\section{Introduction}

The Arabian Sea is a unique environment for studying the forced upper ocean response, with strong and distinct atmospheric forcing regimes, and a clear separation in the time domain between mesoscale oceanic variability and variability in the atmospheric forcing. It is influenced by a unique monsoonal seasonal cycle, with strong reversing wind forcing, a strongly evaporative freshwater flux over most of the basin, and strong annual mean heat gain.

Two primary tasks are undertaken in this thesis. The first is to use observations on a number of different scales to quantify and characterize the upper ocean heat budget and the processes affecting it (among them mesoscale variability, coastal upwelling and offshore transport) in the central Arabian Sea. The second is to identify the effect of highfrequency (diurnal time scale for heat and synoptic time scale for wind) surface forcing on vertical mixing, and to consider how this changes the dynamic and thermodynamic response of a three-dimensional model of the Arabian Sea. Finally, the robustness of the results of the 3-D modeling are examined by considering how sensitive the response to high-frequency forcing is to the model formulation, under a wide range of surface forcing, and under the seasonal cycle of the monsoon. 


\subsection{Outline}

The rest of this chapter is devoted to setting the context for what will follow. The surface forcing over the Arabian Sea is dominated by the seasonal cycle of the monsoon, described in the following section. The ocean responds quite clearly to this forcing, and the final section of this chapter gives an overview of previous studies of the Arabian Sea oceanic response to the monsoon, from observations and modeling. It also summarizes some of the important results from recent fieldwork in the Arabian Sea.

The subject of Chapter 2 is the upper ocean heat budget and the processes that contribute to it. My approach begins with the use of data from a moored array to quantify the terms in the upper ocean heat budget, including the horizontal advective flux. Then additional data from remote sensing and a SeaSoar survey are used to determine the context and general spatial distribution of observed large horizontal advections, and to identify the water mass properties and spatial structure of a coastal filament which reaches the site of the moored array.

Observations at the moored array show rapid diurnal cycling in the mixed layer depth, and the response of the upper ocean to short time scale synoptic variability in the wind forcing. Inspired by this, in Chapter 3 I discuss the potential increase in vertical mixing and exchange forced by high-frequency forcing, then use a three-dimensional circulation model of the Indian ocean to examine the effect of high-frequency wind forcing and the diurnal cycle in the surface heat flux on the predictions of oceanic evolution.

In a complement to the modeling work in Chapter 3, the subject of Chapter 4 is how the increased vertical exchange driven by diurnal cycling is sensitive to the model formulation, and the physical processes represented by different models.

Finally, Chapter 5 provides a summary and discussion of the major results of the thesis. 


\subsection{Surface forcing and the monsoon}

The seasonal reversal of the atmospheric monsoon circulations are a major feature of the tropics. The principal monsoon systems are shown in Fig. 1.1 [Webster, 1987]. Surface winds stretch across the equator from the wintertime to the summer hemisphere, particularly in the eastern hemisphere, dominated by the north-south land-sea contrast provided by the continent of Asia. These circulations are driven by the differential surface heating caused by the large contrast in the specific heat capacity, and thus the temperature response to insolation, of the land and ocean surfaces.
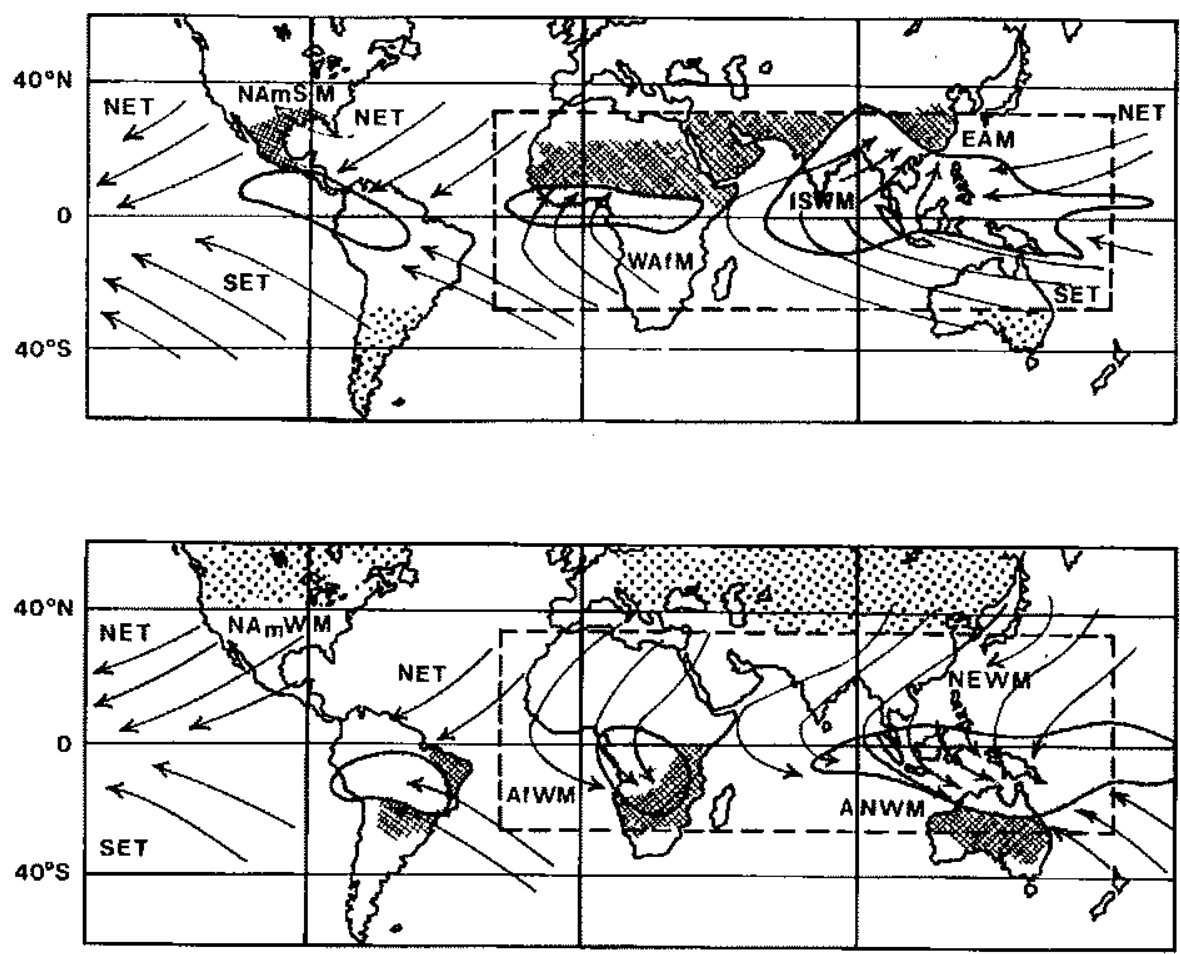

Figure 1.1 The principal monsoon systems in the boreal summer (top) and winter (bottom). Shaded areas indicate rainfall maxima and cross-hatched areas have the highest surface temperatures. Mean winds are marked by the arrows. After Webster [1987]. 
Over the Arabian Sea, the monsoon circulation leads to a seasonal cycle of cold, dry northeasterly winds during the winter northeast (NE) monsoon, and warm, moist, and very strong southwesterly winds during the summer southwest (SW) monsoon. A unique feature of the SW monsoon winds over the Arabian Sea is the development of a remarkably strong and steady wind jet first described by Findlater [1969]. The Findlater Jet (Fig. 1.3) has some of the strongest and steadiest surface winds to be found, with speeds in excess of $15 \mathrm{~m} \mathrm{sec}^{-1}$. The wind stress patterns associated with the Findlater Jet force oceanic upwelling to the northwest and convergence and downwelling to the southeast.

Surface heat flux climatologies [Josey et al., 1999] show that during the SW monsoon the mean heat flux over the Arabian Sea is everywhere positive, with values averaging between $30-60 \mathrm{~W} \mathrm{~m}-2$, though much higher along the Arabian coast, where the SW monsoon winds generate active coastal upwelling. Older climatologies often indicated a net heat loss over the Arabian Sea during the SW monsoon associated with wind-driven strong latent heat fluxes. In fact the latent heat fluxes are limited by the near-saturation of the air [Weller et al., 1998], which also reduces the longwave heat loss. During the NE monsoon, there is a mild heat loss over the northern Arabian Sea. In the annual mean the net surface heat flux is positive everywhere over the Arabian Sea.

\subsection{Oceanic response}

The strong seasonal cycle in the surface forcing over the Arabian Sea leads to a strong seasonal cycle in the circulations of the western Arabian Sea. Outside of the regions of SW monsoon coastal upwelling, the SSTs are generally quite high (averaging between 27 and $29^{\circ} \mathrm{C}$ ), and thus even small variations in temperature may produce significant impacts to the atmospheric circulation [Palmer and Mansfield, 1984]. No definitive links between the Arabian Sea SST and the strength of the monsoon circulation have been found, though Shukla [1987] found a correlation between heavy monsoon rainfall and subsequent negative SST anomalies. The net annual heat input into the ocean over the Arabian Sea must also be carried southward by the ocean circulation, and forms an 
important part of the total combined atmospheric-oceanic meridional heat transport in the Indian Ocean sector [Hastenrath and Greischar, 1993], both on the seasonal and the annual mean time scales.

\subsubsection{Basinwide response}

The strongest oceanic response to the seasonal surface forcing is the annual reversal of the Somali current on the basin's western boundary [Schott, 1983]. During the SW monsoon, the northward flowing Somali current has a strong transport and peak currents up to $3.7 \mathrm{~m} \mathrm{sec}^{-1}$. The strong currents give rise to a strong mesoscale eddy field. The wind field leads to upwelling along the Arabian coast. Associated with this SW monsoon upwelling region, persistent jets of cold upwelled water are observed extending from the Omani coast, often reaching hundreds of kilometers into the interior.
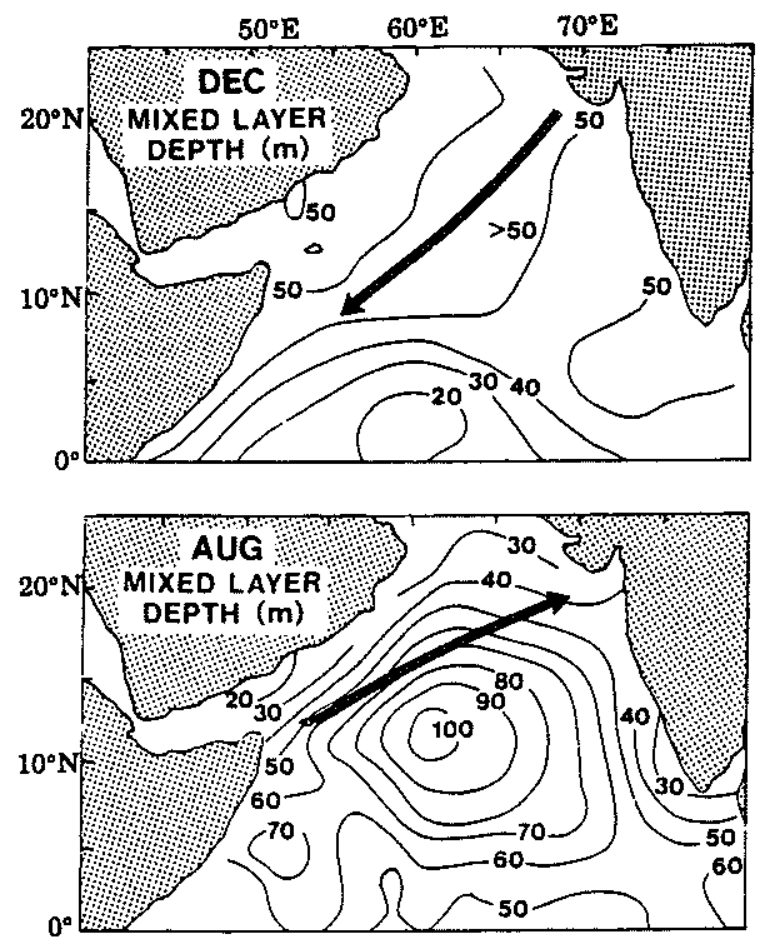

Figure 1.2 The NE and SW monsoon mixed layer depth climatology, with the axis of the wind maximum marked by the arrow. After [Bauer et al., 1991]. 


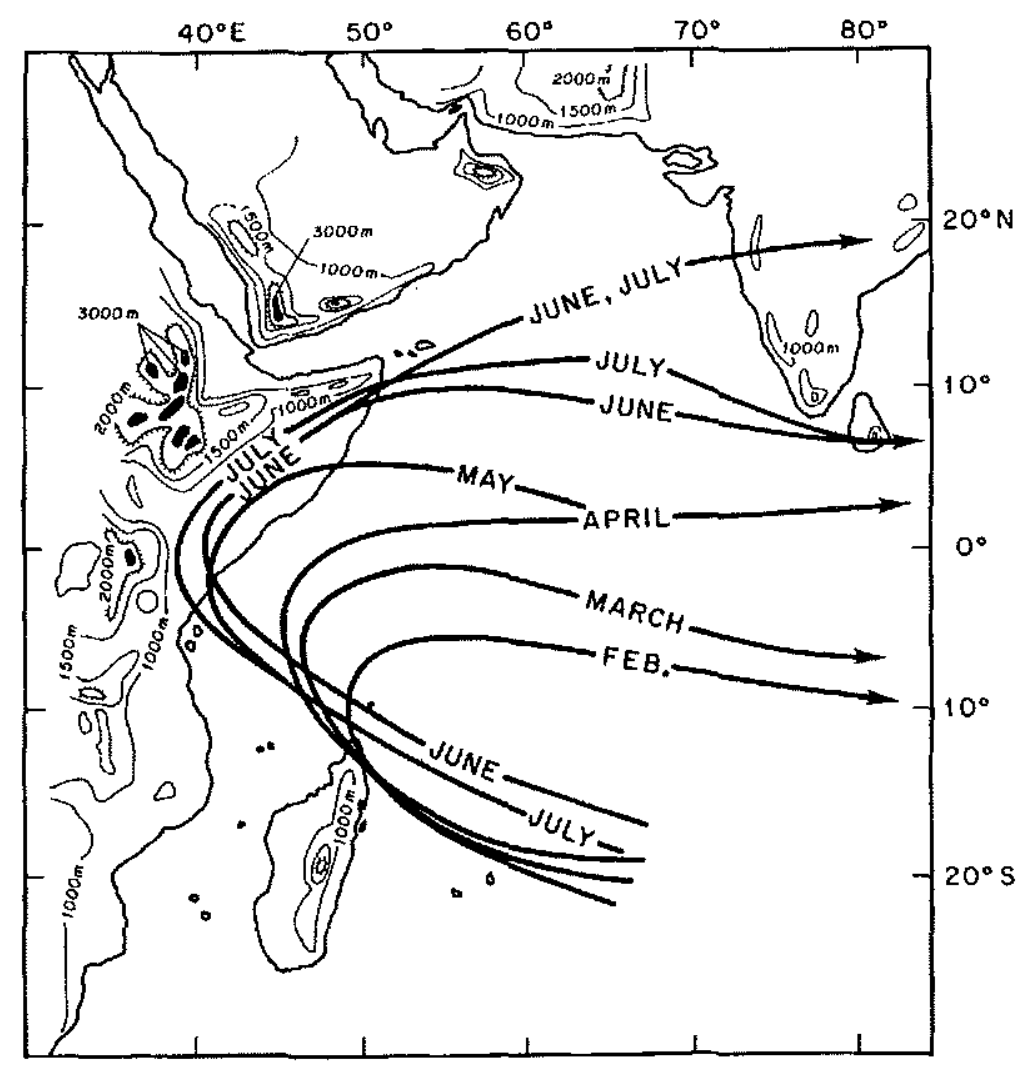

Figure 1.3 The climatological mean position of the maximum in the Findlater Jet over the Arabian Sea, after Knox [1987].

A striking feature of the upper ocean [Rao et al., 1989] is the deepening and cooling of the mixed layer in the central northwestern Arabian Sea during both the SW and NE monsoon seasons. A canonical explanation for the deepening and observed gradients in mixed layer depth during the SW monsoon is given by Bauer et al. [1991] (Fig. 1.2), who propose that shoreward of the Findlater jet, open-ocean upwelling pulls the thermocline closer to the surface, yielding shallower mixed layers, while on the offshore side, wind stress curl-driven downwelling deepens the mixed layers. More recently Lee et al. [2000] have shown that variations in turbulent wind-driven entrainment are more likely to be the cause of this gradient in mixed layer depth, though this cannot fully explain the observed mixed layer depth patterns, which are likely also influenced strongly by horizontal advection [Rao et al., 1989]. 


\subsubsection{Modeling efforts}

A number of predictive models of the Arabian Sea and Indian Ocean circulations, using monthly mean climatological forcing fields (including McCreary et al. [1993], Bruce et al. [1998], Murtugudde et al. [1998]), capture the basic features and timing of major currents and temperature variations. Other modeling studies have focused on the heat transport and meridional overturning circulation in the Indian Ocean (Wacogne and Pacanowski [1996], Garternicht and Schott [1997], and the related modeling studies Lee and Marotzke [1997] and Lee and Marotzke [1998]). In each, the surface Ekman drift, which in the northern Indian Ocean is southward in the annual mean, driven by the strong SW monsoon winds, is an important component of the meridional heat flux. This southward transport of warm water is replaced by upwelled water, which in the northern Indian Ocean is supplied by a generally shallow northward flow in the thermocline, although the models differ in the details of this transport.

Modeling work [Keen et al., 1997; Young and Kindle, 1994] has also suggested that offshore advection of coastal upwelling is an active process in the Arabian Sea, contributing to productivity in the center of the basin.

\subsubsection{Recent observations}

Recent field work in the Arabian Sea has provided some new insight into the dynamics of the upper ocean, particularly during the SW monsoon. The Forced Upper Ocean Dynamics experiment in 1994 and 1995 focused on the physical and bio-optical upper ocean response to the strong monsoonal forcing in the Arabian Sea, and was conducted in concert with the U.S. JGOFS Arabian Sea Expedition [Smith et al., 1998]. Investigations included a ship-borne ADCP survey [Flagg and Kim, 1998], which found that the predominant velocity signal in the north central Arabian Sea, in the JGOFS survey marked in Fig. 1.4 and away from the Somali current, was that of mesoscale eddies, with elevated levels of eddy kinetic energy along the Arabian coast. A series of four SeaSoar surveys [Lee et al., 2000] captured the variability of the upper ocean across the axis of the 

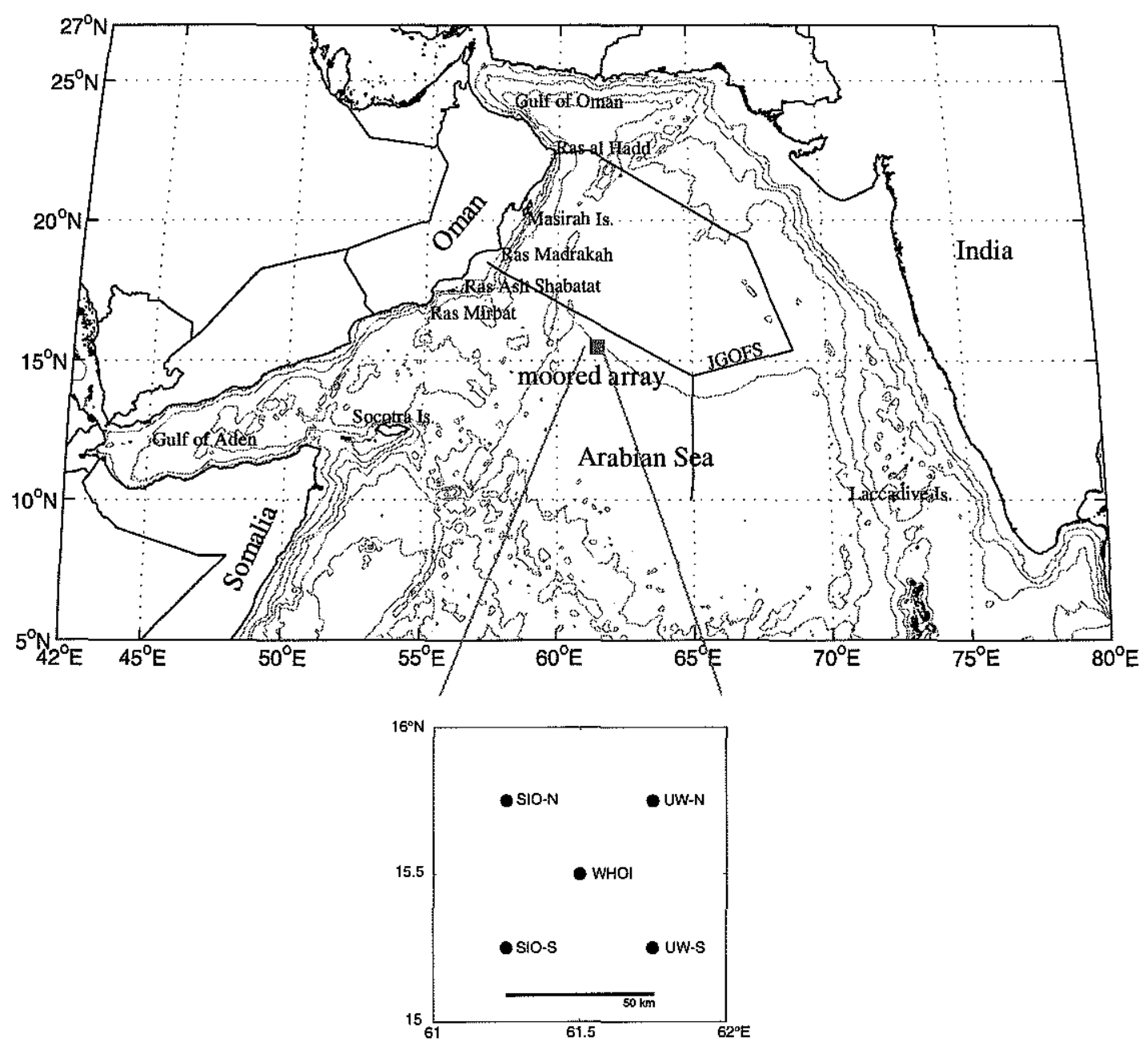

Figure 1.4 The moored array, marked by the gray square, in the north central Arabian Sea, was one component of the Forced Upper Ocean Dynamics Experiment. The black line marks the line formed by the stations of the JGOFS survey, and the repeated track of ADCP observations. Seasoar sections were taken along the southern line and in 'radiator' sections inshore and offshore of the moored array. The inset shows the pattern of moorings in the array, which measured about $50 \mathrm{~km}$ per side. Gray contours mark depth at $200 \mathrm{~m}$, and every $1000 \mathrm{~m}$ thereafter.

Findlater Jet, as well as a forming coastal filament. This features was also seen in satellite imagery [Brink et al, 1998; Arnone et al., 1996; Manghnani et al., 1998].

The work here builds on the observations made at a moored array located in the north central Arabian Sea $\left(15.5^{\circ} \mathrm{N}, 61.5^{\circ} \mathrm{E}\right.$, Weller et al. [1998]). An overview of the data 


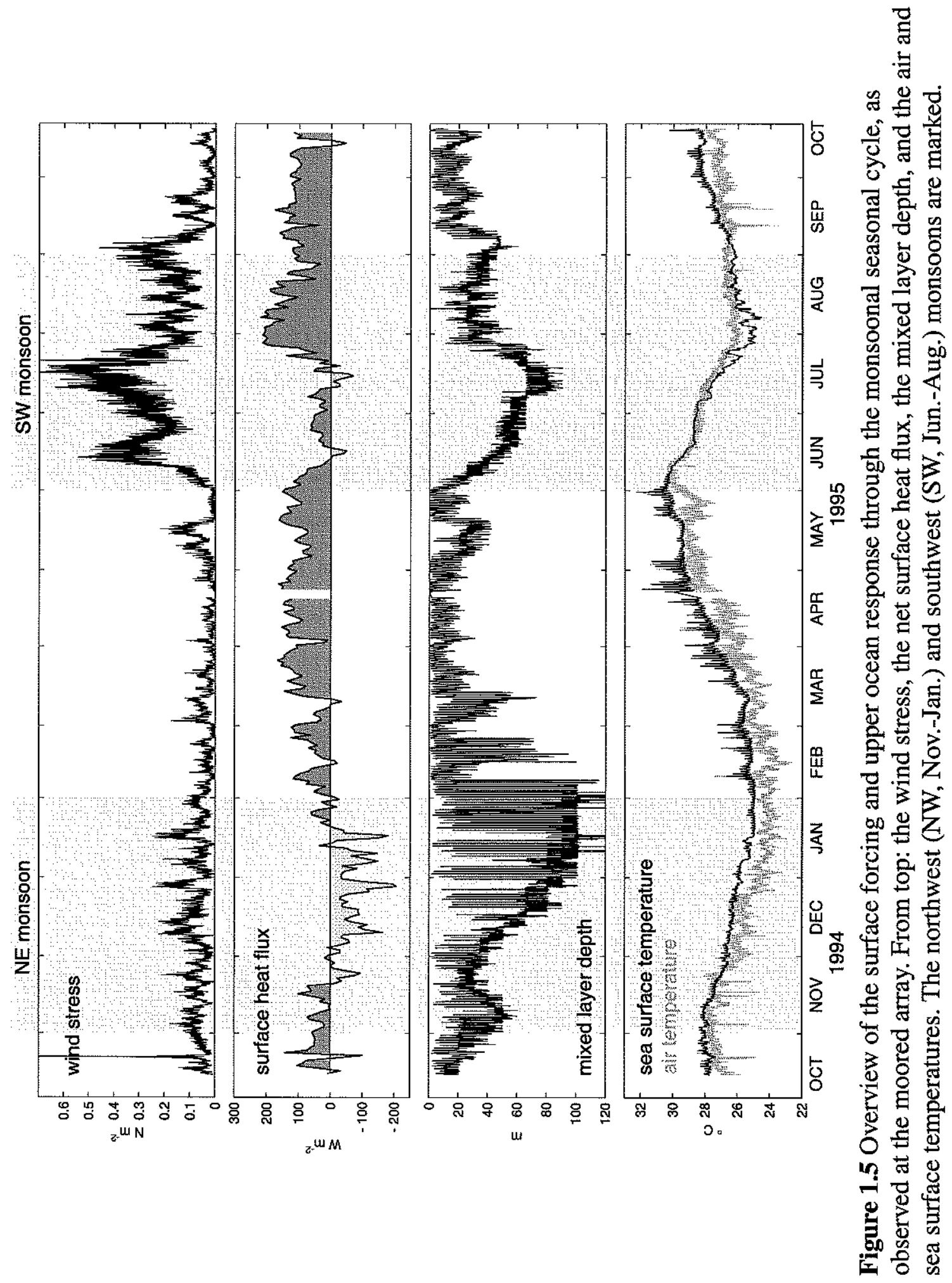


from the central mooring in the array is shown in Fig. 1.5. The surface forcing and response is dominated by the signals of the two monsoon seasons. The NE monsoon (November-January) is marked by a negative (oceanic cooling) surface heat flux and moderately elevated winds, while the SW monsoon (June-August) has a generally moderate to strong positive heat flux and very strong wind stresses. The oceanic response at the site of the mooring to both monsoons is similar: a deepening and cooling of the mixed layer. During the NE monsoon this is locally driven primarily by convective cooling and during the SW monsoon by wind-driven entrainment [Fischer, 1997].

A comparison of the surface fluxes measured at the site of the central WHOI buoy in the array with products from various numerical weather predictions and climatologies built some confidence in particular products. The Fleet Numerical (FNMOC), National Centers for Environmental Prediction (NCEP) and European Centre for Medium-Range Weather Forecasting (ECMWF) analysis wind stresses matched the buoy winds well, while the Southampton Oceanography Centre surface heat flux climatology [Josey and Oakley, 1997; Josey et al., 1999] for 1994-1995 had a very similar seasonal cycle of net surface heat flux, including a SW monsoon net heating, which was lacking in a number of other heat flux climatologies.

The next chapter in this thesis builds on these recent observations made in the Arabian Sea. 


\section{Chapter 2}

\section{Mesoscale eddies and the upper ocean heat budget in the Arabian Sea}

\subsection{Introduction}

The upper ocean heat budget is influenced by numerous factors, among them solar heating, surface heat losses, turbulent and convective entrainment, horizontal heat flux divergences (advection), and vertical advection induced by Ekman pumping or associated with mesoscale flows. A number of models have successfully treated the mixed layer as being governed by one-dimensional processes [Price et al., 1986; Large et al., 1994], ignoring horizontal and vertical advection. But in a region of strong oceanic gradients Rudnick and Weller [1993] found that the horizontal advection of heat was the dominant term in the upper ocean heat balance. The horizontally-advective terms have also been found important in the western Pacific warm pool region [Feng et al., 1998], in the upper ocean heat and salinity budgets. In the eastern North Atlantic subduction region, Spall et al. [2000] found both horizontal and vertical advection important in the annual mean heat budget of the upper ocean.

During the ONR-sponsored Forced Upper Ocean Dynamics experiment, conducted in coordination with the U.S. JGOFS Arabian Sea Expedition [Smith et al., 1998], an effort 
was made to assess the relative contributions of these various processes. A moored array of surface and subsurface moorings sampled the upper ocean from October 1994 to October 1995, covering a full monsoonal cycle. The array took observations of the evolution of the vertical structure at four sites and allowed estimations of the surface forcing from surface meteorology, oceanic horizontal gradients and velocities, and thus advective fluxes.

The net surface heat flux has a strong diurnal cycle, though its daily mean varies on the synoptic to seasonal time scales (see Fig. 1.5). During the NE monsoon, it is generally negative, with the ocean losing heat. During the intermonsoon seasons it is strongly positive, and generally positive during the SW monsoon, except during the few days when the wind stress reaches its maximum. Estimation of the one-dimensional heat balance using the central mooring in the array [Weller et al., 2000] suggests that there is a reasonable balance between the input of heat through the surface heat flux and the oceanic heat gain for certain periods of the year (Fig. 2.1), when the oceanic heat gain is integrated from the surface to below a depth where losses from turbulent fluxes are thought to be important. These windows include the end of the NE monsoon and through the spring intermonsoon, and the end of the SW monsoon and the fall intermonsoon. There are some major departures from this balance, notably in November and December, and in June and July. During these periods the heat content of the upper ocean changes rapidly owing to a process other than the surface heat flux.

The main goals of the work in this chapter are to quantify the upper ocean heat budget at a highly instrumented site in the central Arabian Sea, and identify the physical processes associated with the dominant terms. Data from the moored array allow an estimation of some of the major terms in the heat budget: the temperature trend, the surface heat flux, and the horizontal advective heat flux. A rough balance between the temperature trend and the horizontal heat flux is found in the early NE monsoon, and in the latter part of the SW monsoon, precisely when the one-dimensional heat budget fails, and is the subject of the following section. 


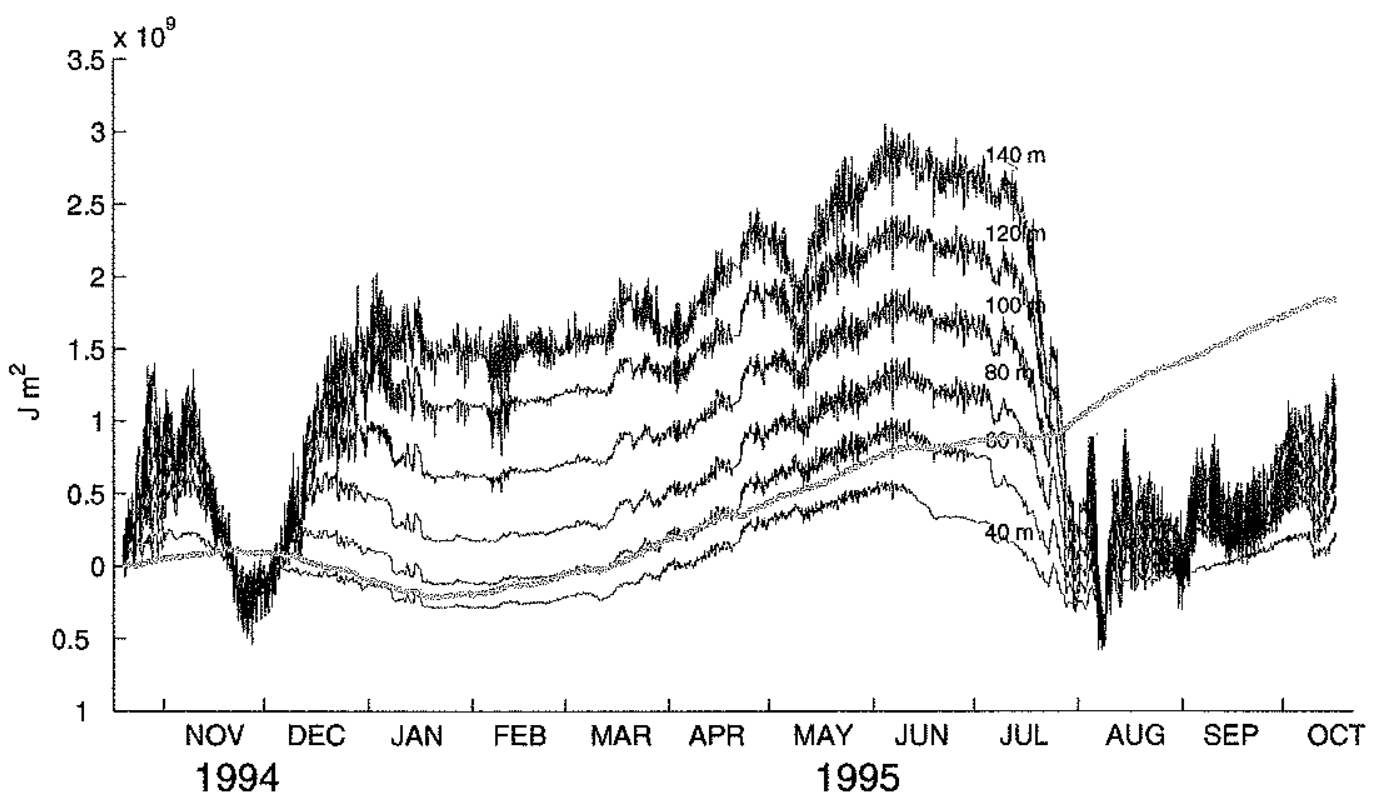

Figure 2.1 One-dimensional balance between heat in the ocean, integrated to a fixed depth (thin black lines) and the heat transferred by the surface heat flux (thick gray line). When the slopes of each match, the oceanic heat gain is roughly in balance with the net surface heat flux. This occurs at the end of the NE monsoon and through the spring intermonsoon (January-May), and roughly, at the tail end of the SW monsoon and into the fall intermonsoon (August-October). The periods of major departure from this 1-D balance are during the early NE monsoon (Octoberearly December) and the SW monsoon (June and July).

To build on the understanding afforded by the limited spatial but high temporal resolution of the moored array, a number of additional data sources are consulted. Satellite altimetry and sea surface temperature imagery have reasonable spatial resolution of the mesoscale features which are found to be associated with the strong horizontal advective fluxes at the moored array, and are the subject of Section 2.3. The cooling of the mixed layer during the SW monsoon is found to be in part associated with offshore export of coastally upwelled water in a well-defined filament. In addition to providing a broader spatial context to describe the observed horizontal heat fluxes, the now seven year long record of altimetry over the Arabian Sea allows a characterization of the spatial distribution and seasonality of the mesoscale energy, and thus some information on how charac- 
teristic the moored site is compared to the rest of the basin. The filament structure and offshore export of upwelled water are the focus of Section 2.4. While the moored observations have high time resolution and limited spatial resolution, four SeaSoar (towed, undulating CTD) surveys with high spatial resolution both horizontally and vertically were made during the year. One of these surveys captured a snapshot of the filament as it moved offshore, before reaching the site of the mooring. A comparison of the temperature and salinity characteristics of the filament waters and the time evolution of these characteristics at the array is consistent with the offshore export of coastally upwelled water in the filament. In addition, the SeaSoar survey affords a view of the structure of the filament, with higher spatial resolution than possible with the remotely sensed data.

The combination of these three types of data, from the moored array, remotely sensed from satellites, and from the SeaSoar survey, yields an integrated picture of the physical processes affecting the upper ocean heat budget in the Arabian Sea, one impossible to form with any one type of data alone, and is the subject of the discussion in the closing Section 2.5.

\subsection{Heat budget from the moored array}

The data from the moored array are used to estimate the terms of the equation of the conservation of heat,

$$
\rho_{0} C_{p}\left[\frac{\partial T}{\partial t}+\mathbf{u} \cdot \nabla T+w \frac{\partial T}{\partial z}\right]=\left(\frac{\partial}{\partial z}\right)(q-r)
$$

where $T$ is the temperature, $t$ is time, $\mathbf{u}$ is the vector horizontal velocity, $\nabla$ is the horizontal gradient operator, $w$ is the vertical velocity, $z$ is the vertical coordinate (positive upwards), $q$ is the penetrating solar heat flux, $r$ is the turbulent heat flux, $\rho_{0}$ is a reference density (assumed constant at $1025 \mathrm{~kg} \mathrm{~m}^{-3}$ ) and $C_{p}$ the specific heat capacity of seawater (assumed constant at $\left.3994 \mathrm{~J} \mathrm{~kg}^{-1} \circ \mathrm{C}^{-1}\right)$. The trend in heat $\left(\rho_{0} C_{p} T\right)$, plus horizontal and vertical advection of heat, are balanced by the vertical divergence of solar and turbulent 
heat fluxes.

Turbulent fluxes were not measured at the moored array, so after examination of the vertically-resolved horizontal heat flux, the terms in the vertically-integrated conservation of heat are estimated:

$$
\rho_{0} C_{p}\left[\int_{-h}^{0} \frac{\partial T}{\partial t} d z+\int_{-h}^{0} \mathbf{u} \cdot \nabla T d z+\int_{-h}^{0} w \frac{d T}{d z}\right]=Q_{0}
$$

where the depth $-h$ is assumed to be below the depth of turbulent fluxes. The first term on the left hand side is the temperature trend (which is estimated from the observed changes in temperature), the second the horizontal advection of heat (estimated from the velocity and temperature gradients across the array), and the third term is the vertical advection of heat, and is a residual term, since the vertical velocity is also not directly measured. The right hand side, $Q_{0}$, is the surface heat flux (measured at the central element of the array). The vertical integration below the depth of turbulent penetration has eliminated the turbulent flux divergence. Limited by instrument depth, the depth $-h$ is here always $125 \mathrm{~m}$, which is well below the maximum depth of the mixed layer (about $100 \mathrm{~m}$ during the NE monsoon). Each of the terms in (2.2) has units of $\mathrm{W} \mathrm{m}^{-2}$, and can be compared directly.

\subsubsection{Data}

The location for the moored observations, centered at $61.5^{\circ} \mathrm{E}, 15.5^{\circ} \mathrm{N}$, was selected for its proximity to the climatological axis of the atmospheric Findlater Jet and its distance from the complicating effects of the coast (see Fig. 1.4). Five elements were deployed in a square approximately $55 \mathrm{~km}$ on each side (Fig. 2.2) in $4020 \mathrm{~m}$ water depth, from October 1994 to October 1995. Surface meteorological and subsurface oceanographic instrumentation on the moorings yielded the first concurrent, high quality record of near-surface atmospheric forcing and upper ocean response over the full monsoonal cycle [Weller et al., 1998]. The elements making up the array had two deployments, the first from October through April, covering the NE monsoon and the spring intermon- 
soon, and the second a redeployment from April through October, with newly calibrated sensors in place for the SW monsoon and the shorter fall intermonsoon.

The two eastern elements were subsurface profiling current meters (PCMs), measuring a profile of currents, temperature and salinity between 20 and $200 \mathrm{~m}$ every four hours. Only the southern PCM mooring, UW-S, returned data. The two western elements were surface toroid buoys, SIO-N and SIO-S, each of which supported a downward-looking Acoustic Doppler Current Profiler (ADCPs) and a series of temperature recorders spaced along the mooring line. The central element was a surface discus buoy, WHOI, which supported a series of instruments measuring temperature, salinity, and currents. The surface moorings were instrumented with basic meteorological sensors, and the central mooring additionally with measurements of the incoming shortwave and longwave radiation. The central mooring surface meteorological data were then used to estimate the surface heat flux for the array.

The spacing of the elements was designed to resolve the typical horizontal variability in the ocean based on satellite imagery and the local Rossby radius of deformation (the first baroclinic mode deformation radius is $64 \mathrm{~km}$, based on a CTD cast at the site of the central mooring). A pre-deployment XBT survey of the area surrounding the array site found horizontal variations on the order of $1.0-1.5^{\circ} \mathrm{C}$, with scales much larger than the spacing of the array elements. Estimates of the horizontal decorrelation length scale of temperature from four SeaSoar surveys [Lee et al., 2000] varied from 25 to $100 \mathrm{~km}$ depending on the time of year and distance offshore. Horizontal variability on the small end of these estimates, not resolved by the array, may be a source of unaccounted error in the calculation. Salinity and chlorophyll concentration both had significantly smaller scales than temperature, though there is no attempt to resolve them in the array.

The data return in temperature and velocity, the two elements required to estimate the horizontal heat flux, is quite good (Fig. 2.2). All four elements of the array returned data in temperature and velocity for the first deployment (October 1994-April 1995), while during the second deployment, the triangle formed by the three moorings SIO-S, WHOI, and UW-S are used in the calculation due to the failure of the majority of the tempera- 

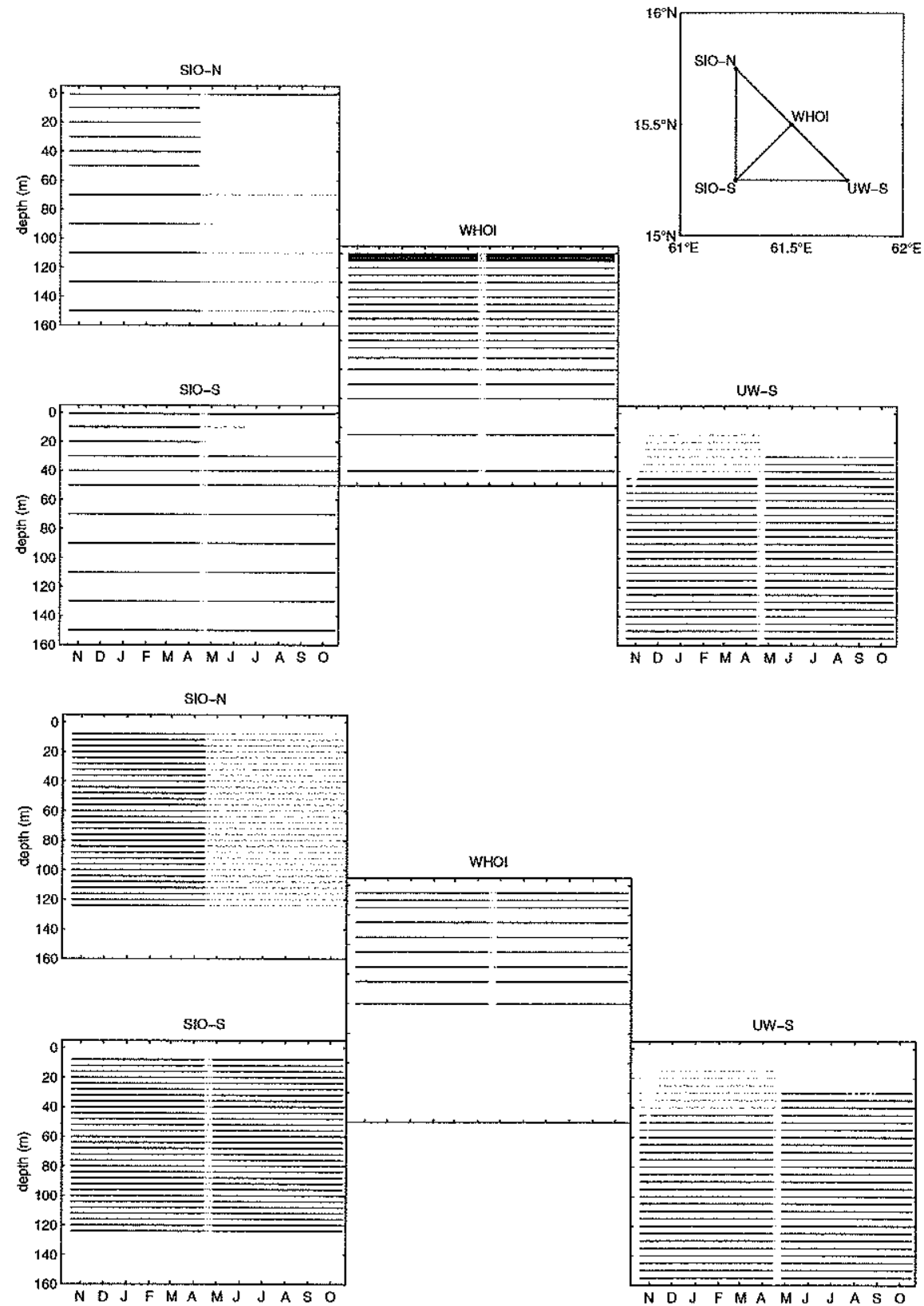

Figure 2.2 The data coverage of the moored array in (top) temperature and (bottom) velocity. The horizontal axis is time, marked in months (1994-95) and the vertical axis is depth. Dark lines indicate data actually used in the advective flux estimate. During the first deployment data from all four moorings are used, while during the second deployment data are drawn largely from SIO-S, WHOI, and UW-S, except for surface temperature from SIO-N, due to instrument failures. Mooring tilt caused by strong currents in November 1994 limited the upper extent of the UW-S PCM instrument, which was set closer to the surface than desired. 
ture recorders on the SIO-N mooring. Since UW-S had no near-surface instrumentation, with a minimum depth of about $20 \mathrm{~m}$, the surface temperature and gradient is estimated from the triangle defined by SIO-N, SIO-S, and WHOI, estimated for the central point of the original triangle during this second deployment. The data included in the calculation are averaged to four hours, the time base of the UW-S PCM profiles.

The terms in the conservation of heat are estimated for the central point of the four (three) moorings used in the first (second) deployment. The horizontal gradient in temperature is estimated from the moored point measurements.

\subsubsection{Method}

The data contain variability on all spatial and time scales, including those unresolved by the array. The data are first filtered using a truncated series of empirical orthogonal functions (EOFs), which extracts the variability that is coherent across the array [Rudnick and Davis, 1988]. The EOFs are the ordered series of eigenvectors of the covariance matrix of the measurements. Because of the widely varying vertical spacing between measurements over the four moorings, the covariance matrix is weighted by a representative height, so that in this case the EOFs are the eigenvectors of the weighted covariance [Müller and Siedler, 1992]

$$
\overline{u_{i}(t) \cdot u_{j}(t)} \cdot \sqrt{h_{i} h_{j}}
$$

Here $u_{i}(t)$ and $u_{j}(t)$ are two time series of temperature or velocity, and $h_{i}$ and $h_{j}$ are the representative vertical range associated with each time series. In this way the average variance over depth is represented in the EOFs, and highly sampled portions of the ocean are not overrepresented.

The first two EOFs in temperature and velocity are shown in Fig. 2.3 and Fig. 2.4, for each deployment. The first two EOFs in temperature, and the first in velocity, have uniform vertical structure across the array, for both deployments. The first EOFs are associated with between $74 \%$ and $90 \%$ of the variability, and the spectra of the time series 

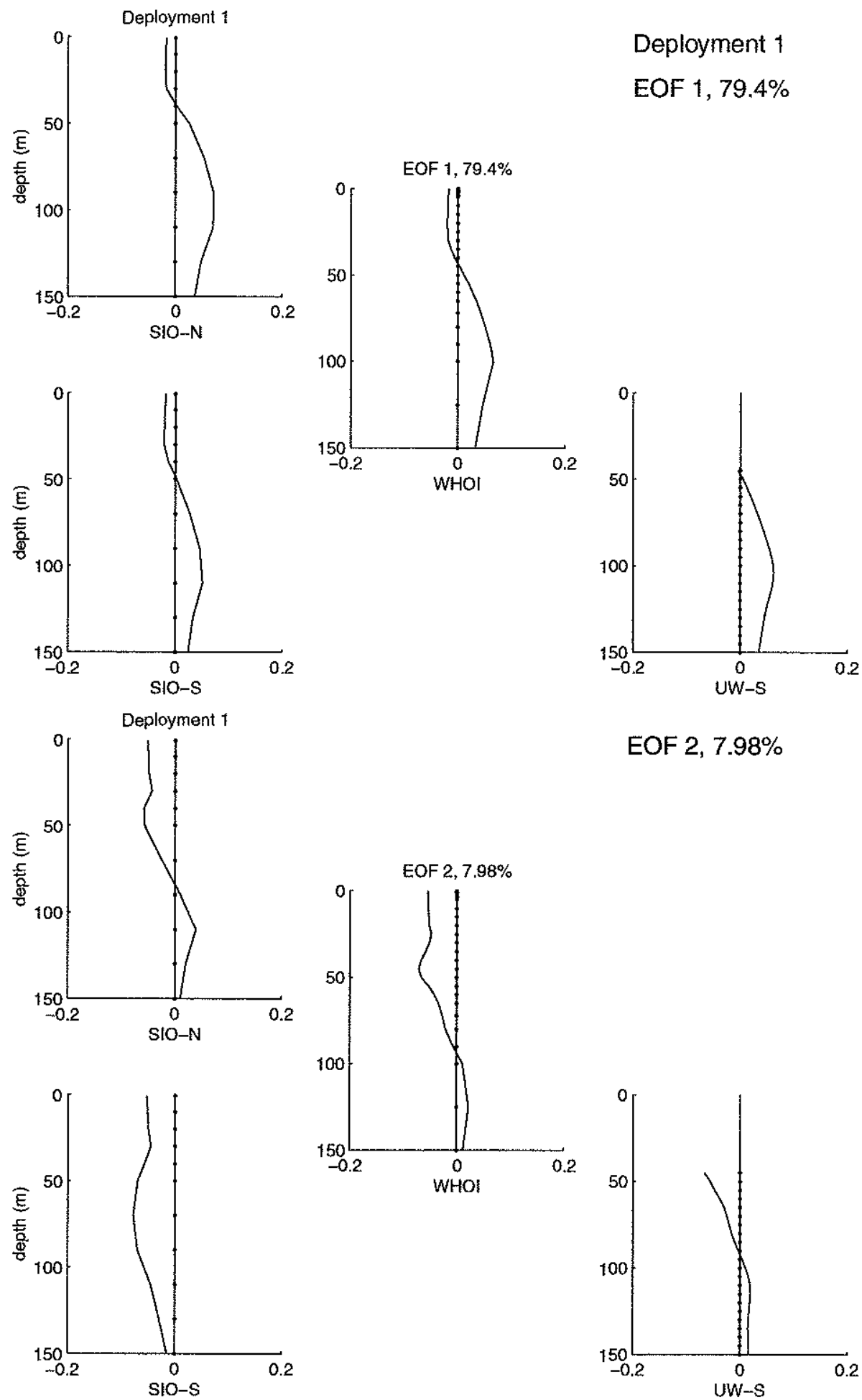

EOF $2,7.98 \%$

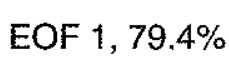



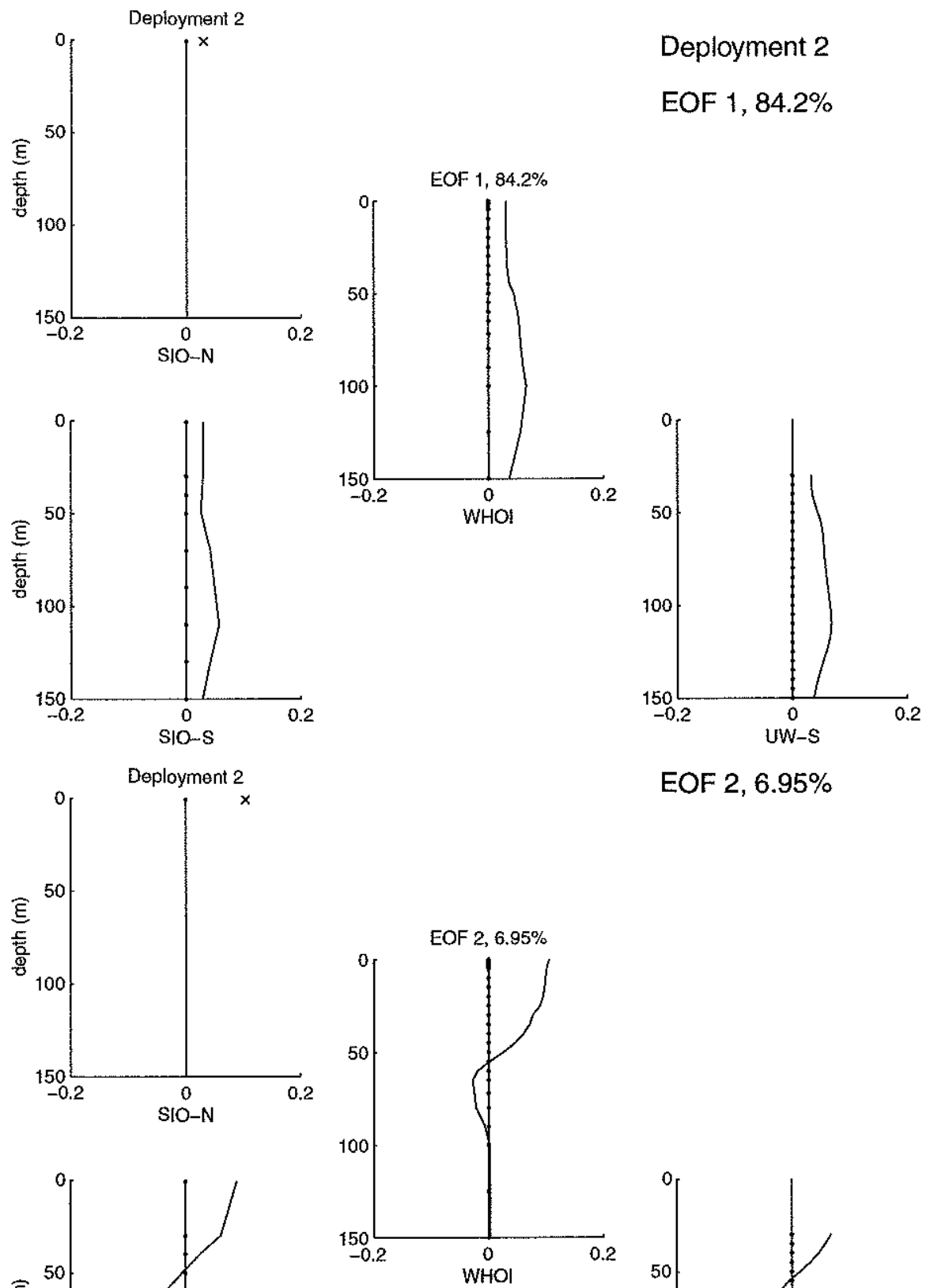

EOF 2, 6.95\%
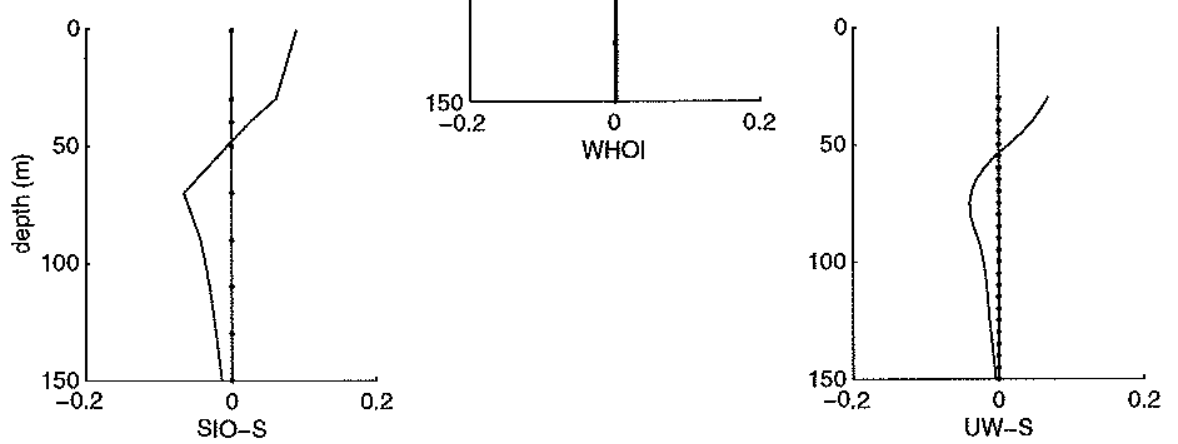

Figure 2.3 B The first two array EOFs of temperature for the second deployment (SW monsoon and fall intermonsoon). Here the largest signal of variability is uniform in sign across all moorings and at all depths, with a slight emphasis around $100 \mathrm{~m}$. 
associated with them are red, with the most energy at the longest captured time scales. Higher EOFs have increasingly white spectra in their associated time series. The spatial uniformity across the array in the first two EOFs, taken along with the spatial variability in the few higher EOFs that still retain significant amounts of associated low-frequency time variability, suggests that the array has been scaled to successfully capture a good portion of the horizontal variability at the site.

The first deployment first EOF for temperature (Fig. 2.3A, associated with $79.4 \%$ of the variability) emphasizes changes centered around $100 \mathrm{~m}$ depth. There is a mild cooling (warming) in near-surface temperatures accompanying the warming (cooling) at depth, though the time series associated with the EOF 1 and 2-which is associated with $7.98 \%$ of the variability and - are nearly out of phase during the time of maximum variability, early in the deployment (October and November and more mildly into December). Taken together, they indicate that the biggest changes in temperature take place below the surface, centered between 50 and $100 \mathrm{~m}$. During the second deployment, the first EOF in temperature (Fig. 2.3B, associated with $84 \%$ of the variability) is uniform in depth and across the array, with a slight emphasis around $100 \mathrm{~m}$. The time series associated with this EOF suggests that there is a strong change, a cooling, uniform across the array and fairly uniform in depth, starting in the last week of July and lasting through the first two weeks of August. Higher EOFs, associated with less of the total variability, begin to exhibit both higher vertical and greater spatial differentiation across the array.

The first EOFs in velocity for each deployment are uniform in vertical structure across the array, with a surface intensification, and a drop in magnitude from the nearsurface high to about half at $100 \mathrm{~m}$ (Fig. 2.4A and B). The strongest variability in these first EOFs is similar to that of the temperature EOFs, strongest in October through December, and in late July and into August.

The temporal mean and the first three or four EOFs of velocity and temperature are retained in the filter: 

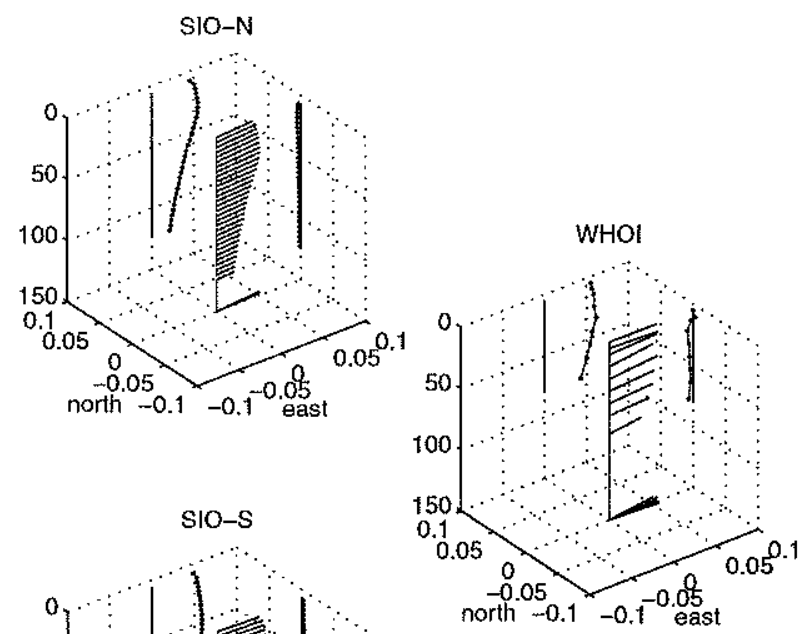

Deployment 1
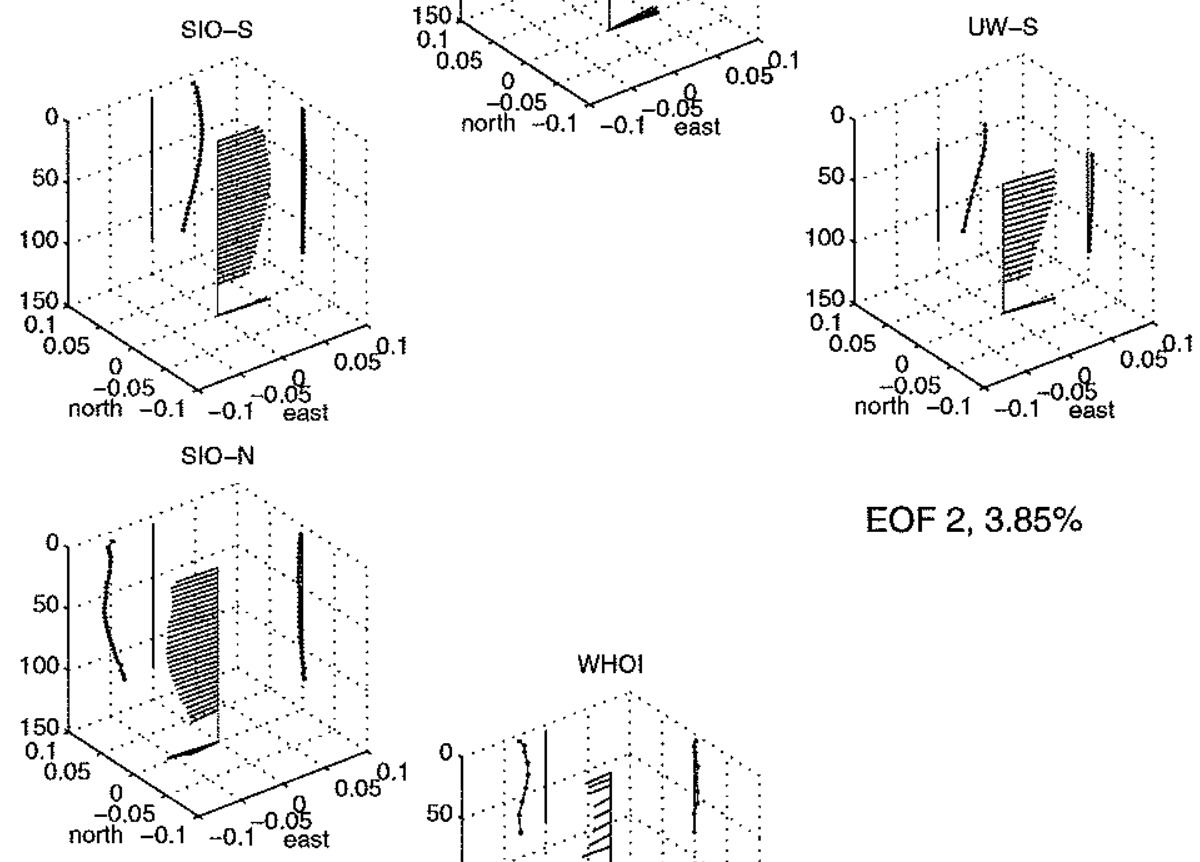

EOF $2,3.85 \%$
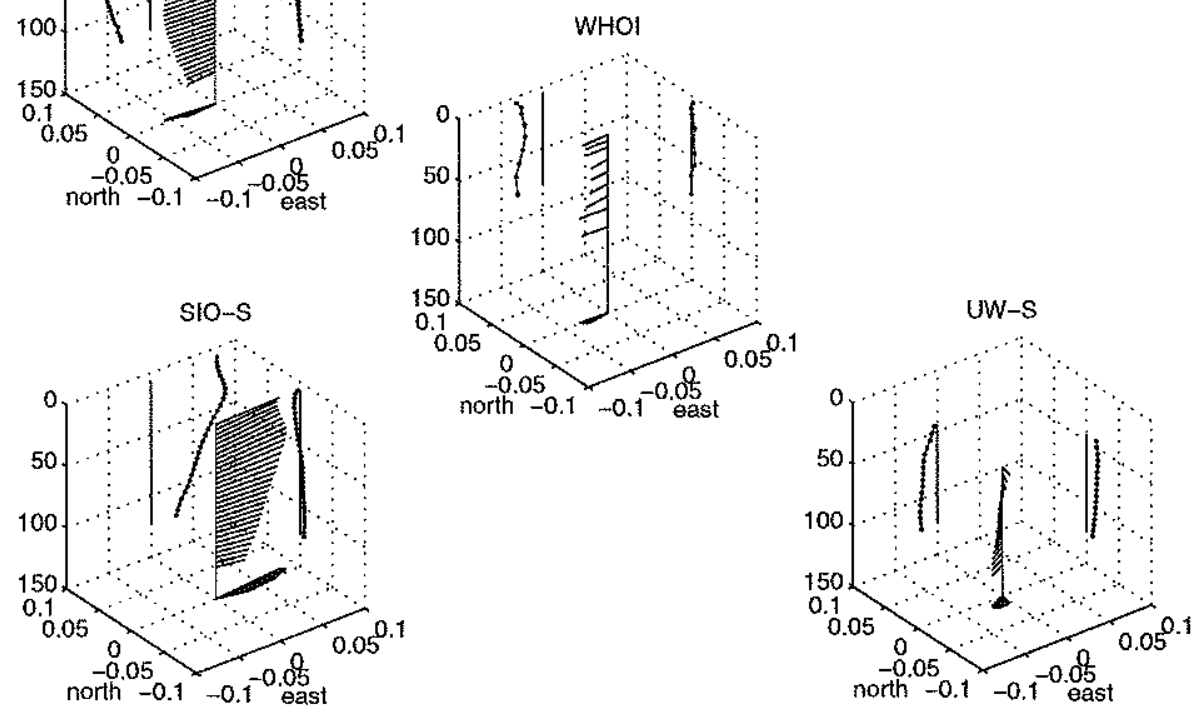

Figure 2.4 A The first two array EOFs of velocity for the first deployment. For aid in visualization, the tips of the velocity vectors are projected onto the $\mathrm{x}-, \mathrm{y}-$, and $\mathrm{z}$ axes on the sides of the box. The first EOF is quite uniform in direction across the moorings and in depth, while the second EOF is associated with both a north-south velocity shear (with positive vorticity) and a small divergence. 


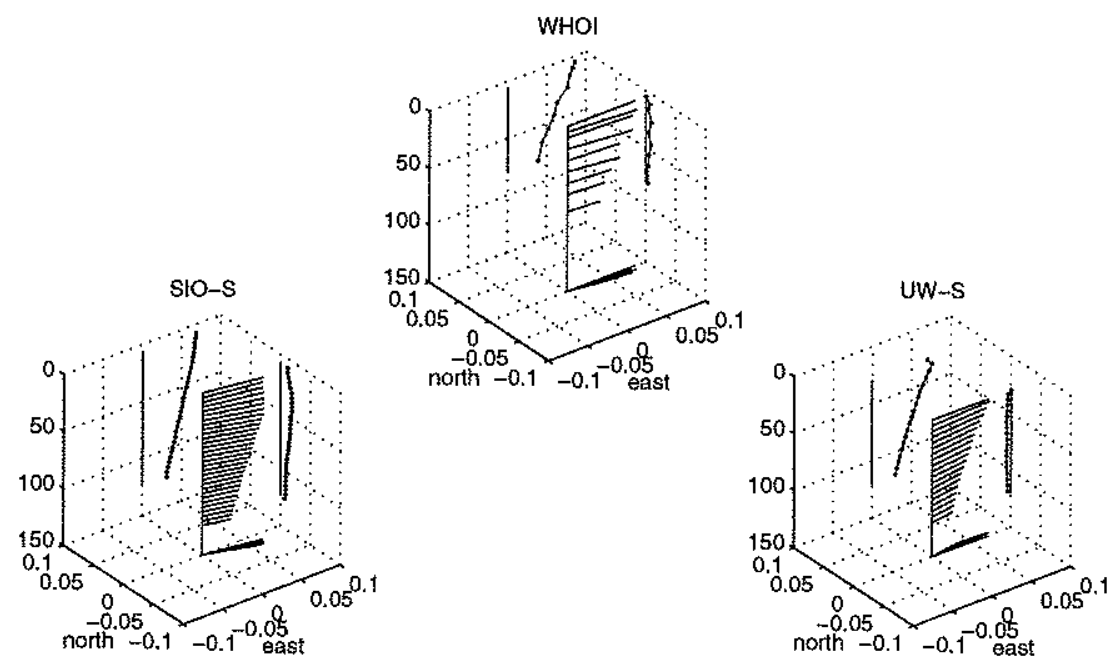

EOF $2,14.0 \%$

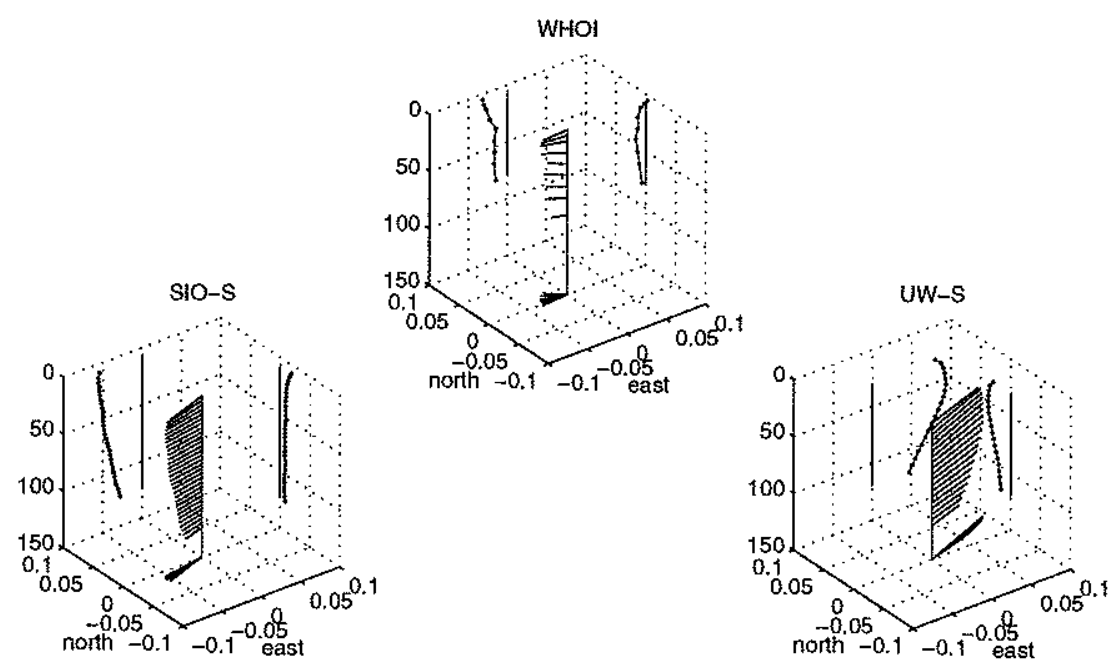

Figure 2.4 B The first two array EOFs of velocity for the second deployment. Since temperature was unavailable from SIO-N, the velocity there was not used. As in the first deployment, the first EOF is associated with fairly uniform velocities across the moored array and in depth, although surface-intensified. The second EOF is associated with a divergence and a small positive vorticity. 
a
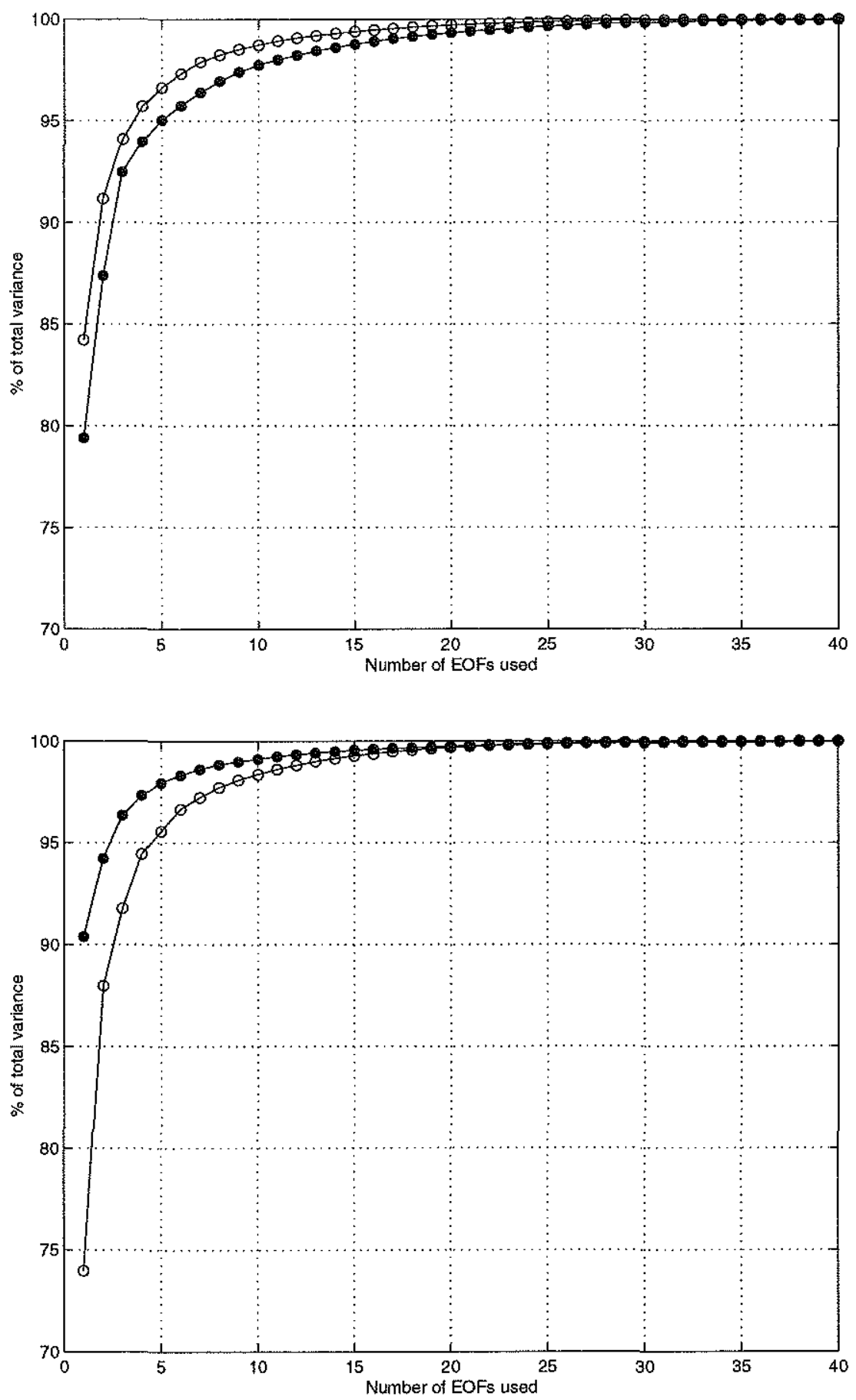

Figure 2.5 The EOF variance spectrum for (a) temperature and (b) velocity. Closed dots are for the first deployment, open for the second. 


$$
\begin{gathered}
\mathbf{u}\left(\mathbf{x}_{n}, t\right)=\mathbf{u}_{0}\left(\mathbf{x}_{n}\right)+\sum_{i=1}^{m} \alpha_{i}(t) \mathbf{u}_{i}\left(\mathbf{x}_{n}\right) \\
T\left(\mathbf{x}_{n}, t\right)=T_{0}\left(\mathbf{x}_{n}\right)+\sum_{i=1}^{m} \beta_{i}(t) T_{i}\left(\mathbf{x}_{n}\right),
\end{gathered}
$$

where $\mathbf{x}_{n}$ enumerates the instrument position, $\mathbf{u}_{0}$ and $T_{0}$ are the time means, and $\mathbf{u}_{i}$ and $T_{i}$ are the EOFs associated with the amplitudes $\alpha_{i}$ and $\beta_{i}$. The cutoff at $m=3$ for the first deployment and $m=4$ for the second deployment was made in each case based on a sharp drop in the remaining percentage of the variability associated with the EOF (see Fig. 2.5). Using this type of filtering selectively extracts the variability on the scales that are coherent across the array. The total variance retained by the filtering varied between $92.5 \%$ and $96.4 \%$, depending on the deployment and variable.

\subsubsection{Uncertainty}

The uncertainty in the estimation of the various terms in the heat budget is important in the understanding of how it closes, and can potentially come from a number of sources: the error in the measurements made by the moored instrumentation, unresolved spatial variability which makes it through the EOF filtering process, and potential mooring line tilt during strong currents, yielding measurements higher (because of the surfacecompliant buoyancy in the moorings) in the water column than expected. The UW PCM instrument measured pressure, and so line tilt is not a source of error for this mooring.

The dominant uncertainty in the horizontal heat flux (second term in (2.1)) comes from the error associated with the spatial filtering. This error can come from large-scale variability that is not retained in the EOF filtering or, more likely, in small-scale variability that is retained. The magnitude of this uncertainty can be estimated from the variance in the first neglected EOF, which is assumed to have (and observed to have) similar short time scale variability as the included EOFs. The rms error in the temperature from this estimate varies slightly between the two deployments, but is much larger than the instru- 
ment error or potential error from mooring tilt, and is $0.25^{\circ} \mathrm{C}$ for the first deployment and $0.18^{\circ} \mathrm{C}$ for the second. The similarly defined rms error in the velocity, at 2.2 $\mathrm{cm} \mathrm{sec}^{-1}$ for the first deployment and $1.8 \mathrm{~cm} \mathrm{sec}^{-1}$ for the second, is likewise much larger than any other sources of uncertainty.

The filtered values of the temperature and velocity at each mooring were spline-fitted (along with their associated error) onto a fixed $5 \mathrm{~m}$ resolution grid in the z-direction, providing estimates of the horizontal structure of temperature and velocity at every level. No velocity measurements were made below $80 \mathrm{~m}$ on the WHOI mooring, so the estimate of the velocity at the central point of the array is given by the remaining measurements of velocity, and gradients are not computed. The value and $x-y$ gradients of the temperature and each component of the velocity are estimated from the three or four elements at each fixed depth on the grid, using a least squares planar fit. Expressed in the terminology of linear inverse models [Wunsch, 1996],

$$
\mathbf{E} \mathbf{x}=\mathbf{y} \quad \text { or } \quad\left[\begin{array}{ccc}
1 & x_{1} & y_{1} \\
\ldots & \\
1 & x_{n} & y_{n}
\end{array}\right]\left[\begin{array}{c}
\bar{u} \\
u_{x} \\
u_{y}
\end{array}\right]=\left[\begin{array}{c}
u_{1} \\
\ldots \\
u_{n}
\end{array}\right],
$$

where $\mathbf{E}$ is the model matrix, containing the positions of the three or four array elements $\left(x_{n}, y_{n}\right)$ distributed about the central point of the array, $\mathbf{x}$ is the parameter vector containing the mean and $\mathrm{x}$ - and $\mathrm{y}$-gradients of the variable $(u$, representing temperature or one component of velocity), and $\mathbf{y}$ is the data vector, containing the values of the temperature or velocity at each point in the array. Expression in this format allows for an easy estimation of the parameters $\mathbf{x}$ by inversion of the model matrix $\mathbf{E}$. The errors associated with the parameters are also simply expressed as [Wunsch, 1996]

$$
\mathbf{P}=\left(\mathbf{E}^{T} \mathbf{E}\right)^{-1} \mathbf{E}^{T} \mathbf{R}_{n n} \mathbf{E}\left(\mathbf{E}^{T} \mathbf{E}\right)^{-1}
$$

where $\mathbf{R}_{n n}$ is the error covariance matrix for the data $\mathbf{y}$, estimated as described above. The error associated with the temperature, velocity and gradients is thus readily computed for 
each fixed depth. As an example, the error associated with the array central point temperature is shown in the rightmost panel of Fig. 2.6. The error varies with deployment and varies in depth, but is generally around $0.1{ }^{\circ} \mathrm{C}$. The estimated horizontal gradients in temperature are above the level of uncertainty for a majority of the time period sampled. There are however periods of time when the estimated gradient is not significantly different from zero, the longest of which comes during the NE monsoon.

The uncertainty in the temperature, velocity, and gradients from the array are propagated into the individual terms of the upper ocean heat budget ((2.1) and (2.2)). The vertical integration of the heat flux terms on the left hand side of (2.2) reduces the error by integrating over a number of degrees of freedom. Since the first EOFs in temperature and velocity across the mooring were so dominant, and in large part fairly vertically uniform, I assume that the vertical integration is an integration over only four degrees of freedom, represented by each mooring.

The uncertainty in the estimate of the temperature trend term (the first term of (2.2)), which is calculated as differences in temperature over the time scale of the sampling, is dependent not on this sampling time scale, but on the time scale of variability in the temperature. The temperature trend is coherent over the 4 hour time scale of the measurements, so the error is based on the decorrelation time scale of the noise, represented by the first ignored EOF. This time scale is about 40 hours, yielding an error in the vertically-integrated short-term temperature trend of $180 \mathrm{~W} \mathrm{~m}^{-2}$. The temperature trend term, measuring the change in heat content integrated to a fixed depth, is significantly different from zero for a majority of the observed period.

The uncertainty in the heat advection term (second term in (2.1) or (2.2)) is nonlinear, as it is dependent on both the velocity and the gradient in temperature. The uncertainty is largest when the velocities are largest, coincident with the largest horizontal heat fluxes. It is only these large horizontal heat fluxes that rise above the level of uncertainty, however. Integrated vertically, the uncertainties range from a minimum of 50 to a maximum of $1300 \mathrm{~W} \mathrm{~m}^{-2}$ in the first deployment, and a maximum of $890 \mathrm{~W} \mathrm{~m}^{-2}$ dur- 
ing the second deployment. But the strong horizontal heat fluxes (maximum estimate of about $4500 \mathrm{~W} \mathrm{~m}^{-2}$ ) are significantly different from zero.

The third term in (2.2), the vertical advection of heat, is not estimated directly, since no direct measurements of vertical velocity are available. It is estimated as the residual of all the other terms, and so contains the accumulated uncertainty, both explicitly estimated and unaccounted-for, from the other terms.

The error in the final term of (2.2), the net surface heat flux, is estimated to be 15 $\mathrm{W} \mathrm{m}^{-2}$, and is insignificant compared to both the magnitude of the net surface heat flux and the other uncertainties in the calculation.

\subsubsection{Results}

There is a twice-yearly cycle of sea surface temperature and mixed layer response to the surface forcing evident in the array average temperature (Fig. 2.6). The mixed layer deepens in response to convective cooling during the NE monsoon, while the SST cools under the effect of this entrainment as well as the surface cooling. The mixed layer shoals with restratification and an SST rise during the intermonsoon. The winds of the SW monsoon again bring mixed layer deepening and cooling. But the one-dimensional heat balance (Fig. 2.1) has already made clear that the oceanic response is not entirely a simple response to the surface forcing. Below the influence of the surface forcing, the thermocline depth varies considerably during the year. The $21^{\circ} \mathrm{C}$ isotherm for example, which is never incorporated into the mixed layer, and represents the upper thermocline, varies in depth from a minimum of about $60 \mathrm{~m}$ at the beginning of the NE monsoon, then drops below $120 \mathrm{~m}$ for the rest of the NE monsoon and into the SW monsoon. It shoals suddenly at the end of July, coincident with a sharp reduction in SST and a shoaling of the mixed layer. The change in temperature at a fixed depth in this region, below the influence of surface fluxes, over the course of the year (a range of $7.7^{\circ} \mathrm{C}$ at $100 \mathrm{~m}$ ) is as large or larger than the change in the SST $\left(6.0^{\circ} \mathrm{C}\right.$ near the surface).

The periods of apparently non-local response of the array temperature field are mirrored in the array velocity field (Fig. 2.7). The strongest velocities of the year come dur- 

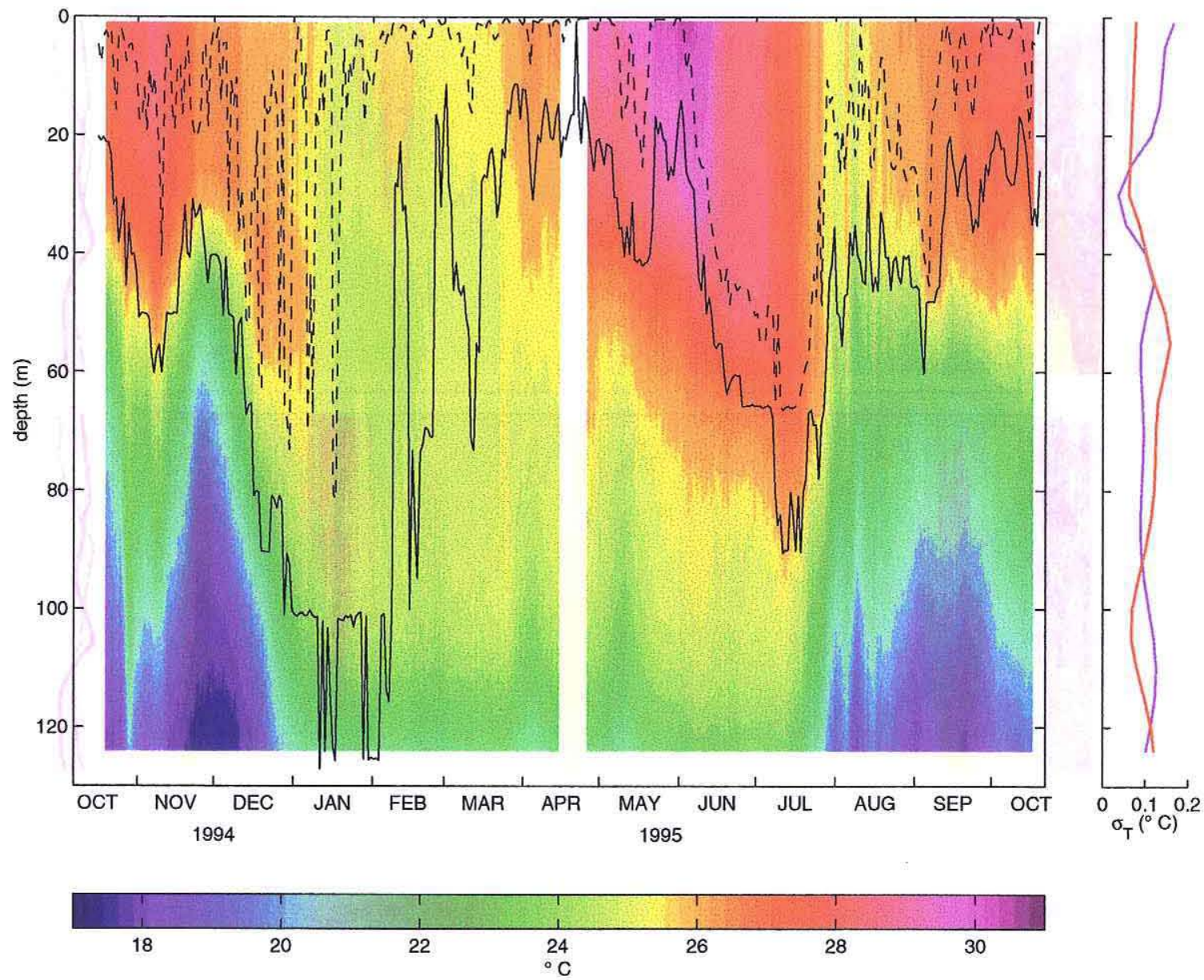

Figure 2.6 The array average temperature is shown in the main panel, while the error due to the EOF filtering as is shown at right, blue for the first deployment and red for the second. The error is generally around $0.1^{\circ} \mathrm{C}$ though it varies in depth. The daily minimum (dotted) and maximum (solid) mixed layer depths are shown as recorded at the WHOI mooring, from a $0.1^{\circ} \mathrm{C}$ difference from SSTcriterion.

ing the beginning of the NE monsoon, beginning with a strong southeastward velocity which turns northeastward through December. Another strong signal is the east and southeastward velocity in July and August. These are coincident with the strong thermocline depth changes already noted. The velocities, though surface-intensified, are also fairly constant across the mixed layer base suggesting that they are not locally winddriven. 

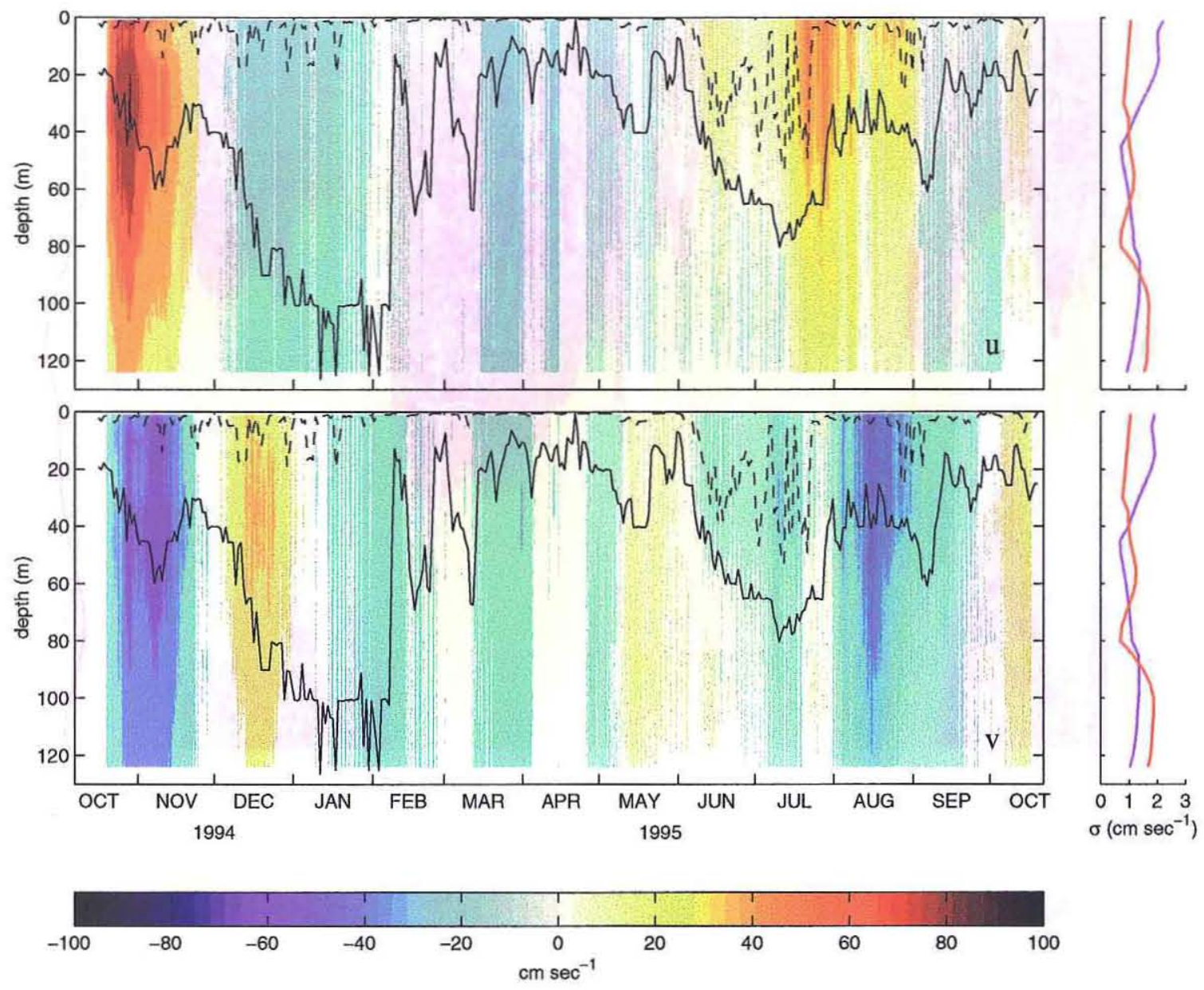

Figure 2.7 The array average east (u, top) and north (v, bottom) components of the velocity. Error due to EOF filtering is shown at right, blue for the first deployment and red for the second. The daily minimum (dotted) and maximum (solid) mixed layer depths recorded at the WHOI mooring are shown in black.

The observed velocity field is also largely in geostrophic balance with the estimated temperature gradient field. A complex regression between the array average velocity shear and horizontal temperature gradient at $100 \mathrm{~m}$ shows a correlation of 0.89 and a spatial phase difference of $89.8^{\circ}$. The skill is thus 0.79 (the correlation squared) so $79 \%$ of the variability in the shear is linearly related to the variability in the horizontal temperature gradient. The amplitude of the regression coefficient between the shear and temperature gradient is theoretically $\alpha g / f$ from the thermal wind relationship, where the thermal expansion coefficient $\alpha=\rho_{0}^{-1} d \rho / d T$, and assuming a tight and linear tempera- 


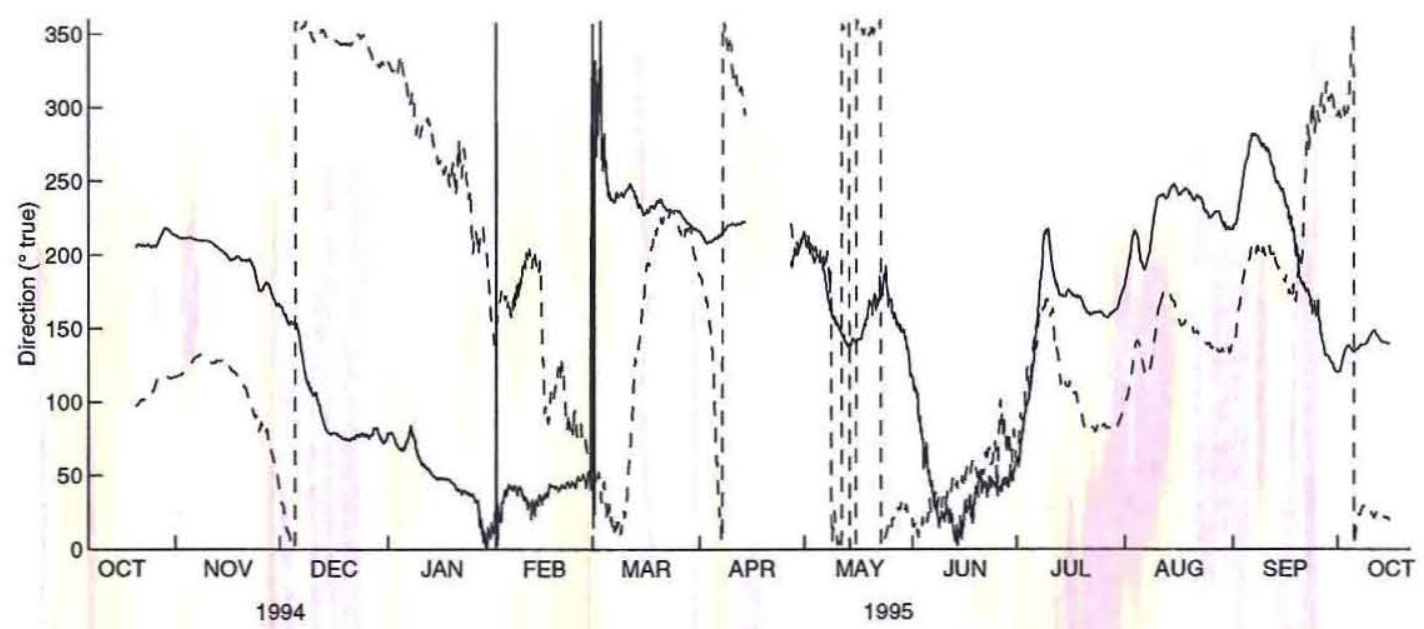

Figure 2.8 Direction of the temperature gradient (solid) and velocity (dashed) calculated from 48-hour lowpass filtered data at $80 \mathrm{~m}$. During times of strong current the relationship between the two is very close to geostrophic.

ture-salinity relationship. The regression coefficient between the shear and temperature gradient at $100 \mathrm{~m}$ yields a value of $\alpha=2.26 \times 10^{-4}{ }^{\circ} \mathrm{C}^{-1}$, while the true value for surface water of temperature $24^{\circ} \mathrm{C}$ and salinity 36.2 (typical for $100 \mathrm{~m}$ depth) is $2.91 \times 10^{-4}{ }^{\circ} \mathrm{C}^{-1}$. Despite the fact that the TS relationship is neither tight nor necessarily linear (see the upcoming Section 2.4.2 and Section 2.4.3), since salinity tends to be compensating, the value is reasonable. These values of correlation and regression are typical for rest of the upper thermocline as well, though reduced within the mixed layer.

The strongest signals in the vertically-resolved temperature trend term (Fig. 2.9 top) of the upper ocean heat budget (2.1) are below the mixed layer, in the upper thermocline. The temperature trend, and all the rest of the records that will be displayed in the upper ocean heat budget have been lowpass-filtered (after all calculations) with a 96-hour cutoff to eliminate variations associated with the dominant tidal ( $\mathrm{M}_{2}, 12.4$ hour) diurnal (24 hour) and inertial (44 hour) periods. The strong signals in the temperature trend, localized to the upper thermocline, occur in November and December, near the beginning of the NE monsoon, and again in late July, near the tail end of the SW monsoon. They are associated with the strongest velocities, and biggest excursions in thermocline depth. 

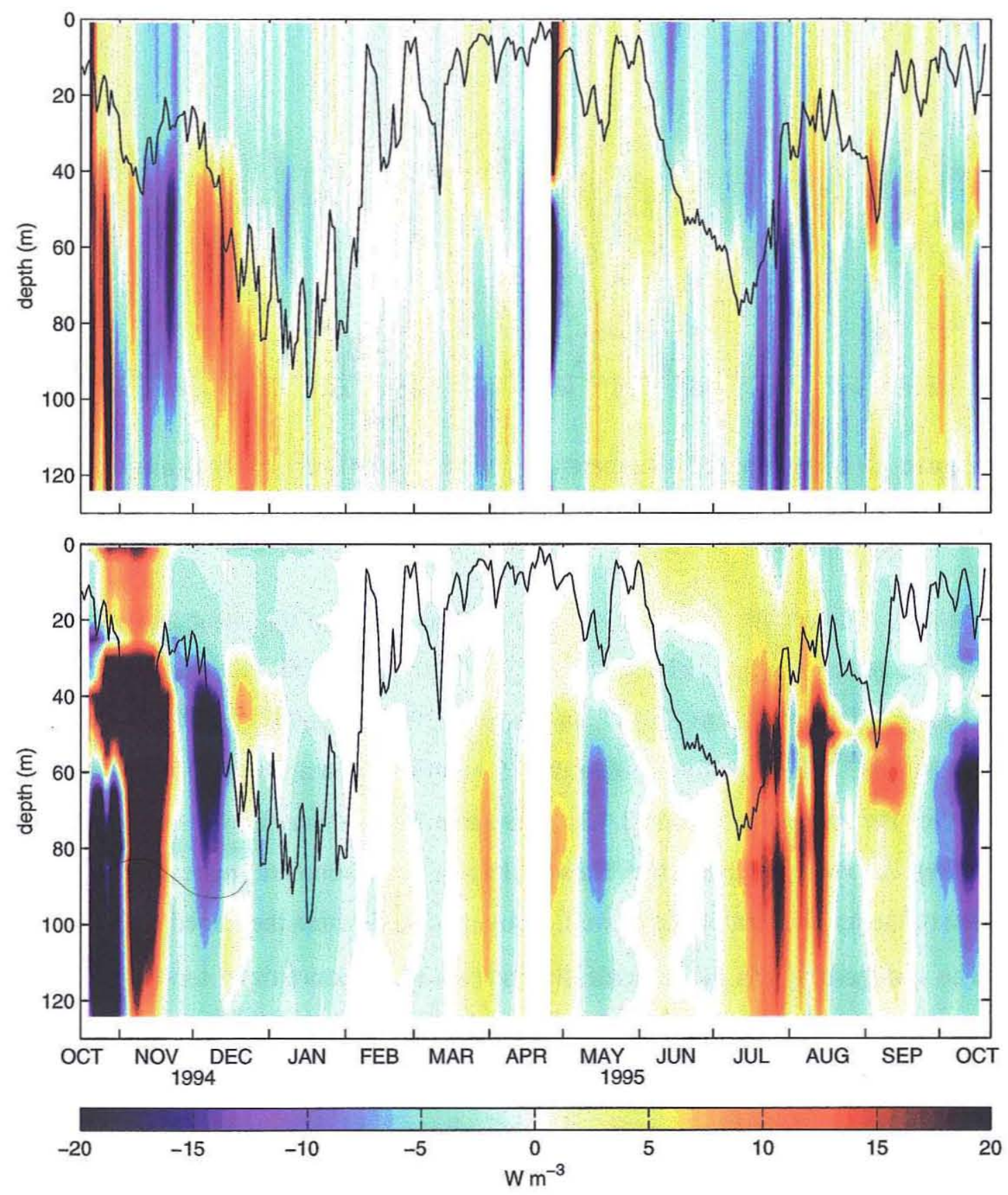

Figure 2.9 The vertically resolved temperature trend (top) and horizontal heat advection (bottom), both 96-hour lowpass filtered, with the daily mean mixed layer depth (black line). The horizontal heat advection has a large error associated with it (see following figure), though the large signals below the mixed layer in October-December and July-August are above the error level. 


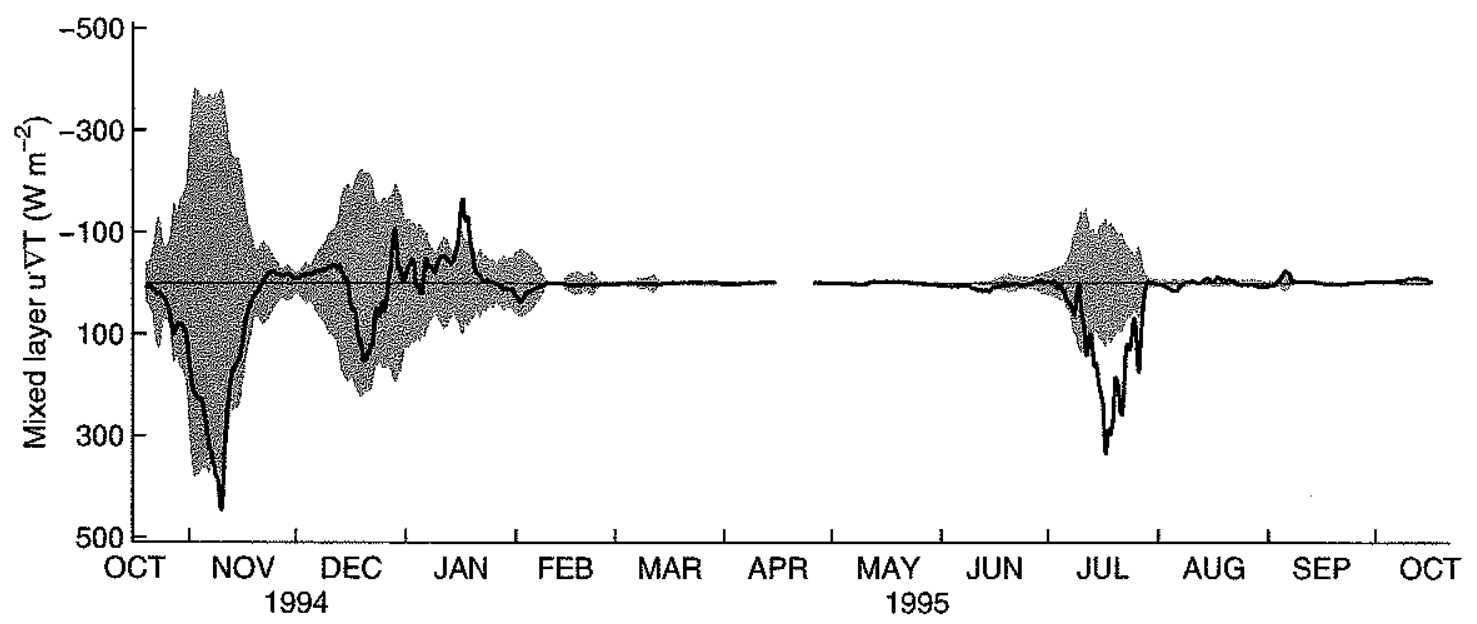

Figure 2.10 The horizontal advection of heat integrated only over the daily average mixed layer depth (as measured at the central WHOI mooring). The only significant (above error level) strong horizontal advection within the mixed layer occurs during the SW monsoon in July, a cooling. There are only two very short periods during the NE monsoon when the horizontal heat flux is above the level of error in the calculation. Note the y-axis is reversed.

There is also a signal of the mixed layer cooling throughout the mixed layer deepening periods of the NE and SW monsoons.

These strong signals in the temperature trend are in many cases roughly matched by oppositely-signed signals in the vertically-resolved horizontal heat flux (Fig. 2.9 bottom). These signals are also strongest within the upper thermocline, below the mixed layer. In fact, during the first deployment nearly none of the signal within the mixed layer is significantly above the uncertainty (see Fig. 2.10 ), while in the second deployment the mixed layer horizontal heat flux is marginally significant, and positive (cooling). Below the mixed layer, the signal is strongest again in the early NE and late SW monsoon, linked with the thermocline variability and strong currents. This contrast across the mixed layer base during the NE monsoon suggests the advection of variability in the thermocline depth, topped by a fairly uniform mixed layer. The mixed layer appears to be not as horizontally homogeneous during the SW monsoon. 


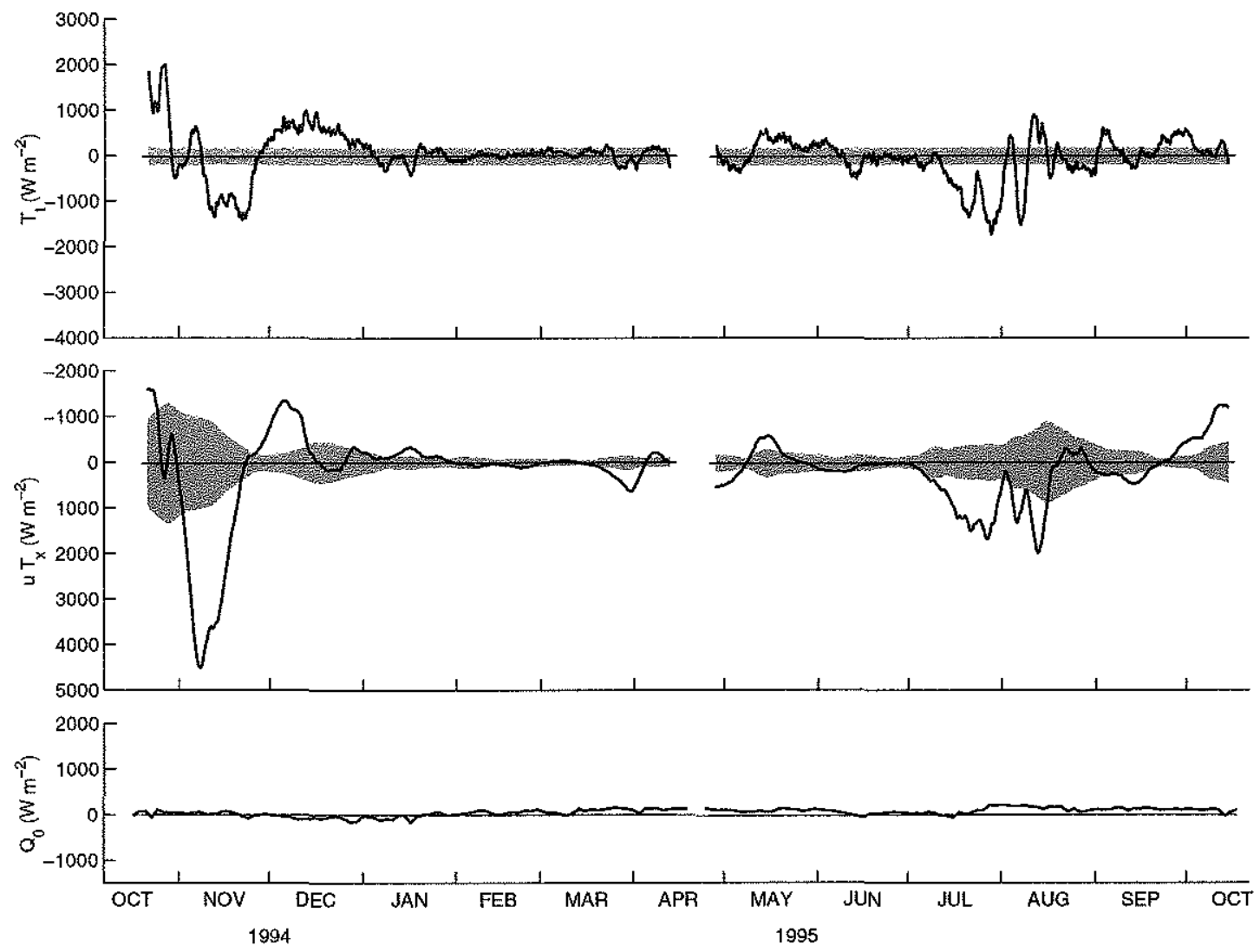

Figure 2.11 Terms in the heat budget, vertically integrated between the surface and $125 \mathrm{~m}$ : the time trend (top), horizontal advection (middle), and the surface heat flux (bottom). The y-axis scale for horizontal advection is reversed, the temperature trend and horizontal advection terms tend to roughly cancel each other. Uncertainty is marked by the grey outline around the zero line.

The vertically integrated heat budget (Fig. 2.11) confirms the suggestion that the temperature trend and horizontal advection of heat, integrated between the surface and 125 $\mathrm{m}$, have a rough balance when the signals are large. This rough balance exists from the beginning of the deployment through the early NE monsoon (October - December 1994), during a short period in May, and in the late SW monsoon (July and August 1995). The surface heat flux, by comparison, appears to be unimportant in the heat budget integrated from the surface to $125 \mathrm{~m}$.

The residual term in the heat budget, representing the vertical heat flux due to Ekman pumping or other vertical motions (as well as potentially unresolved processes), yields an 
estimate of the vertical velocity necessary to close the heat budget. The vertical velocity is assumed to linearly decay to zero at the surface, and $w$ is calculated at $125 \mathrm{~m}$, at the base of the vertical integration (as in Price et al. [1978]). The result is shown in Fig. 2.12, and suggests that several strong episodic downwelling events, and some smaller upwelling events are necessary to close the heat budget. The strength of these vertical velocities (up to $0.02 \mathrm{~cm} \mathrm{sec}^{-1}$ ) corresponds to velocities up to $18 \mathrm{~m} \mathrm{day}^{-1}$. This is consistent with the velocities reported in the vicinity of strong fronts, estimated from closing heat and mass budgets [Rudnick and Weller, 1993], as well as those reported in the vicinity of a coastal upwelling filament in the California Current system [Shearman et al., 1999], estimated from a density and velocity survey. In this case they are more often downwelling, since the estimate of the horizontal heat flux is generally more cooling (positive) than the temperature trend. While the estimate of uncertainty indicates that the strongest of these vertical velocities are significant, the uncertainty does not include the possibility that small-scale horizontal variability not resolved by the array has affected the estimate of the horizontal heat flux.

\subsubsection{Ekman pumping}

A number of studies [Bauer et al., 1991; McCreary et al., 1993] have emphasized the role of Ekman pumping in setting the mixed layer depth structure across the Arabian Sea. Both note the generally deeper mixed layers to the right of the Findlater jet wind axis and shallower mixed layers towards the Arabian coast, consistent with open-ocean Ekman upwelling and downwelling. Lee et al. [2000] revisited this idea by examining climatology, and found that local surface forcing (entrainment driven by wind and/or heat forcing) appeared to have a much stronger effect than Ekman pumping on influencing the mixed layer depth, though neither, nor the combination, could fully explain the observed patterns of mixed layer depth. At the site of the moored array, underneath the rough axis

of the Findlater Jet, Ekman pumping is not expected to play as large a role as it might elsewhere in the basin. 

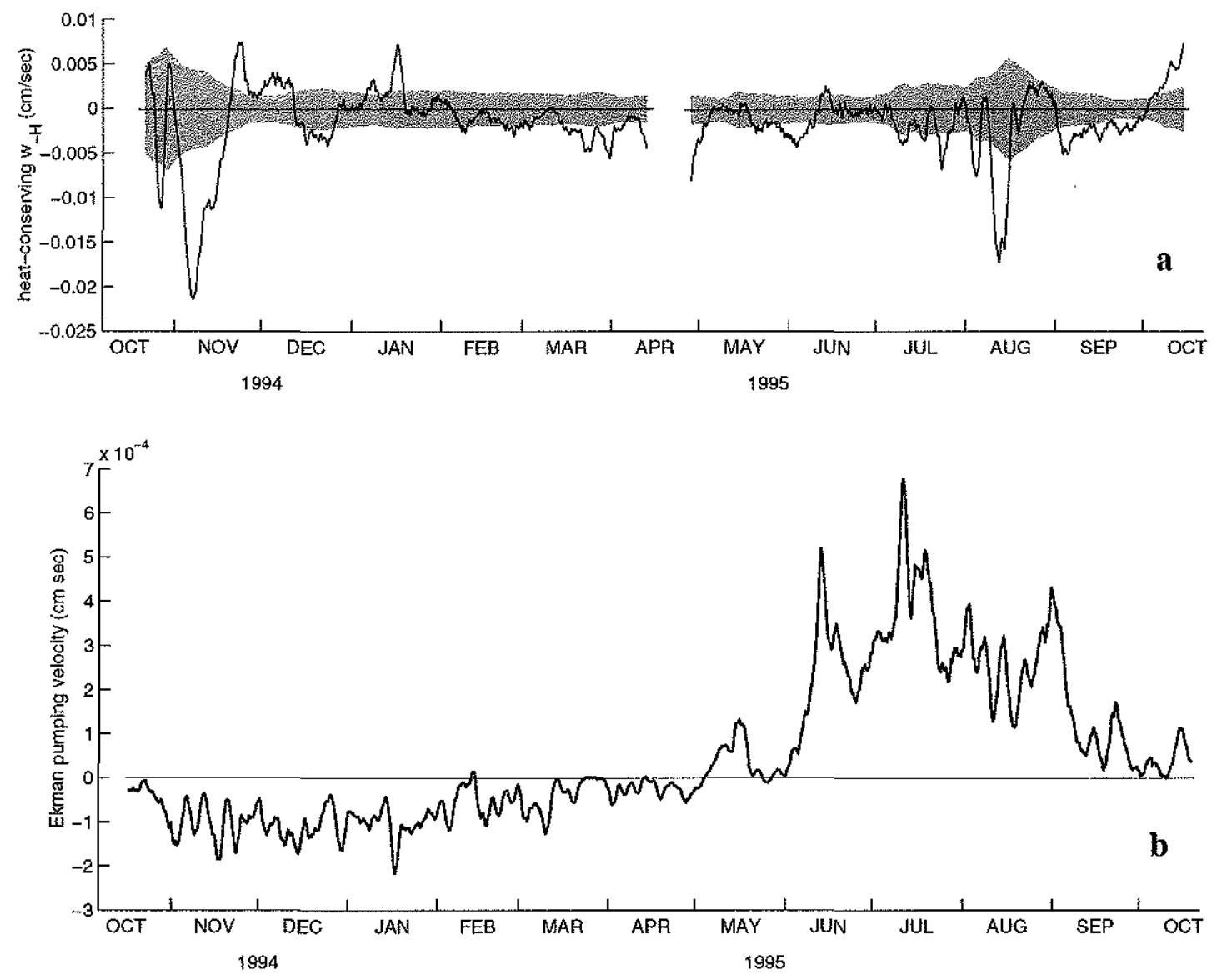

Figure 2.12 (a) The derived vertical velocity from closing the heat budget. Uncertainty marked by the grey outline about zero. (b) Ekman pumping at the site of the mooring as estimated from ECMWF wind stresses. This estimate of vertical velocity is much smaller (note scale) than that derived from closure of the heat budget.

One estimate of the Ekman pumping at the moored array, from ECMWF wind stresses, is shown in Fig. 2.12b. During the SW monsoon with its strong, maintained zonal wind stresses, the latitudinal variation in Ekman transport becomes an important factor in calculating the net Ekman pumping vertical velocity [Fischer, 1997],

$$
w_{\text {Ekman }}=\nabla \times\left(\frac{\bar{\tau}}{\rho_{0} f}\right)=\frac{1}{\rho_{0} f_{0}}\left(\nabla \times \bar{\tau}+\frac{\beta_{f}}{f_{0}} \tau^{x}\right)
$$

where the divergence of the Ekman transport yields two terms, a curl of the wind stress, 
and a term related to the latitudinal variation in Ekman transport ( $\beta_{f}$ is gradient in the planetary vorticity $f$, and $\tau^{x}$ is the eastward component of the wind stress $\bar{\tau}$ ). The second term is particularly emphasized in near-equatorial regions, where $\beta_{f}$ is largest and $f_{0}$, the local planetary vorticity, smallest. The magnitude of the vertical velocity is quite small

(less than $1 \mathrm{~m}^{-1 a y}{ }^{-1}$ ), certainly much smaller than the estimates of what is required to close the heat budget. It also has the wrong sign, so at the site of the moored array, appears to have a very small contribution to the heat budget and mixed layer deepening.

\subsubsection{Discussion}

The estimation of the terms of the heat budget of the upper ocean over one year, integrated to a fixed depth of $125 \mathrm{~m}$, suggests that there is a rough balance between the temperature trend and horizontal heat advection during certain periods: the NE monsoon (October-December), and during the latter part of the SW monsoon (July-August). The balance is not exact, and there is a significant residual that must be closed by vertical advection of heat, particularly during the NE monsoon. During these time periods, the magnitude of the temperature trend and horizontal heat flux dwarf the contribution from the surface heat flux, even though the one-dimensional heat content balance (Fig. 2.1, a time integration of the first and last terms of (2.2)), suggests that the oceanic heat content is reasonably well explained by the surface heat flux during the rest of the year.

The vertical integration of the heat budget to a fixed depth performed here must be differentiated from a mixed layer heat budget, since in some ways the upper ocean heat budget (the former) underestimates the importance of the surface heat flux. An important contributor to a mixed layer heat budget, and thus to the evolution of the sea surface temperature, is the entrainment flux at its base, driven by both the surface heat and momentum fluxes. This turbulent entrainment flux could not be estimated from the data here, necessitating the integration to a fixed depth below the influence of turbulent fluxes. So while the surface heat flux was dwarfed by the estimated size of the temperature trend and horizontal advective flux (Fig. 2.11), the horizontal heat flux integrated over just the mixed layer was only significantly different from zero for a few weeks during the SW 
monsoon. While taking into account the error in the estimate of the horizontal heat flux, this would imply that the surface-driven processes are important to the changing SSTs during the rest of the year. During the net surface heating of the early SW monsoon, the only process acting to cool the SST is wind-driven entrainment. At other times during the year, horizontal fluxes deeper in the water column vary what the mixed layer entrains into, and so SSTs are forced by a combination of surface and horizontal heat fluxes.

\subsection{Remote Sensing of the Surface Evolution}

The moored array allowed a detailed view of the terms of the heat budget, with limited information about the broad scale characteristics of these flows. Remotely sensed data can set the context of the surface flow and can be used to yield insight into the mesoscale dynamics responsible for the large observed horizontal heat fluxes. These results emphasize the importance of the horizontal advection in transporting heat and in modulating the mixed layer response to surface forcing.

\subsubsection{Data}

\subsubsection{Altimetry}

Satellite ocean altimetry measures the shape of the sea surface, which has a component related to the geoid of the earth, and a much smaller dynamical component which yields information about surface flows. The (time-invariant) geoid is removed from the

signal as best as it is known, but remains a source of uncertainty in the absolute height, particularly over smaller scales. The TOPEX/Poseidon altimeter has been flying and returning data since late 1992, in an orbit with an exact repeat period of ten days, and a nominal track spacing in the Arabian Sea of about $250 \mathrm{~km}$. The ERS-1 and ERS-2 altimeters have been collecting data since 1991, in a variety of orbits. For the period investigated, ERS-1 started in a 168-day exact repeat with 17-day near repeat orbit. On 21 March 1995 this changed to a 35-day exact repeat orbit, with a nominal track spacing in 
the Arabian Sea of about $80 \mathrm{~km}$. The ERS-2 altimeter flew in a 35-day exact repeat orbit starting 21 April 1995. The trade-off between spatial and time resolution in the orbit is apparent, and a combined product which can resolve the mesoscale with reasonable time resolution is used.

Standard error corrections to the altimetry were applied before the two products were combined, and are detailed in Fox [1997]. Additional corrections include an improved tidal model [Desai and Wahr, 1995] for the TOPEX altimetry. The TOPEX and ERS data were then blended and gridded using an optimal interpolation method [Fox, 1997]. First orbit and other environmental errors were removed from both the TOPEX and ERS data using an along-track loess filtering, removing a running least squares fit of a tilt and bias within a sliding window. The window width was approximately 15 degrees in latitude, retaining mesoscale signals, but eliminating larger-scale sea surface height (SSH) variations. The data from the two altimeters were then combined and interpolated onto a $0.25^{\circ}$ grid using a multi-grid preconditioned Cressman analysis [Hendricks et al., 1996]. Interpolated maps were generated every three days, with TOPEX data within \pm 10 and ERS data within \pm 17 days used in the analysis. The initial decorrelation radius used was $200 \mathrm{~km}$, reduced to $100 \mathrm{~km}$.

The combined analysis is first compared to the record from the mooring. To compare heights directly, the dynamic height anomaly at the WHOI mooring was calculated using 36-hour smoothed data over the upper $250 \mathrm{~m}$, which had good temperature and salinity data for the full year. A reference density at a salinity of 35 , temperature of $20^{\circ}$, and at surface pressure, was used. If there is no motion at the lower limit of integration, the dynamic height is equivalent to the height of the sea surface. No direct measurements of velocity at $250 \mathrm{~m}$ are available, but the velocities at $300 \mathrm{~m}$ were much reduced compared to the surface velocities, by an order of magnitude [Fischer, 1997], though not completely negligible. The correlation between the moored dynamic height and the blended altimeter height is good at 0.85 (see Fig. 2.13). In particular, the timing of major changes in the sea surface height in November and December 1994 and in August 1995 are well represented. The sharpness of the changes in the moored record is not reproduced in the 


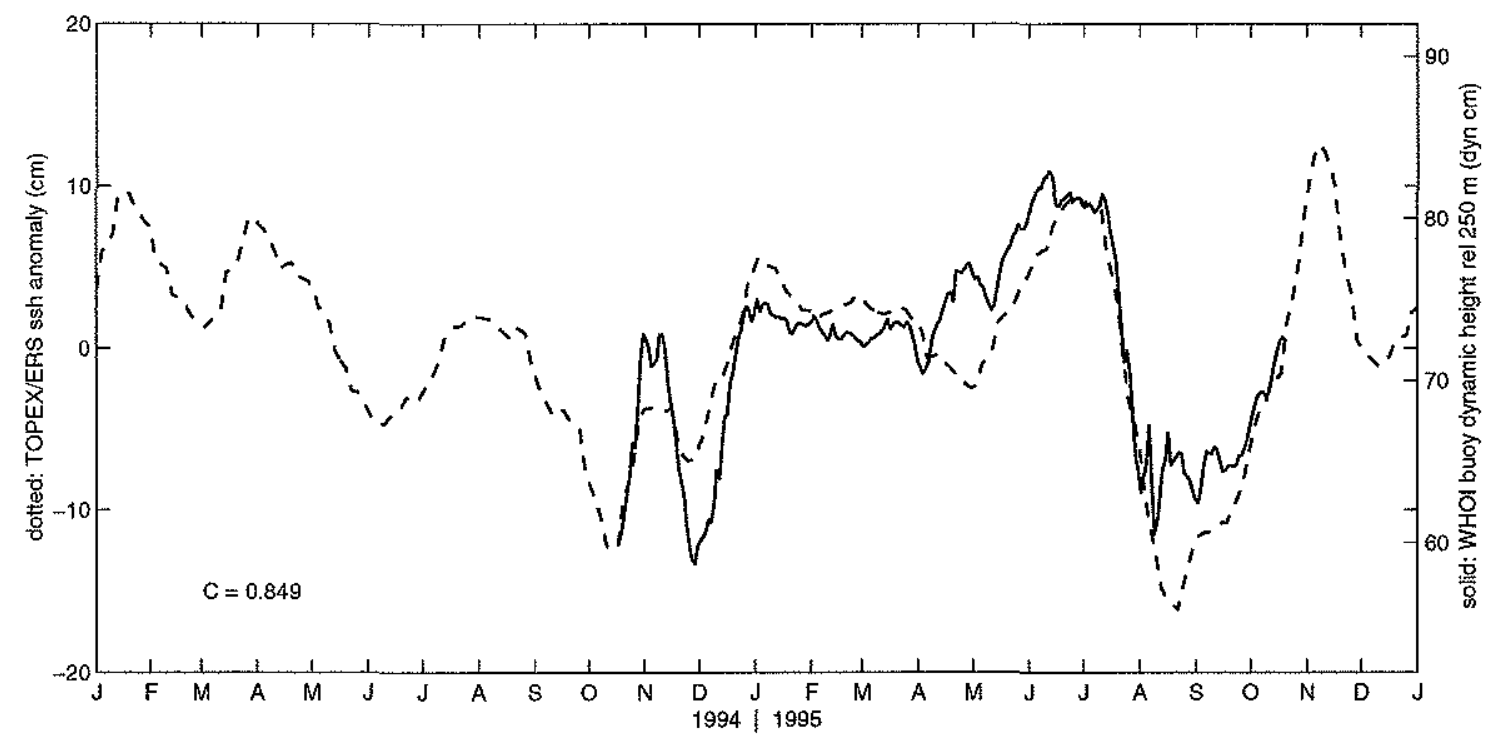

Figure 2.13 Comparison of TOPEX/ERS altimetry ssh anomaly (dashed, every 3 days) and WHOI mooring-derived dynamic height (solid, 36-hour smoothed), The correlation between the two time series is 0.849 .

altimetry, but these differences could be accounted for by smoothing in the mapping method. The surface velocities also compare reasonably well. Fig. 2.14 shows the $5 \mathrm{~m}$ velocity record from the WHOI mooring as 72-hour means along with the geostrophic velocity for the same point from the altimeter record, calculated using a centered difference. While the major currents-including the sweep from a southeastward to northwestward current in November and December 1994 and the change from a strong northeastward to southeastward current in July and August of 1995-are reproduced; there are differences between the two, and the correlation is 0.68 . Since the geostrophic velocity is dependent on the slope of the sea surface, errors in the geoid on the grid scale will manifest themselves as persistent errors in the velocity and may play a role here. Variability in the altimetry smaller than the grid scale creates some noise in the gridded product, which creates greater noise in the derivative quantity of the surface slope. Also, the observed velocities could be associated with density fields too small to show up in the altimetry, and include a small component of directly wind-driven velocity. 


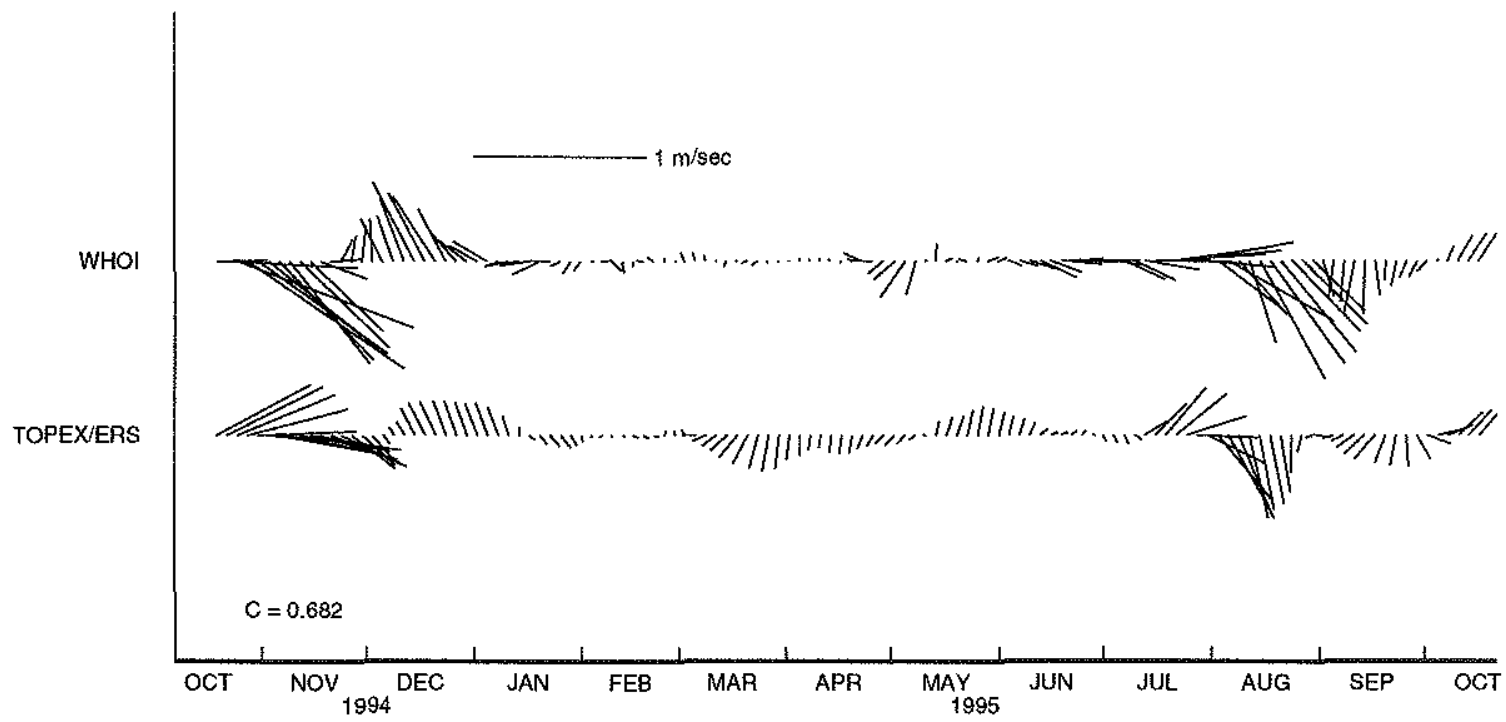

Figure 2.14 Comparison of the surface velocity from the moorings (WHOI $5 \mathrm{~m}$ ) and derived surface geostrophic velocity from the TOPEX/ERS altimetry. Correlation is 0.682 .

\subsubsection{Sea Surface Temperature imagery}

To supplement the altimeter information about the sea surface height and current structure, satellite-derived sea surface temperature is also analyzed. The data used here come from NOAA/NASA Advanced Very-High Resolution Radiometer (AVHRR) Pathfinder SST product. Details of the data extraction and calibration are given in Evans and Podesta [1998], but briefly, the AVHRR estimates the SST from radiation emitted in three bands in the infrared spectrum, where the atmosphere is fairly transparent. The three bands allow for the removal of the variable absorption of water vapor in the atmosphere through an empirical coefficient fit between satellite retrievals and in-situ data. Direct comparison of in-situ and AVHRR-derived SST show that it is more successful at identifying spatial gradients in the temperature rather than the absolute temperature, but this will suit my purpose well. The satellites carrying the AVHRR instruments are in polar sun-synchronous orbits, providing retrievals at nearly the same time each day, one ascending (daytime) pass and one descending (nighttime) pass. The largest difficulty with the AVHRR data is cloudiness, as the IR radiation measured cannot penetrate it. 
The imagery analyzed here is the "best SST" Pathfinder product, which discards poor quality data, generally those with clouds and near the edges of a swath. The nominal resolution of the data is $9 \mathrm{~km}$. To match the time base of the altimetry, daily retrievals of the SST are composited into three-day bins centered on the same time base as the altimetry, although on occasion this is extended to seven or nine-day bins to overcome cloudiness. Only nighttime passes are used, when the skin temperature measured by the AVHRR is presumably more representative of the 'bulk' mixed layer temperature as convection is active. During the daytime sharp gradients in temperature tend to be masked by diurnal heating. The time sequences that are analyzed below were chosen as a balance between even time resolution and cloudiness, which was a particular problem during the SW monsoon.

The overlaid altimetry and SST generally show excellent correspondence. For example at the tail end of the 1994 SW monsoon (see Fig. 2.15a) the contours of the altimetry clearly show the upwelling wedge and retroflection of the Somali current in the Great Whirl, as well as structure extending to the northeast towards the (future) site of the moored array. This structure in the sea surface height is echoed in the sea surface temperature. The data as a whole also show that the north-central Arabian Sea has large mesoscale variability throughout the year, particularly in the regions north and west of the moored array, and during the SW monsoon and the following intermonsoon.

The moored record showed two major episodes of strong horizontal advection (Fig. 2.2), during the beginning of the $1994 \mathrm{NE}$ monsoon, and during the latter part of the 1995 SW monsoon. The discussion here is likewise split.

\subsubsection{Northeast Monsoon}

The moored array was set in October 1994 during a period of strong horizontal advection, which alternated in sign through December 1994 (see Fig. 2.11) from initially negative (warming) to positive (cooling), then back to negative. The dynamic height and altimetry (Fig. 2.13) correspondingly show relatively low sea surface height (SSH) at the time of deployment immediately growing to high SSH through the end of October, 
decreasing during November, then increasing again through December. These are accompanied by strong surface currents changing direction from east and southeastward during October and November to north northwestward during December (Fig. 2.14). The time evolution of the surface fields in SSH and SST for this period are illustrated in Fig. 2.15cf, covering 13 October through 18 December 1994.

The interactions and movement of a pair of eddies are responsible for the strong observed horizontal fluxes. Following the sequence from Fig. $2.15 \mathrm{c}-\mathrm{f}$, the moored array starts in the interior of a cyclonic eddy (c), then encounters the edge of a strong anticyclonic eddy (d). As this eddy pair propagates westward, the moored array again samples the cyclonic eddy (e), then encounters a weaker anti-cyclonic eddy east of the original pair (f). In conditions of baroclinic, surface-intensified currents in geostrophic balance, all demonstrated true in the previous section, locally high (low) SSH will correspond to a deeper (shallower) thermocline. In a comparison of current meter moorings and altimetry, Wunsch [1997] came to the qualitative conclusion that the altimeter tends to reflect the movement of the thermocline, described by the first baroclinic mode. The overview of the array temperature (Fig. 2.6) then matches the interpretation from the altimetry, starting with the shallow thermocline of the cyclonic eddy at deployment, followed by a deepening through early November as the anti-cyclonic eddy of the pair passes by, followed in sequence by shoaling with the cyclonic eddy again in late November and a slower deepening with the adjacent anti-cyclonic eddy. The sequence of currents is also consistent with the altimetry, with the strong east and southeastward currents in October and November (c, d, e) followed by a north northwestward current in December (f). The direct comparison of the altimetry and mooring-derived dynamic height (Fig. 2.13) showed that the mooring recorded more extreme changes in height than the altimetry. The resolution and smoothing of the altimeter data likely masks the sharpness of the front-like structure that passes through the moored array at the edge of each eddy.

While the changes in the SSH at the moored array are large, the gradients in temperature revealed by the SST images are far less dramatic, not exceeding about $0.7^{\circ} \mathrm{C}$ across the eddy pair (Fig. 2.15e). Towards the end of the NE monsoon (f) they are even smaller, 


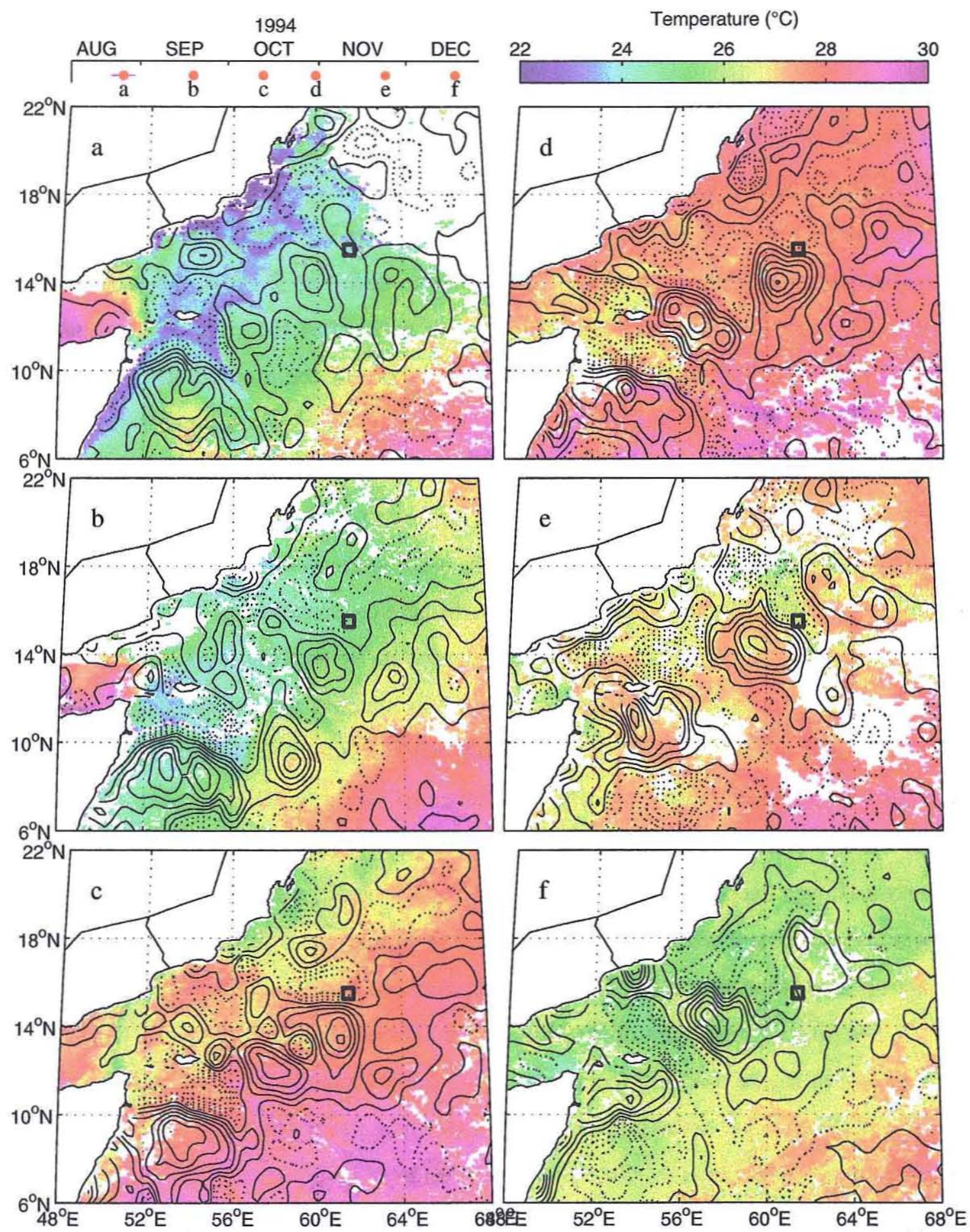

Figure 2.15 NE monsoon time series maps of altimetry and SST. Contours of SSH (every $5 \mathrm{~cm}$, solid for positive, dashed for negative) overlaid on the concurrent AVHRR SST imagery, where white indicates cloudiness. The panels $a-f$ are in chronological order, marked by the axis in the extreme upper left. 
and the SST across a large region of the basin is quite uniform, in contrast to the stronger gradients seen at the onset of the NE monsoon (c). SST is also everywhere reduced following the only extended yearly period of surface cooling over the basin. The verticallyresolved heat flux estimated at the moored array (Fig. 2.9) is consistent with this view. While there are strong heat fluxes at the base of the thermocline, associated with the advection of the large 'topography' of the thermocline past the moored array, the heat fluxes within the mixed layer are quite weak. Since the strongest currents in the deployment occur during this time, the error is quite large, and in fact none of the heat fluxes within the mixed layer during the NE monsoon are significantly different from zero (Fig. 2.10).

The eddy pair that has such a strong effect on the horizontal heat flux at the moored array continues to evolve away from the moored array, finally dissipating at the western boundary well after the NE monsoon. The propagation speed, estimated from the timelongitude slice in Fig. 2.17 is about $10 \mathrm{~cm} \mathrm{sec}^{-1}$, in remarkable agreement with the estimated first baroclinic mode linear Rossby long wave phase speed of $9.0 \mathrm{~cm} \mathrm{sec}^{-1}$. The Rossby wave speed was estimated from the vertical structure eigenfunctions of a buoyancy frequency profile measured by CTD at the moored array during the initial deployment, assuming long waves.

The origin of these mesoscale eddies can be traced back in time several months before the mooring deployment. They first appear as meanders of the Somali current extension, which appears to be a variation of the Socotra Eddy [Fischer et al., 1996], appearing in the $1994 \mathrm{SW}$ monsoon, separating warmer interior waters from cool upwelled water to the north and west (Fig. 2.15a). These meanders develop into mesoscale eddies ( $b$ and $c$ ), the strongest of which grazes the moored array. The development of these eddies from the Somali current extension may explain the sharpness of the front separating the anticyclonic and cyclonic eddies in the sampled pair. This development seems analogous to the development of meanders and rings in other current systems, such as Gulf Stream rings. 
The 1994 SW monsoon seems to have a particularly well-defined Somali current extension when compared to the 1995 SW monsoon, which was sampled by the moored array. Towards the end of the 1994 SW monsoon the Somali current extension is clearly defined in the SST by a sharp gradient of over $2^{\circ} \mathrm{C}$, and its meanders are captured in the altimetry. It extends more than $600 \mathrm{~km}$ northeast of Socotra, nearly to the site of the array. By contrast during the 1995 SW monsoon the Somali current extension seems far less organized, and more limited to the vicinity of Socotra island (more typical of the Socotra Gyre described by Fischer et al. [1996]). While two realizations do not make for a good statistical sample, the range and breakup of the Somali current extension appears to have implications for modulation of the upper ocean heat budget long after each SW monsoon season.

\subsubsection{Southwest Monsoon}

The 1995 SW monsoon (June-September) heat budget estimated for the moored array starts fairly quietly, but a major episode of cooling horizontal advection both within the mixed layer and below is observed during the latter part of the SW monsoon (late Julyearly August), which is roughly balanced in the temperature trend observed at the array. This period from late July through early August is marked by a sharp and sudden decrease in the SSH (Fig. 2.13) and accompanied by strong eastward then southeastward currents (Fig. 2.14). The temperature and salinity profiles (Fig. 2.6 and Fig. 2.21) undergo large changes during this time period. The time evolution of the SSH and SST fields during this period is illustrated in Fig. 2.16.

The development of a broad swath of coastally-upwelled water is evident in the June SST imagery (Fig. 2.16a and b). By June 1995 the ECMWF wind analysis has a broad scale pattern of southwesterly winds, driving coastal upwelling along the Omani coast. Clouds tend to form as the moist, nearly saturated air of the SW monsoon [Weller et al., 1998] meets cool upwelled water, often obscuring the view of the SST in these regions. This is apparent along the coast in the entire two-month sequence depicted in Fig. 2.16. 


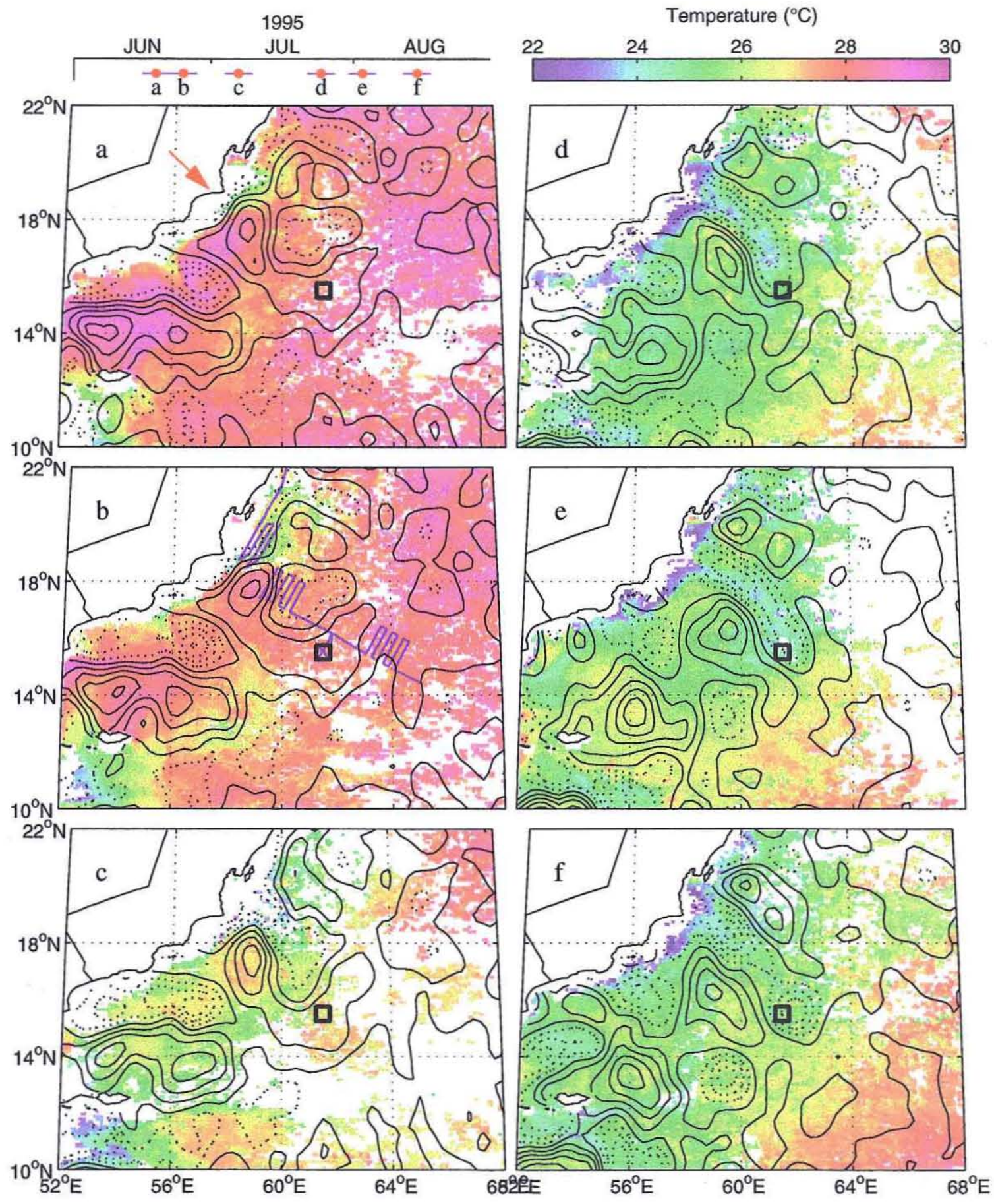

Figure 2.16 SW monsoon time series maps of altimetry SSH and SST imagery. Contours of SSH (every $5 \mathrm{~cm}$, solid are positive, dashed negative) are overlaid on the AVHRR SST imagery. The panels $a-f$ are in chronological order, with the times given by the axis in the extreme upper left. The red arrow in $a$ points to Ra's Madrakah, while the blue lines in $b$ represent the SeaSoar survey track during this period. 
As early as mid-June there is evidence of the offshore transport and development of a filament of cold, upwelled water off of Ras Madrakah (arrow in Fig. 2.16a). The filament continues to develop through July, finally reaching the moored array in late July (Fig. 2.16b, c, d). In its early stages the filament appears to be influenced in part by an anti-cyclonic eddy to its south. A detailed Seasoar survey of the filament was made from 20 June to 3 July 1995, the track of the survey is shown in the concurrent panel of SSH and SST (Fig. 2.16b). This particular filament has been described by Brink et al. [1998], Arnone et al. [1996], and by Manghnani et al. [1998].

The development of the filament includes a strong offshore transport of cool water that reaches the moored array in late July (Fig. 2.16d). This is concurrent with the sharp drop in the observed dynamic height and SSH observed at the moored array (Fig. 2.13). The temperature at the array also shows a sudden shoaling of the thermocline and cooler surface water (Fig. 2.6) coincident with strong heating (see Fig. 1.5). The SST imagery shows a difference between the filament and surrounding waters of about $2-3^{\circ} \mathrm{C}$, consistent with the observed drop at the moored array, and much stronger than the gradients observed during the NE monsoon.

The evolution of the filament after its initial influence on the location of the moored array is slow, and it appears to fall apart and its surface signal subsides. The weakening of the strong offshore jet-like transport is evident through early and mid-August (Fig. 2.16e and f). The SST signature of the filament is obscured by clouds, but the altimetry shows a further separation of the weak cyclonic feature at the end of the filament (Fig. 2.16f) with a disappearance of any noticeable remnants by the end of September 1995.

Moving in the other direction in time, the anticyclonic feature that forms the southwestern boundary of the filament first appears in mid-May of 1995, several hundred kilometers offshore and east of Ras Madrakah. This would support the contention of Manghnani et al. [1998] that the coastal filament formation is dependent on the details of the mesoscale eddy field. A similar linkage between the mesoscale eddy field and the complex flow and filaments of the California Current system has been made [Brink and Cowles, 1991; Strub et al., 1991; Shearmann et al., 1999]. 


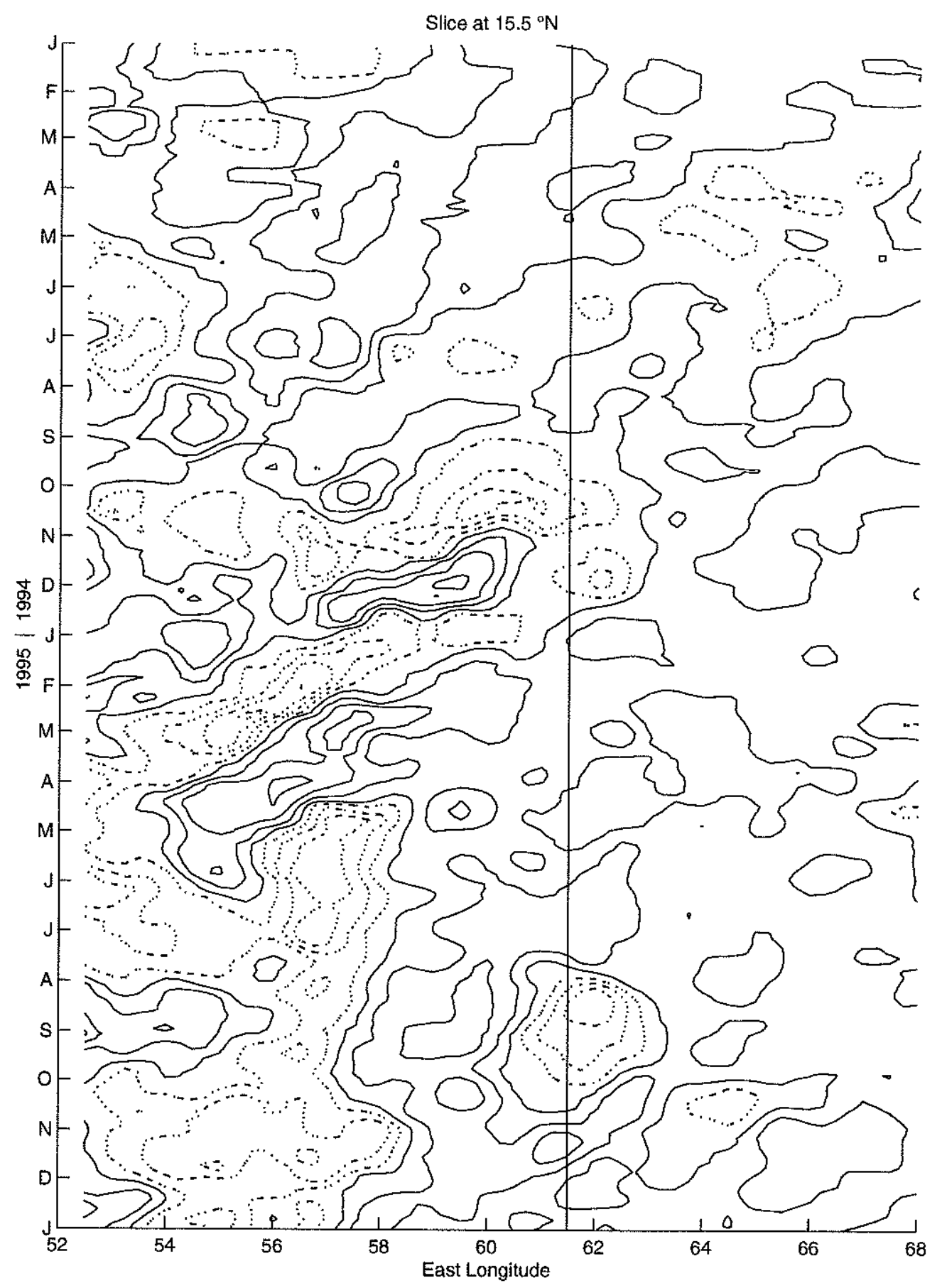

Figure 2.17 Time-longitude plot of ssh anomaly at the latitude $(15.5 \mathrm{~N})$ of the mooring, with the longitude of the mooring marked by the vertical line. Contours (positive solid) every $5 \mathrm{~cm}$. There is evidence of westward propagation of anomalies. The coastal filament appears as a localized area of low ssh in July and August of 1995 at the longitude of the mooring. 


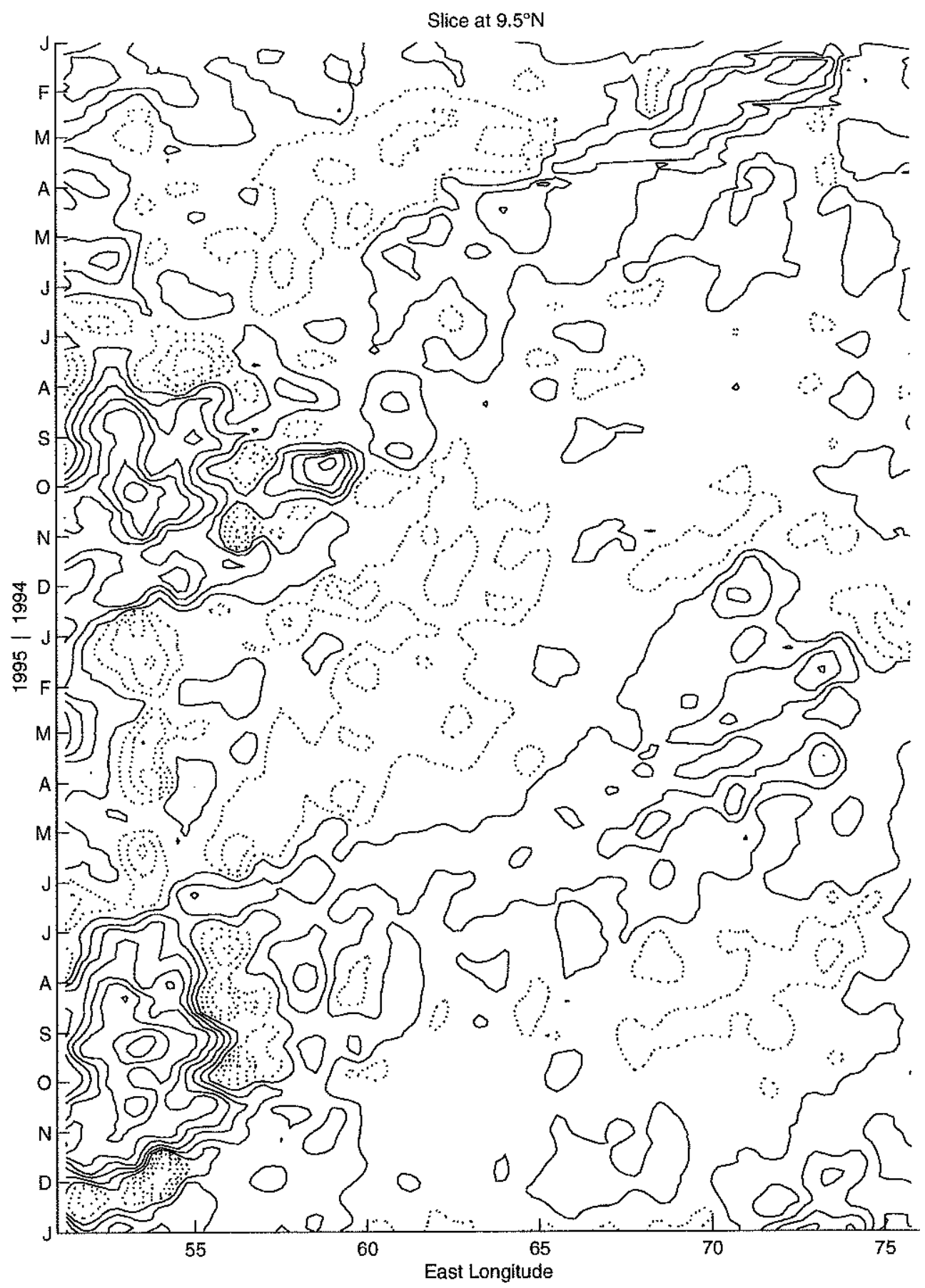

Figure 2.18 Time-longitude plot at $9.5^{\circ} \mathrm{N}$, showing more coherent patterns of westward Rossby wave propagation. 


\subsubsection{Wave propagation}

While the propagation of the NE monsoon eddy pair away from the moored array seems to follow linear Rossby wave dynamics with a nearly matching phase speed, the time-longitude slice at $15.5^{\circ} \mathrm{N}$, the central latitude of the array (Fig. 2.17), indicates that this particular eddy pair is the strongest wave-like signal. The SSH anomalies are generally larger to the west of the array longitude, and smaller to the east, and there is evidence of westward propagation of features, particularly to the west of the array. The filament is observed as a strong depression of the sea surface in August, and there is no clear signal of its propagation westward.

The view several degrees in latitude to the south, at $9.5^{\circ} \mathrm{N}$ (Fig. 2.18), near the center of the formation region of the Great Whirl [Fischer et al., 1996], is different, with strong signals generated seasonally at the eastern boundary, propagating westward. There are clear indications of the formation of multiple anticyclonic eddies in the Laccadive High region (centered about $10^{\circ} \mathrm{N}, 70^{\circ} \mathrm{E}$, see Bruce et al. [1998]) during the NE monsoon, their propagation westward, and final inclusion as remote forcing into the Great Whirl system the subsequent SW monsoon season.

\subsubsection{Basinwide mean and seasonality}

The moored record provides one realization of the upper ocean heat budget at one point for one complete annual cycle. The two periods of strong horizontal advection associated with mesoscale eddies each influenced the heat budget in a different way. During the NE monsoon, mesoscale features with small SST signatures but big variations in thermocline depth propagating westward brought strong horizontal heat fluxes at depth. During the SW monsoon, a coastal filament brought strong horizontal heat fluxes both within the mixed layer and below. So while different features influenced the upper ocean heat budget in different ways, the altimetry affords an opportunity to see the horizontal distribution of these mesoscale features, and some measure of what their influence might be on the upper ocean evolution. 


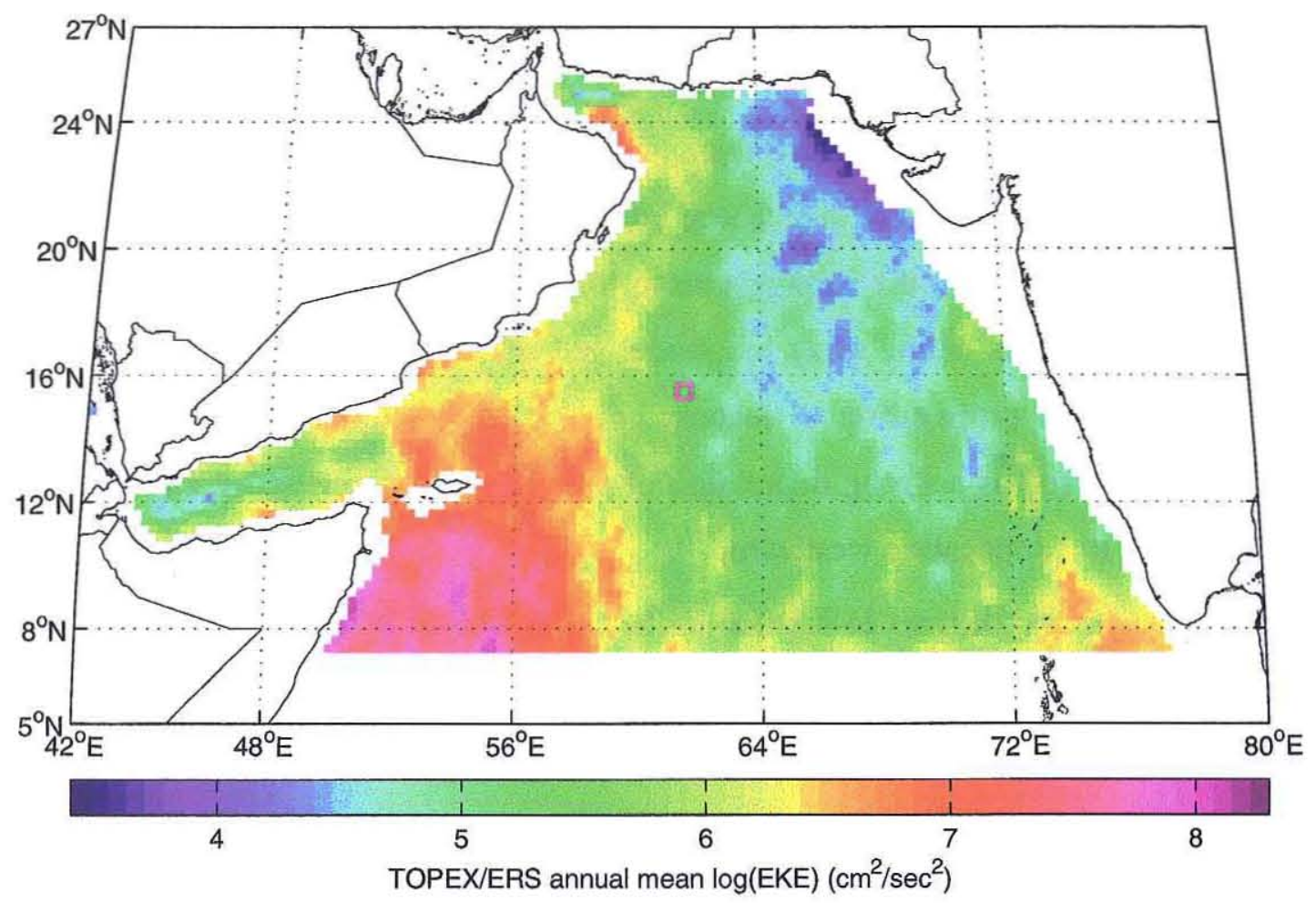

Figure 2.19 Mean eddy kinetic energy (in log scale) from the TOPEX/ERS anomaly field, calculated using data from the seven years 1992-1999. The dominance of the annually reversing Somali current system is apparent, and there are elevated levels along the Arabian coast and at low latitudes along the southernmost extent of the data. The region east of the mooring has low mean EKE.

The mean eddy kinetic energy of the surface field, derived from the altimeter geostrophic velocities over the seven years of available data (1992-1999), is shown in (Fig. 2.19). For this calculation, an 'eddy' is considered anything not in the mean flow, and since the mean of the altimetry has been removed, the EKE is simply the kinetic energy of the surface geostrophic flow described by the altimetry field. This definition of eddy then encompasses the scales from the small coastal filaments to the Great Whirl (GW) of the Somali current.

The map suggests that there is large variability in the EKE distribution in the Arabian Sea. Independent estimates of the surface EKE from ADCP observations during the 
JGOFS cruises [Flagg and Kim, 1998] match the patterns and magnitudes inferred from the altimetry quite well, with elevated levels of EKE (approaching $600 \mathrm{~cm}^{-2} \mathrm{sec}^{-2}$ ) near the Omani coast at Ras Madrakah and Ras al Hadd, dropping suddenly as one moves offshore along the northern JGOFS line (to values below $100 \mathrm{~cm}^{-2} \mathrm{sec}^{-2}$, see Fig. 1.4 for the JGOFS cruise track) and more gradually along the southern line.

In a global analysis of altimeter-derived EKE, Stammer and Wunsch [1999] found the largest eddy source terms were associated with the ocean flow field, with only a small fraction of the EKE associated with the wind, an observation that is consistent with what is found here. Located to the south of Socotra and east of the Somali coast the Great Whirl (GW) in fact dominates the EKE. There are extended regions of elevated EKE both to the north of Socotra and extending east and northeast from Socotra into the region of the Socotra Gyre. There is elevated eddy activity all along the Arabian coast, including into the Gulf of Oman and off the tip of Ras al Hadd, apparently associated with the instabilities of the coastal current. The quietest region of mesoscale activity is found in the northeastern portion of the basin. There is also elevated activity in the Laccadive High region and westward towards the GW, corresponding with the generation and propagation of mesoscale features across the basin as seen in Fig. 2.18. The pattern of crossings in the TOPEX altimetry tracks is evident here, as the TOPEX track separation is wider than the smoothing in the optimal interpolation, and the greatest amount and frequency of data incorporated into the optimal interpolation is found in the vicinity of these TOPEX crossing points.

Is there a seasonality to the EKE field, particularly in nearshore regions? To investigate this, I used all seven years of available altimetry data. The decorrelation time scale in the EKE, set by the propagation of mesoscale features, was generally about 20-30 days, though it varied across the basin. Taking the SW monsoon to be the months of June, July, and August, and the NE monsoon to be November, December, and January, the seven years of data then produces about 25 independent realizations for each monsoon season at each point. Fig. 2.20 shows the difference in mean EKE between the SW and NE monsoon seasons (SW-NE), scaled by the pointwise $90 \%$ confidence limit in the 


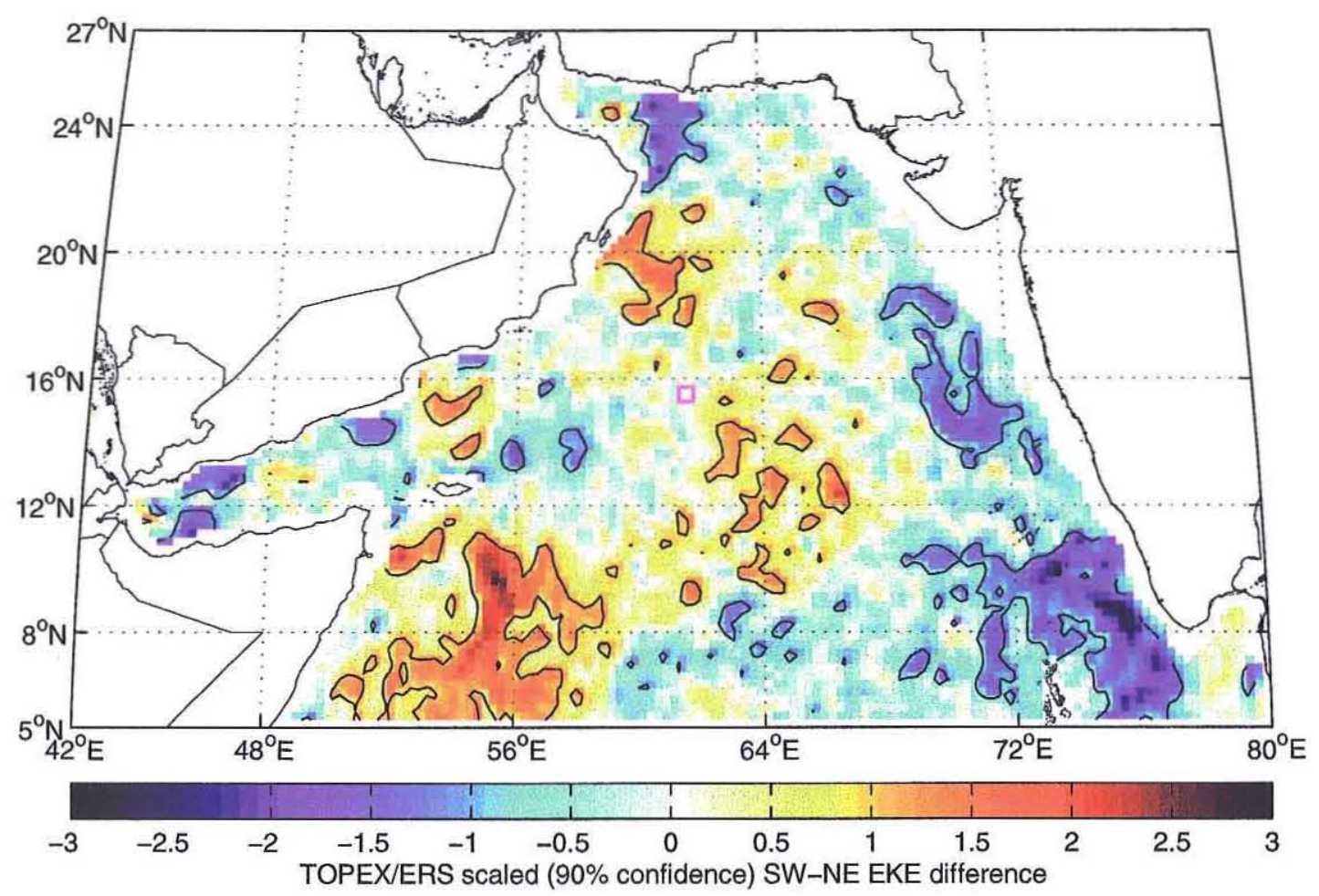

Figure 2.20 The seasonality in EKE: the mean EKE difference between 19921999 SW - NE monsoons, scaled by the pointwise $90 \%$ confidence limit of a difference. Contours are drawn at \pm 1 . A positive (negative) value of one indicates that there is greater (less) EKE, on average, during the SW monsoon over the NE monsoon with $90 \%$ confidence. EKE is elevated during the SW monsoon in the Great Whirl, between Socotra and the Arabian coast, in a region southeast of Masirah, and mildly, in the central portion of the basin. EKE is elevated during the $\mathrm{NE}$ monsoon in the Laccadive High region, along the central Indian coast, in the Gulf of Oman northeast of Ras al Hadd, and mildly in the western Gulf of Aden.

difference. This confidence limit is based on the $90 \%$ confidence tails on the means of the seasonal EKEs, using a 25 degree of freedom $\chi^{2}$ probability distribution. Since the EKE is proportional to the surface geostrophic velocities squared, it is assumed to have a $\chi^{2}$ distribution, and histograms of the EKE distribution roughly bear this out.

During the SW monsoon, elevated levels of EKE are noted in a number of regions. The largest is in the vicinity of the Somali current/Great Whirl, south of Socotra and east of the Somali coast. In low latitudes, because of the spatial filtering inherent in the altim- 
etry processing, the edges of large features such as the Great Whirl are preferentially selected. There is also a region extending offshore about $400 \mathrm{~km}$ southeast from Masirah Island, and another between Socotra and the Arabian coast south of Ras Mirbat. Both of these likely have coastal origins [Brink et al., 1998; Arnone et al., 1996]. Mild elevations in EKE during the SW monsoon are also found in a broad region of the Arabian Sea centered about $64^{\circ} \mathrm{E}, 12^{\circ} \mathrm{N}$, southeast of the moored array. The source of this is unclear. One possibility is that instabilities of the accelerating currents created by the onset of the monsoon could develop into mesoscale features (K. Brink, personal communication). Strong gradients in altimetry and SST images in this region during the SW monsoon (see Fig. 2.15a and b) hint at the existence of a current flowing northeastward, and there are suggestions of such flow in shipdrift climatologies [Rao et al., 1989]. Such a current could be a source of eddy generation and increased EKE, though if it exists, it was obscured in the eddy field in the ADCP observations of Flagg and Kim [1998].

During the NE monsoon, elevated levels of EKE are noted in the Laccadive High region west of the southern tip of India. These are clearly seen propagating westward in the altimetric record (Fig. 2.18). Bruce et al. [1998] suggested that strong negative wind stress curl in this region during the NE monsoon generates eddies, or enhances remotely propagated anticyclonic eddies from the Bay of Bengal. Further regions of enhanced NE monsoon EKE are found along the central Indian coast and in the Gulf of Oman, northeast of Ras al Hadd. Flagg and Kim [1998] described the seasonal progression of the Ras al Hadd Jet, which had its strongest flows during the NE monsoon. There are also mildly elevated levels of EKE in the western Gulf of Aden during the NE monsoon. A more stringent $95 \%$ confidence interval test calls this into doubt, but still shows elevated levels of EKE during the SW monsoon in the Great Whirl and southeast of Masirah, and elevated levels during the NE monsoon northeast of Ras al Hadd, along the central Indian coast, and in the Laccadive High region. 


\subsubsection{Discussion}

The influence of mesoscale flows on the upper ocean heat budget during each observed monsoon season observed is clear. They are large transporters of heat, although in different ways. The $1994 \mathrm{NE}$ monsoon observations were marked by the passage of a mesoscale eddy pair, originally formed in the region of the Somali current extension. This eddy pair advected large changes in the thermocline depth past the moored array, but brought smaller changes in the surface temperature. In contrast the $1995 \mathrm{SW}$ monsoon observations were strongly influenced by the extension of a coastal filament more than $600 \mathrm{~km}$ offshore to the site of the moored array. The filament brought not only a sharply shallower thermocline, but much cooler surface temperatures.

The distribution and seasonality of the eddy kinetic energy measured by the altimetry suggests that mesoscale eddies are widespread in the Arabian Sea, particularly along the Arabian and Somali coasts and at low latitudes. The moored array, in fact, was located in a region with below-average EKE for the Arabian Sea, although there is a large region in the northeast of the basin with even lower EKE. The elevated levels of EKE along the Arabian and Somali coasts during the SW monsoon are particularly relevant, since these eddies may transport coastally-upwelled water offshore, a process captured by the moored array. This offshore transport of coastally-upwelled water then plays an important role not only in the upper ocean heat budget, but directly in the SST evolution.

\subsection{Water mass properties and the mesoscale flow}

Further in-situ observations taken concurrently with the moored array observations allow a clearer view of the events of the SW monsoon. My objective here is to demonstrate that coastally-upwelled water did advect out to the site of the mooring, and to examine the structure of the filament as it relates to the changes observed at the moored array. The changes brought by the coastal filament, which bring new and lasting water mass changes at the site of the mooring, stand in contrast to the changes observed during 
the NE monsoon, which are smaller and more transient. The coastal filament suggests a general mechanism that allows for the incorporation of deeper water upwelled at the coast into the mixed layer and upper ocean well offshore.

\subsubsection{Data}

SeaSoar is an undulating, towed platform containing conductivity, temperature, and pressure sensors, as well as bio-optical sensors. It is typically towed between about 1-300 $\mathrm{m}$ below the surface, with $3 \mathrm{~km}$ horizontal resolution along-track. Four cruises were undertaken during 1994-1995 [Lee et al., 2000], mapping the southern U.S. JGOFS line (Fig. 1.4), intensively surveying two 'radiator' patterns inshore and offshore of the moored array position, and making one 'butterfly' pattern around the moored array. Alerted by AVHRR imagery, the SW monsoon survey (20 June - 3 July 1995) also included a filament radiator survey near the coast between Ras Madrakah and Masirah Island (see Fig. 2.16b). Details of the errors and processing of the SeaSoar data can be found in Lee et al. [2000]. A two-dimensional objective mapping method at fixed depth levels created a three-dimensional gridded 'snapshot' of the upper ocean in each of these radiator patterns (C. Lee, personal communication), which took about 2.5 days to sample. The internal tide, diurnal variations, and near-inertial motions are thus aliased into the data for each survey, but are not large enough to obscure mesoscale features and the geostrophic flow.

The UW-S mooring was the only one of the four returning data in the array which measured concurrent high-resolution profiles of both salinity and temperature, using a profiling current meter (PCM). The PCM is a sliding-wire instrument measuring horizontal currents, temperature, and salinity [Eriksen et al., 1982] averaged into $5 \mathrm{~m}$ bins. One profile between about 20 and $200 \mathrm{~m}$ depth was made every four hours. 

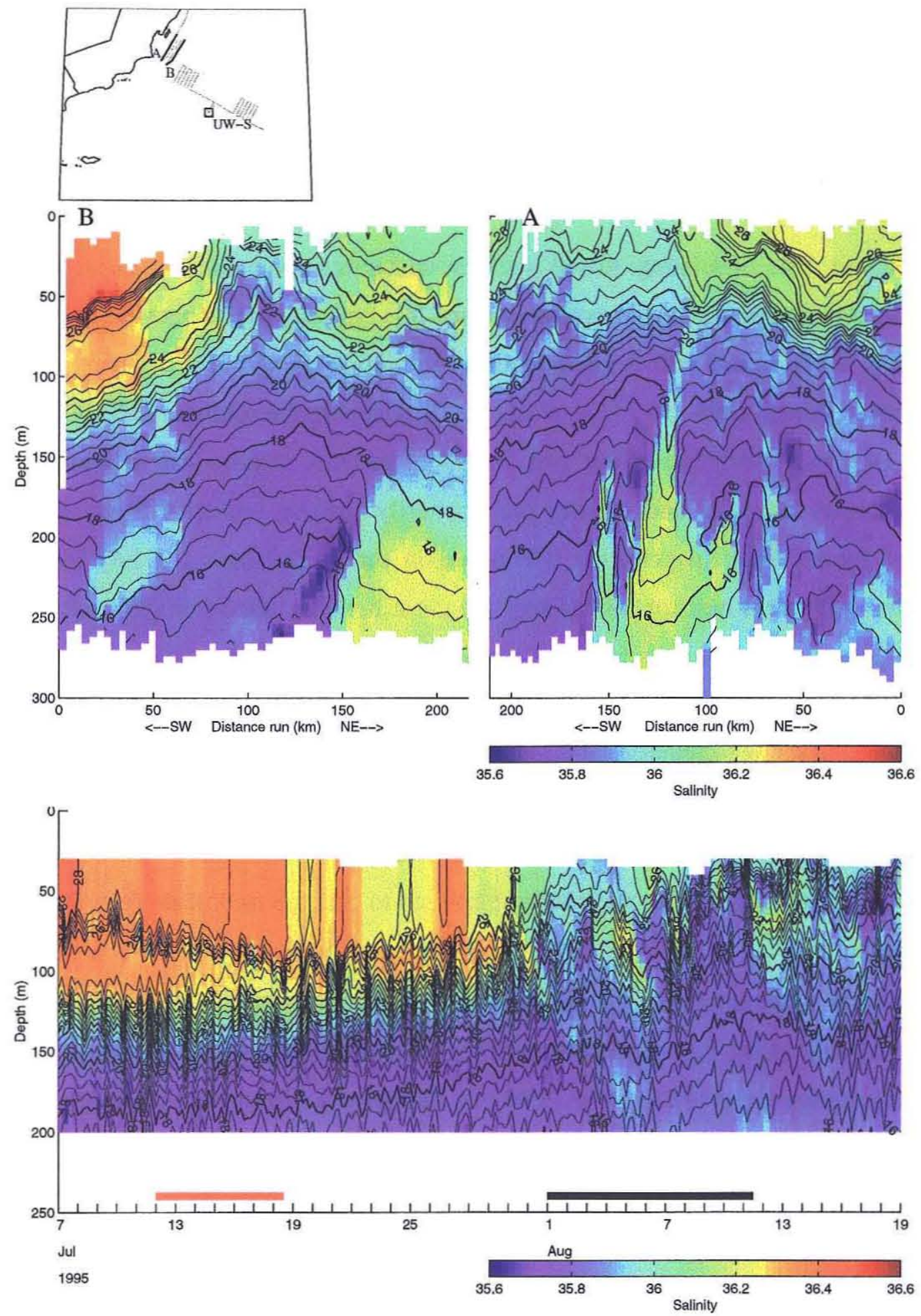

Figure 2.21 Sections across the SW monsoon filament, through space using the Seasoar (top, with inset map showing the location of the two sections), and in time at the UW-S mooring (bottom, where bars indicate times extracted in Fig. 2.22). 


\subsubsection{Water mass changes during the SW monsoon}

At the time of the SW monsoon SeaSoar survey, coastally-upwelled water is just beginning to be advected offshore (Fig. 2.16b). The inner, filament radiator is nearly entirely within the upwelled water. Two slices from the filament radiator are shown in the upper panel of Fig. 2.21. Slice A ranges from $50-100 \mathrm{~km}$ offshore, while slice B is about $75 \mathrm{~km}$ farther offshore. The southwestern corner of slice B has some of the high surface salinity (36.3 and up) water characteristic of the Arabian Sea as a whole. The strongest filament velocities are associated with the strongly tilting isotherms found in this southwestern corner. The surface waters on the coastal side of this front have the characteristics (salinity less than 36.2 and temperatures less than $25^{\circ} \mathrm{C}$ ) of the deeper water (100$150 \mathrm{~m}$ ) farther offshore, with only slightly elevated temperatures. Both slices (and the entire filament radiator) are primarily composed of this fairly low-salinity and cool-temperature water. There is a fair amount of interleaved structure in the salinity data, including large masses of water with characteristics of the diluted upper part of Persian Gulf water (which mixes in along the 26.6 isopycnal surface from high salinities, up to 37 in the Gulf of Oman, here diluted to 36.2, Wyrtki [1971]) concentrated below $200 \mathrm{~m}$.

Coincident in time with the strongest horizontal heat fluxes of the SW monsoon (Fig. 2.11 late July through early August), the salinity and temperature structure at the moored array changes suddenly (Fig. 2.21 bottom panel). The high surface salinity that has been characteristic of the record thus far is replaced with surface salinities that are the same as those found in the upper thermocline. The temperature drops throughout the water column.

To examine whether coastally-upwelled water does in fact move to the site of the moored array, the temperature-salinity (TS) properties of the coastally-upwelled water sampled by the SeaSoar survey are compared to the changing TS properties observed at the mooring. The SeaSoar filament radiator was surveyed from 21-24 June 1995, nearly one month before the observed change in TS properties at the moored array. The entire filament radiator is tagged as 'filament' water, and its TS properties are displayed in 

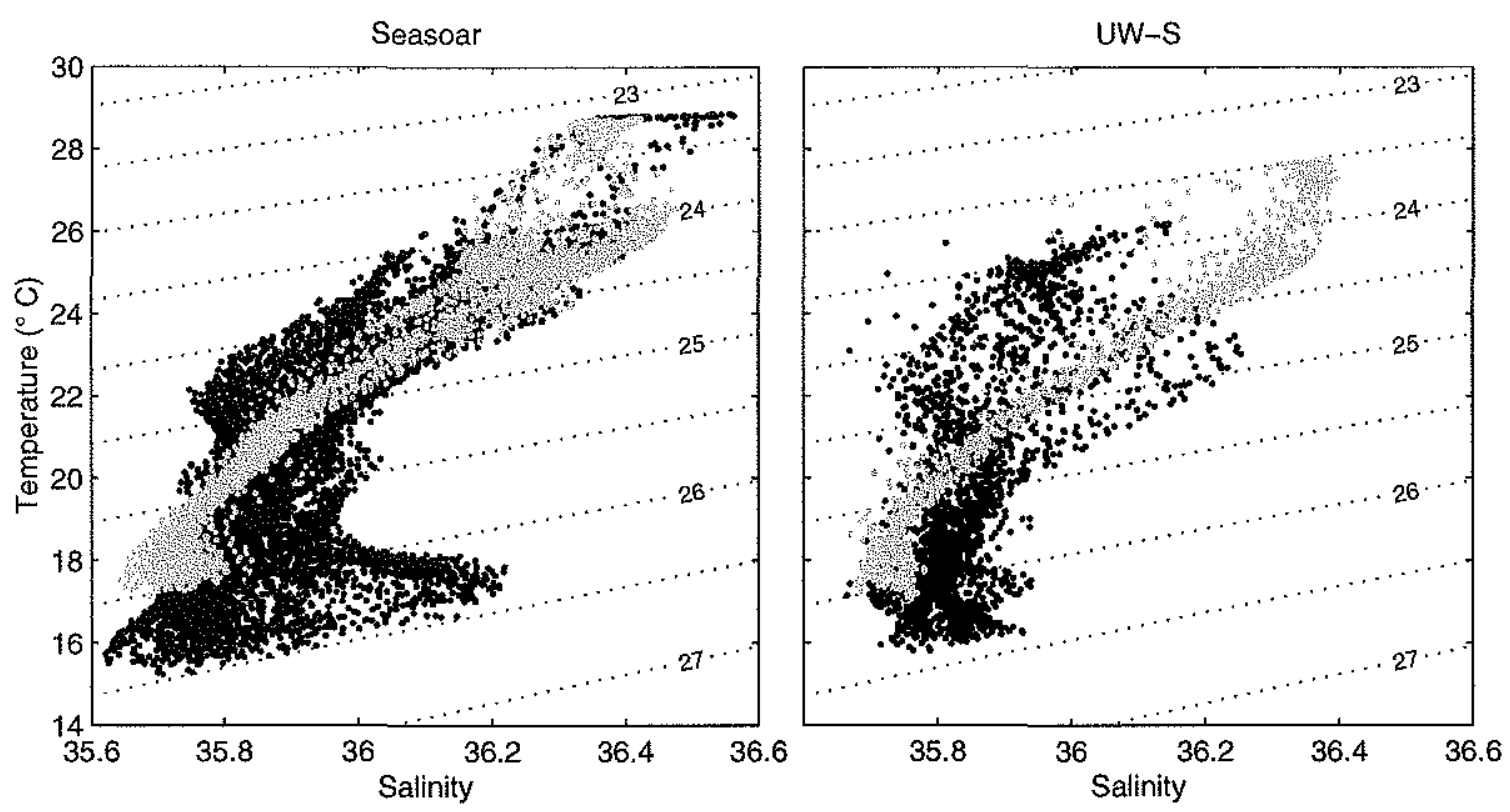

Figure 2.22 TS diagrams depicting the difference between the mean water mass during the SW monsoon (gray) and the coastally upwelled water (black). The left panel shows Seasoar spatial data, while the right panel shows the UW-S moored time series data. The distinguishing characteristics of the upwelled water are the two lobes above and below the mean water mass line. The lobe above is coastally upwelled water that has been in contact with the atmosphere, warming it, while the lobe below is remnants of the Persian Gulf outflow.

black in the left panel of Fig. 2.22. The gray are the TS properties sampled by the SeaSoar in the butterfly pattern made around the moored array (29-30 June 1995), representative of the composition of offshore waters. The right-hand panel in Fig. 2.22 contains TS properties measured in a fixed spot at the UW-S mooring during two different time periods, separated by the strong advective event, which are marked by the black and gray (red) bands at the bottom of the lower panel of Fig. 2.21. The gray marks the period from 12-18 July 1995 before significant advection has taken place, representative of the water mass properties at the moored array in the early part of the SW monsoon. The black marks the period from 1-11 August, after a period of strong horizontal advection.

The gray in each panel traces similar water masses, with high salinities in the nearsurface compensated by much warmer temperatures. This is not surprising, since the sam- 
ples come from the same geographic region, separated in time by about two weeks. The black samples in each panel are separated by about $500 \mathrm{~km}$ and one month in time, so similarities between the two, and differences from the mean SW monsoon TS properties in gray, are strong indicators of offshore transport of coastally-upwelled water, as suggested by the SSH and SST imagery. In the SeaSoar survey, there are two primary differences between the onshore (black) and offshore (gray) properties. In the deepest portions of the survey there is a strong presence of saline (35.9-36.2) water on the 26.0-26.5 isopycnals, compensated in temperature. This is likely the upper diluted part of Persian Gulf water [Wyrtki, 1971] which makes its way from the Gulf of Oman along the Omani coast, often in discrete masses. The other major difference comes in lighter density classes, where waters with salinities between 35.8 and 36.2 appear closer to the surface and warmer than in the offshore survey. A reasonable inference is that deeper waters are being drawn to the surface in coastal upwelling, then undergoing transformation (heating) under the influence of air-sea fluxes. The surface heat fluxes estimated from bulk measurements made aboard the $\mathrm{R} / \mathrm{V}$ Thompson are strongly positive in the filament survey (about $200 \mathrm{~W} \mathrm{~m}^{-2}$ in the daily average), and remain positive in the inshore radiator survey (about $100 \mathrm{~W} \mathrm{~m}^{-2}$, Lee et al. [2000]).

The strong horizontal advection at the site of the moored array one month later brings with it water with quite different TS properties. Like the coastally-upwelled water sampled by the SeaSoar, at the deepest range (around $200 \mathrm{~m}$ ) there is an increase in density (up to 26.5) and an increase in salinity. Though it is not as pronounced as the strong salinities on the 26.5 isopycnal sampled by in the filament survey, this is indicative of some mixing with the Persian Gulf water. Near the surface, salinities are lower than before, more typical of the mid-depth (100-150 m) waters previously, but have higher temperatures than those observed in the filament survey. This would again be consistent with the contact these waters have had with the atmosphere under the strongly heating fluxes of the SW monsoon. Taken together, the filament SeaSoar survey and the changing TS properties at the fixed point of the moored array are consistent with coastally- 
upwelled waters making their way from near-shore areas well offshore to the site of the moored array.

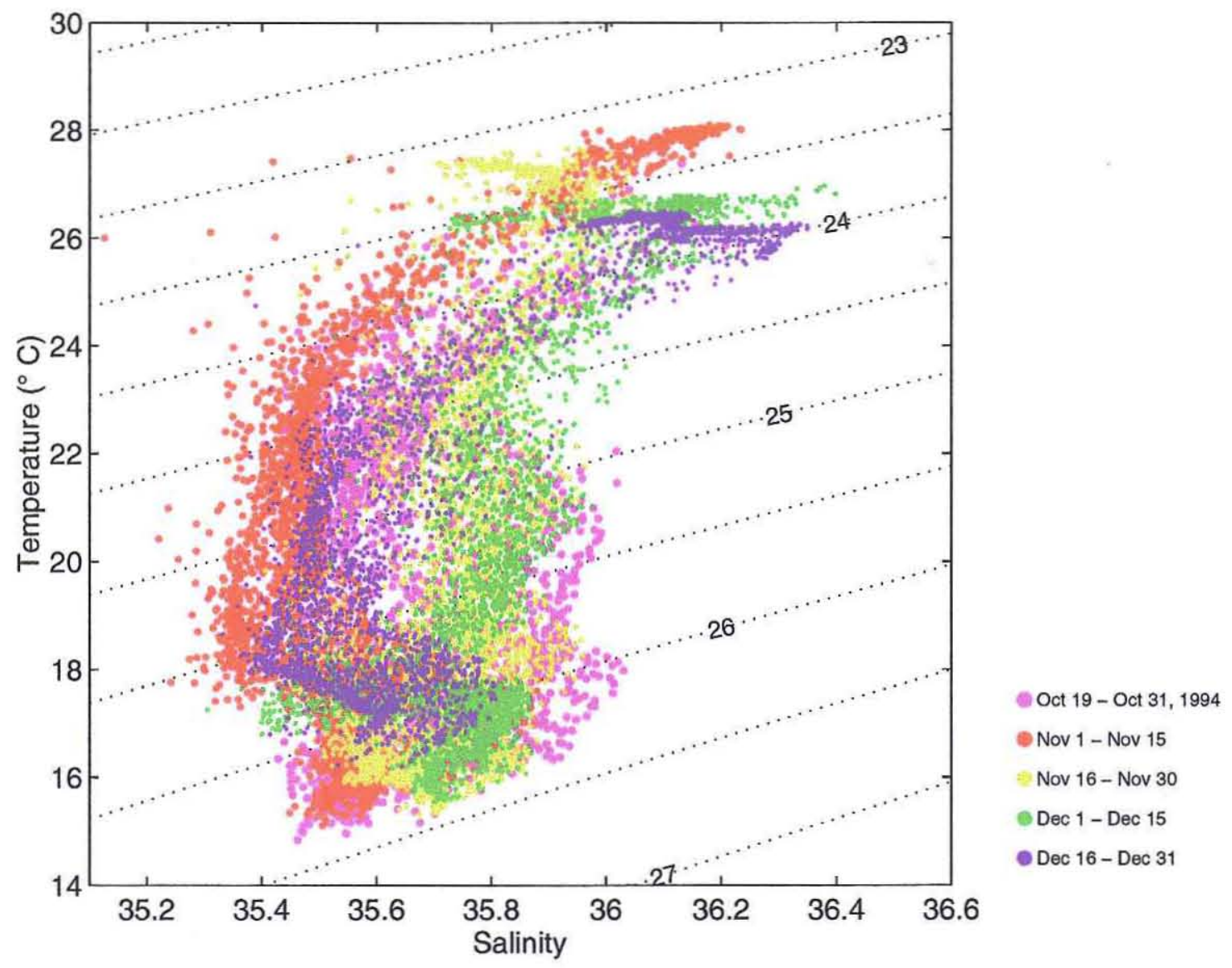

Figure 2.23 TS diagram depicting the evolution of water masses during the eddy passage of the early NE monsoon, from the UW-S PCM instrument. Water of intermediate depth (between the 24 and 26 isopycnal surfaces) begins the record with a wide range of salinities (35.5-36, purple), becomes fresh under the influence of the anticyclonic mesoscale feature ( $r e d$ ), then saltier under the influence of the cyclonic feature (yellow and green), then fresher again in the next anticyclonic feature (blue). Near-surface waters do cool with time, but exhibit less variability in TS space. 


\subsubsection{Water mass changes during the NE monsoon}

In contrast to the lasting change in water mass properties brought by the coastal filament, the changes during the strong horizontal heat advection of the NE monsoon are smaller and more temporary. Fig. 2.23 shows the evolution of TS properties from the UW-S mooring under the influence of the sequence of cyclonic and anticyclonic mesoscale features passing by the moored array. Water of intermediate depth (between the 24 and 26 isopycnal surfaces, all above $200 \mathrm{~m}$ ) becomes fresh under the influence of the first anticyclonic mesoscale feature (Fig. 2.15d), then saltier with the cyclonic feature (Fig. 2.15e), and fresher again with the passage of the next anticyclonic feature (Fig. 2.15f). This suggests that the inferred Somali current extension acts as a boundary between two water masses below the mixed layer, and moves back and forth across the moored array through the NE monsoon.

\subsubsection{Structure of the SW monsoon coastal filament}

The temperature of the coastally-upwelled water increases as it travels offshore in the strongly heating conditions of the SW monsoon. This suggests that salinity is a more conservative tracer of water masses than temperature. At the site of the mooring and in the offshore regions of the SeaSoar survey during the SW monsoon, the 36.1 isohaline surface falls between 100 and $150 \mathrm{~m}$ in depth, in the upper thermocline. Very close to the coast it outcrops, and is a good marker of the strong front between the coastally-upwelled and offshore waters. The shape of this surface in the SeaSoar survey is indicated in Fig. 2.24a. The surface outcrops along the southwestern and northeastern edges of the filament radiator, then outlines the extension of the filament through the center of the inshore radiator. It does not outcrop in this region, but appears very close to the surface in the northeastern portion of the inshore radiator, descending to about $50-60 \mathrm{~m}$ as the filament extends offshore. The surrounding waters, at the southwestern end of the filament radiator and surrounding the filament in the inshore radiator, are much like the waters 

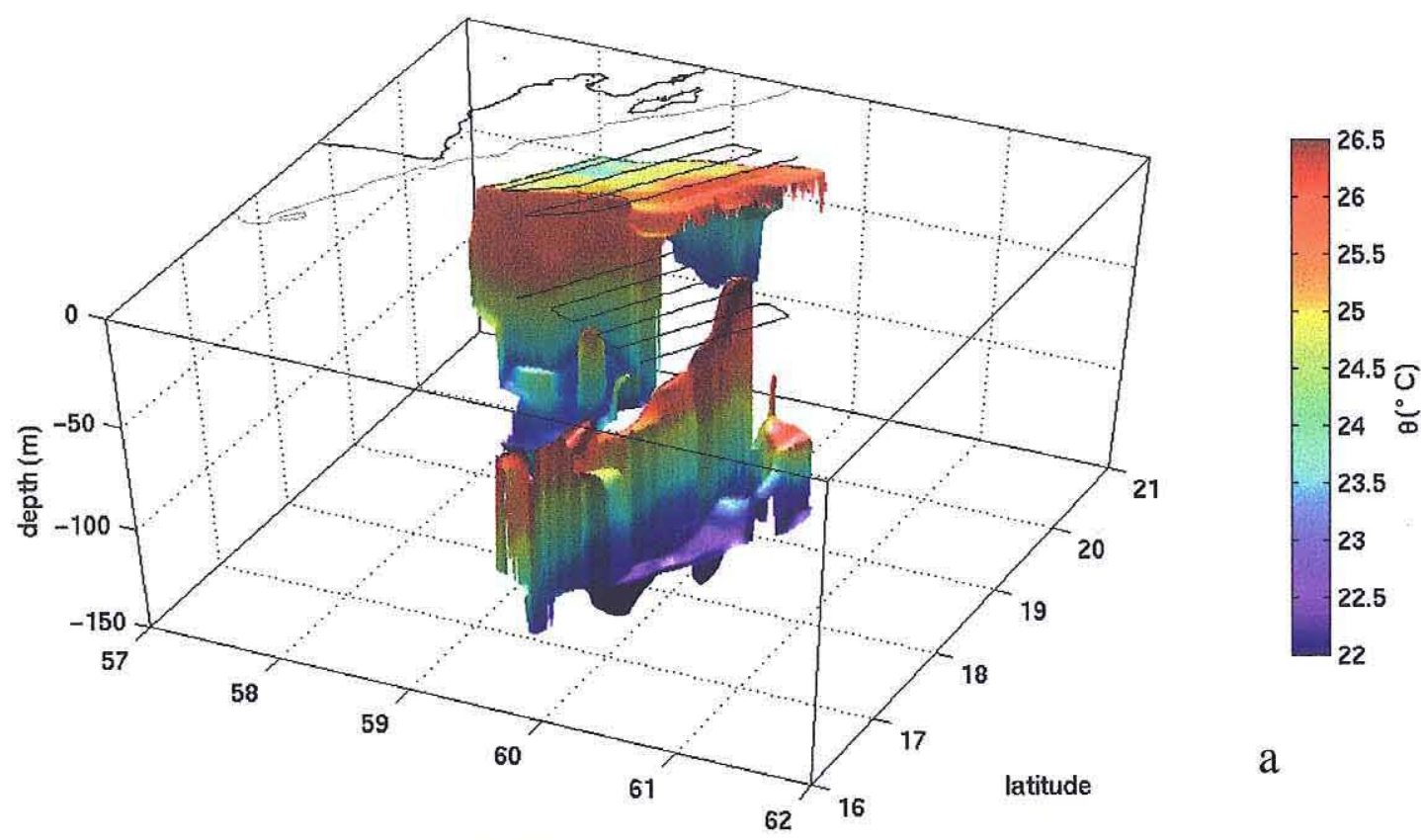

longitude

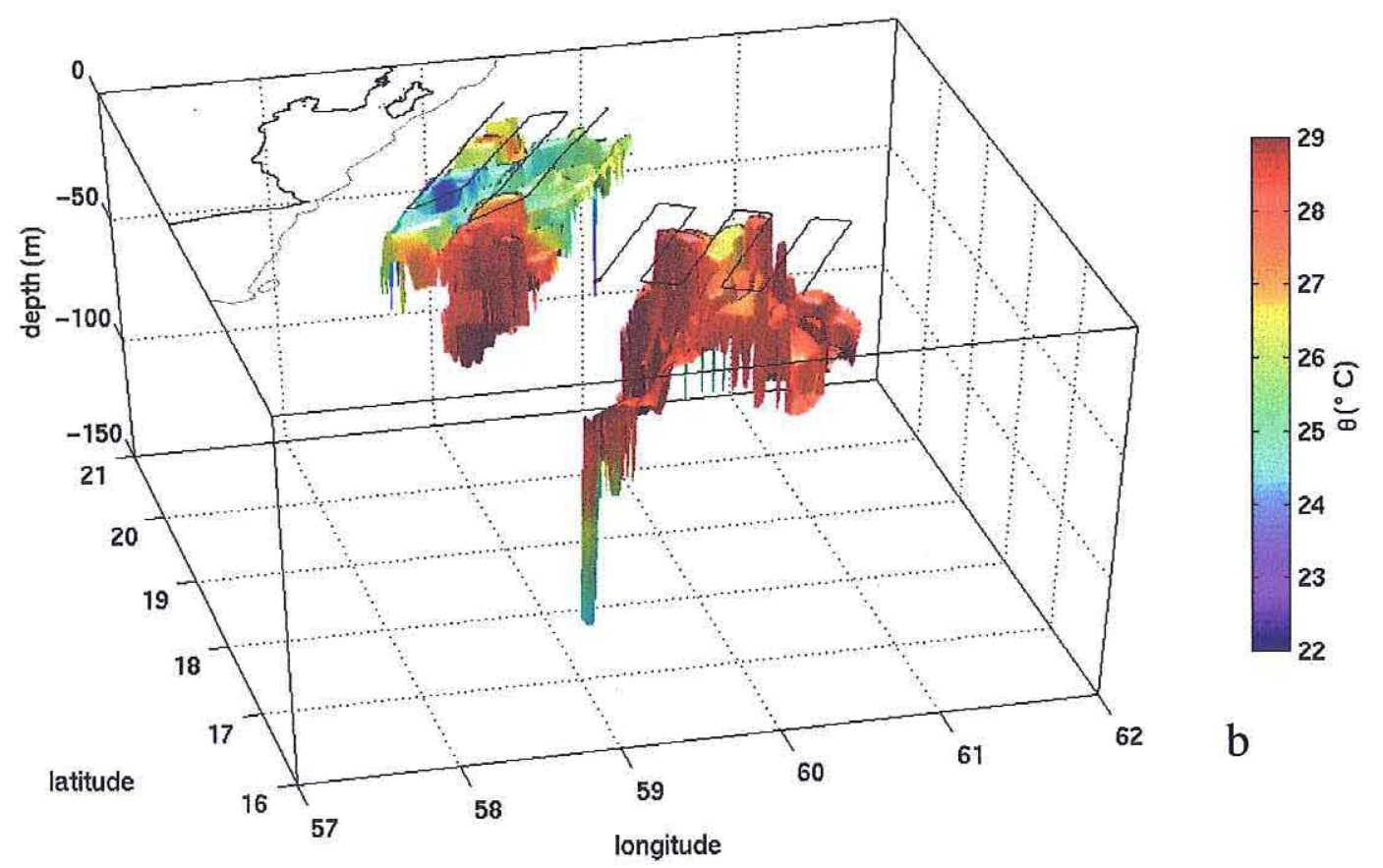

Figure 2.24 a: A visualization of the temperature (theta) on the surface of constant 36.1 salinity, from objectively mapped Seasoar data. In the filament radiator (closest to shore), the 36.1 isohaline surface outcrops, and the temperature shown is the near-surface temperature. $\mathbf{b}$ : Mixed layer theta on the surface representing the mixed layer depth. Note that the view angle and color scale are different from $a$. The filament has a shallower and cooler mixed layer than surrounding areas. Solid and gray lines are the coast and $200 \mathrm{~m}$ isobath. 
observed offshore, with the 36.1 isohaline surface between 100 and $150 \mathrm{~m}$ in depth, though seemingly deeper on the southern and western sides of the filament.

The temperature along the isohaline surface increases markedly as it outcrops, from about 22.5 to about $25.5^{\circ} \mathrm{C}$, still well below the surface temperatures farther offshore. At the time of the survey the SW monsoon winds have been active for nearly a month, inducing coastal upwelling for as long. A quick calculation indicates that a $200 \mathrm{~W} \mathrm{~m}^{-2}$ surface heat flux for one month will heat a layer $50 \mathrm{~m}$ deep by $2.5^{\circ} \mathrm{C}$. The mixed layers in the filament survey are about $30 \mathrm{~m}$ deep. As the filament moves offshore, the 36.1 isohaline surface deepens, but the temperature on the surface increases further, up to a maximum of 26.5. This is consistent with the water mass properties sampled early in the filament life (from SeaSoar) and later at the moored array. The filament also outlines a region of shallower and cooler mixed layer depth (Fig. 2.24b), again consistent with the

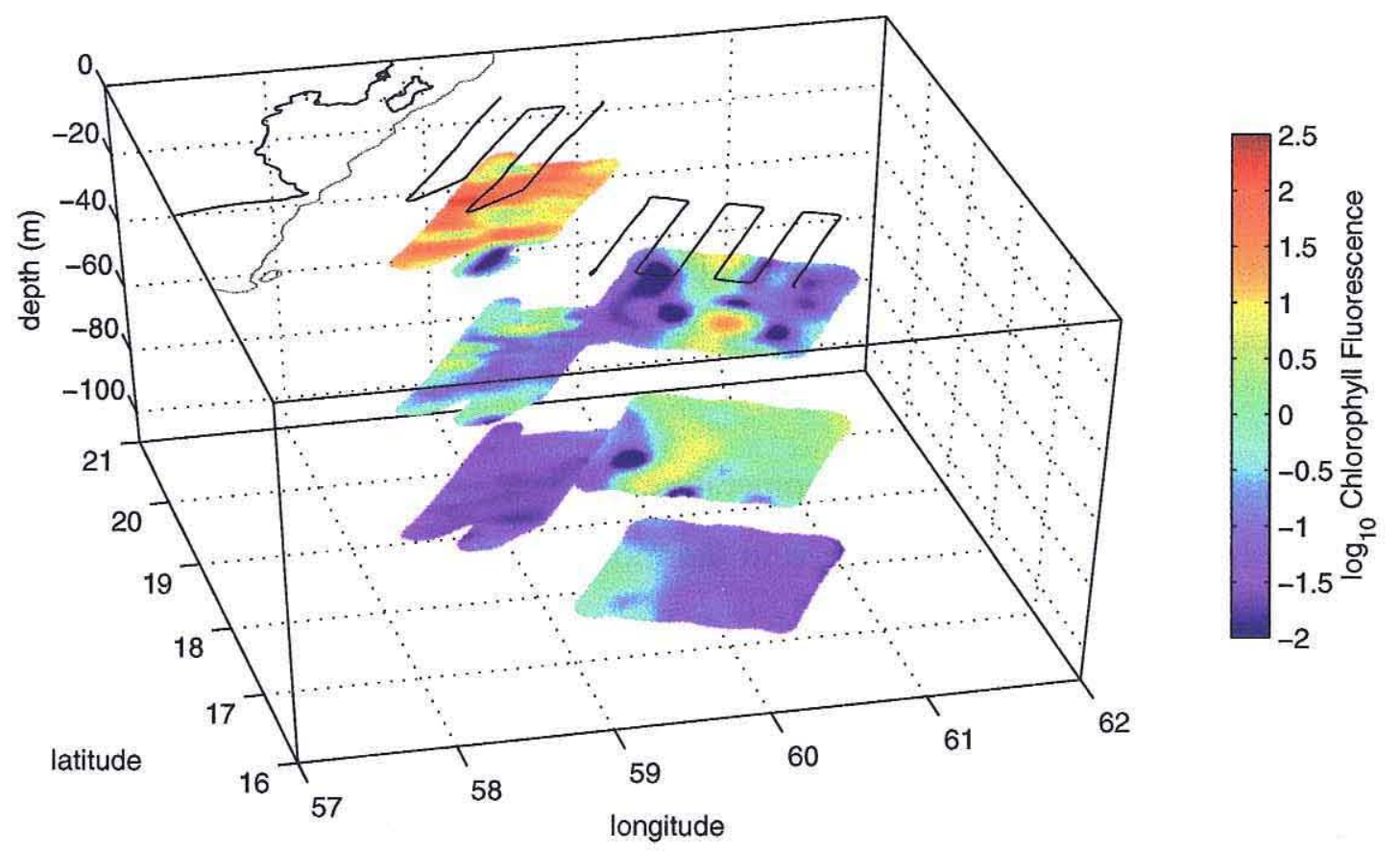

Figure 2.25 The chlorophyll concentration at the fixed depths of 16, 62, and 102 $\mathrm{m}$. A strong near-surface chlorophyll maximum is evident in the coastallyupwelling region and in the filament as it extends offshore. Solid and gray lines are the coast and $200 \mathrm{~m}$ isobath. 
sudden shoaling and cooling of the mixed layer observed at the moored array when the filament arrives in late July.

The coastally-upwelled water and the filament are also associated with increased productivity, seen in the chlorophyll $a$ concentrations observed by SeaSoar (Fig. 2.25). The highest concentrations occur in the top $50 \mathrm{~m}$, and remain elevated along the filament, though there is a decrease from the concentrations found closest to the shore. There is also considerable patchiness along the thin filament in the inshore radiator.

\subsection{Summary and discussion}

An estimation of the terms in the upper ocean heat budget in the Arabian Sea during a monsoonal cycle was made using data from a moored array. A rough balance between the horizontal heat flux and temperature trend is dominant during early NE monsoon and latter part of SW monsoon. A closure of the heat budget suggests that strong, passing downwelling (and some upwelling) events are associated with the passage of the edges of mesoscale features across the array. The mixed layer temperatures were quite uniform and gradients small during the NE monsoon, with horizontal advection limited to the rapid changes in depth of the thermocline. During the SW monsoon, coastally-upwelled water reaches the site of the mooring, with horizontal heat fluxes within the mixed layer as well.

Concurrent satellite sea surface temperature imagery and altimetry confirms that the strong horizontal heat fluxes estimated at the moored array are associated with the passage of mesoscale features. During the NE monsoon, the passage of a series of eddies (an anticyclonic/cyclonic pair, then a persistent region of weak anticyclonic flow) caused the strong horizontal heat fluxes at the moored array. The temperature imagery showed weak surface temperature gradients across the features, so the strong horizontal heat fluxes were associated with variations in the thermocline thickness that form the structure of the mesoscale eddies. These eddies formed at the tail end of the previous SW monsoon just to the south of the moored array, perhaps as instabilities of the Socotra Gyre/Somali cur- 
rent extension. During the SW monsoon, the source of the strong pulse of cooling horizontal advection is recently coastally upwelled water, carried offshore in a strong filament. Altimetric imagery from a number of years suggest that this offshore transport of cool upwelled water, which happened to pass by the moored array, is not an isolated incident, but one that repeats with some regularity, and in preferential locations.

Before the coastal filament reached the site of the array, it was sampled using the SeaSoar towed profiler. This provided a more detailed visualization of the three-dimensional structure of the filament, and additional support to the idea that coastally-upwelled water has made it to the site of the mooring, $600 \mathrm{~km}$ offshore. The export of this water offshore and to the mooring site then becomes an important part of the yearly heat budget at the moored array. The surface heat flux, while small compared to the horizontal heat fluxes integrated over the control volume, is persistent and positive throughout the year. The cooling horizontal heat flux, including a heat flux in the mixed layer, then is the restoring term that prevents a year-on-year buildup of heat.

How representative is this moored time series for the interior of the Arabian Sea? The decorrelation time scales of temperature measured at the moored array are on the order of 30-40 days, so the record has sampled about 10 of these time scales. In reality, only two major events passed by the array in the year it was on station, and so the mean heat budget captured here cannot be termed representative. Other sources of information, such as the time series of the altimetry, suggest that this type of coastal export of upwelled water is not unusual, so one can argue for its importance in the overall heat budget of the Arabian Sea. And the moored array is located in a region that is of somewhat below average surface EKE for the Arabian Sea, so the strong horizontal heat fluxes in the upper ocean budget measured there may be of even greater importance elsewhere in the basin.

Beyond the importance to the heat budget, the passage of eddies at the moored array was often coincident with jumps in the observed biological productivity, as seen in elevated chlorophyll a levels [Dickey et al., 1998]. The strongest signal in this record is coincident with the horizontal heat flux of an anticyclonic region at the beginning of December. Unfortunately this is also coincident with the beginning of the negative sur- 
face heat flux and the beginning of locally surface-driven convection, so in this case the cause of the bloom, local vertically-driven mixing, horizontal advection, or vertical motions associated with the mesoscale eddy, cannot be easily determined. The signal is clearer when associated with the arrival of the coastal filament at the end of July. Moored sensors recorded a peak at this time, consistent with the elevated levels found within the filament during the SeaSoar survey. Beyond pulses in the near-surface productivity, pulses in the mass flux, organic and inorganic carbon flux, and biogenic silicate and calcium carbonate fluxes out of the euphotic zone were captured in a sediment trap close to the moored array [Honjo et al., 1999], also associated with the passage of the SW monsoon coastal filament. While locally surface-driven mixing events are still important in mixing nutrients upwards and triggering blooms, the effect of the secondary circulations and transports associated with mesoscale features appears important as well.

Although there were not enough measurements to estimate the salinity budget at the moored array, there was generally a strong vertical salinity gradient, with saltier water overlying fresher water, formed from the strong balance towards evaporation over precipitation over the Arabian Sea. In fact the surface buoyancy flux, which when negative can drive convective entrainment into the mixed layer, has a significant contribution from salinity through the evaporative flux [Fischer, 1997]. The filament brings fresher water, upwelled from depth, to the surface (Fig. 2.21). In an analog to the heat budget, the freshening provided by this export of coastally upwelled water is a restoring term that prevents the year-on-year buildup of salinity.

While the mixed layer response at the moored array is fairly one-dimensional for limited periods of time, the upper ocean is affected by a wide variety of phenomena, including mesoscale eddies, offshore transport of coastally-upwelled water, vertical velocities associated with the secondary flow in the mesoscale and frontal features, all of which play a role in the upper ocean heat budget. 


\section{Chapter 3}

\section{Rectification of high-frequency heat and wind forcing in an Arabian Sea model}

\subsection{Introduction}

\subsubsection{High-frequency surface forcing}

The surface forcing over the Arabian Sea has variability associated with a broad range of time scales. The seasonal time scale, associated with the monsoon, is dominant, but variability on synoptic and diurnal time scales is strong as well. A surprising amount of synoptic variability is found in the wind stress observed at the Arabian Sea mooring site, even during the strong SW monsoon. The European Centre for Medium Range Weather Forecasting (ECMWF) analysis of the wind stress (Weller et al. [1998] and Sec. 5) had a strong correspondence with the observed moored winds, and suggests that this level of variability occurs basinwide during the SW monsoon. The net surface heat flux has its strongest variability on the diurnal time scale, driven by the daily cycle of solar heating.

The observed oceanic response to surface forcing on these shorter time scales is quite clearly observed. Diurnal variability in the mixed layer depth was large during the NE monsoon, with a range of over $100 \mathrm{~m}$ as the mixed layer shoaled to within several meters 

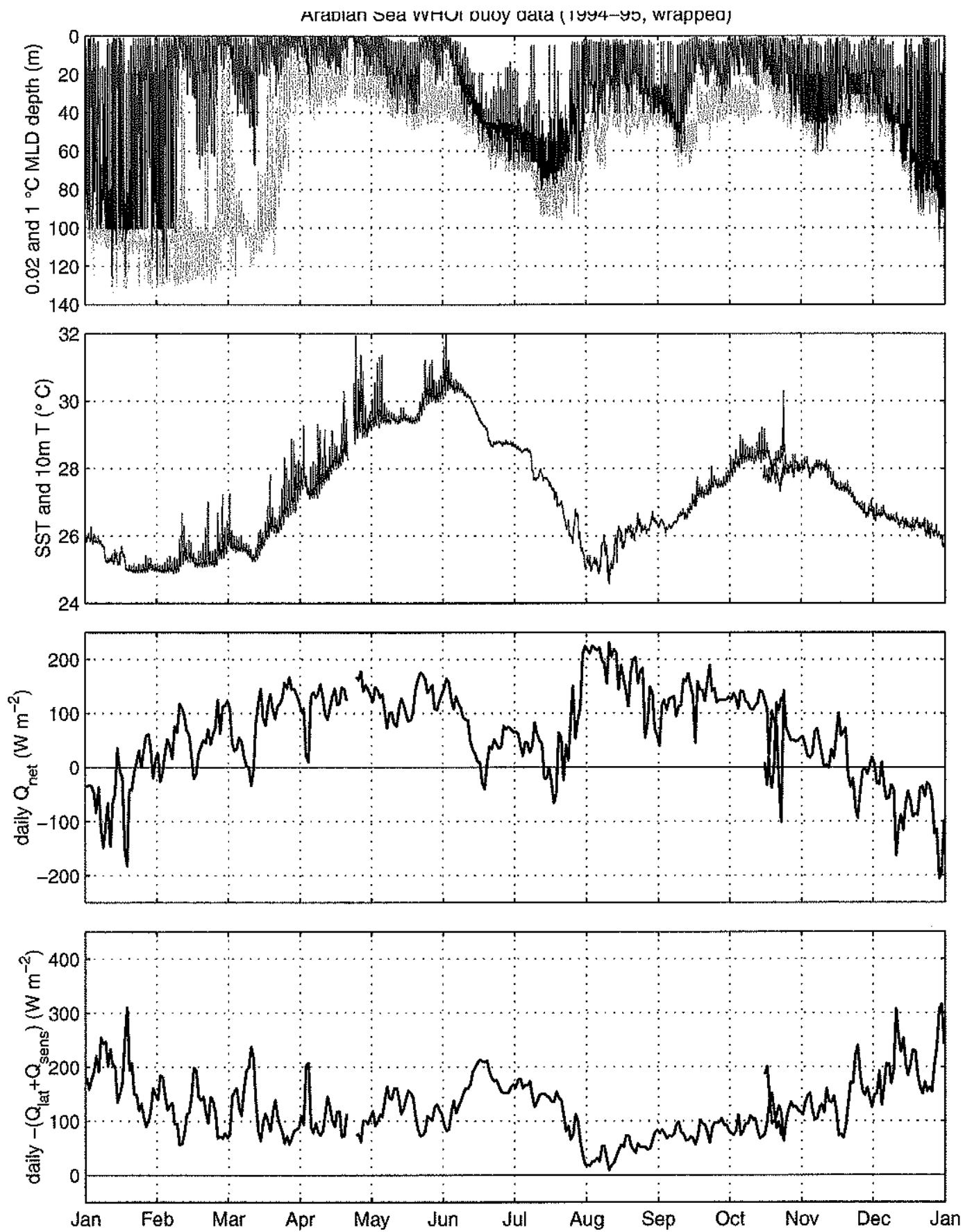

Figure 3.1 Arabian Sea WHOI buoy observations. From top: the mixed layer depth using a $0.02^{\circ} \mathrm{C}$ (black) and $1^{\circ} \mathrm{C}$ (gray) criterion, SST, the daily averaged net surface heat flux $Q_{n e t}$, and the sum of the surface latent and sensible heat losses. The moored data runs from October 1994 through October 1995, so there are a few days of overlap 
of the surface during the day, and deepened during net nighttime cooling conditions (Fig. 3.1). During the $\mathrm{SW}$ monsoon, this diurnal variability was reduced by the wind generation of turbulent mixing. Correspondence between synoptic-scale variability in the wind forcing and the upper ocean response can also be seen in the mixed layer depth evolution, particularly during the SW monsoon and at the tail end of the NE monsoon (see Fig. 1.5). This level of variability in the surface forcing is not often used in conjunction with predictive ocean models.

\subsubsection{Rectification of high-frequency surface forcing}

The importance of horizontal advective processes on the upper ocean evolution was made in Chapter 2. The high level of high frequency surface variability both in the atmospheric forcing and in the oceanic response led to a desire to explore what potential effects this had on the evolution of the vertical structure of the upper ocean, and in turn how this might interact with three-dimensional flows.

The bulk of the work in this chapter, which focuses on the effect of high frequency surface forcing on a three-dimensional regional model of the Arabian Sea and Indian Ocean, was inspired by the following simple experiment.

\subsubsection{One-dimensional model of the Arabian Sea upper ocean response}

The Price Weller Pinkel (PWP, Price et al. [1986]) mixed layer model predicts the one-dimensional evolution of the upper ocean under prescribed surface forcing. It has three simple mixing criteria: a static instability criterion that mixes density inversions, a bulk Richardson number mixing criterion which acts to form a bulk mixed layer, and a gradient Richardson number mixing criterion, which parameterizes instabilities due to shear generation of turbulent energy. (It is described in further detail in Chapter 4.)

The model was initalized with a CTD profile taken in the vicinity of the central WHOI mooring at its initial deployment in October 1994. It was then forced with the observed surface forcing from the WHOI mooring, in four different variations. To 
explore what effect the high-frequency (diurnal, inertial, and intraseasonal) time scales in the surface forcing have on the upper ocean evolution, alternate time series of monthly means in the surface wind and heat forcing, linearly interpolated to the $1 / 2$ hour timestep of the model, were generated. Monthly mean forcing is common for three-dimensional models. The model was first forced with the monthly mean wind and heat forcing (base case). Two more runs added either the high-frequency full resolution wind or heat forcing. And the final run added both the full resolution wind and heat forcing.

The results of these integrations are shown in Fig. 3.2. The most striking feature of the SST prediction is that all four model runs end up with temperatures between $32-34^{\circ} \mathrm{C}$ after one year of integration, higher than the observed SST (black line) by $4-6^{\circ} \mathrm{C}$. In light of the results of Chapter 2, emphasizing the role of horizontal advection, this is not too surprising. Interestingly, the SST evolution predicted by the full surface forcing (green line) is in remarkably good agreement with the observed SST until mid-June. This implies that the strong horizontal advection below the mixed layer observed at the beginning of the record does not influence SST predictions greatly. The horizontal advective heat flux within the mixed layer was not significantly different from zero at this time, and the large term in the upper ocean heat budget came from changes in the thermocline depth advected through the moored array by mesoscale eddies. While the SST prediction by the model is quite good through the NE monsoon and into the spring intermonsoon, the NE monsoon mixed layer depths are far shallower than what was observed (see Fig. 1.5), and deepen monotonically through the end of January under the influence of the net surface heat loss. The observed mixed layer, in contrast, deepens and shoals through October and November, before becoming much deeper again in December, following the changing depth of the upper thermocline.

In contrast to the NE monsoon, there is a strong divergence in the predictions of SST from the observed SST during the SW monsoon. The difference between the observed SST and the PWP model prediction with the fully-resolved surface forcing grows most dramatically in July and into the beginning of August, precisely when the horizontal heat flux into the mixed layer was found to be strongest. The mixed layer depth prediction for 


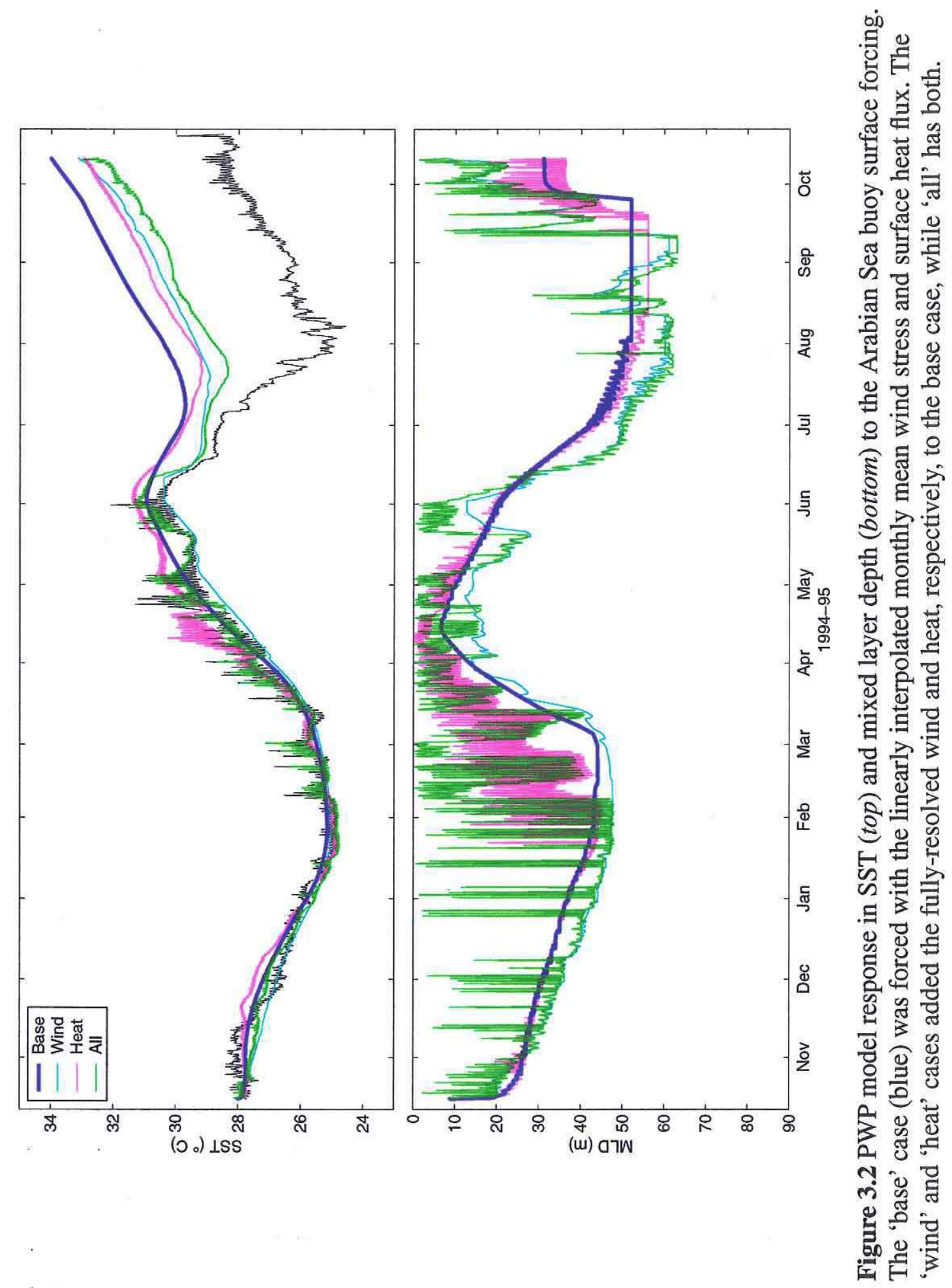


the beginning of the SW monsoon is not too far off from what is observed, including the reduction in its diurnal variability, but the predicted MLD stays deeper than observed in August and into September, again when the horizontal heat flux brought a different vertical structure to the moored array. So while the upper ocean structure, including the heat content to a fixed depth, is highly dependent on horizontal advection and mesoscale features of all types, the SST evolution appears more robust, responding strongly to the surface fluxes, and to horizontal advection only when significant fluxes within the mixed layer are present. This may be a bit of an overstatement, since the surface fluxes control the SST in part through entrainment of deeper waters, and so if the structure of these deeper waters changes significantly, or the total depth of the mixed layer changes significantly (which did take place here), the amount and characteristics of the entrained water will change as well.

Outside of the lack of horizontal advection, the four model runs have an interesting divergence in their SST prediction, reaching $1.5^{\circ} \mathrm{C}$ by the end of the year, despite having the same surface fluxes in the monthly mean. The base case (blue line) reproduces the general character of the mixed layer deepening and cooling, with its twice-yearly cycle. The addition of the fully-resolved heat flux, with diurnal forcing (magenta line) changes the SST prediction, raising it during the spring intermonsoon, and lowering at the peak of the SW monsoon by about $1^{\circ} \mathrm{C}$, a change that persists to the end of the integration. This difference is echoed in the MLD prediction, which is shallower during the spring intermonsoon and deeper during the SW monsoon with the addition of the diurnal cycle. The addition of the fully-resolved wind to the base case (cyan line) lowers the SST prediction during the spring intermonsoon, and in the SW monsoon, with deeper MLDs throughout much of the year. After one year of integration, the high-frequency wind likewise reduces the SST prediction by about $1^{\circ} \mathrm{C}$.

Finally, the addition of both the high-frequency wind and heat forcing (green line) drops the final SST prediction even further, to about $1.8^{\circ} \mathrm{C}$ below the base case after one year. The biggest change comes during the SW monsoon. The fully-resolved MLD prediction restratifies to be shallower than the base case, like the HF heat case, but during 
deepening phases is deeper than the base case, often matching the HF wind case. During the SW monsoon the fully-resolved run has the deepest predicted mixed layers, indicating a maximum of surface-driven vertical mixing.

\subsubsection{Rectification}

What causes this increased vertical mixing and SST reduction under high-frequency surface forcing?

High frequency wind forcing provides additional energy for vertical mixing as compared to a monthly mean, leading to deepening and entrainment cooling of the mixed layer. One way to approach surface-driven vertical mixing is to assume a balance between the generation of turbulent kinetic energy (TKE) integrated over the mixed layer and its destruction and the creation of potential energy by entrainment at the base of the mixed layer (see Kraus and Businger [1994], Section 6.4). A number of bulk mixed layer models are built directly on making some form of this balance (including the Kraus and Turner [1967] KT model used later), and others are derived from similar ideas. Wind generation of turbulence is proportional to $u_{*}^{3}$, proportional to $\tau^{3 / 2}$. Because of the curvature in the relationship between $\tau^{3 / 2}$ and $\tau, \overline{\left(\tau^{3 / 2}\right)} \geq(\bar{\tau})^{3 / 2}$, where the overbar denotes a time mean, in an amount depending on the variability in $\tau$ (see Fig. 3.3). There is therefore more energy available for vertical mixing in a resolved wind stress. The net result in the mean-forced case is expected to be less surface-driven vertical mixing, and therefore a shallower and warmer mixed layer. When the vertical velocity structure is resolved, and a balance between local shear generation of TKE and vertical mixing is accounted for (using a gradient Richardson number mixing, which is not in the KT model used in this chapter), the resolved wind stress will result in additional inertial energy in the current field and additional shear in the inertial band, providing another potential source of increased vertical mixing. In addition, vertical mixing is an irreversible process, and its time history, coupled with the surface heat flux, will lead to changes in the time evolution of an SST prediction. This one-dimensional response to the winds could then interact with the other processes in a three-dimensional model 


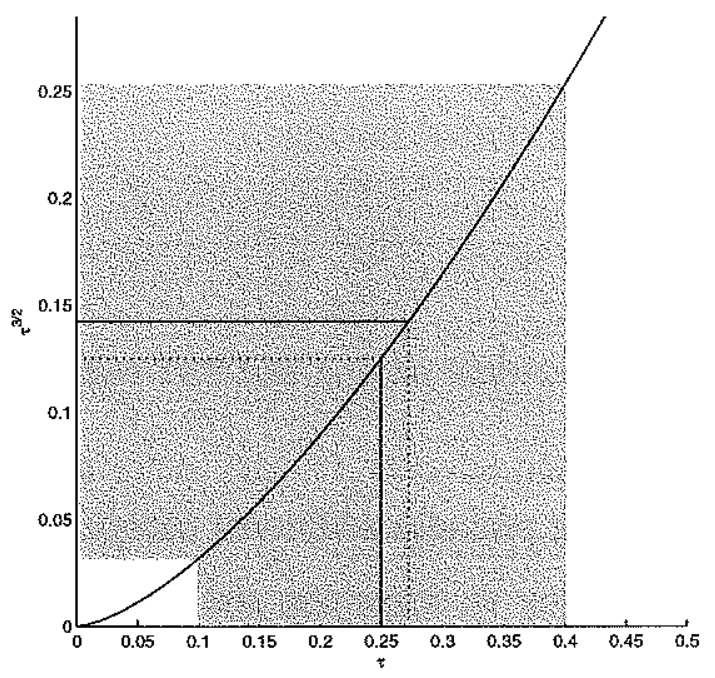

Figure 3.3 Comparison of the wind stress $\tau$ with $\tau^{3 / 2}$, which is proportional to the energy available for entrainment in the Kraus-Turner mixed layer model. In the example above, the wind stress is distributed evenly about its mean, which creates a mean $\tau^{3 / 2}$ that is larger than $(\bar{\tau})^{3 / 2}$. A resolved wind stress will thus have more energy available for mixing than the mean wind stress.

There is not a simple energetic argument describing how diurnal cycling in the heat flux might alter mean vertical mixing, as there is for the wind. The balance between buoyant production of TKE and entrainment is dependent on the phase of the diurnal cycle, as well as the mixed layer depth and buoyancy flux. But in a model that includes shear generation of turbulence, diurnal cycling will modulate the appearance of shear at the base of the mixed layer, changing the shear profile in the stratified region below and therefore the vertical mixing. Also, nighttime convection is observed to be penetrative [Lien et al., 1995], that is vertical mixing extends beyond the region necessary for static stability and into the stably stratified region under the mixed layer. This would increase mixing below the mixed layer in the mean, although it is a process included in neither the KT nor PWP models. Diurnal cycling appears to increase mixing below the mixed layer rather than directly at its base, in turn affecting the evolution of the mixed layer. Again, this one-dimensional response could then interact with the other processes in a threedimensional model. 


\subsubsection{Modeling background}

While forcing ocean models with monthly mean climatologies is common, fewer models have been run with high-frequency wind forcing [Chen et al., 1999; Grima et al., 1999; Liu et al., 1996; Rochford et al., 2000]. Many of these studies note a reduction of the surface temperature associated with increased vertical mixing driven by the surface winds. Richardson et al. [1999], however, found that the mixed layer depth in the equatorial ocean is dependent on the total momentum input under the influence of wind squalls characteristic for the region, rather than the time evolution.

Even fewer models have been used to isolate the effect of solar diurnal variability. Sui et al. [1997] studied the response of a one-dimensional upper ocean model to daily mean and diurnally-resolved surface heat forcing in the western equatorial Pacific. They found that the diurnal mixing cycle was essential in maintaining the temperature stratification in a one-dimensional model, and that resolution of this cycle was necessary to capture the full nonlinear response of the mixed layer in response to intraseasonal (shorter than seasonal time scale) forcing. Wang et al. [1998], also focusing on the equatorial Pacific but using a large-eddy simulation (LES) model, found deep penetration of vertical mixing well below the mixed layer during nighttime cooling. Observations of strong nighttime penetrative turbulence at the equator were made by Lien et al. [1995]. Building on the LES study, Large and Gent [1999] found that long integrations of the Large et al. [1994] (KPP) mixed layer model that included a diurnal cycle matched the LES results well. These studies were all done with essentially one-dimensional models. McCreary et al. [2000] added the diurnal cycle to a layer regional model of the Indian Ocean (very similar to the one I will use here), and at the site of the Arabian Sea moored array (Chapter 2), found that diurnal cycling changed the evolution of mixed layer depth and temperature by delaying restratification, and by introducing additional vertical mixing below the mixed layer. 


\subsubsection{Approach}

The central question of this work is: what effects do the expected changes in vertical mixing processes have in combination with the full dynamics of a three-dimensional model? The work lies somewhere in between a predictive and a process study: I will examine the changes in time evolution brought by diurnal cycling and high frequency winds on a basin-wide basis, making the central question one of a process study. But, the model is set in a realistic basin, forced with realistic forcing, and I will use the observations at the site of the Arabian Sea mooring to evaluate the performance of the model, depending on the predictive ability of the model.

The model is an evolution of the McCreary et al. [1993] (hereafter MKM) Indian Ocean model, and is a reduced-gravity, thermodynamically active layer model. It has a complexity less than that of a GCM, with only 4 degrees of freedom in the vertical. It has an explicit representation of the mixed layer using a Kraus-Turner [Kraus and Turner, 1967] bulk mixed layer (ML) scheme. So while it has a reduced vertical complexity which allows for numerous model runs and for simplicity in the interpretation of processes, it does have an explicit mixed layer model that responds on short time scales to surface forcing. It is therefore well-suited to the purpose of the study. The predictive ability of the embedded mixed layer model compared to others with greater levels of physical realism is addressed in Chapter 4, as a check on the robustness of the findings.

The high-frequency forcing, in both heat and in the wind stress, change the predictions of sea surface temperature, mixed layer depth, currents, and heat transports, both on the seasonal and annual time scales. Many of these changes are driven locally by the surface forcing's direct effect on the mixed layer evolution, but some of these changes depend on interactions between local and changed remotely-forced responses.

The chapter has six further sections. The next describes the model in detail, including the parameterization of vertical entrainment and detrainment processes, and the surface forcing used in the model runs. The model solution forced by monthly mean climatology is described in Section 3.3, and serves as a reference for comparisons with previous stud- 
ies, and for the departures in further model solutions. Section 3.4 provides an analysis of the differences between a model run including the diurnal cycle in the heat flux and one without. Section 3.5 examines the addition of high time resolution in the surface wind forcing, and Section 3.6 adds both high frequency wind and diurnal forcing. Finally, a discussion and summary round out the chapter in Section 3.7.

\subsection{The 4-1/2 layer model and surface forcing}

The 4-1/2 layer model used here is an evolution of McCreary et al. [1993], and very similar in formulation to McCreary et al. [2000], also related to Han [1999]. The four layers represent the mixed layer, a diurnal thermocline layer which shields the lower layers from the rapid cycling of the mixed layer, a seasonal thermocline layer, and the permanent thermocline (see Fig. 3.4b). The model is a reduced-gravity baroclinic formulation, so the deepest (' $1 / 2$ ') layer is at rest.

\subsubsection{The model equations}

The model equations are the conservation of momentum

$$
\begin{gathered}
\left(h_{i} \bar{u}_{i}\right)_{t}+\nabla \cdot\left(\bar{u}_{i} h_{i} \bar{u}_{i}\right)+f \hat{k} \times h_{i} \bar{u}_{i}+h_{i}\left\langle\nabla p_{i}\right\rangle / \rho_{0}=\delta_{i 1} \bar{\tau} / \rho_{0}+w_{i}^{+} \bar{u}_{i+1}+w_{i}^{-} \bar{u}_{i} \\
-w_{i-1}^{+} \bar{u}_{i}-w_{i-1}^{-} \bar{u}_{i-1}+v \nabla^{2}\left(h_{i} \bar{u}_{i}\right)+v_{4} \nabla^{4}\left(h_{i} \bar{u}_{i}\right)-\gamma h_{i} u_{i} \hat{i},
\end{gathered}
$$

the conservation of mass

$$
h_{i t}+\nabla \cdot\left(h_{i} \bar{u}_{i}\right)=-\delta_{i 1}(E-P)+w_{i}+w_{i-1}+\delta_{i 4} w_{c}+\kappa_{h} \nabla^{2} h_{i}-\kappa_{h 4} \nabla^{4} h_{i},
$$

and the conservation of temperature,

$$
\begin{aligned}
& T_{i t}+\bar{u}_{i} \cdot \nabla T_{i}=Q_{i} / h_{i}+w_{i}^{+}\left(T_{i+1}-T_{i}\right) / h_{i}-w_{i-1}^{-}\left(T_{i-1}-T_{i}\right) / h_{i} \\
& +\delta_{i 3} w_{3}^{+}\left(T_{e}-T_{4}\right) / h_{3}-\delta_{i 4} w_{3}^{+}\left(T_{e}-T_{4}\right) / h_{4}+\kappa_{T} \nabla^{2} T-\kappa_{T 4} \nabla^{4} T .
\end{aligned}
$$



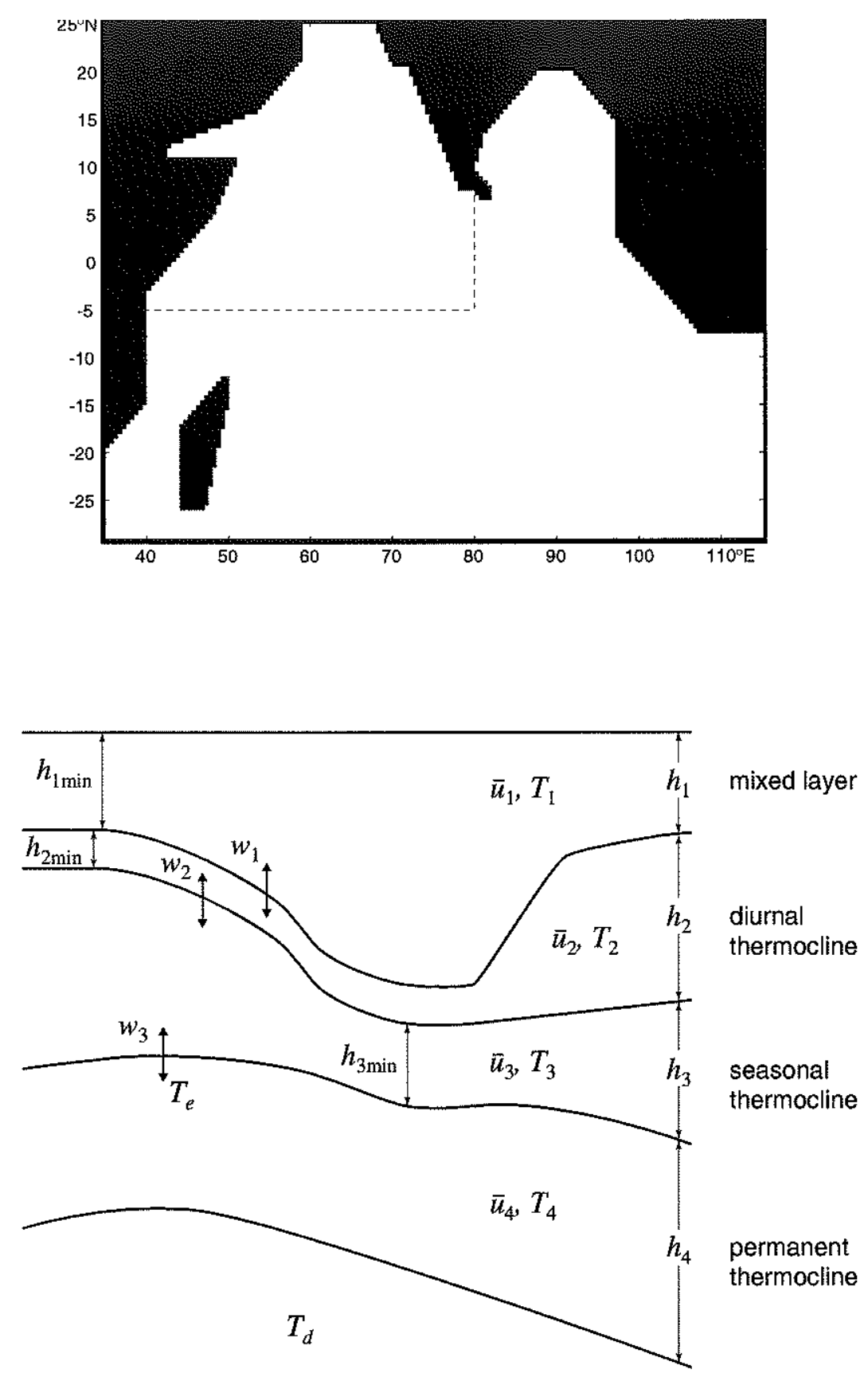

Figure 3.4 The boundaries of the Indian Ocean model (top), with the region analyzed intensely outlined by the dashed line. The western, northern, and eastern boundaries are closed, while the southern boundary is open. The vertical layer structure of the model (bottom). The model has four active layers with velocities $\bar{u}_{i}$, temperatures $T_{i}$, and depths $h_{i}$, overlying a deep inert layer with temperature $T_{d}$. Water is transferred between layers with velocities $w_{i}$, though layers 1-3 are not allowed to become thinner than their minimum depth. 
In the equations above, the subscript $i(i=1,2,3,4)$ refers to the active layers, and $\delta_{i j}$ is the Kroenecker delta, equal to one if $i=j$, zero otherwise. The instantaneous values of the velocity, layer thickness, and temperature are represented by $\bar{u}_{i}=\left(u_{i}, v_{i}\right), h_{i}$, and $T_{i}$. The Coriolis parameter is $f$, and the forcing is represented by the wind stress $\bar{\tau}=\left(\tau_{x}, \tau_{y}\right)$, evaporation $E$ and precipitation $P$ (which, since it comes into play only in mass conservation, is virtually negligible), and the layer heat flux $Q_{i}$. The depth-averaged pressure gradient is $\left\langle p_{i}\right\rangle / \rho_{0}$. There is Laplacian and biharmonic mixing of the momentum, mass, and temperature, with the coefficients $v, \kappa_{h}, \kappa_{T}$, and $v_{4}, \kappa_{h 4}, \kappa_{T 4}$. Terms containing the vertical velocity $w_{i}$ conserve properties when water is exchanged between layers. The superscripts $w_{i}^{+}=\max \left(w_{i}, 0\right)$ and $w_{i}^{-}=\min \left(w_{i}, 0\right)$ denote the positive or negative portion of the vertical velocity. A correcting vertical velocity $w_{c}$ conserves mass in the domain by restoring flows out of the southern boundary in the southwestern corner of the domain in layer 4 . At the top surface, $w_{0}, \bar{u}_{0}$, and $T_{0}$ are set to zero. There is no transfer between layer 4 and the resting deep ocean, so $w_{4}=0$. The term proportional to $\gamma$ damps the zonal velocity near the southern boundary, and is necessary for model stability. Entrainment of water from the thermocline (layer 4) is treated specially, with entrainment into layer 3 of water of temperature $T_{e}$, rather than $T_{4}$. The water of temperature $T_{e}$ lies between $T_{3}$ and $T_{4}$, and is meant to represent water from the upper, rather than the main thermocline. MKM found this was necessary to prevent upwelling regions from becoming too cold. This entrainment temperature is defined

$$
T_{e}=\max \left(S S T_{\min }(y)-3^{\circ} \mathrm{C}, T_{3}\right),
$$

where $\operatorname{SST}_{\min }(y)$ is the annual minimum SST observed along the latitude line defined by $y$, so assuming that upwelled water is slightly colder than this minimum.

Model layers 1 and 2, the mixed and diurnal thermocline layers, are thermodynamically independent, but dynamically are linked, with $\bar{u}_{1}=\bar{u}_{2}$ and the layers having a collective combined density $\bar{\rho}=\left(h_{1} \rho_{1}+h_{2} \rho_{2}\right) /\left(h_{1}+h_{2}\right)$. The first layer represents the mixed layer, and under diurnally varying surface heat forcing, will deepen at night, and become quite shallow during the day. Layer 2 is the diurnal thermocline, which essen- 
tially acts as a short-term memory, preserving the contents of the shoaled mixed layer during the day, so that nighttime entrainment initially encounters what has been detrained during the day.

The depth-averaged pressure gradient in each layer is given by

$$
\frac{\left\langle\nabla p_{i}\right\rangle}{\rho_{0}}=\sum_{j=1}^{i} \nabla\left(g^{\prime}{ }_{5 i} h_{j}\right)+\sum_{j=i+1}^{4} \nabla\left(g_{5 j}^{\prime} h_{j}\right)-\frac{1}{2}\left(h_{i}+\sum_{j=1}^{i-1} 2 h_{j}\right) \nabla g_{5 i}^{\prime},
$$

where the reduced gravity $g_{i j}^{\prime}=g\left(\rho_{i}-\rho_{j}\right) / \rho_{0}$, and the density of layer $i$ is $\rho_{i}=\rho_{0}\left(1+\alpha T_{i}\right)$. The thermal coefficient of expansion is $\alpha$, and for simplicity salinity is not considered in this model, as I will focus on the role of high frequency forcing in the vertical mixing and temperature evolution. The convention here is that when the upper limit of the sum is less than the lower, the sum equals zero. Since temperature evolves freely, part of $\nabla p_{i}$ is dependent on $z$. The expression in (3.5) is derived by averaging the $z$-dependent part over each layer [McCreary and Kundu, 1988].

The surface heat flux of the model is represented as the sum of the net solar and longwave heat fluxes $Q_{r}$, prescribed by climatology, and model-developed latent $Q_{H}$ and sensible $Q_{s}$ heat fluxes. These model-developed fluxes evolve with the model solution, and provide a better-matched total surface heat flux than a direct application of climatology. How well they do match climatology is one indication of the fitness of the model, and will be touched on below. The latent and sensible heat fluxes are functions of the model SST $T_{1}$, and specified climatological values of the air temperature $T_{a}$, specific humidity $q_{s}$, and scalar wind $V$, computed using the standard bulk aerodynamic formulae:

$$
\begin{aligned}
& Q_{H}=\rho_{a} L_{v} c_{e} V\left(q_{s a t}-q_{s}\right) \\
& Q_{s}=\rho_{a} C_{p a} c_{s} V\left(T_{a}-T_{m}\right)
\end{aligned}
$$

where $\rho_{a}=1.175 \mathrm{~kg} \mathrm{~m}^{-3}$ is the density of air, $L_{v}=2.44 \times 10^{6} \mathrm{~J} \mathrm{~kg}^{-1}$ is the latent heat of 
vaporization, $C_{p a}=1004 \mathrm{~J} \mathrm{~kg}^{-1}{ }^{\circ} \mathrm{C}^{-1}$ is the specific heat capacity of air, $c_{e}$ and $c_{s}$ are empirical coefficients, and $q_{s a t}$ is the saturation specific humidity at the model sea surface temperature.

Penetration of solar heat is represented by

$$
Q(z)=\phi Q_{r} e^{k z}+(1-\phi) Q_{r} e^{k^{\prime} z}
$$

where $k=1 / 30 \mathrm{~m}, k^{\prime} » 0.1 \mathrm{~m}^{-1}$ making the second term negligible when $z$, is of any significant depth (the model has a minimum depth of the first layer of $10 \mathrm{~m}$ ), and $\phi=0.4$ is the fraction of the radiation that is penetrative. This is a simplification (because in practice the shortest wavelengths are absorbed entirely within the first layer, also for the lumping together of the net longwave and shortwave solar radiation) of the double-exponential profile presented in Paulson and Simpson [1977]. The net heat flux in each layer is then

$$
Q_{i}=Q\left(\sum_{j=1}^{i-1} h_{j}\right)-Q\left(\sum_{j=1}^{i} h_{j}\right)-\delta_{i 1}\left(Q_{H}+Q_{S}\right)
$$

the difference between the input and output of solar heat in each layer, with the latent and sensible heat losses being removed from the surface mixed layer.

The formulation of the cross-interfacial velocities represent the mixing processes, so important to the study here. For layer 1 (the mixed layer),

$$
w_{1}=w_{k}+w_{1 c}
$$

where $w_{k}$ represents entrainment and detrainment from the bulk mixed layer according to Kraus-Turner physics [Kraus and Turner, 1967], and $w_{1 c}$ is a correction velocity that keeps $h_{1} \geq h_{1 \text { min }}$ for numerical stability. The mixed layer depth is primarily controlled by 


$$
w_{k}=\left\{\begin{array}{l}
\frac{P_{r}}{\frac{1}{2} g h_{1} \Delta \rho^{\prime}}, P_{r}>0 \\
\frac{h_{\mathrm{MO}}-h_{1}^{-}}{2 \Delta t}, P_{r} \leq 0
\end{array}\right.
$$

where the production of turbulent kinetic energy (TKE) by wind and heat forcing is

$$
P_{r}=m u_{*}^{3}-\frac{1}{2} g h_{1} \alpha Q_{1}
$$

the density jump at the base of the mixed layer is

$$
\Delta \rho^{\prime}= \begin{cases}\rho_{2}-\rho_{1}+\delta \rho, & h_{2}>h_{2 \min } \\ \rho_{3}-\rho_{1}, & h_{2}=h_{2 \min }, h_{3}>h_{3 \min } \\ \rho_{4}^{\prime}-\rho_{1}, & h_{2}=h_{2 \min }, h_{3}=h_{3 \min },\end{cases}
$$

and the Monin-Obukhov depth is obtained from a balance between the production and destruction of TKE

$$
h_{\mathrm{MO}}=\frac{m u_{*}^{3}}{\frac{1}{2} g \alpha Q_{1}} .
$$

The layer 1 depth at the previous timestep is $h_{1}^{-}$, the timestep is $\Delta t$ and appears in the numerator as $2 \Delta t$ because of the leapfrog numerical scheme, the ocean friction velocity is $u_{*}, m=2$ is an efficiency factor for the conversion of wind-stirring to TKE, and $g$ is the acceleration due to gravity. When the production of TKE is positive, the mixed layer deepens through entrainment. When destruction of TKE dominates, the mixed layer instantly detrains to the Monin-Obukhov depth. When the mixed layer is entraining, it entrains water from the next shallowest layer that is not at its minimum depth. However, the water 
entrained from layer 4 has a density $\rho_{4}^{\prime}$ based on the entrainment temperature $T_{e}$, and so is less dense than $\rho_{4}$.

The entrainment and detrainment at the base of the diurnal thermocline layer is given by

$$
w_{2}=w_{d}+w_{r}+w_{2 c},
$$

where $w_{d}$ is a detrainment term

$$
w_{d}=-\frac{\left(h_{1}+h_{2}-\left(h_{1 \min }+h_{2 \min }\right)\right)}{t_{d}}
$$

and $t_{d}=15$ days. This term adjusts the depth $h_{2}$ so that the sum of layers 1 and 2 approaches its minimum with a time scale $t_{d}$, assuring that the $h_{2}$ generally reaches its minimum at night when $h_{1}$ is at its maximum. This does not occur during periods of very rapid detrainment of the mixed layer, such as the one associated with the beginning of the intermonsoon period (see Fig. 3.20). The correction term $w_{2 c}$ assures the minimum depth $h_{2 \min }$ is never violated. And $w_{r}$ is an entrainment term that ensures the total depth $h_{1}+h_{2}$ is large enough so that the bulk Richardson number of layers 1 and 2 is greater or equal to 0.4 . The term is necessary to keep the model numerically stable in the Somali current during the SW monsoon [McCreary et al., 1993].

Finally, entrainment and detrainment at the base of the seasonal thermocline layer is given by

$$
w_{3}=w_{s}+w_{3 c} \text {. }
$$

The subduction velocity $w_{s}$ is a parameterization of the subduction process of Woods and Barkman [1986], where water in the deeper part of the seasonal thermocline layer is subducted into the thermocline when the mixed layer shoals during the intermonsoon season. It is represented as 


$$
w_{s}=-\frac{Q \theta(Q)}{Q^{\prime}} \frac{\left(h_{1}+h_{2}+h_{3}-H_{s}\right)^{2}}{t_{s} H_{s}} \theta\left(h_{1}+h_{2}+h_{3}-H_{s}\right)
$$

where $\theta$ is the Heaviside step function, $t_{s}=90$ days is the subduction time scale, $H_{s}=65 \mathrm{~m}$ is the subduction reference depth, and $Q^{\prime}=40 \mathrm{~W} \mathrm{~m}^{-2}$ is a scaling parameter to bring the factor involving $Q$ to order one. Layer 3 therefore detrains when $Q$ is positive and the sum of the first three layers is thicker than the specified reference depth. The velocity $w_{3 c}$ ensures that the minimum depth $h_{3 \min }$ is not violated.

Since the southern boundary is not closed, mass is not necessarily conserved in the model, and to correct for this the velocity $w_{c}$ is applied to keep mass conserved in the model domain. It is applied in the permanent thermocline (layer 4) in the southwestern corner of the model domain. In practice, the model is adjusted each timestep such that $h_{4} \rightarrow h_{4}+h_{c}(x, y)$, where $h_{c}$ is the corrective mass adjustment in the southwestern corner. This occurs well south of the study region, and has no impact on the results here.

\subsubsection{Numerical method}

The model equations are solved on a staggered grid with a horizontal resolution of 55 $\mathrm{km}$ (nominally $0.5^{\circ}$, eddy permitting if the horizontal viscosity is low enough). Values of $h$ and $T$ are calculated in the center of the boxes described by the grid, while $u$ and $v$ velocity are located at the zonal and meridional edges (a C-grid scheme). The model is integrated using a leapfrog scheme with a timestep $\Delta t$ of 0.5 hours. Successive time levels are averaged every 11 steps to eliminate the time-splitting instability.

For numerical stability, the minimum depths of the first three layers are prescribed, with $h_{1 \min }=10 \mathrm{~m}, h_{2 \min }=1 \mathrm{~m}$, and $h_{3 \min }=10 \mathrm{~m}$. Since the diurnal forcing can lead to large changes in $h_{1}$ and $h_{2}$ within one timestep, the layer 1 and 2 equations for temperature are integrated semi-implicitly.

The model domain is that of the Indian Ocean north of $29^{\circ} \mathrm{S}$, with a simplified coastline geometry (see Fig. 3.4a). The model is closed to the north, west, and east, with no 
throughflow connection to the Pacific. The coastlines are vertical walls, and the boundary conditions applied at these walls are

$$
u_{i}=v_{i}=h_{\text {in }}=T_{\text {in }}=0
$$

where the subscript $n$ refers to the partial derivative normal to the boundary. The southern boundary is open, and the zero-gradient boundary conditions

$$
u_{i y}=v_{i y}=h_{i y}=T_{i y}=0
$$

are applied there. The zonal velocity $u_{i}$ creates a numerical instability, and so is damped by a term proportional to $\gamma$, which is zero $300 \mathrm{~km}$ and north from the boundary, and reaches its prescribed value at the southern boundary. There is no restriction on $v_{i}$, so flows can enter and exit the southern boundary.

Table 3.1: List and values of the model parameters

\begin{tabular}{lll}
\hline \multicolumn{1}{c}{ Parameter } & \multicolumn{1}{c}{ Notation } & \multicolumn{1}{c}{ Value } \\
\hline Initial layer thickness & $H_{1}, H_{2}, H_{3}, H_{4}$ & $10,20,35,300 \mathrm{~m}$ \\
Minimum layer thickness & $h_{1 \min }, h_{2 \min }, h_{3 \min }$ & $10,1,10 \mathrm{~m}$ \\
Initial layer temperatures & $T_{3}^{*}, T_{4}^{*}$ & $18,15{ }^{\circ} \mathrm{C}$ \\
Temperature of the deep ocean & $T_{d}$ & $0{ }^{\circ} \mathrm{C}$ \\
Coeff. of thermal expansion & $\alpha$ & $-2.5 \times 10^{-4}{ }^{\circ} \mathrm{C}^{-1}$ \\
Laplacian mixing of mom. and temp. & $v_{,} \kappa_{T}$ & $5000 \mathrm{~m}^{2} \mathrm{sec}^{-1}$ \\
Laplacian mixing of mass & $\kappa_{h}$ & $1000 \mathrm{~m}^{2} \mathrm{sec}^{-1}$ \\
Bihamonic mixing coefficients & $v_{4}, \kappa_{T 4}, \kappa_{h 4}$ & $1 \times 10^{13} \mathrm{~m}^{4} \mathrm{sec}^{-1}$ \\
Maximum strength of damping & $\gamma$ & 1 day $^{-1}$ \\
Diurnal detrainment time scale & $t_{d}$ & 15 days \\
Subduction reference depth & $H_{s}$ & $65 \mathrm{~m}$ \\
Subduction time scale & $t_{s}$ & 90 days \\
Heat flux scaling parameter & $Q^{\prime}$ & $40 \mathrm{~W} \mathrm{~m}{ }^{-2}$ \\
Wind-stirring efficiency & $m$ & 2.0 \\
\hline
\end{tabular}


The values of the parameters used in the model are listed in Table 3.1. The initial surface temperature is set to annual mean Rao et al. [1989] climatology, and the initial diurnal thermocline layer (layer 2) temperature is set $T_{e}$ plus $1^{\circ} \mathrm{C}$. The values of the parameters are in many cases historical choices that match previous models, but are reasonable values. The values of Laplacian mixing are fairly high, preventing the vigorous development of mesoscale eddies.

\subsubsection{Surface forcing}

The wind forcing for the model comes from two products, the FSU monthly mean pseudostress, averaged from 1970 to 1996 Legler et al. [1989], and ECMWF six-hour analysis winds and stresses from 1994-95. The FSU wind climatology has a resolution of $2^{\circ}$, and was linearly interpolated to the model space grid, and linearly interpolated in time when applied to the model.

The ECMWF winds have a resolution of $1.125^{\circ}$ in longitude and $1.121^{\circ}$ in latitude. Because of the somewhat simplified coastline geometry adopted by the model (see Fig. 3.4), the ECMWF landmask and model landmasks did not match exactly. To prevent the application of air-land stresses on the ocean, creating large and spurious coastal upwelling and downwelling, all points in the ECMWF grid that had any land content were eliminated. Neighboring interior oceanic wind values from the ECMWF grid were then extended towards the coast whenever there was a gap between the ECMWF and model landmasks. This occurred primarily along the western coast of India, surrounding Madagascar, and along the Indonesian and Australian coasts. To compare the model results with the Arabian Sea buoy observations, the model is forced by a repeating October 1994-October 1995 (360 days total, for easy comparison to the standardized 30-day months of the FSU runs) ECMWF wind, with a five-day linear transition between 1994 and 1995 in the overlap period. An alternate monthly-average dataset was also created for the period October 1994-October 1995, so that the effect of the high-frequency winds could be isolated outside of any differences between the ECMWF analysis and FSU climatological winds. 
The thermal forcing fields are calculated from the climatological fields of the net shortwave radiation $Q_{S W}$, net longwave radiation $Q_{L W}$, air temperature $T_{a}$, and specific humidity $q_{s}$, derived from the climatology of Rao et al. [1989], based on the Comprehensive Oceanographic and Atmospheric Data Set (COADS), and scalar wind $w_{s c}$ from either FSU or ECMWF. The model's net latent and sensible heat fluxes and evaporation are calculated using these fields. Precipitation $P$ is provided by Legates and Willmott [1990], and evaporation $E$ from the latent heat flux.

Table 3.2: Run names

\begin{tabular}{lll}
\hline Name & \multicolumn{1}{c}{ Wind product } & Diurnal heat forcing \\
\hline F & FSU & no \\
FD & FSU & yes \\
E & ECMWF monthly mean & no \\
EH & ECMWF 4x daily & no \\
EHD & ECMWF 4x daily & yes \\
\hline
\end{tabular}

Two separate ten-year integrations were made to spin the model up from rest. The first is the genesis of the runs using the climatological FSU wind, while the second was spun up with the repeating 1994-95 ECMWF monthly mean winds. There were five additional five-year runs with various permutations of surface forcings, which are the basis for the analyses presented in this chapter. Selected runs beyond this timeframe were made, and are discussed below when appropriate. The next section in this chapter examines the result of two runs (F and FD) whose only difference is the inclusion of the diurnal cycle in the solar heating. The second part of the chapter focuses on two runs ( $E$ and EH) whose difference is in the frequency of the specified wind forcing, and a third run (EHD) which adds the diurnal heat cycle to the high-frequency wind forcing. The final year of these runs always forms the basis of the analysis. 


\subsection{Mean forced solution}

The solution forced by mean monthly heat and FSU wind climatologies (Run F) is similar to solutions described in MKM and elsewhere, but for completeness, a general description of the oceanic response in the Arabian Sea is reported here. This will provide a basis for describing the departures exhibited in other model solutions with different surface forcings. Section 3.3.1 and Section 3.3.2 focus on the two monsoon seasons, when the surface forcing is strongest. The annual mean solution is examined in Section 3.3.3, and the evolution at the Arabian Sea buoy site is examined in Section 3.3.4.

\subsubsection{SW monsoon}

The most energetic forcing of the year comes during the SW monsoon, with strong southwesterly winds covering much of the Arabian Sea, concentrated in the western portion of the basin (Fig. 3.28). In response to the wind forcing, the model solution's Somali current develops to its maximum strength, reaching velocities in the surface layer of 2.85 $\mathrm{m} \mathrm{sec}-1$ (Fig. 3.5). Strong offshore currents at about $6^{\circ} \mathrm{N}$ and a retroflection create the Southern Gyre (SG, Schott [1983]), centered about $4^{\circ} \mathrm{N}$. The Great Whirl, another retroflection of the Somali current centered farther north, at about $9^{\circ} \mathrm{N}$, does not form in the model, a deficiency it shares with other versions of the MKM model forced by the FSU wind stress climatology, though there are suggestions that the formation of a separated GW/SG system is dependent on interannual variability [Subrahmanyam and Robinson, 2000].

The currents in the seasonal thermocline, layer 3 , are tied closely to the surface currents, with strong northward flows along the Somali coast and a retroflection offshore. The deepest currents, in the permanent thermocline (layer 4), flow northward along the Somali coast and the coast of Oman, closing the losses due to strong upwelling in these areas. This deep current that develops at the height of the SW monsoon does not exist in observations, but may develop as a result of the limited vertical resolution of the model 

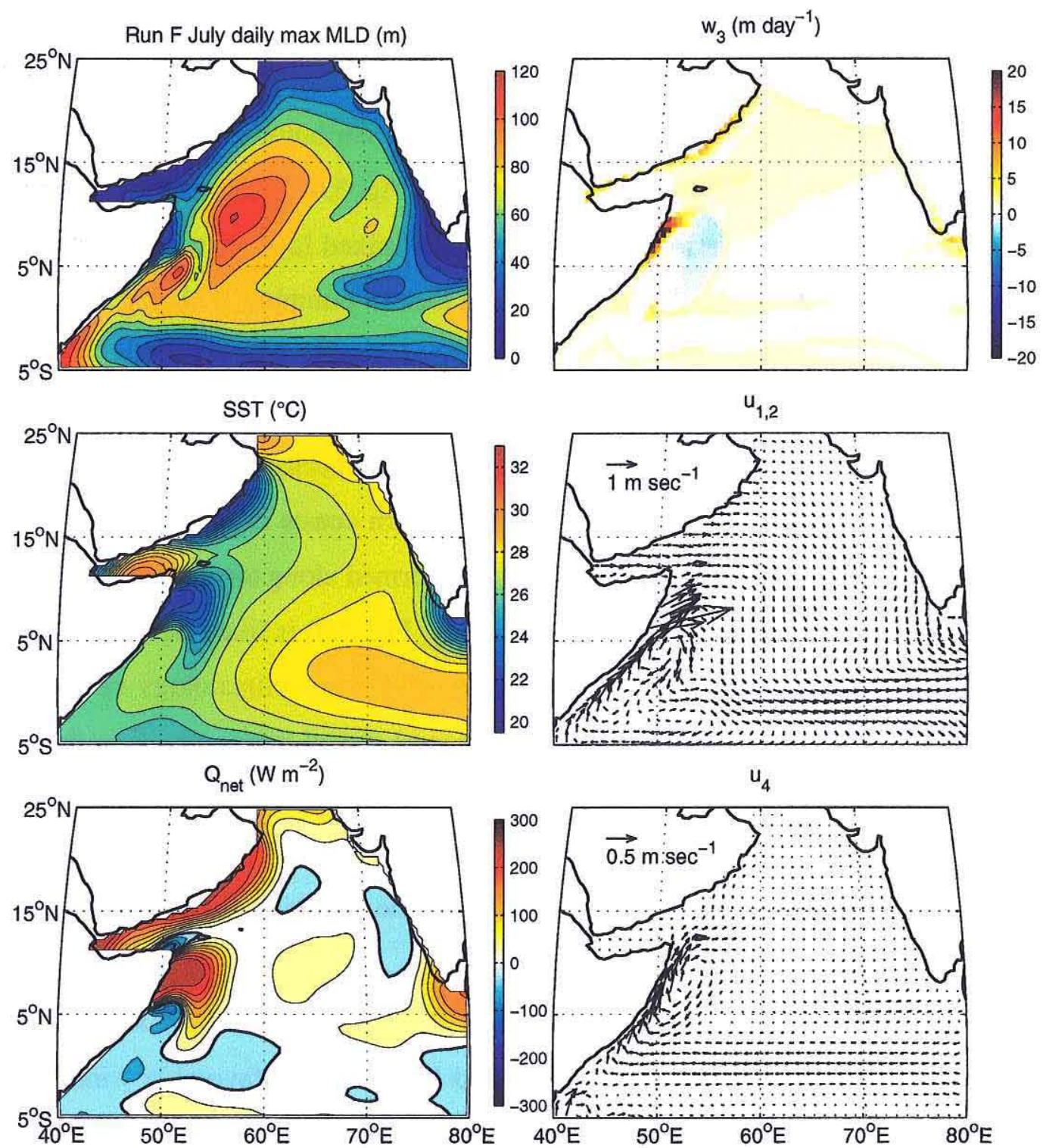

Figure 3.5 July Run F: model solution snapshots (mid-month) of the daily mean mixed layer depth (MLD, with $10 \mathrm{~m}$ contours), the sea surface temperature (SST, $0.5^{\circ} \mathrm{C}$ contours $)$, the net surface heat flux $Q_{\text {net }}\left(30 \mathrm{~W} \mathrm{~m}^{-2}\right.$ contours, with the zero contour emphasized), entrainment/detrainment velocity out of the permanent thermocline layer $\left(w_{3}\right)$, and surface and layer 4 velocities (on a reduced resolution $1^{\circ}$ grid, with layer 4 velocities on a different scale). 
[McCreary et al., 1993]. It replaces a weak southward Somali Undercurrent that appears in May from the region of about $5^{\circ} \mathrm{N}$ to the equator.

The mixed layer $\left(h_{1}\right)$ fields are their deepest during the SW monsoon in a large bowlshaped area that is coincident with the strongest wind forcing (Fig. 3.28). An examination of the mass balance (3.2) shows that the strongest contributor to this deepening is the wind-driven entrainment velocity contribution to $w_{1}$ (Fig. 3.6). There is a secondary contribution from the advective term, both in the shallow mixed layers along the Somali and Arabian coasts, and in offshore deepening due to Ekman pumping. This interpretation is consistent with Lee et al. [2000], who, using climatological forcing fields, found SW monsoon mixed layer deepening is more strongly forced by local wind mixing than Ekman pumping, and speculated that horizontal transport mechanisms must be important in maintaining the shallow mixed layers off the western coasts of the Arabian Sea. The hook of shallow mixed layers in the model solution formed along the northern edge of the Southern Gyre (about $6^{\circ} \mathrm{N}$ on the western boundary, Fig. 3.5) is likewise due to horizontal advection of the sharp zone of coastal upwelling. Levitus climatology of the mixed layer depth (Fig. 3.7, top left panel) shows the deepest mixed layers significantly farther east than in the model solution. This is a deficiency of the solution that is repeated under both the FSU and ECMWF surface wind forcing, suggesting that the Kraus-Turner scheme with the parameters used here overestimates the strength of wind-forced entrainment.

Another important feature of the mixed layer depth field is the very shallow mixed layers along the southern Indian coast, generated by upwelling-favorable winds. MKM noted the formation of this region in May as the SW monsoon winds begin to blow with a strong equatorward component along the Indian coast. By July the eastern edge of the coastal upwelling region has detached from the coast and is propagating into the interior as a Rossby wave packet. This feature has important implications on the mixed layer depth throughout the year, and can be seen clearly in all of the layer depth fields $\left(h_{1}+h_{2}\right.$ and $h_{4}$ are shown in Fig. 3.15). The relative shallowness of the mixed layer in the vicinity of $65^{\circ} \mathrm{E}, 10^{\circ} \mathrm{N}$ is in fact a remnant of the previous SW monsoon coastal upwelling 

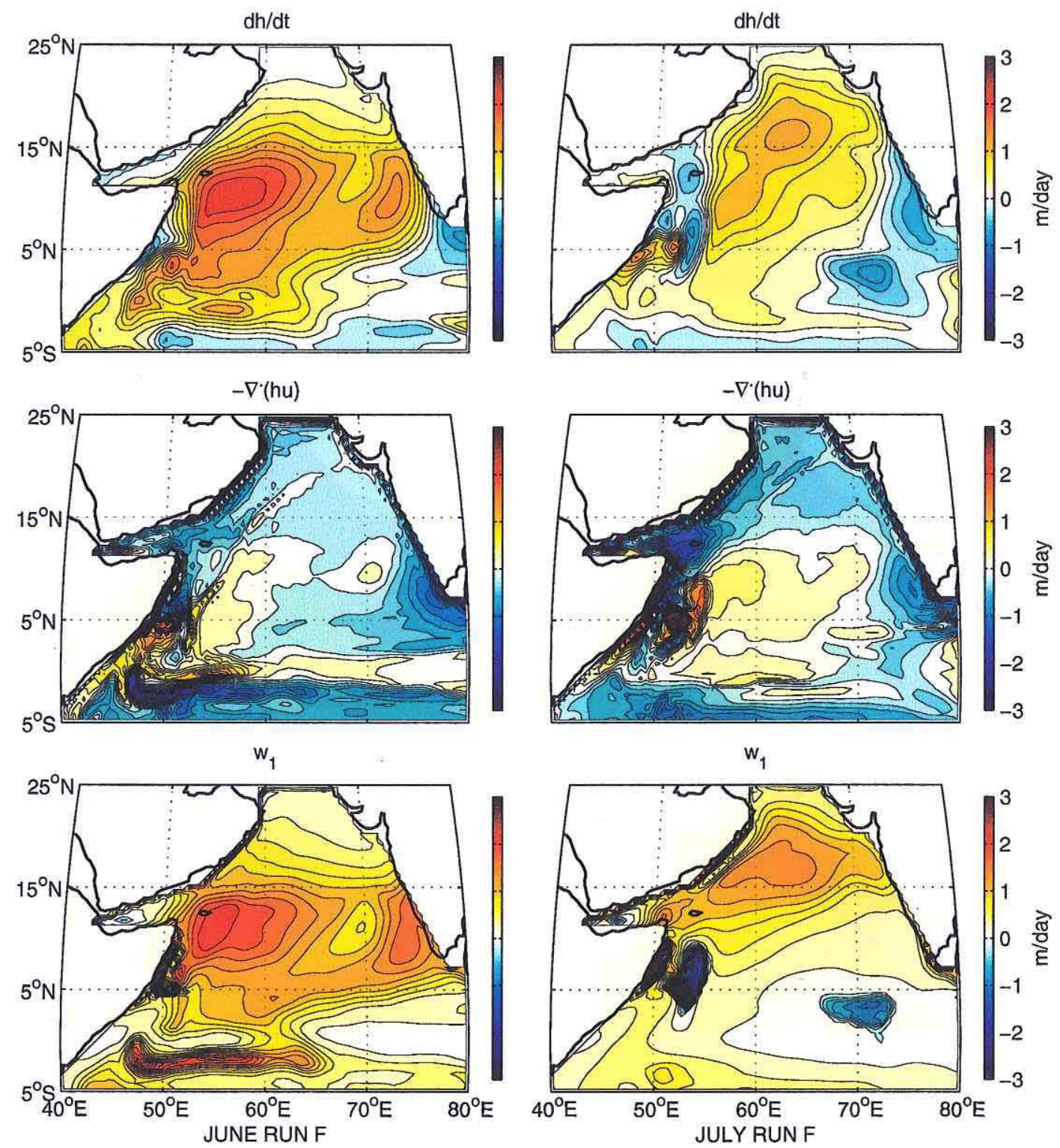

Figure 3.6 The time change, advective, and vertical velocity terms in the mass balance (3.2), for June (left) and July (right). The major contribution to the SW monsoon mixed layer depth pattern (Fig. 3.5 top left) comes in June, and is primarily made up of locally-driven vertical velocities, rather than Ekman convergence or divergence. There is a mild contribution to the deepening from Ekman convergence on the right hand side of the Findlater Jet in July, much smaller than the locally-driven vertical velocity. The mass balance for the NE monsoon is similar with a much stronger contribution to mixed layer formation from locally-driven vertical mixing, rather than Ekman pumping. 


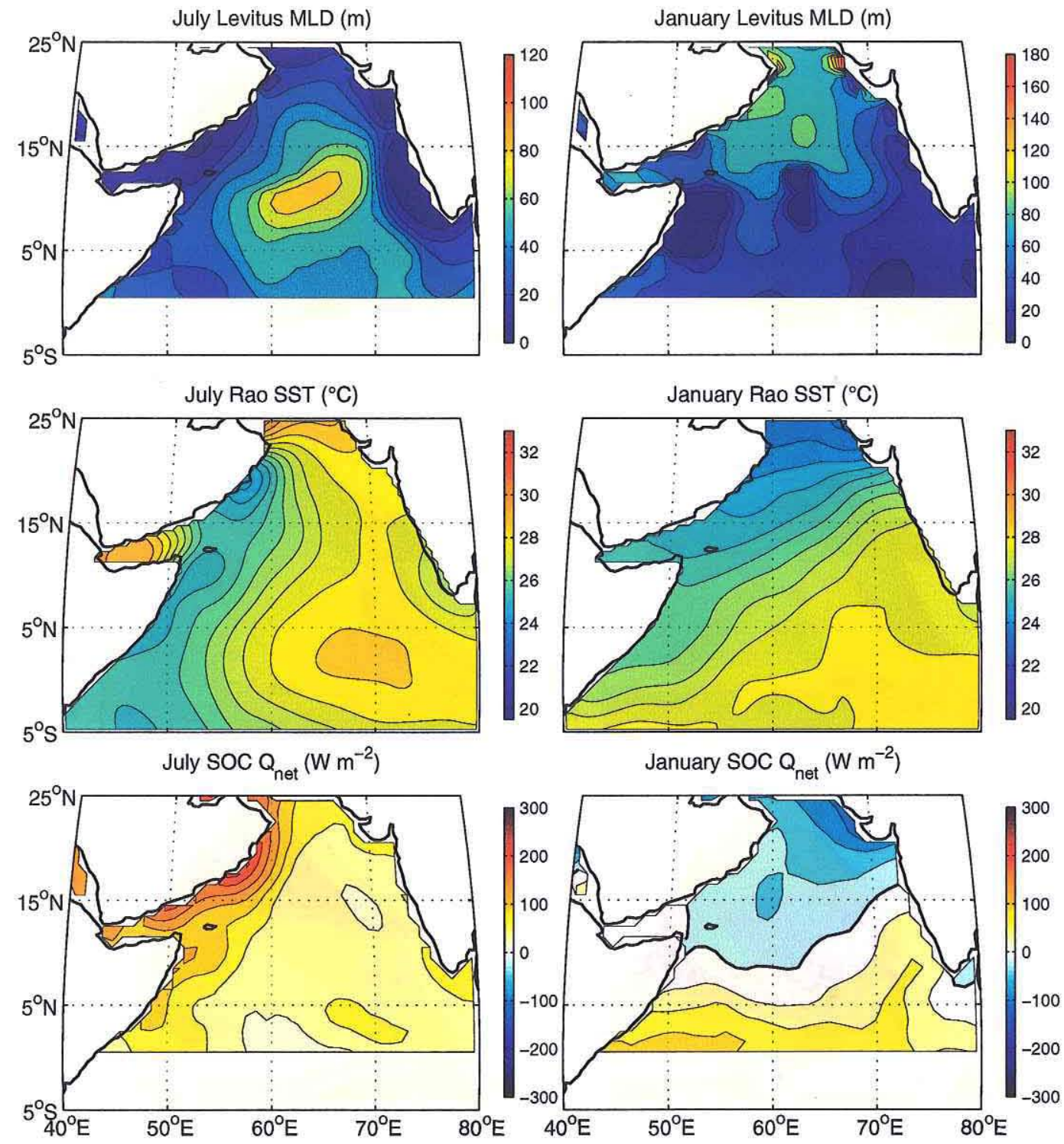

Figure 3.7 July and January climatology of the mixed layer depth (Levitus, $30 \mathrm{~m}$ contours), SST (Rao, $0.5^{\circ} \mathrm{C}$ contours), and the net surface heat flux (SOC, $30 \mathrm{~W}$ $\mathrm{m}^{-2}$ contours).

that has propagated into the interior. Farther south where the gradient of the planetary vorticity increases and the Coriolis parameter decreases, the waves move westward at a faster pace. Ekman convergence driven by the eastward component of the winds is strong at the equator, and a band of deep mixed layer depth is evident there. 
The strongest signals in the SST (Fig. 3.5) are in regions of coastal upwelling, along the northern Somali, the Arabian, and the southern Indian coasts. The general pattern of SST matches the climatology (Fig. 3.7), though the regions of strongest cooling are not represented in the climatology. Higher-resolution data (see Chapter 2) suggest that this might be a function of the averaging in the climatology, as there are regions that are as cool as $22^{\circ} \mathrm{C}$ in the surface AVHRR SST imagery. The imagery also suggest episodic offshore transport of this cool, upwelled water.

The patterns of upwelling velocity (represented in Fig. 3.5 by $w_{3}$, the entrainment out of the permanent thermocline) match the coolest SSTs, and are strongest along the Somali coast. The net surface heat flux is strongly positive in these upwelling regions, matching the SOC climatology (Fig. 3.7). The strong heat fluxes are due to a number of factors. The cool SSTs lead to a reduced longwave heat loss in the Rao climatology. The strong air-sea temperature difference drives the sensible heat flux into an oceanic heating, opposing latent heat losses, which are reduced with the reduced saturation specific humidity created by cool SSTs. Unlike the climatology, however, which is everywhere strongly (between 30 and $60 \mathrm{~W} \mathrm{~m}^{-2}$ ) positive over the Arabian Sea, the model net surface heat flux hovers just above zero outside the upwelling zones. In regions of higher SST, such as along the central Indian coast in the vicinity of $15^{\circ} \mathrm{N}$, in the interior of the Southern Gyre, and along the equator, the model heat flux is an oceanic loss.

The equatorial current structure of the model (Fig. 3.5) has the same patterns and deficiencies as MKM. In the model, the surface southward flow in the Arabian Sea joins a strong eastward equatorial countercurrent just south of the equator, and there is a fairly strong westward current, farther south at about $5^{\circ} \mathrm{S}$. The surface currents north of the equator grow increasingly eastward in the eastern portion of the basin. The flow is similar in layer 3, and the countercurrent flow is reversed in layer 4. Observations show the strongest zonal current during the SW monsoon to be centered around $5^{\circ} \mathrm{N}$, the eastwardflowing Indian Monsoon Current, which is poorly represented in the model. 


\subsubsection{NE monsoon}

The NE monsoon reaches its peak in January, with northeasterly winds covering much of the basin, concentrated again in the western portions, and strongest along the Somali coast (Fig. 3.28). In response to these winds, a strong southward Somali current develops, with peak speeds of about $1.3 \mathrm{~m} \mathrm{sec}^{-1}$ (Fig. 3.8). It follows the coast from about $7-8^{\circ} \mathrm{N}$ across the equator to about $2^{\circ} \mathrm{S}$, where it turns offshore, retroflecting slightly and flowing eastward just south of the equator. The layer 3 current is similar, though the retroflection is more pronounced, the strongest eastward flow is north of the equator, and there is a significant flow component northward across the equator, east of the coastal region. The layer 4 current opposes the surface currents along the coast, flowing north to about $2^{\circ} \mathrm{N}$. Farther north the layer 4 currents match the surface currents, flowing southward.

The mixed layer deepens again during the NE monsoon in a large band extending from the Somali coast northeastward. The deepest mixed layers in the model solution reach $90 \mathrm{~m}$ (Fig. 3.8). In the model there is a good correspondence between the surface heat flux and the mixed layer depth, with the regions of heat loss overlying the deepest mixed layers. The mixed layers in the Levitus climatology (Fig. 3.7) are much shallower, though there is a lack of data in certain regions. The model surface currents follow this structure in the surface layer depth to some extent, with a weak westward flow around 7$8^{\circ} \mathrm{N}$ which bifurcates when reaching the coast, the northward branch creating a weak coastal countercurrent that flows into the Gulf of Aden, and the southward branch joining the Somali current.

Another major feature of the mixed layer depths is a large region of very shallow mixed layer extending north from the equator to about $5^{\circ} \mathrm{N}$. Despite the strong net heat flux into this area, it is a local minimum in the temperature, providing a clue that it has dynamical origins. In fact it is the result of the SW monsoon coastal upwelling along the Indian coast, which has propagated far westward (see Fig. 3.15). It is also locally forced by Ekman pumping driven by the westward winds along and north of the equator. The 

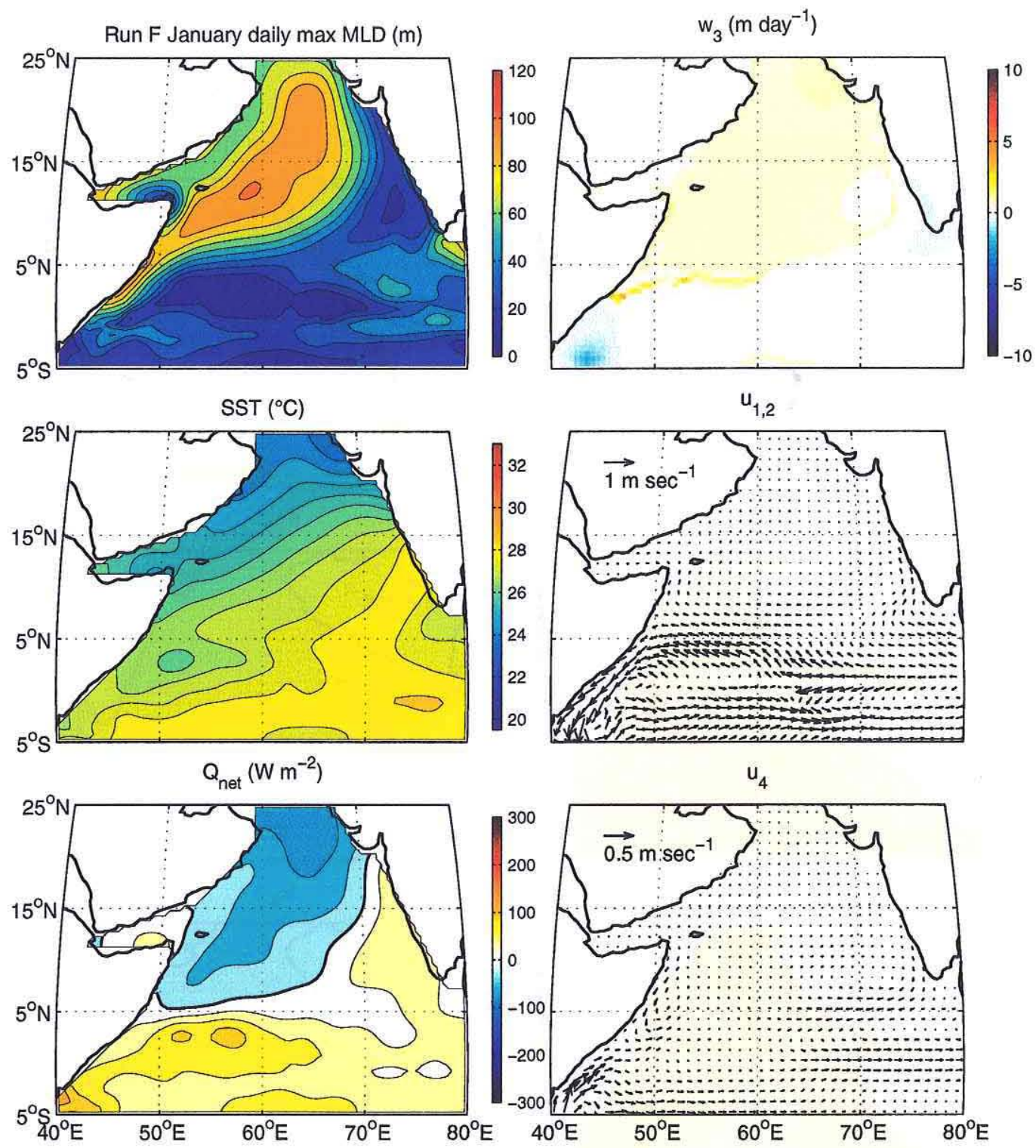

Figure 3.8 As in Fig. 3.5, except for January Run F. The color scale on $w_{3}$ has changed.

signal of the upwelling can be seen in the $w_{3}$ field. The flow fields in the upper layer respond to this feature, with strong geostrophically-balanced flows westward to the north and eastward on its southern flank, just north of the equator.

The SST response during the NE monsoon is also linked with the surface heat flux, with cooler temperatures to the north, matching well with the climatology. There is a 


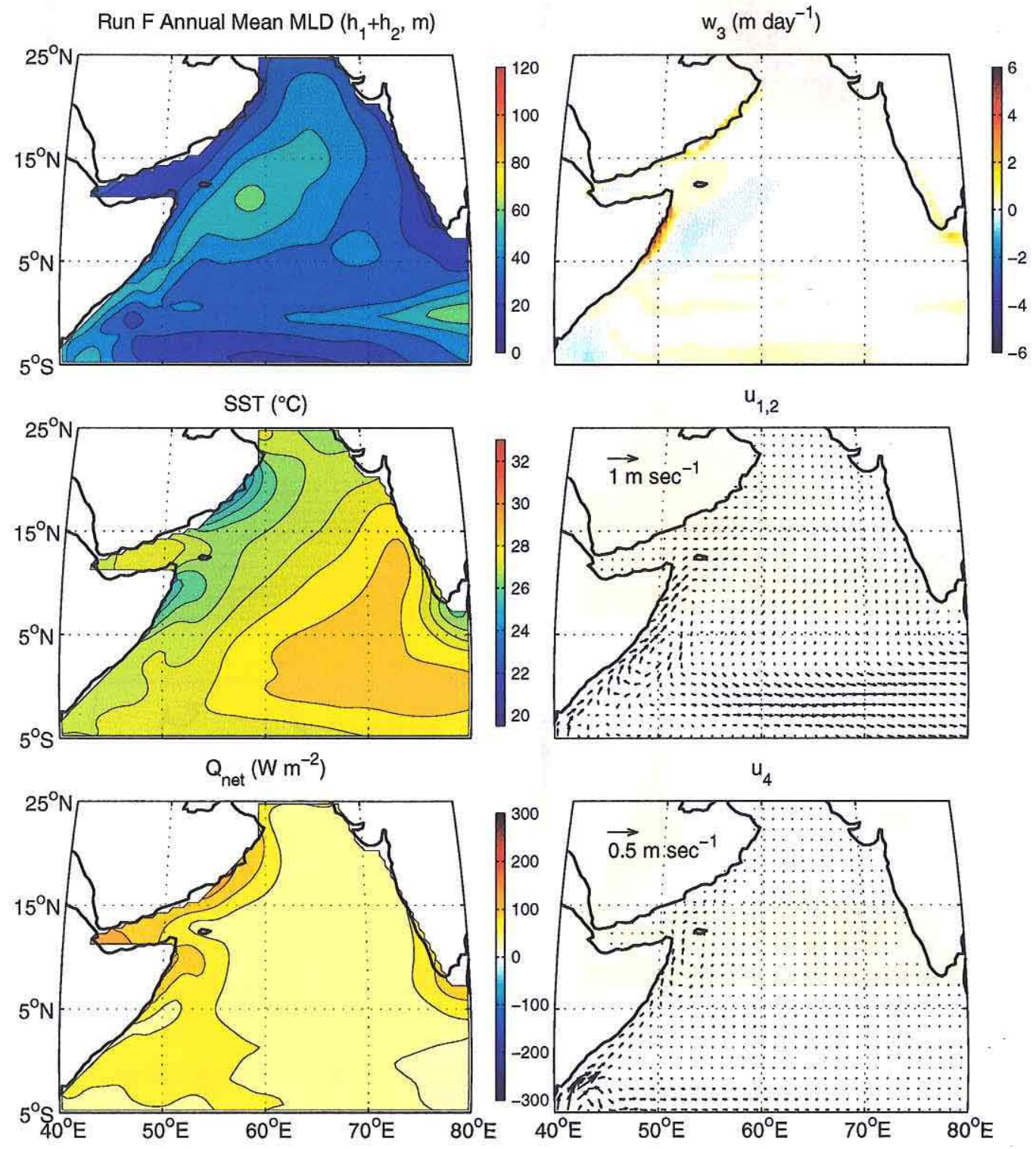

Figure 3.9 An overview of the annual mean model solution, Run F. The annual mean mixed layer depth is represented by the sum of layers 1 and 2 , which is a good approximation of the daily maximum mixed layer depth. Otherwise, as in Fig. 3.5, with a reduced color scale on $w_{3}$. 
band of cool temperatures north of the equator, associated with the shallow mixed layers discussed above.

Finally, a northward surface current and deeper southward-flowing countercurrent develop along the coast of India. MKM notes that this feature is primarily forced by remote forcing, propagating as coastal Kelvin waves from the Bay of Bengal.

\subsubsection{Annual mean}

The annual mean circulation and features of the model solution are in many ways dominated by the strong response of the SW monsoon (Fig. 3.9). There is no real dynamical significance to the fields, but they do show the pathways of mass and heat transport that exist on the annual mean basis, and provide a basis for comparison with further model runs.

There is a net surface heat flux over the entire basin, strongest at the coasts in the regions of SW monsoon upwelling. The net yearly gain over the Arabian Sea north of $6.75^{\circ} \mathrm{N}$ (the southernmost latitude where the Arabian Sea is cut off from the Bay of Bengal) is $0.28 \mathrm{PW}$ in run $\mathrm{F}$. The surface temperature also carries the signature of the upwelling zones, strongest along the Arabian coast, in reasonably good agreement with
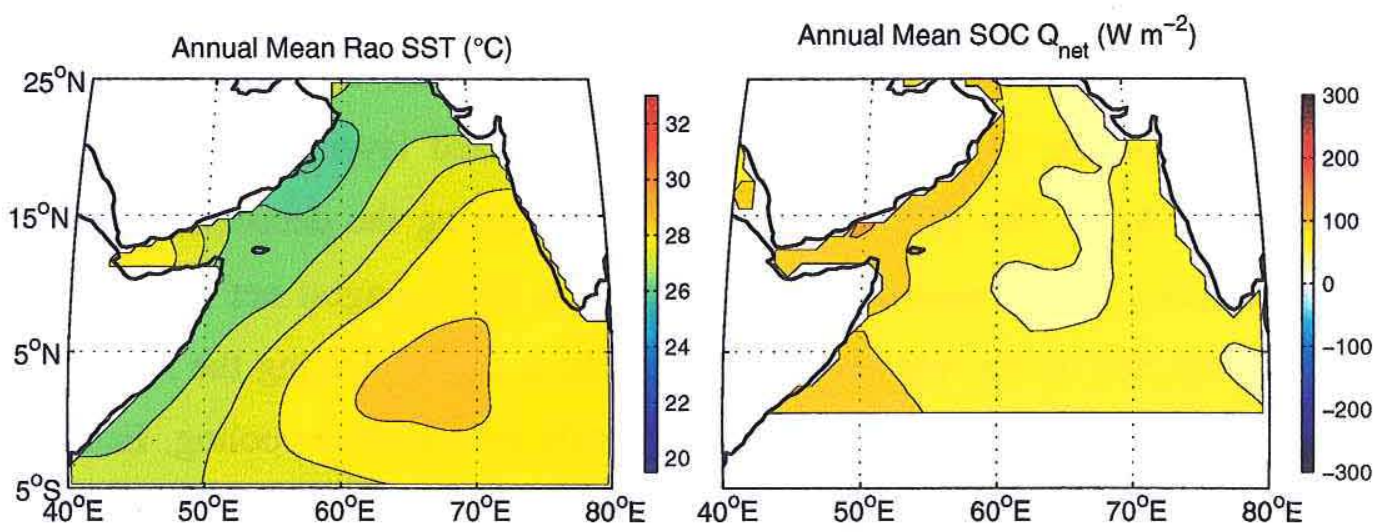

Figure 3.10 Climatology of annual mean SST (Rao, $0.5^{\circ} \mathrm{C}$ contours) and the net surface heat flux (SOC, $30 \mathrm{~W} \mathrm{~m}^{-2}$ contours). The net heat flux is everywhere positive into the ocean. 
the annual mean climatology, although it is cooler than climatology (matching individual observations better, though the Somali coastal upwelling is coolest in nature) in the upwelling regions. The surface circulation has a strong northward component along the Somali coast, with a southward flowing retroflection about $400 \mathrm{~km}$ east, and a broad southward flow across much of the interior reaching towards the equator. The deeper layers share the same northward-flowing Somali coastal current, and are linked to the surface layers with regions of upwelling along the Somali and Arabian coasts.

The net mass and heat transport can be roughly seen in this circulation, with warm surface waters, heated by an annual net heat flux, being transported south by the winds, and being replenished with a northward flow of cooler water at depth along the western boundary. The zonally-averaged mean circulation and heat transport will be addressed in Section 3.4.6, in comparison with the diurnally-forced run.

\subsubsection{Buoy site}

The layer depths and SST evolution predicted by the model for the site of the Arabian Sea buoy at $15.5^{\circ} \mathrm{N}, 61.5^{\circ} \mathrm{E}$, are shown in Fig. 3.11. The characteristic twice-yearly cycle of mixed layer deepening and cooling is reproduced in the model (compare to Fig. 3.1). The deepening during the SW monsoon comes in response to increasing wind stress in June, boosting the production of TKE $P_{r}$. The mixed layer continues to deepen through August, reaching a maximum of about $105 \mathrm{~m}$, when weakening wind stresses and an increase in the surface heat flux drop the mixed layer depth to the MoninObukhov depth $h_{M O}$. The SST drops by over $4^{\circ} \mathrm{C}$ during the deepening period. The shorter of the two intermonsoon seasons, marked by the strongest net heat flux of the year, allows the SST to recover partially, rising about $2.5^{\circ} \mathrm{C}$. During the NE monsoon, deepening, starting in November, is driven primarily by a surface cooling. Entrainment continues until the beginning of February, reaching a depth of just over $100 \mathrm{~m}$. During this time the SST loses what has been gained during the intermonsoon. The longer intermonsoon season in the spring produces the shallowest mixed layers, and allows temperatures to build to their highest point, at nearly $30^{\circ} \mathrm{C}$. The diurnal thermocline layer 

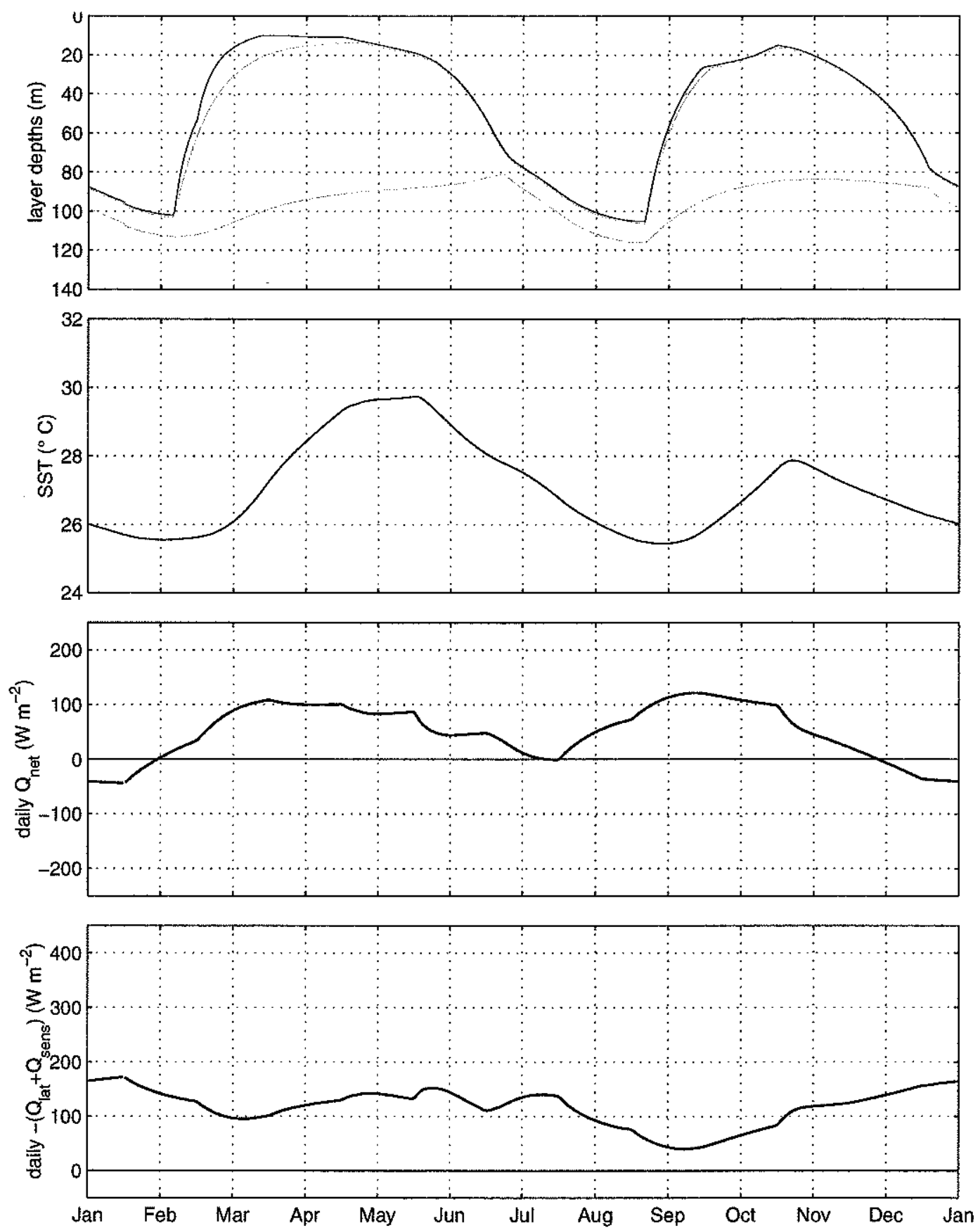

Figure 3.11 Run F Model solution at the site of the Arabian Sea buoy $\left(61.5^{\circ} \mathrm{E}\right.$, $15.5^{\circ} \mathrm{N}$ ). From top: the mixed layer depth (black) and the boundaries between layers 2,3 , and 4 (gray), the layer 1 temperature (SST), the daily average net surface heat flux, and the daily average sum of the surface latent and sensible heat losses. 
follows the mixed layer very tightly staying at its minimum depth throughout the year, except at times when the mixed layer detrains very rapidly, particularly at the end of the NE monsoon. Since the detrainment rate is dependent on the depth of the lower interface of layer 2 (3.16), the rate of detrainment is reduced when the mixed layer is very thin, also at the end of the NE monsoon.

While the most salient feature-the twice yearly cycle of mixed layer deepening and cooling-is reproduced, the model solution is lacking in a number of respects (compare Fig. 3.1 with Fig. 3.11). The SW monsoon model mixed layer is much deeper than observed, and persists longer. Part of this difference, towards the end of July and into August, is caused by the advection of coastally-upwelled water to the site of the observations (Chapter 2), which the model does not reproduce. It does not develop the strong variability along the Arabian coast seen in the altimetry (also Chapter 2). The peak SST in the record comes too early by nearly a month, and the drop is not as precipitous in the latter half of the SW monsoon. This last difference is also attributable to the advection observed at the mooring.

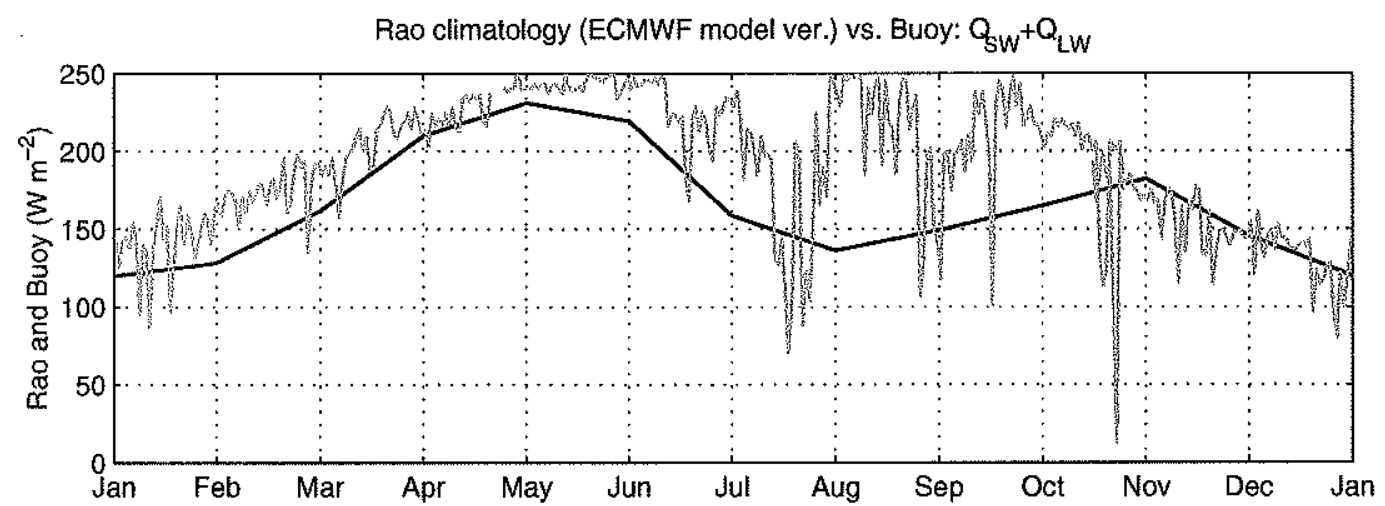

Figure 3.12 Surface forcing at buoy site: the Rao climatology of solar and longwave surface heat flux $\left(Q_{\mathrm{SW}}+Q_{\mathrm{LW}}\right)$ used to force the model (black), and the observed values from the WHOI mooring (gray). The largest difference comes in the latter part of the SW monsoon (late July-August) when the values observed at the buoy are much higher than the climatology, coinciding with the cool advected water of a coastal filament. This dramatically reduced the longwave heat loss. 
The model net heat flux is in reasonable agreement with the observed heat flux, with two broad maxima associated with the spring intermonsoon and the tail end of the SW monsoon, a heat loss during the NE monsoon, and nearly no heat loss even at the height of the SW monsoon. The latent and sensible heat losses are very similar to the observed, though of course lacking the resolution of shorter events. The largest difference in the net heat flux, the sharp jump in August observed but not reproduced in the model, is again associated with the advective drop in surface temperatures at the moored array, reducing the outgoing longwave heat loss, an event that cannot be captured in a climatology.

\subsubsection{Summary}

Overall the model solution is strongly influenced by the local surface fluxes. The patterns of mixed layer depth during each monsoon are primarily influenced by surfacedriven entrainment (Fig. 3.6). During the SW monsoon this is wind-driven, during the NE monsoon surface cooling-driven. However, wind-driven coastal upwelling during the SW monsoon not only leads to strong changes in the depth and temperature fields along the Somali and Arabian coasts, but the upwelling along the Indian coast sets up Rossby wave propagation into the interior with lasting effects. This wave propagation affects layer depths, and with interactions with local surface fluxes, affects the evolution of both the depth and temperature fields into the following NE monsoon. These effects are strongest in the southern Arabian Sea and in particular in near-equatorial regions.

\subsection{Diurnally forced solution}

The sole difference between the diurnally-forced solution (Run FD) and the meanforced solution (Run F) is the addition of a diurnal cycle to the incoming solar heat flux. It takes the form 


$$
Q_{r}\left(t^{\prime}\right)=\left\{\begin{array}{cc}
-\pi \bar{Q}_{r} \cos \left(2 \pi t^{\prime} / t_{d}\right), & 6<t^{\prime}<18 \\
0, & \text { otherwise }
\end{array}\right.
$$

where $t^{\prime}$ is expressed in hours, and $t_{d}=24$ hours. Thus the daily integrated solar heating is equivalent to $\overline{Q_{r}}$, which, in all runs, is the linearly interpolated monthly climatology of Rao et al. [1989]. The mixed layer dynamics in response to this change in the diurnal, but not the mean forcing, is the subject of this section. I start with the response during the SW and NE monsoons (Section 3.4.1 and Section 3.4.2) and the model response at the buoy site (Section 3.4.3). The terms contributing to the temperature evolution at the mooring site are then examined (Section 3.4.4). The final two subsections deal with the annual mean properties and circulation, and the mass, heat, and temperature budgets across the basin.

\subsubsection{SW monsoon}

Not surprisingly, many of the features of the model solution remain the same. The primary change in the circulation is a strengthening of the Somali current to over $3 \mathrm{~m} \mathrm{sec}^{-}$

1 , accompanied by farther northward penetration of the current, to about $7^{\circ} \mathrm{N}$ (Fig. 3.13 , compared to Fig. 3.5). The recirculation of the Southern Gyre is more tightly bound to the coast (Fig. 3.14). The strength of the eastward equatorial countercurrent is reduced, particularly farther east in the domain. Likewise, the strength of the westward zonal flow at $5^{\circ} \mathrm{S}$ is reduced.

Lower layer circulations have similar changes. The seasonal thermocline (layer 3, not shown) coastal circulation also moves towards the coast. The northern boundary of the Southern Gyre is less distinct in run FD. The equatorial countercurrent in this layer now has a strong southward cross-equatorial component absent in run $\mathrm{F}$. The most prominent change in the thermocline circulation (layer 4) is a small increase in the northward velocity along the Somali coast north of $5^{\circ} \mathrm{N}$. These changes in the velocity field are reflected in the momentum fields, and so represent increased energy in the flows. 

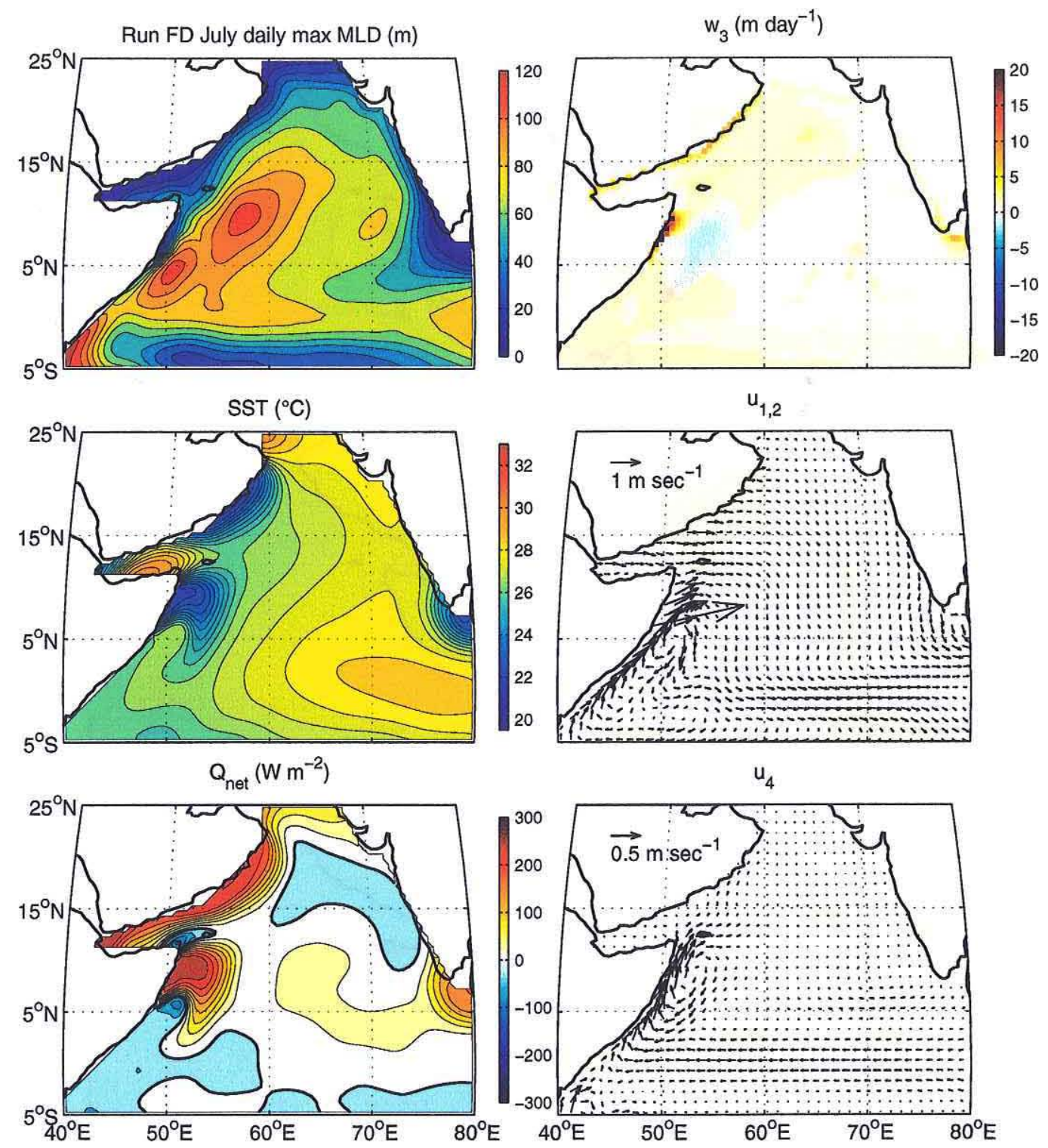

Figure 3.13 July Run FD overview: As in Fig. 3.5, except for run FD, including the diurnal cycle in solar heating.

The bowl-shaped maxima of mixed layer depths centered around $57^{\circ} \mathrm{E}, 10^{\circ} \mathrm{N}$ remains, though generally the mixed layers in this region are shallower in run FD, and the contrasts with the surrounding region reduced. While the region of very shallow mixed layers along the Arabian coast persists unchanged, the shallow regions north of the Southern Gyre are deeper in run FD (Fig. 3.14). The penetration farther north of the SG 

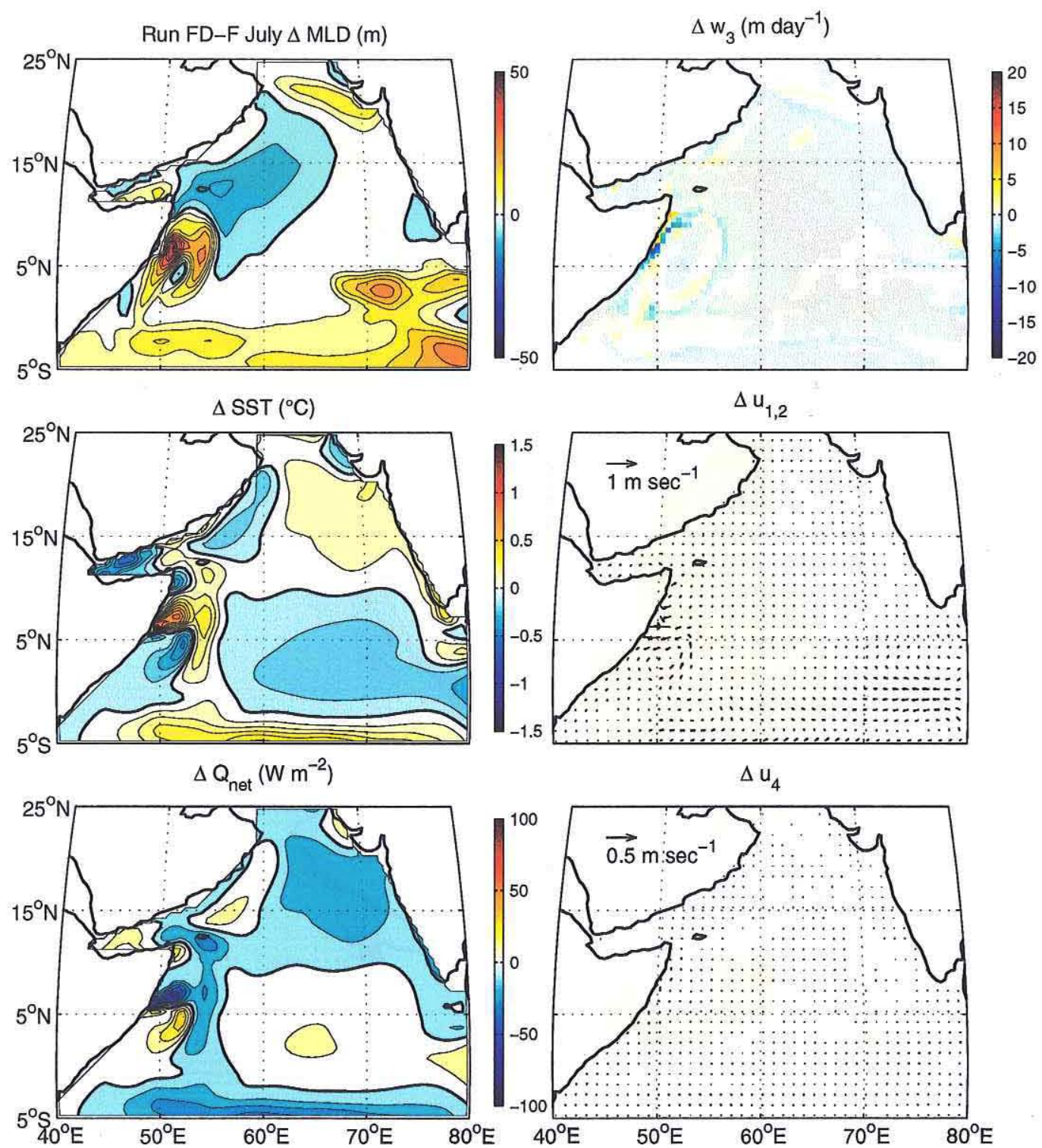

Figure 3.14 An overview of the differences between the model run FD - run F for July. The change in mixed layer depth $(\triangle \mathrm{MLD}$, contours every $5 \mathrm{~m}$, with the thickest line denoting the zero contour), the sea surface temperature ( $\Delta \mathrm{SST}, 0.1^{\circ} \mathrm{C}$ contours), the net surface heat flux $\left(\Delta Q_{n e t}, 10 \mathrm{~W} \mathrm{~m}^{-2}\right.$ contours), the layer $3 / 4$ cross-interfacial velocity $\left(w_{3}\right)$, and the upper layer and layer 4 velocities.

affects the horizontal advection of mass in the upwelling wedge, but even taking this into account the mixed layers are deeper in run FD. 
The dynamically important upwelling along the southern Indian coast remains in run FD, and $h_{1}$ fields along the coast are at their minimum depth, as in run F. Farther offshore, however, in the westward propagation of these features, there are significant differences between the two runs. The increased vertical mixing brought about by the diurnal cycle appears to damp the vertically alternating currents (southward flowing in the surface layers and northward in the thermocline) that are associated with the propagating (mode-2) Rossby wave packet. Near the equator, the region of very shallow mixed layer that has propagated westward to nearly $65^{\circ} \mathrm{E}$ in run $\mathrm{F}$ is present in run FD (Fig. 3.5 and Fig. 3.13), but has layer depths that are up to $25 \mathrm{~m}$ deeper. Likewise the finger created by a local minimum in mixed layer depth extending to about $67^{\circ} \mathrm{E}, 10^{\circ} \mathrm{N}$ in run $\mathrm{F}$ is reduced in amplitude in run FD. This change in the propagation of Rossby wave packets can be seen in the time-longitude plot Fig. 3.15, which repeats the final year for clarity. The twice-yearly cycle of mixed layer deepening and shoaling tends to obscure this propagation somewhat in the upper layers, but it is very clearly seen in the deepest layer depth. The layer depth amplitude of the wave packet disturbance is reduced in run FD, along with the associated currents (not shown).

During the SW monsoon the SST field is once again dominated by the cool temperatures associated with the upwelling regions along the Somali, Arabian, and Indian coasts. The diurnally-forced model (run FD) has broad regions that are generally cooler in temperature, with the exception of the northeastern corner of the basin, and a zonal band along $5^{\circ} \mathrm{S}$. The difference field also shows a dipole (Fig. 3.14) that is a result of the northward displacement of the SG.

The net surface heat flux is again marked by strong gains at the upwelling locations. In the broad regions where the SST is cooler in run FD the net surface heat flux is also very slightly stronger (Fig. 3.14). In other places, where the SSTs are warmer in run FD, the net surface heat flux is reduced, tipping the balance towards a loss. These regions include the basin north of $10^{\circ} \mathrm{N}$ and east of $61^{\circ} \mathrm{E}$, the wedge north of the SG, and the zonal band along $5^{\circ} \mathrm{S}$. 


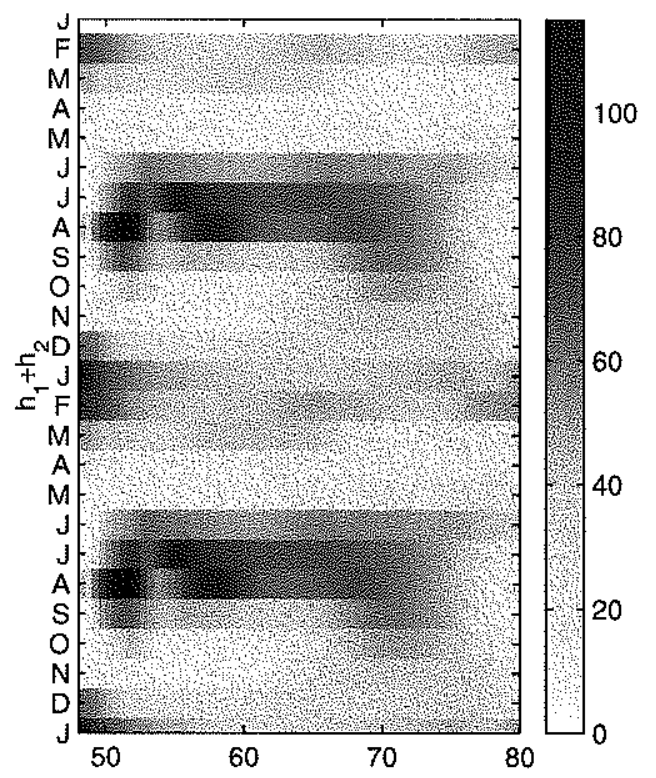

Run F

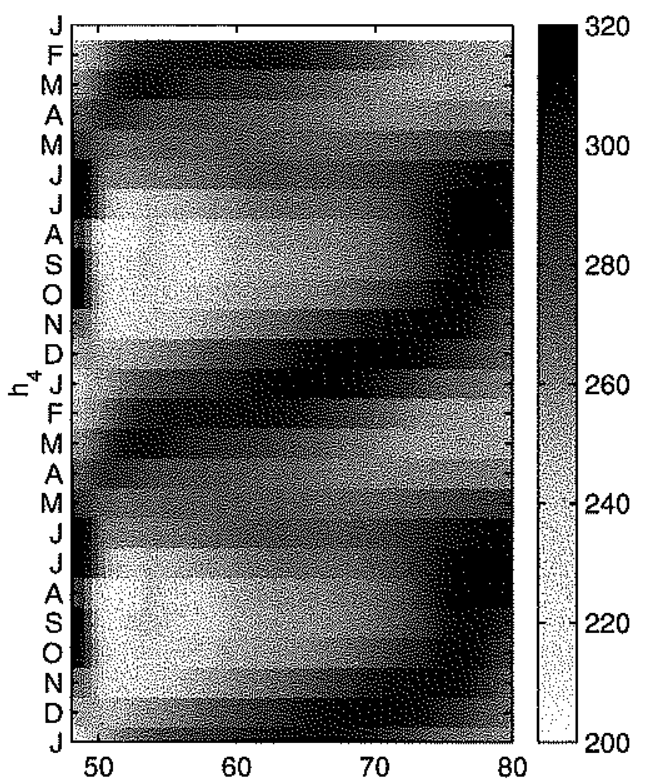

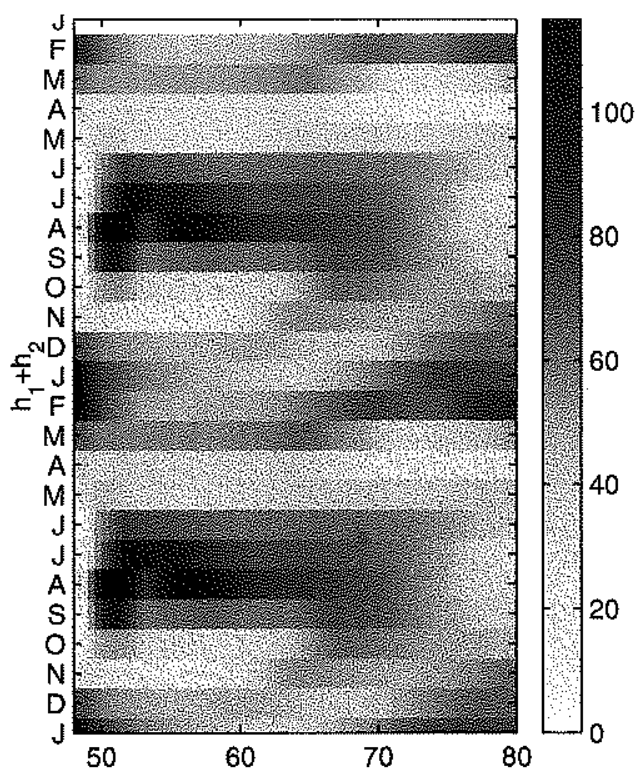

Run FD

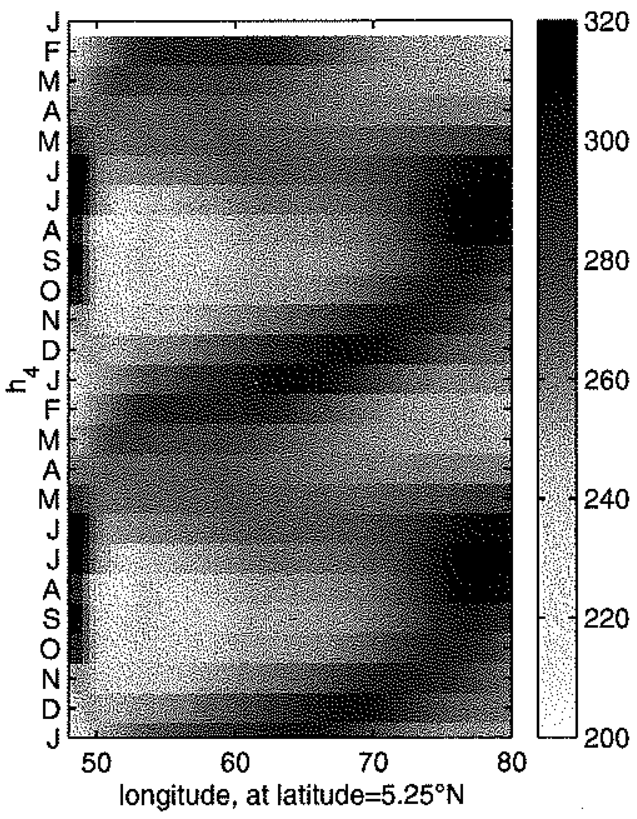

Figure 3.15 Propagation of $h_{1}+h_{2}$ and $h_{4}$ at the fixed latitude of $5.25^{\circ} \mathrm{N}$, for run $\mathrm{F}(l e f t)$ and run FD (right). The last year of the model solution has been repeated for clarity. The westward propagation of shallow mixed layers formed along the Indian coast during the SW monsoon is masked partially by the seasonal cycle in the upper layers. The surface layers are thicker in run FD, and the amplitude of the disturbance reduced. 
An examination of the strength of each term in the temperature evolution equation (3.3) shows that the two major contributing terms to the cooling during the July are the horizontal advection of heat and cooling due to upwelling or entrainment (Fig. 3.16). Cooling driven by upwelling is very strong immediately at the Somali, Arabian, and southern Indian coasts, with values regularly exceeding $1^{\circ} \mathrm{C} /$ day directly at the coast. However the sharp gradients created by this upwelling are quickly mixed away, as seen in the dissipative term. In run $\mathrm{F}$, there is also a strong zonal band of upwelling along $5^{\circ} \mathrm{S}$. In the interior, entrainment drives a broad cooling, which is also contributed to by a broad southward advection of cooler water. The horizontal advection of heat is very active along the Arabian coast, transporting upwelled water offshore. It is also strong in the wedge north of the SG, again transporting upwelled water offshore. And it contributes to cooling by transporting upwelled water off the southern tip of India. The surface heat flux tends to oppose the cooling in the upwelling zones, but it not strong enough to overturn the trend. Locally near the Somali current, the dissipation of temperature can boost or lower the temperature through horizontal mixing.

The difference between the temperature trend terms in runs F and FD is moderate during the SW monsoon. The largest signals are broad regions of slightly increased cooling across the interior, and slightly reduced cooling at the Arabian coast in run FD. However this moderate change is achieved by the balance of two large changes of opposite sign (Fig. 3.16B). The cooling due to upwelling along the Arabian coast and into the Gulf of Aden is stronger and occurs over a broader region away from the coast. It is opposed by a stronger net heat flux into the model. This same pattern is seen in the region of westward propagation of the Indian coastal upwelling, extending westward to about $63^{\circ} \mathrm{E}$. There is, however, reduced upwelling in the zonal band along $5^{\circ} \mathrm{S}$, keeping the temperatures warmer in run FD.

Although upwelling into the surface mixed layer generally increases over the basin, the upwelling out of the permanent thermocline (Fig. 3.13) is reduced. This suggests that the diurnal thermocline layer plays an important intermediary role. The strongest 

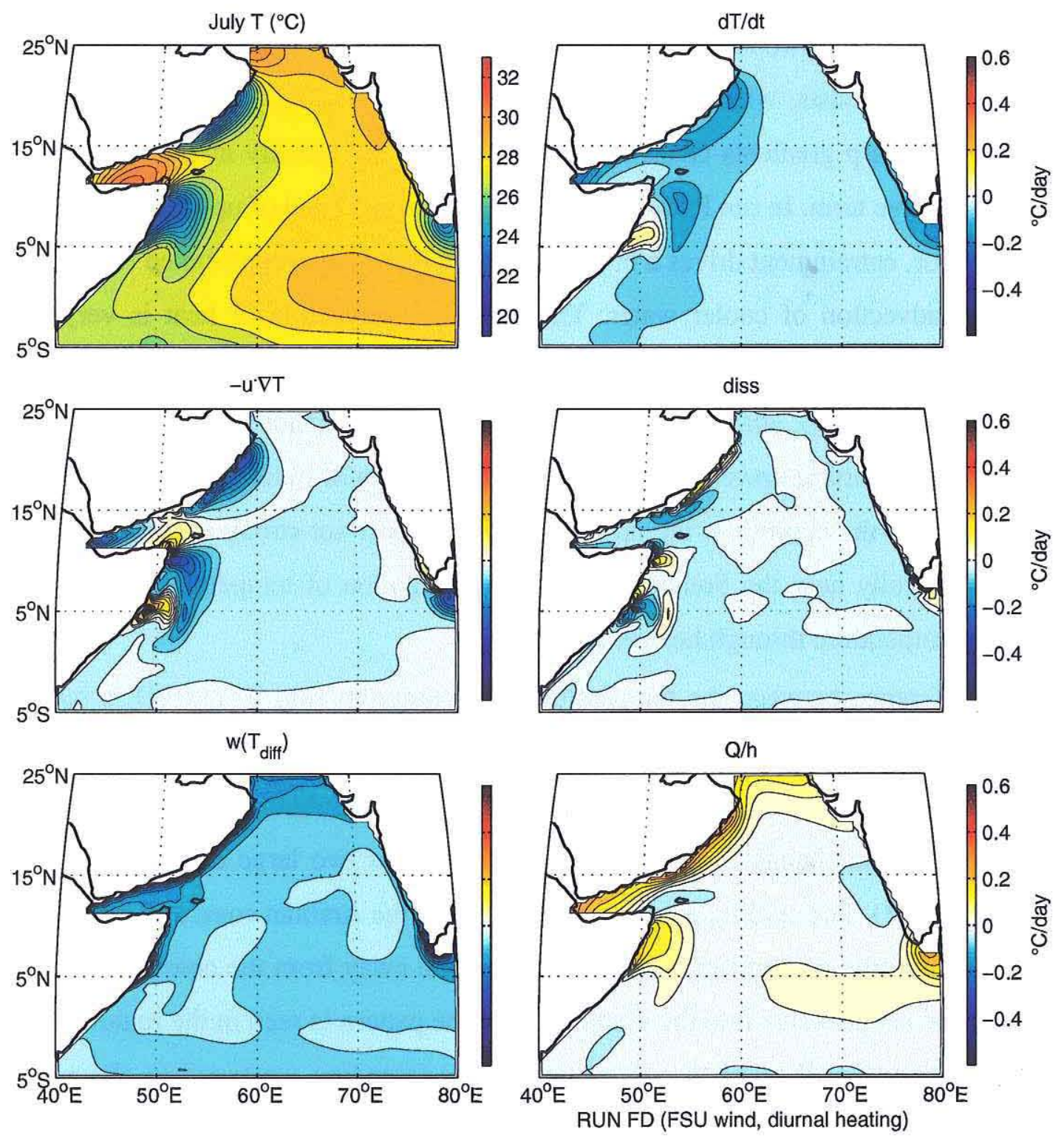

Figure 3.16 A July Run FD: terms in the temperature budget of layer 1 (the mixed layer). First, for reference, the mean July solution SST. Then from left-right, topbottom: the temperature trend, horizontal advection, dissipation, entrainment cooling, and solar heat flux in to the layer, all in monthly mean, and all on the same color scale (contours every $0.04{ }^{\circ} \mathrm{C} /$ day). 

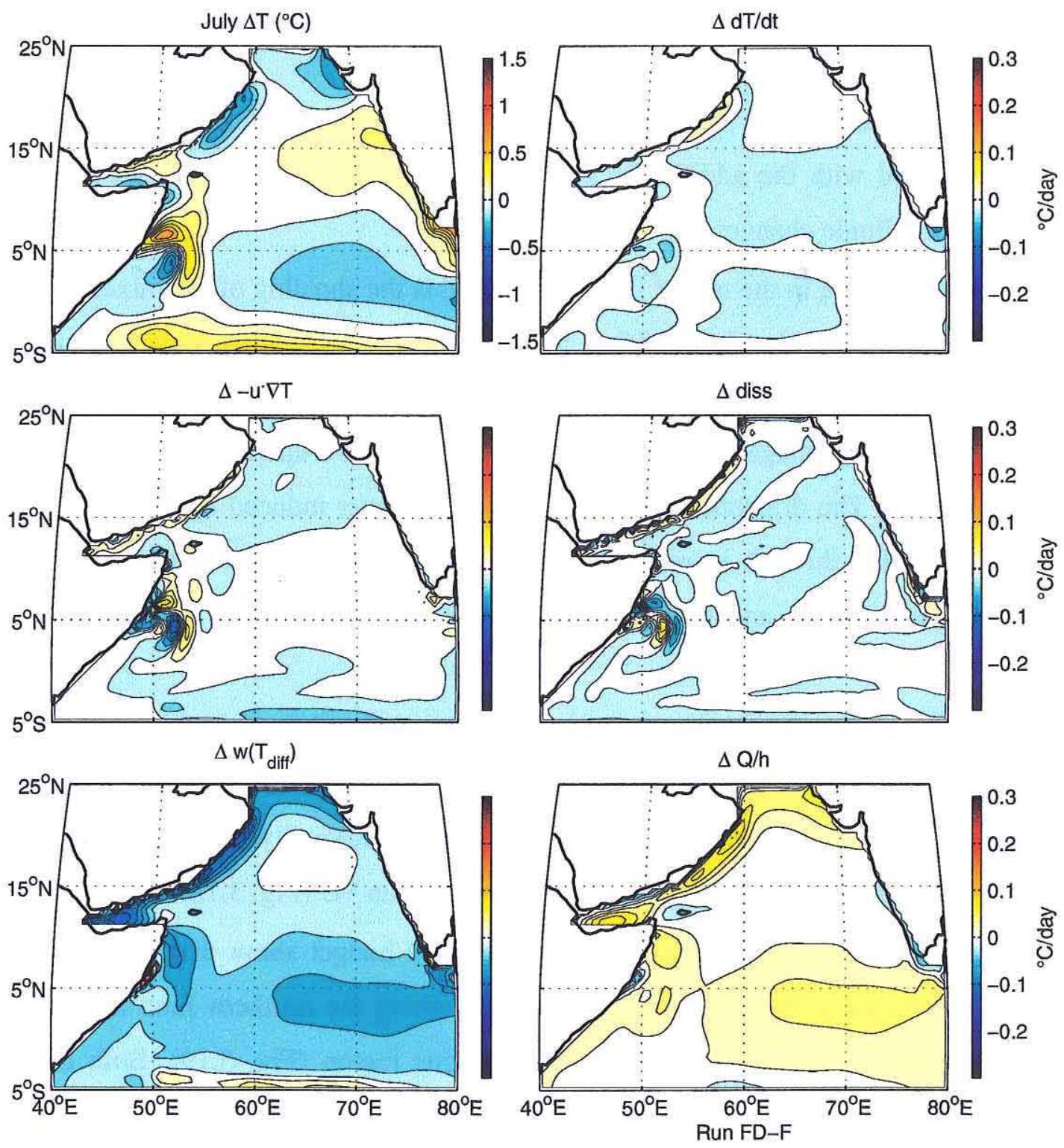

Figure 3.16 B As in Fig. 3.16A, except now the difference between Runs FD-F. Contours are now every $0.1^{\circ} \mathrm{C}$ for $\Delta T$, and $0.02{ }^{\circ} \mathrm{C} /$ day elsewhere. 
upwelling still occurs along the northern Somali coast, though it is shifted closer to shore in run FD (Fig. 3.14).

\subsubsection{NE monsoon}

Again in January at the height of the NE monsoon, the basic features of the circulation are retained with the addition of diurnal cycling (Fig. 3.17). There are, however, some large amplitude changes.

The major feature in the mixed layer depth field is the shoaling of the mixed layers in the broad equatorial region from $5^{\circ} \mathrm{S}$ to $5^{\circ} \mathrm{N}$, and extending slightly northward near the southern tip of India. As previously mentioned, north of the equator this is a result of the changed westward propagation of the previous SW monsoon upwelling along the southern Indian coast. The dramatic thinning of the mixed layer induced by the upwelling is reduced in run $\mathrm{FD}$ through increased vertical mixing of momentum between the upper and thermocline layers, and the signal that propagates westward is thus weaker (Fig. $3.15)$.

This is the region of greatest difference in SST as well. While run F has a cold tongue extending eastward north of the equator, in run FD this is absent. The temperatures in this region are $0.6^{\circ} \mathrm{C}$ or more warmer in run FD. The geostrophically-balanced currents surrounding the region of thin mixed layer are reduced in run FD (Fig. 3.18).

An examination of the terms in the temperature budget show that this difference comes from a combination of reduced upwelling along the northern limb and reduced horizontal transport along the southern limb of this region (Fig. 3.19). Both of these changes are due to interaction between the local surface fluxes and the changed (propagated) layer depth. Run $\mathrm{F}$ has a much thinner mixed layer, allowing the moderate upwelling wind forcing of the $\mathrm{NE}$ monsoon to force a much stronger temperature response in the region north between the equator and $5^{\circ} \mathrm{N}$, but only in the western portion of the basin where the winds have reasonable strength (see Fig. 3.28). The geostrophic currents set up by the region of thin MLD also advect cooler temperatures eastward along the southern limb of the region, adding to the cooling in run F. In run FD, 

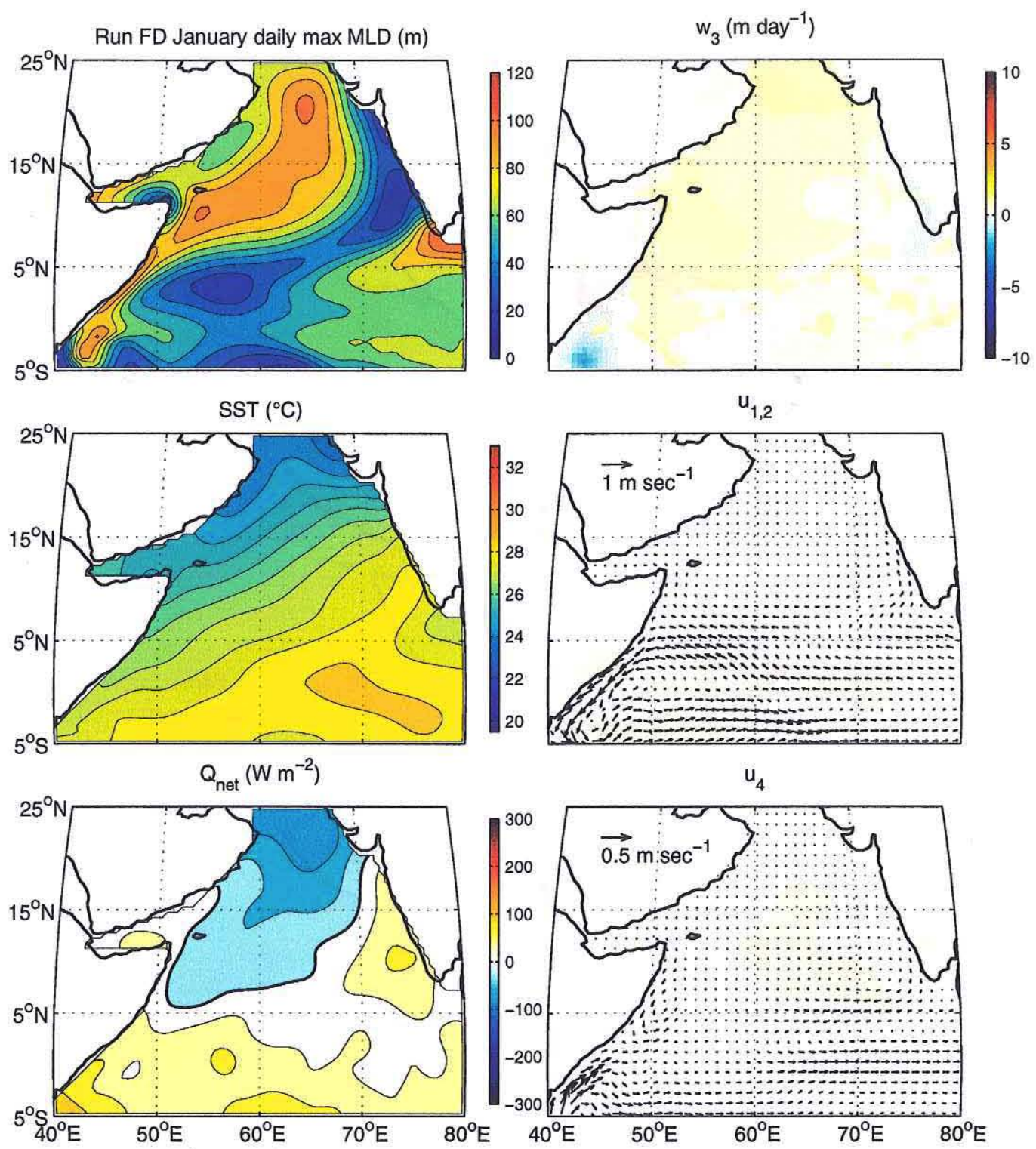

Figure 3.17 January Run FD: as in Fig. 3.13, except for January.

the region of relatively thin ML depth propagating westward from the previous SW monsoon Indian coastal upwelling is far thicker, for reasons mentioned above. When confronted with the upwelling-favorable winds of the NE monsoon, this region does not thin to the point where it requires upwelling from deeper layers, so the upwelling cooling is absent. Since the depth contrast between this region and surrounding regions is reduced, 

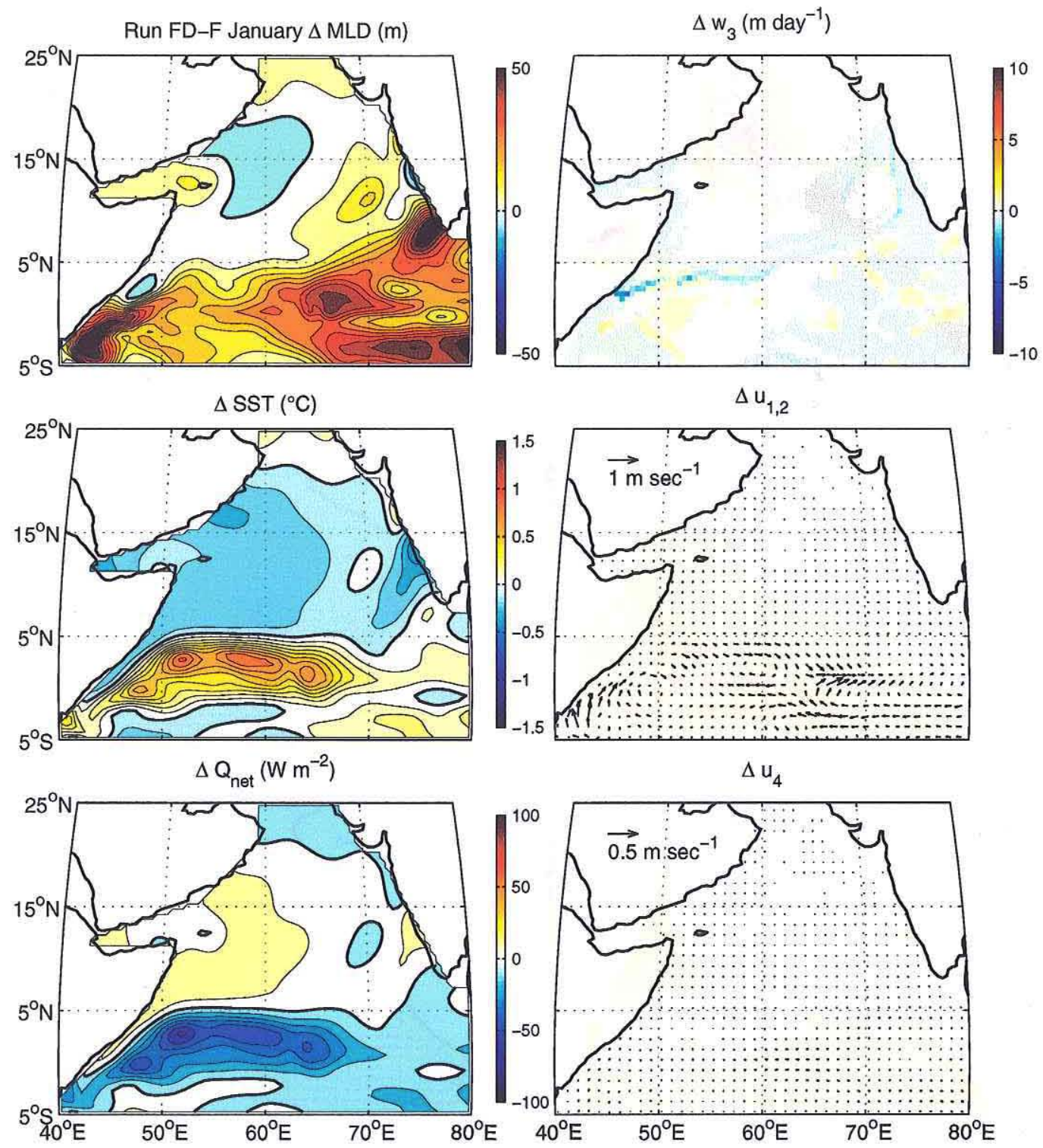

Figure 3.18 Difference January run FD - run F. As in Fig. 3.14 except for January. The largest differences occur in the near-equatorial regions.

the geostrophic currents set up along its perimeter are also reduced (Fig. 3.18), and the eastward advection of cool water is reduced.

Farther north (around $10^{\circ} \mathrm{N}$ ) and off the coast of India, by contrast, the region of thin mixed layer depth associated with the previous SW monsoon coastal upwelling is cooler in run FD. The mixed layer here is somewhat deeper, and the temperature budget in the 

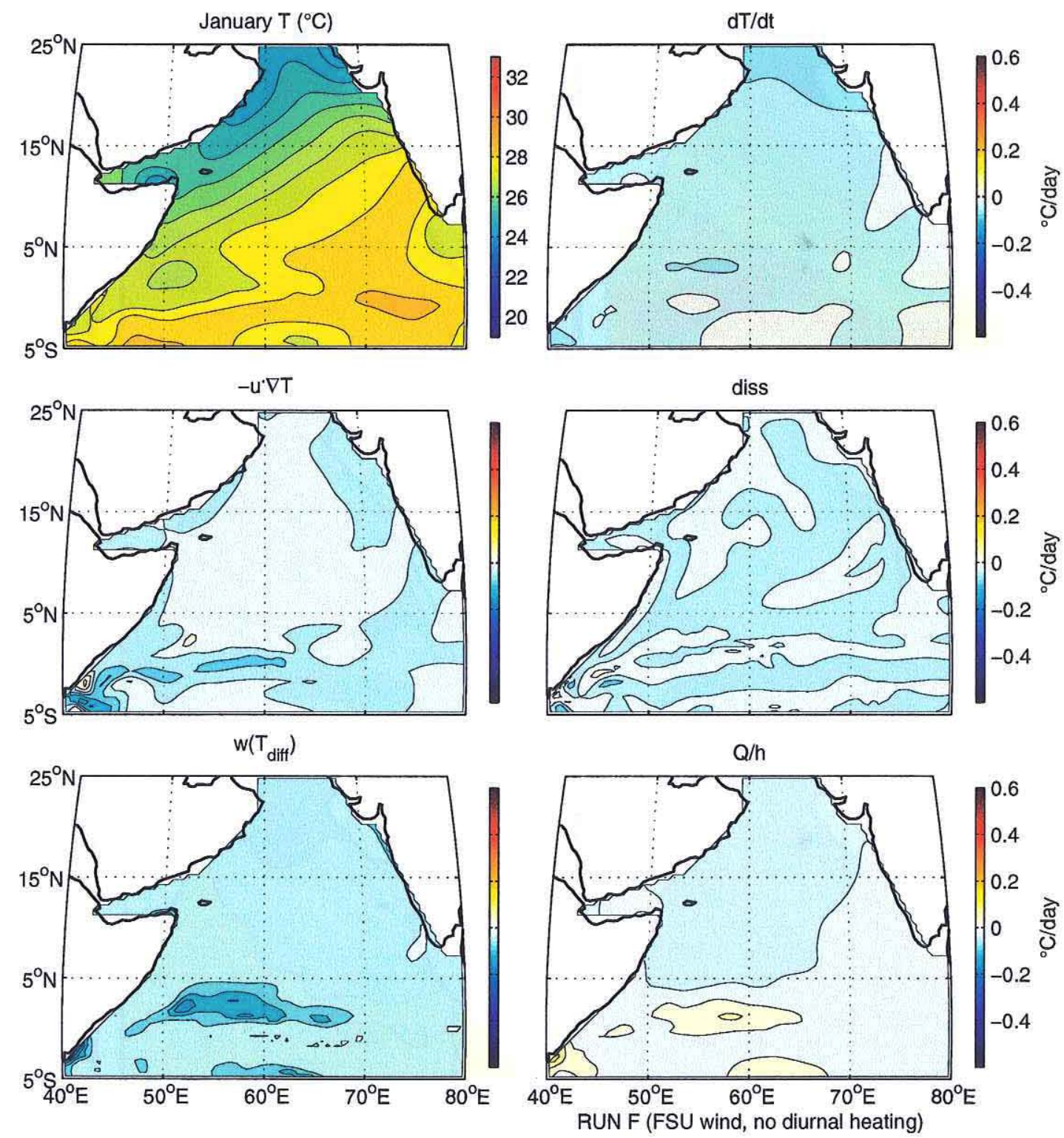

Figure 3.19 A January Run F, terms in the surface layer temperature budget. As in Fig. 3.16A, except for January. 

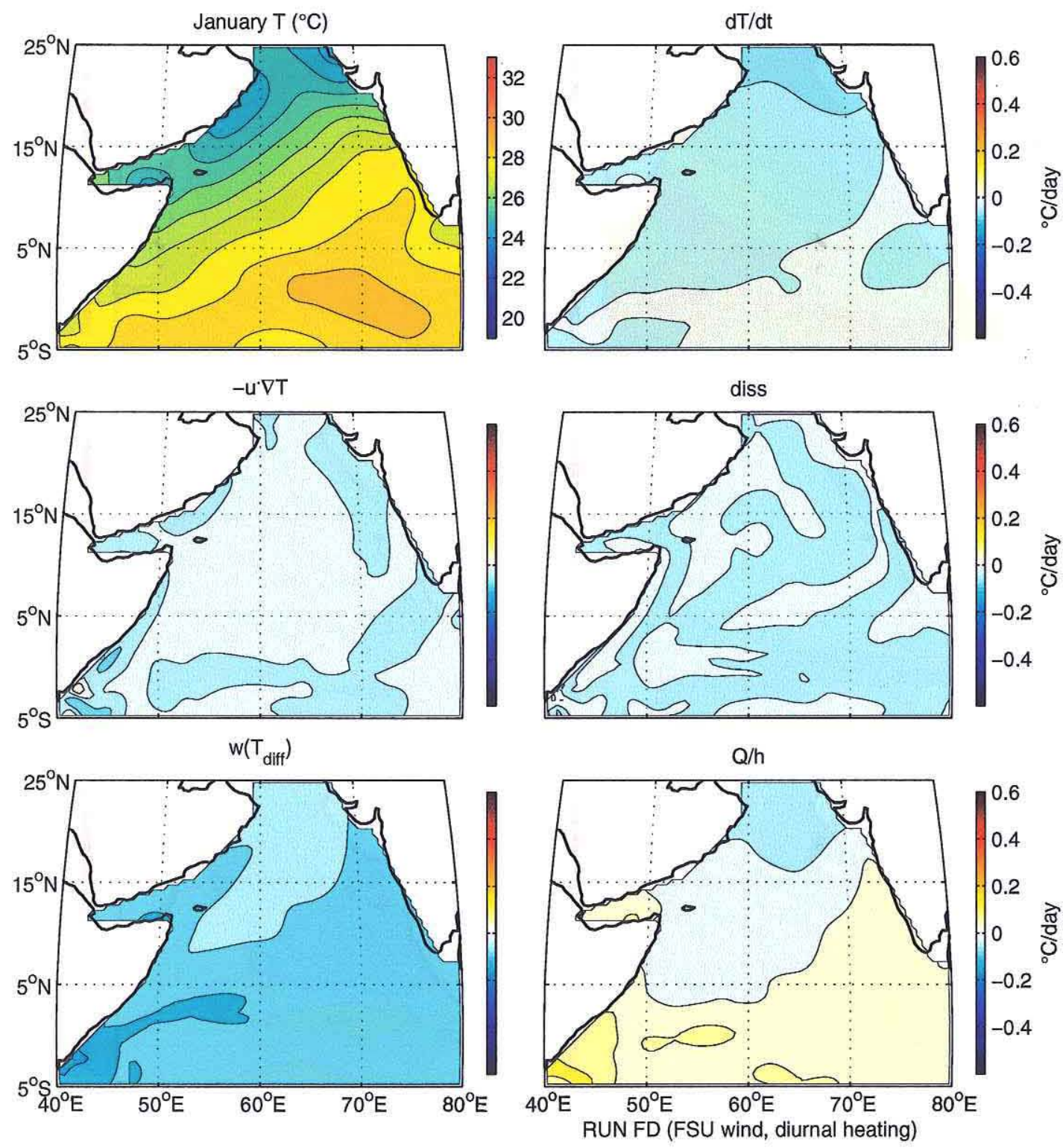

Figure 3.19 B January run FD, terms in the surface layer temperature budget. As in Fig. 3.19A except for Run FD. 

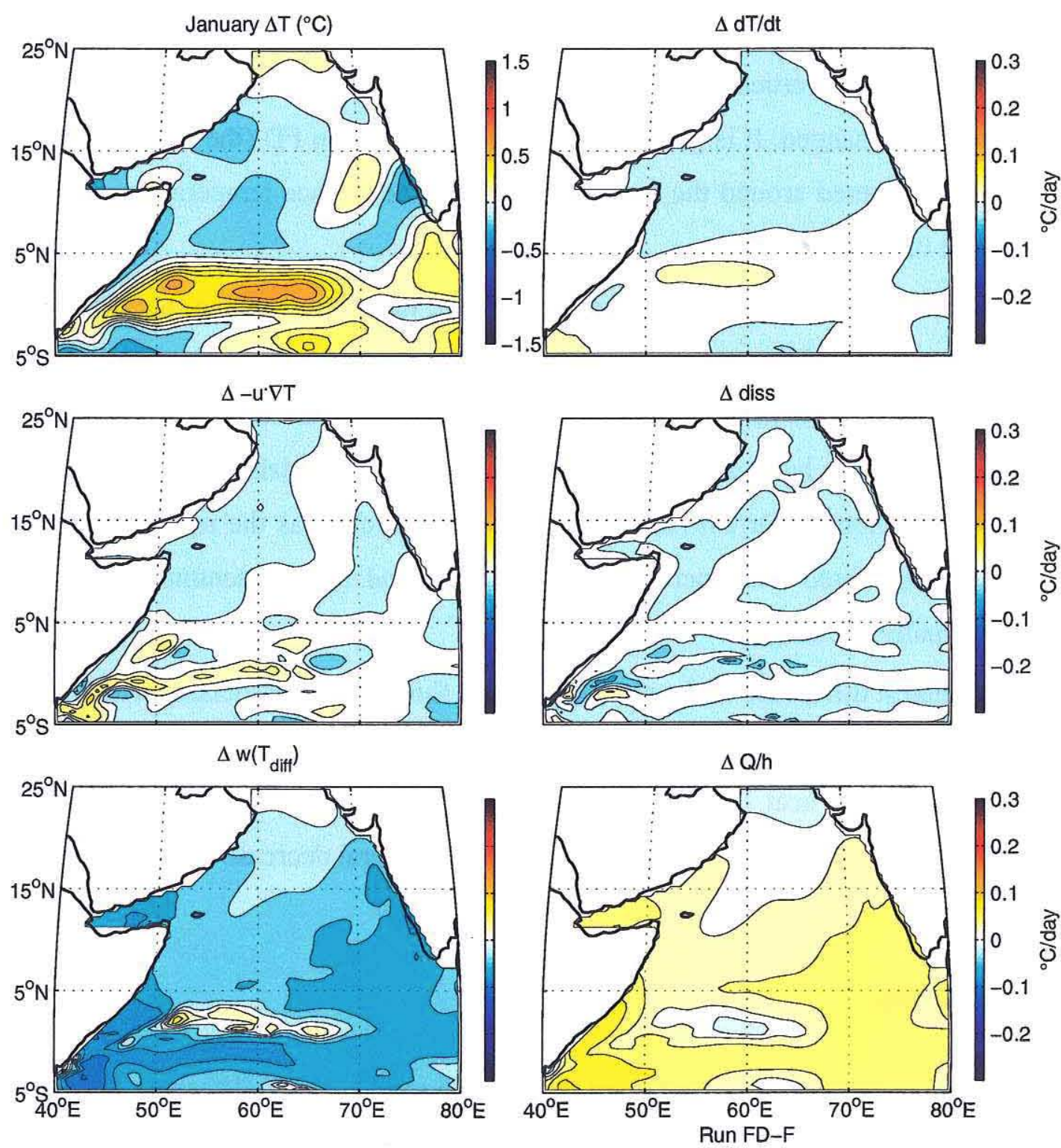

Figure 3.19 C January, difference in the terms of the surface layer temperature budget, run FD - run F. As in Fig. 3.16B except for January. 
region indicates the cooling is associated with increased entrainment into the mixed layer in the diurnally-forced run. Ekman transports are weaker farther away from the equator, and therefore the potential effects of upwelling into surface layers are less prevalent. The mixed layer here responds primarily to local surface forcing, and in this case the diurnal cycling increases the vertical mixing, reducing SST. The mixed layer depth elsewhere in the basin is less changed. It is generally slightly deeper in run FD (the exception being a broad region centered around the mooring site), and the surface temperatures are everywhere about $0.4-0.5^{\circ} \mathrm{C}$ cooler.

The surface velocities during January are similar, though reduced in magnitude in the diurnally-forced run. The southward-flowing Somali current has a peak velocity of 0.75 $\mathrm{m} \mathrm{sec}^{-1}$ instead of $1.35 \mathrm{~m} \mathrm{sec}^{-1}$, and as mentioned above, the currents surrounding the region of thin surface layer depth north of the equator are diminished. The net southward transport of the Somali current remains unchanged, however, as the reduced currents in run FD are associated with increased layer depths, and the momentum in each layer remains virtually unchanged.

The strongest difference in the net surface heat flux is again associated with the equatorial regions, where the increased SST in run FD decreases the net gain, and the difference is a net surface heat flux that is cooler by up to $50 \mathrm{~W} \mathrm{~m}^{-2}$. Across the rest of the basin, associated with the decreased SSTs, there is a general decrease in the cooling of 5$10 \mathrm{~W} \mathrm{~m}^{-2}$.

\subsubsection{Buoy site}

The rapid cycling of the mixed layer depth is the most striking difference between the diurnally-forced and mean-forced solutions at the site of the Arabian Sea buoy (see Fig. 3.11 and Fig. 3.20). The diurnal cycle in the heating causes a diurnal cycle in the mixed layer depth that varies between the minimum depth $\left(h_{1 \min }\right)$ and a nighttime maximum for much of the year. This diurnal cycle is reduced during the SW monsoon, as the strong winds keep the Monin-Obukhov depth $\left(h_{M O}\right)$ fairly deep (3.14). The diurnal thermocline layer tracks the maximum depth of the mixed layer quite well. 

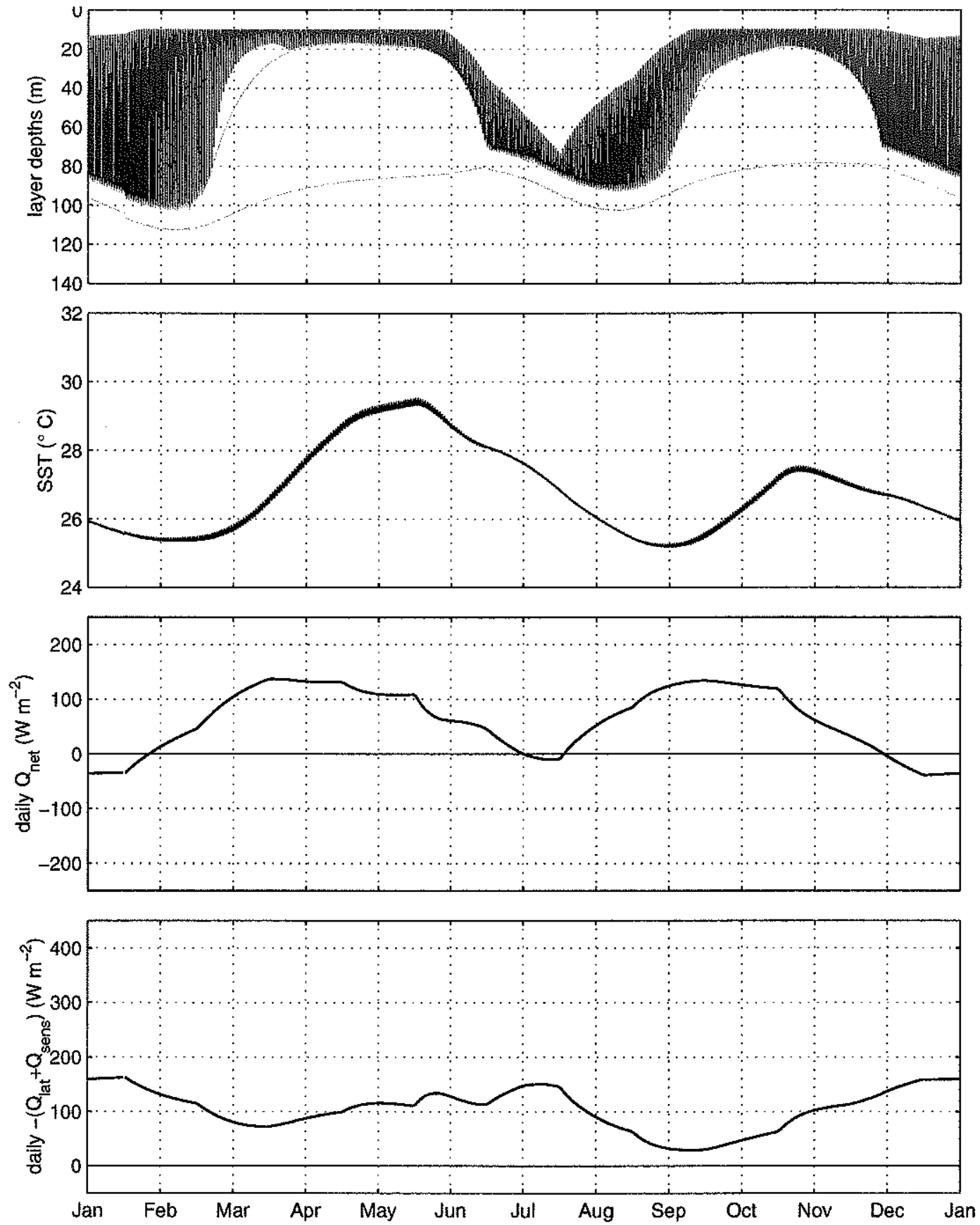

Figure 3.20 Run FD model solution at the mooring site. As in Fig. 3.11 except for run FD.

The deepening during the SW monsoon occurs a little earlier and lasts later into the intermonsoon in run FD. The maximum depth of the mixed layer is also reduced from 
$105 \mathrm{~m}$ to about $90 \mathrm{~m}$. This broadening of the $\mathrm{SW}$ monsoon response was noted by McCreary et al. [2000], and was in fact a major reason for the introduction of diurnal forcing in that coupled physical-biological model.

The temperature response in run FD at the site of the mooring is very similar to run $\mathrm{F}$. The largest differences are cooler SSTs during both the spring and fall intermonsoon seasons. This is also when the largest diurnal temperature response in run FD occurs, driving greater exchanges with the layers below. During the deepening phase of the SW monsoon, there is also a short period of time when the temperature prediction in run FD is greater than in run F, associated with the reduced depth of entrainment. Finally, the surface heat flux is greater in run FD as compared to run F during the two intermonsoon seasons, associated with the reduced sea surface temperature, which result in decreased losses from the surface.

\subsubsection{Point heat budget}

Chapter 2 emphasized the role of horizontal advection associated with mesoscale eddies in the upper ocean heat budget. In the moored observations, I lacked the turbulent entrainment data necessary to isolate the heat budget of the mixed layer, instead integrating over a fixed depth. The models allow me to look directly at what causes sea surface temperature variations.

The terms in the temperature conservation equation (3.3) for the equivalent moored position are shown in Fig. 3.21, averaged every ten days. Consider first the balance in run $\mathrm{F}$ (solid lines). During the NE monsoon (November, December, and January), the drop in temperature (green line is negative) results from both direct cooling through the sea surface (black line) and entrainment (red line) driven by this surface cooling. In the spring intermonsoon, the temperature rises due to solar heating. In May, the temperature trend reverses as the winds pick up. While there is still solar heating, entrainment cooling (red line) begins to dominate, and the strength of the solar heating to the layer is reduced as the mixed layer thickens, since the heating term is inversely proportional to the layer depth. The cooling is due to the wind-driven entrainment from mid-May through the 


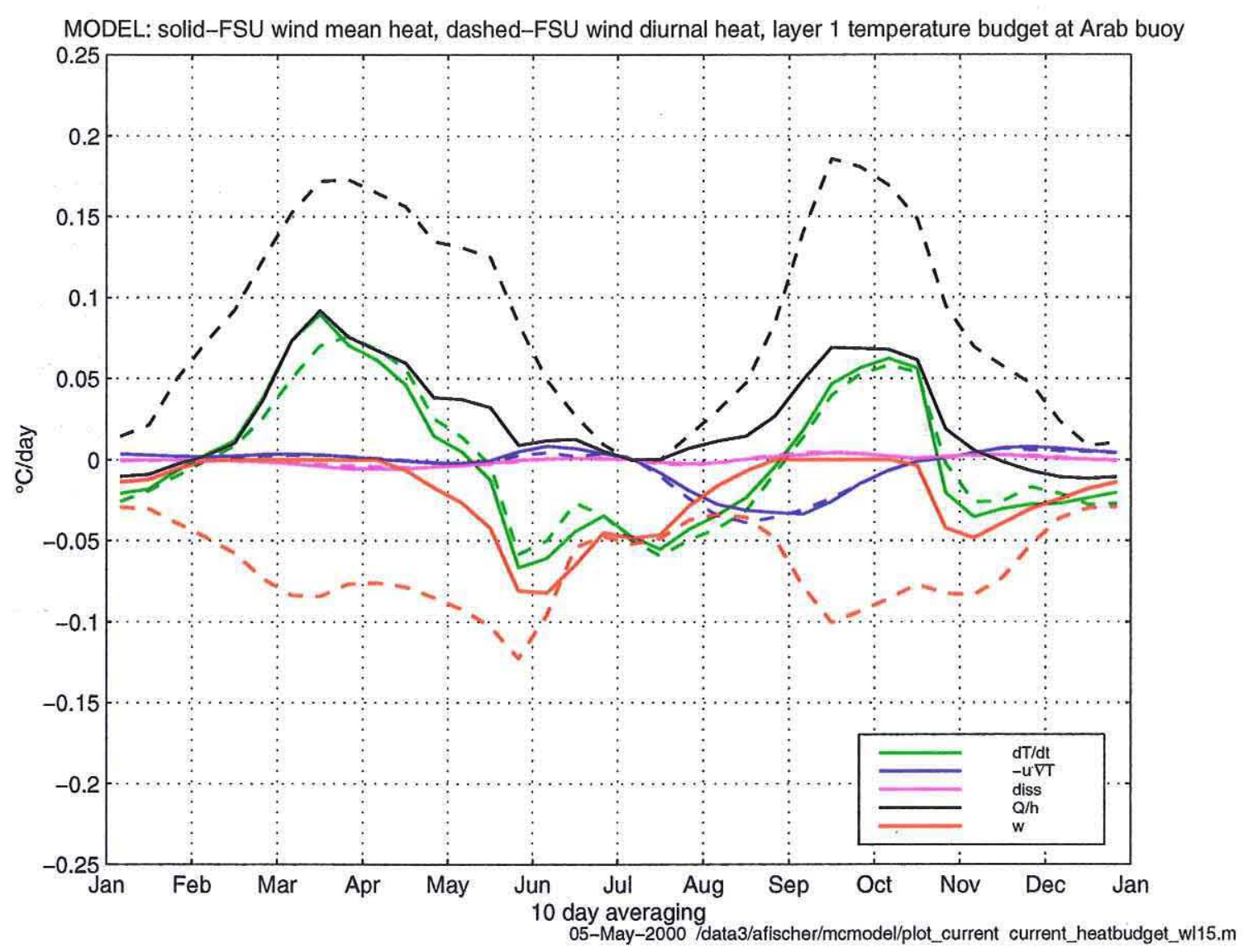

Figure 3.21 Terms in the model solution surface temperature budget at the mooring site, including the temperature trend (green), layer input from solar heating (black), upwelling (red), horizontal advection (blue), and dissipation (magenta, which is negligible). Solid lines are from the last year of run F, dashed from run $\mathrm{FD}$, all averaged every 10 days.

height of the SW monsoon in July. In the latter part of the SW monsoon, from mid-July through August, the entrainment cooling is somewhat reduced, but is joined by advective cooling (blue line). Towards the end of August, reduced winds allow the mixed layer to shoal, and in response the surface heating term increases and entrainment cooling is by definition shut down. Advective cooling keeps the mixed layer temperature dropping until the end of August. In September, despite still strong levels of advective cooling, the mixed layer temperature increases sharply due to its shallow depth. The heating remains strong through mid-October, dropping in November from a combination of direct sur- 
face-forced cooling and entrainment. The entrainment is driven initially by a small increase in the wind stress, then when the surface flux turns negative, by convective entrainment.

A comparison to the heat budget estimated at the mooring is not clean, since the budget over the mixed layer in the model is being compared to the budget over a fixed depth in the data. Nevertheless there are some parallels. The moored heat budget (Fig. 2.11) showed a cooling horizontal heat flux in a series of pulses from mid-July through August, and a small pulse in September. The model temperature budget shows a broad cooling horizontal advection from mid-July through the end of September. In the model this comes from a broad offshore current bringing cool water from the coastal upwelling along the Arabian coast, contributing to the surface layer cooling. The model does not develop the eddies or filaments that modulated the SW monsoon cooling seen in the observations, and so the model surface temperature does not show the same sharp drops in the latter part of the SW monsoon. The moored budget also showed strong negative and positive horizontal heat fluxes associated with the passage of mesoscale eddies in November and December, during the NE monsoon. These are entirely absent from the model. Interestingly, when the moored horizontal heat fluxes are vertically resolved (see Fig. 2.9 and Fig. 2.10), the fluxes within the mixed layer were only significant during the SW monsoon cooling. During the NE monsoon, the strong fluxes were primarily associated with the passage of the varying topography of the upper thermocline associated with the eddies. This is one reason the model and observed surface temperatures do not differ tremendously during the NE monsoon, since they respond chiefly to the surface rather than horizontal fluxes.

Now consider the difference between the mean-forced (run F) and diurnally-forced model solutions (run FD, dotted lines in Fig. 3.21). The most striking difference is that while the temperature evolution (green line) is quite similar to run $\mathrm{F}$, the balance between heating (black) and entrainment cooling (red) is dramatically different. Even when the mean surface heating is negative during the NE monsoon, the mean heat flux into the mixed layer is positive. This is a result of the rapid diumal cycling of the mixed layer. 
During the daytime heating phase, the mixed layer is quite shallow, so the solar heating term in the temperature equation (divided by the layer depth) is very strongly positive. During the nighttime cooling phase, the mixed layer is deep, so the cooling term is reduced. The net effect in the mean is a much more strongly positive heating term. This is tempered, however, by a much stronger exchange with the layer below, the diurnal thermocline layer. Each night most of this layer is part of the mixed layer, and so participates in the surface heat loss. During the day, the mixed layer shoals dramatically, and the diurnal thermocline layer retains the water that was part of the previous night's mixed layer. When the mixed layer deepens again, there is then a very strong entrainment cooling flux, as most of the diurnal thermocline layer is incorporated. This large positive/negative balance between the heat flux and entrainment cooling terms is reduced during the SW monsoon, when the amplitude of the diurnal cycle is reduced owing to the increased wind forcing.

In mean-forced case the temperature of layers 1 and 2 can become quite decoupled, despite the fact that layer 2 is so thin, and its position so coupled with layer 1 . There is much more exchange between layers 1 and 2 in the diurnal case, which is reflected in the point heat budget as a much stronger entrainment cooling. The reduction in the density difference between the layers increases the initial rate of entrainment (see (3.11)). The temperature of layer 3 is also much more tightly coupled with the surface, and rises throughout run FD. There is no real linking of the temperatures of the upper layer and layer 3 in run F. A lot of exchange between layers is driven solely by the diurnal cycling. The layer interface between layers 2 and 3 (the diurnal and seasonal thermocline layers) has a small vertical movement each day associated with the formulation of the model. When the mixed layer shoals during the day, the layer 2 interface detrains slightly (see (3.16)), allowing the diurnal thermocline layer to retreat when the mixed layer shoals on the seasonal or intraseasonal time scale. If, however, the mixed layer deepens to its previous night's depth or deeper, the layer 2 interface follows. The net effect, due solely to the diurnal cycling, is an exchange between layers 2 and 3. If layer 3 approaches its minimum, there can also be an exchange with layer 4 (the permanent thermocline). This sub- 
mixed layer mixing was dubbed 'diurnal pumping' by McCreary et al. [2000]. There is observational evidence of deep mixing below the mixed layer associated with the diurnal cycle [Lien et al., 1995], and this cycle appears in LES models of the upper ocean as well [Wang et al., 1998]. But the sub-mixed layer mixing in the model is in essence a byproduct of the model design, an 'accidental' parameterization. How well it represents submixed layer mixing compared to higher-resolution mixed layer models is investigated in the next chapter.

There are some small differences in the other terms between the mean and diurnally forced runs. The horizontal advection of cooler temperature is a little stronger in run FD, particularly in August, and a mild advection of warmer water in June is reduced. The temperature trend term, while similar in both runs, is generally shifted a little later in run FD, resulting in the seasonal maxima and minima arriving a little later in the diurnally forced run (compare Fig. 3.11 and Fig. 3.20).

\subsubsection{Annual mean fields}

The annual mean flow field, as before, is dominated by the strength of the response during the SW monsoon. The differences between the two runs are similar to the circulation differences noted during the SW monsoon (Section 3.4.1), with a somewhat stronger and more coastally bound northward-flowing Somali current and retroflection as the Southern Gyre.

The largest differences come in the thermodynamic fields (Fig. 3.22). The annual mean mixed layer depth (here represented as the sum of the mixed layer and diurnal thermocline as a good approximation of the daily maximum mixed layer depth) is everywhere deeper in the diurnally-forced run. The surface temperature, again marked by the cool SSTs in coastal upwelling regions, is cooler by an average of about $0.3-0.4^{\circ} \mathrm{C}$ in the diurnally-forced run everywhere north of about $4^{\circ} \mathrm{N}$. It is warmer, particularly in the western portion, of the zonal band that surrounds the equator. This difference is due to the changed interaction between westward propagating waves and the surface forcing during the NE monsoon, noted in Section 3.4.2. The net surface heat flux difference 

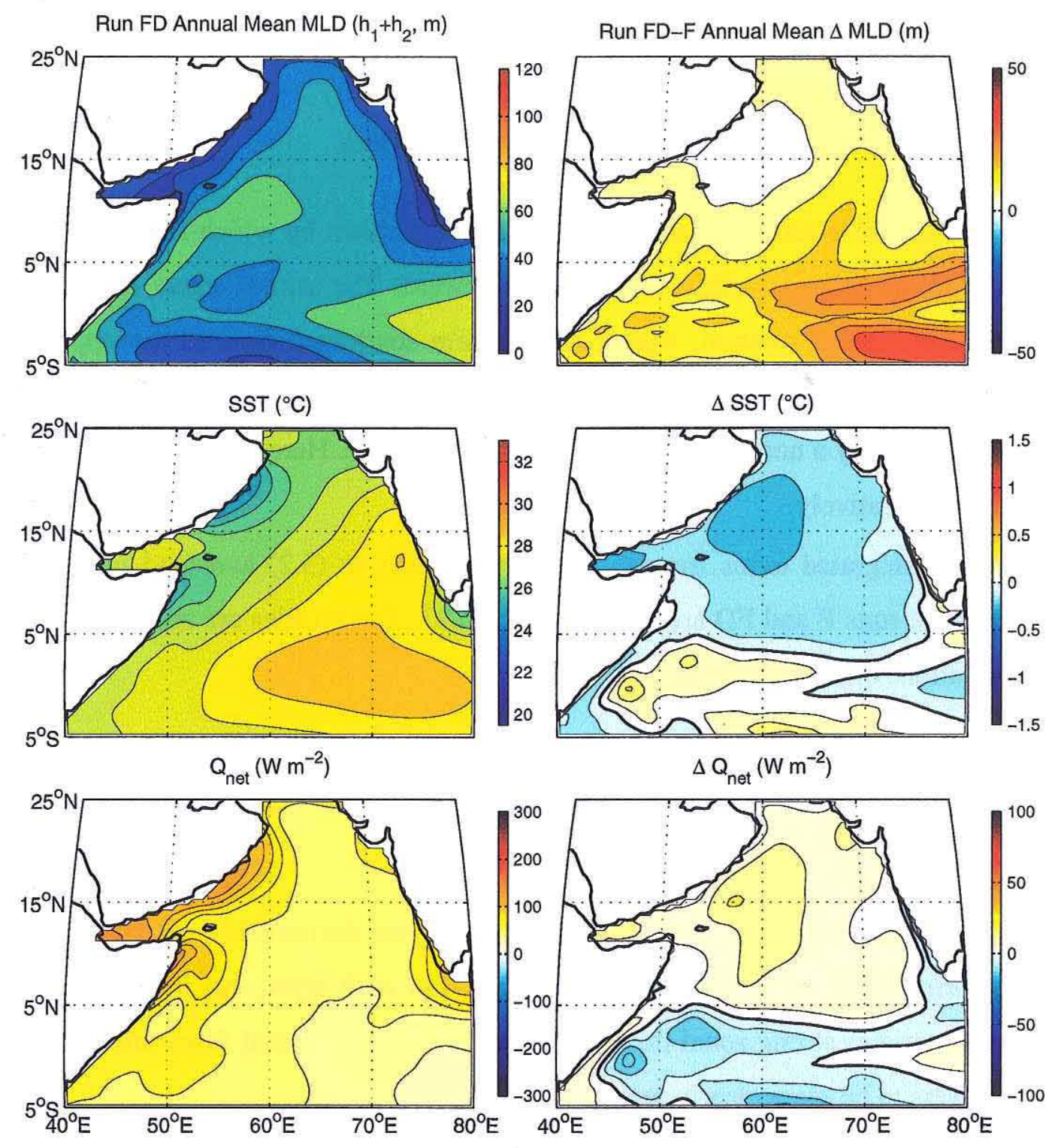

Figure 3.22 Annual mean run FD (left) and the difference run FD - run F (right) of the thermodynamic variables. From top: daily maximum mixed layer depth (represented by sum of first two layers), sea surface temperature (SST), and surface heat flux $\left(Q_{\text {net }}\right)$. Contours as in Fig. 3.13 and Fig. 3.14.

exhibits patterns very similar to the differences in SST, with an increase of about 5-15 W $\mathrm{m}^{-2}$ over most of the basin north of $4^{\circ} \mathrm{N}$. The means in this region averaged between 60 and $90 \mathrm{~W} \mathrm{~m}^{-2}$, so the difference represents a significant fraction of the mean. The net sur- 
face heat flux into the Arabian Sea north of $6.75^{\circ} \mathrm{N}$ increases to $0.32 \mathrm{PW}$ in run FD from $0.28 \mathrm{PW}$ in run $\mathrm{F}$, and is $0.33 \mathrm{PW}$ in the SOC climatology.

\subsubsection{Basinwide mass, temperature, and heat budgets}

The meridional overturning circulation is the mechanism by which the Indian Ocean transports its net annual surface heat gain southward. The annual mean fields gave a rough sense of this circulation, with a broad warm southward flow in the upper layer driven by the SW monsoon winds, replaced by upwelling along the Somali and Arabian coasts, fed in turn by a northward current in the thermocline. Here I'll look at this circulation more quantitatively.

Spatially integrated terms from the continuity equation (3.2) averaged in time over the last year of runs F and FD are shown in Fig. 3.23. The profiles are zonal and meridional integrations of each term, for each layer:

$$
A(y)=\int_{y x_{e}}^{y_{n} x_{y}} \int a(x, y) d x d y
$$

where $a(x, y)$ stands for each term in (3.2), $y_{n}, x_{e}, x_{w}$ are the northern, eastern, and western boundaries of the basin, and $y$ is the latitude. For each layer, this integration eliminates the sometimes strong zonal flows, allowing the net meridional flows and exchanges between layers to be more clearly seen.

Consider first the mass budget for the mean-forced model solution (run F, solid lines in Fig. 3.23). The dissipative terms (magenta) are negligible in most of the domain, and never become a significant portion of the budget in any layer. The term proportional to $w_{c}$ is only applied near the southern boundary as a mass correction for the model, and so does not appear in the analysis here. This leaves a balance in each layer between the meridional transport (the area integral of the mass transport divergence, blue lines), vertical entrainment and detrainment (red lines), and the net time trend for the year (green 

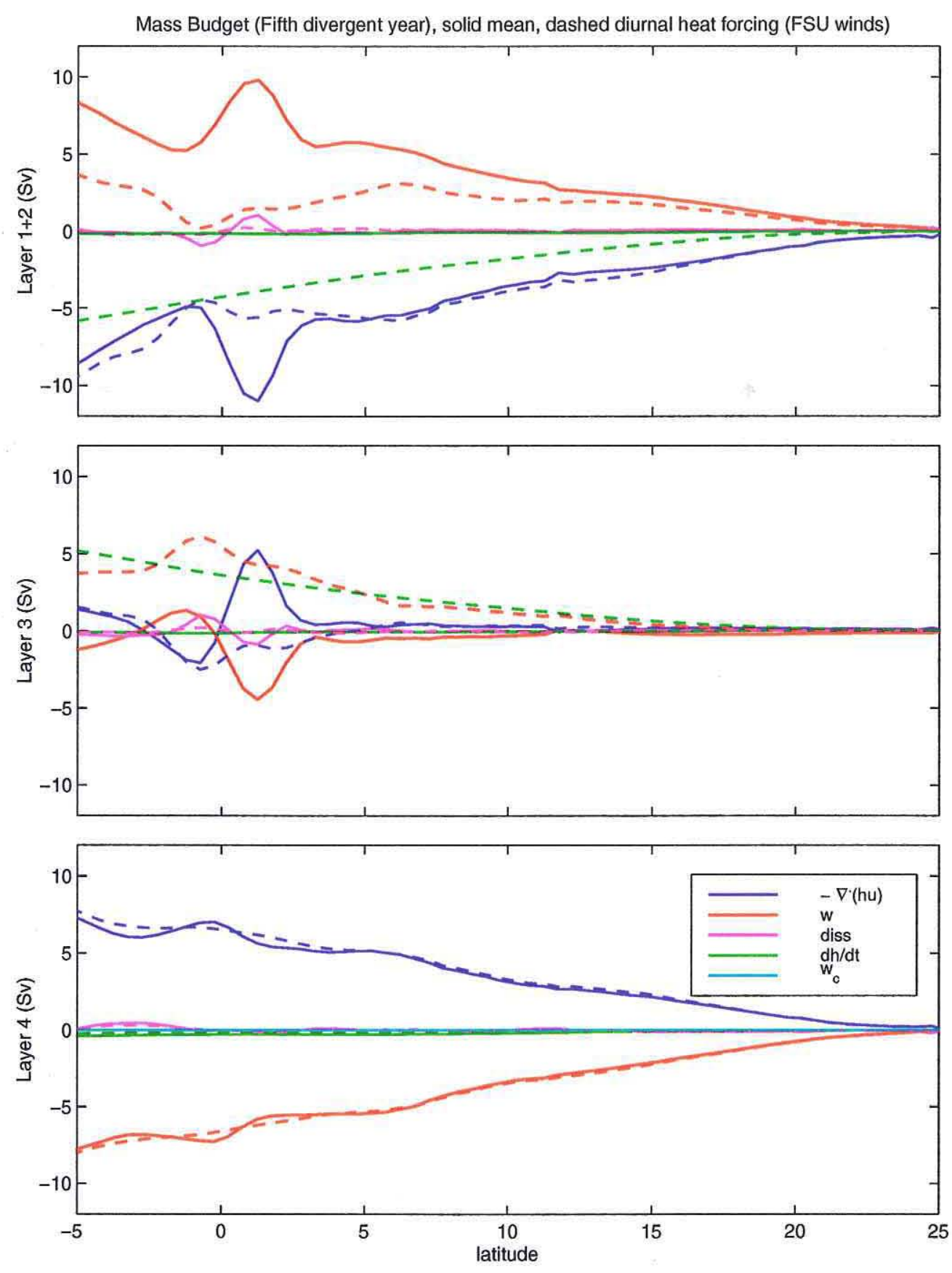

Figure 3.23 Spatially integrated terms from the continuity equation (3.2), by layer, over the last year of integration. Since layers 1 and 2 are dynamically linked they are treated as a single layer. Solid lines are from run F, dashed from run FD. The blue lines, the integrated mass divergences, are the total meridional mass transport across latitude lines in each layer. The red lines are the integrated entrainment and detrainment north of the latitude line, so a negative (positive) slope indicates a gain (loss) of mass in a layer. 
lines), if any. In the mean-forced model solution there is a negligible time trend, so in each layer the balance is between meridional and vertical transport.

The area integral of the mass transport divergence (blue lines in Fig. 3.23) represents the meridional transport across a latitude line in the layer. The area integral of the vertical entrainment and detrainment (red lines) represents the total mass lost or gained through this process north of a latitude line, and so its slope is related to the local strength of upwelling or downwelling. A negative slope (increasing southwards) indicates a local gain of mass through vertical velocities.

In the first two layers (which are dynamically linked) the meridional transport grows increasingly negative (blue line) moving southward away from the northern boundary, a result of increasing net southward mass transport. This is balanced by upwelling into the layers, as the net vertical transport (red) increases moving southward. The increase in the latitudinal slope of the net vertical transport between $12^{\circ} \mathrm{N}$ and $4^{\circ} \mathrm{N}$ indicates that upwelling into these layers is stronger here, as confirmed by the mean annual field of $w_{3}$ (Fig. 3.9). In the region north of $3^{\circ} \mathrm{N}$ the upwelling into layers 1 and 2 is fed by layer 4 , which loses mass to upwelling (red line bottom panel Fig. 3.23). So north of $3^{\circ}$ there is a simple meridional roll circulation, with southward transport in the uppermost layers driven by the wind balanced by upwelling and northward transport in the thermocline (layer 4).

In the region surrounding the equator there are two shallow rolling circulations confined to the upper layers and the seasonal thermocline (layer 3). Between about 1 and $3^{\circ} \mathrm{N}$ there is a strong upwelling into the upper layers, indicated by the slope of the net vertical transport (red line in upper panel of Fig. 3.23). Between $1^{\circ} \mathrm{N}$ and $1^{\circ} \mathrm{S}$ there is an equivalent detrainment out of the upper layers, again indicated by the slope of the net vertical transport, which returns to the value it had at $3^{\circ} \mathrm{N}$. Within the upper layers, this upwelling and downwelling is closed by an increased southward transport between $3^{\circ} \mathrm{N}$ and $1^{\circ} \mathrm{S}$. In layer 3 the reverse is occurring, with a strong northward transport (peaking at $5 \mathrm{~Sv}$ ) between $1^{\circ} \mathrm{S}$ and $3^{\circ} \mathrm{N}$, balanced by a loss of mass through vertical transport north of $1^{\circ} \mathrm{N}$ and a gain south. This describes a closed circulation, a roll, with southward trans- 
port in the surface layer, northward transport in layer 3, closed by upwelling and downwelling. There is a weaker roll of the opposite sense, with a narrower latitudinal extent, south of this one.

This circulation is not a literal roll, but rather the result of averaging over a number of cross-equatorial currents in the western Arabian Sea (see the annual average circulation in Fig. 3.9). Although the meridional and zonal integration that yields the description of this roll extends all the way across the Bay of Bengal to the eastern boundary of the model, the primary contribution to the circulations occurs in the western part of the basin in all the model solutions presented here.

These shallow meridional rolls focused around the equator are not present in MKM, which lacked the seasonal thermocline layer and so the requisite vertical resolution to allow the rolls to develop. A single very shallow meridional overturning roll appears in a number of other model solutions of the Indian Ocean (the seasonally forced models of Garternicht and Schott [1997], Lee and Marotzke [1998], and the annual mean forced model of Wacogne and Pacanowski [1996]), although in each of these the surface flow is northward, and crosses the equator. The cell crossing the equator here flows in the opposite direction, though this is quite sensitive to the wind forcing, and the stronger crossequatorial roll in the ECMWF wind-forced solutions does flow northward (Section 3.5.6).

How does the diurnal forcing change the meridional mass circulation? Despite the changes in the fields of both the annual mean and seasonal circulations and layer depths (Fig. 3.14 and Fig. 3.18), the integrated meridional transport in all the layers is nearly unchanged north of $3^{\circ} \mathrm{N}$ (blue dashed lines in Fig. 3.23) in run FD. Since the meridional overturning circulation is driven by the wind, this is not surprising. What has changed is the balance between upwelling (red dashed lines) and the appearance of a yearly mass flux from layer 2 into layer 1 (green dashed lines), shown as a loss of mass from the upper layers and a gain in the mass of layer 3 . In longer integrations of the model, this mass flux remained, and the surface layers grew increasingly shallower. In fact the model eventually became numerically unstable. In a run with a slower detrainment time scale for the diurnal thermocline (layer 2, see (3.16)), the mass flux was slower, but as persis- 
tent. This is a disadvantage of the formulation of the model that limits it to shorter integrations, and needs improvement.

Another big difference between runs F and FD is the collapse of the shallow southward-flowing cross-equatorial meridional overturning. In the diurnally-forced run, the weaker (now only) southern cell extends slightly north across the equator, seen most clearly in the layer 3 southward transport (blue dashed line in Fig. 3.23) which is strongest just south of the equator. The existence of this meridional cell is dependent on the independence of the seasonal thermocline layer from the surface layers. Looking at the model evolution at the point of the mooring (Section 3.4.3 and Section 3.4.4) demonstrated that the coupling between layers has increased. This is in essence a reduction in the vertical degrees of freedom in the model, which may prohibit this overturning cell from developing. The cell also results from a sum across strong horizontal circulations. The strongest circulations in this region occurred during the NE monsoon, surrounding the region of shallow mixed layer propagating westward off the Indian coast from the previous SW monsoon. The diurnal cycling acted to prevent the mixed layers in this region from reaching $h_{1 \min }$ (Section 3.4.2). This eliminated the upwelling driven north of the equator by the NE monsoon winds, since the mixed layers were deeper, and so eliminated one limb of the overturning cell.

The meridional mass circulation is the vehicle for the southward transport of the strong heat gain over the Arabian Sea and the northern Indian Ocean. Defining the 'heat' in each layer to be $h_{i} T_{i}$, a combination of (3.2) and (3.3) yields the equation for the conservation of heat,

$$
\begin{aligned}
& \left(h_{i} T_{i}\right)_{t}+\nabla \cdot\left(h_{i} \bar{u}_{i} T_{i}\right)=Q_{i} \\
& +\left[w_{i}^{+} T_{i+1}+\left(w_{i}^{-}-w_{i-1}^{+}\right) T_{i}-w_{i-1}^{-} T_{i-1}+\left(\delta_{i 3}-\delta_{i 4}\right) w_{3}^{+}\left(T_{e}-T_{4}\right)\right] \\
& +\delta_{i 4} w_{c} T_{4}+\left\{h_{i} \kappa_{T} \nabla^{2} T_{i}-h_{i} \kappa_{T 4} \nabla^{4} T_{i}+T_{i} \kappa_{h} \nabla^{2} h_{i}-T_{i} \kappa_{h 4} \nabla^{4} h_{i}\right\} .
\end{aligned}
$$

The terms enclosed in square brackets represent gains and losses of heat through entrainment and detrainment. The terms in curly brackets are due to dissipation. So the time 
derivative of the heat at any point is the result of heat transport divergences, solar heating and surface fluxes, entrainment and detrainment, the mass correction in the southwest corner of the model, and dissipation terms. These terms were averaged during the integration of the last year of each run, and are shown in Fig. 3.24.

The profiles of heat transport are, not surprisingly, very much related to the profiles of the meridional mass transport. An additional term is provided by surface and penetrative heat fluxes to each layer, which are everywhere positive. North of $3^{\circ} \mathrm{N}$, the heat transport consists of a net gain of heat in the surface layers, with smaller amounts of heating in the lower layers. A strong southward (negative) horizontal transport of heat occurs in the surface layers, which is balanced both by the solar heating and a gain of heat associated with the mass gain by upwelling from lower layers. The mild heating of layer 2 is balanced by a loss of heat to the upper layers, and a northward heat flux in the deepest layer balances its loss of heat to upper layers. The heat transport associated with the shallow equatorial meridional overturning cells closely follows the mass transports, exhibiting the same large difference between runs F and FD.

The net southward heat transport, summed over all layers (blue line in Fig. 3.25), compares favorably with other studies, larger than the estimates of Garternicht and Schott [1997] and smaller than those of Lee and Marotzke, [1998] and Wacogne and Pacanowski [1996], smaller also than the climatological study of Hastenrath and Greischar [1993]. Although the surface southward and deeper northward transport of heat are slightly stronger in run FD over run F, the sum over all layers is very nearly the same, with a very small reduction in run FD centered about $5^{\circ} \mathrm{N}$. The other terms in the overall annual mean heat budget are more problematic. The net surface heating is stronger than the southward heat transport, and even more so in the diurnally-forced run. Despite heat losses into dissipation, and rather strong ones near the equator in run F, there is a net heat gain by the ocean in both runs. The model is not in steady state. In the case of run FD, this net heat gain is as strong as the southward heat transport (but matches the SOC climatology better). MKM addressed a similar problem with a restoring (cooling) heat flux in the deepest layer, which has been eliminated in this formulation of the model. 

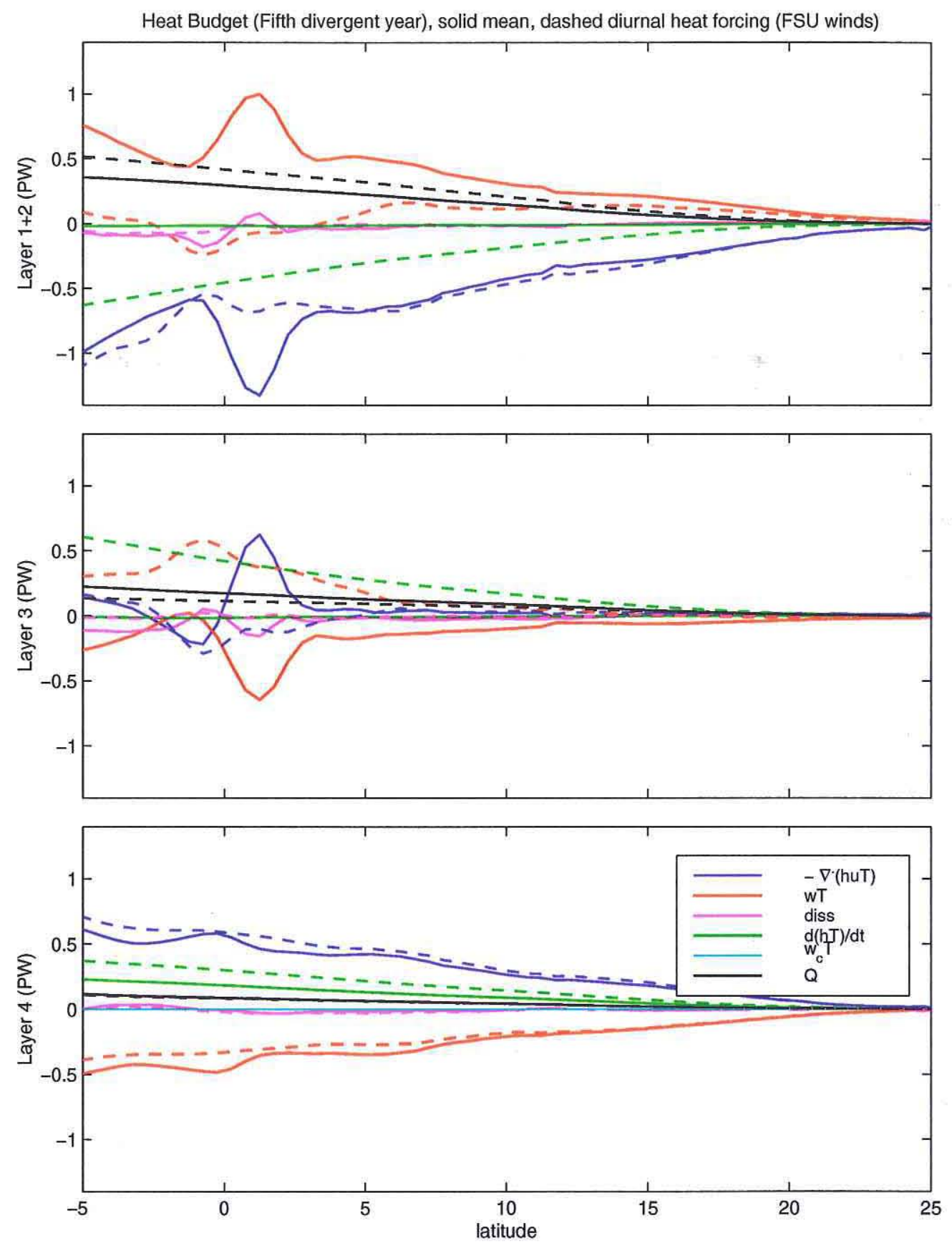

Figure 3.24 Spatially integrated terms from the heat conservation equation (3.23). Solid lines are from run F, dashed from run FD. The blue lines indicate total meridional heat transport in the layer, the red lines are gains and losses of heat through vertical transport, and the black lines are the heat gains from the penetrative surface flux. The trends (green lines) are not always zero. 


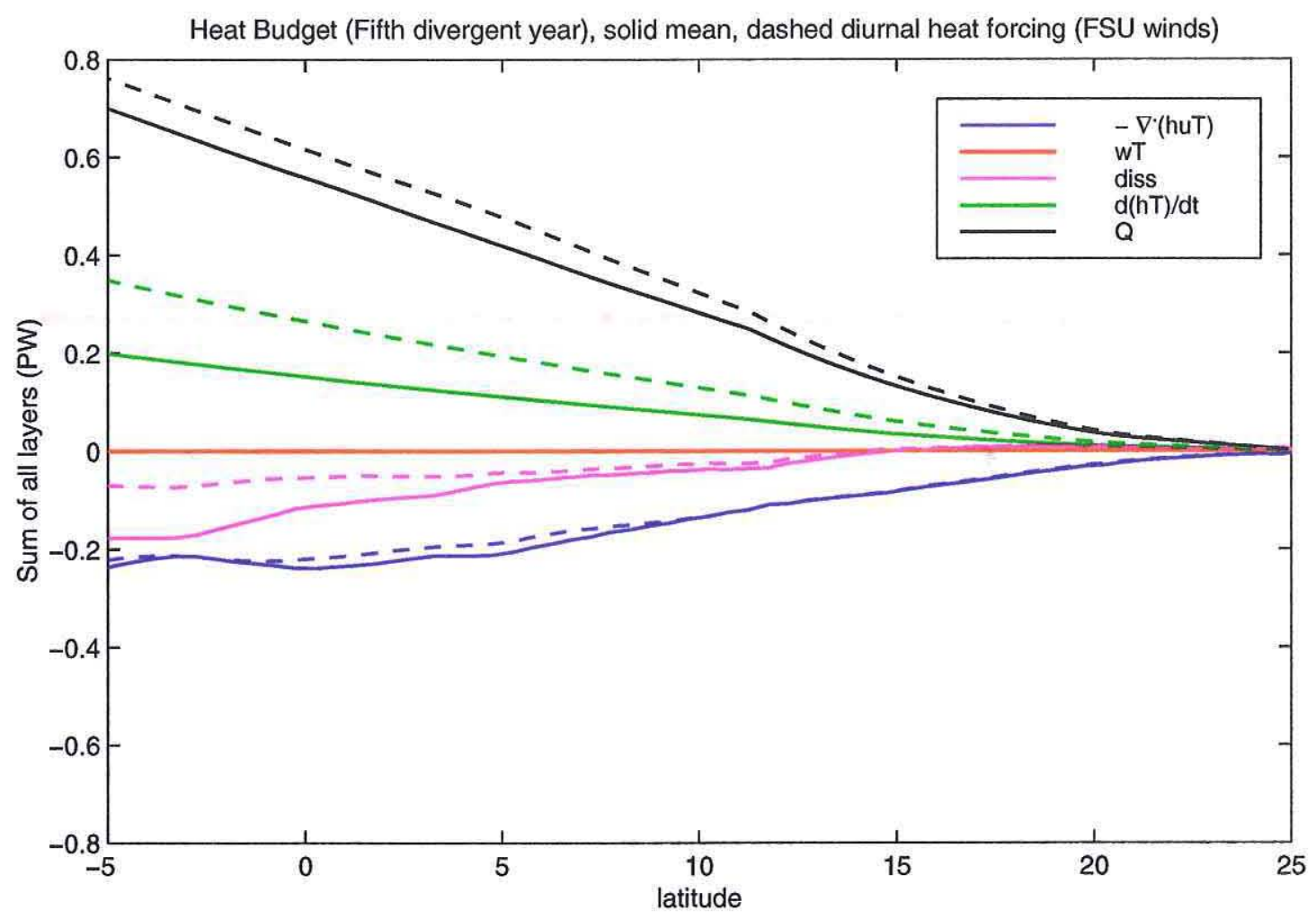

Figure 3.25 Terms in the annual mean heat budget (Fig. 3.24), summed over all layers. Solid is run F, dashed run FD.

The net heat budget averaged over the year is the sum of terms that are large and vary strongly on the seasonal time scale. This is shown by time-resolved heat budgets over the last year of the model integration, averaged over the fixed domain of just the Arabian Sea north of $6.75^{\circ} \mathrm{N}$, the latitude defined by the southernmost extent of India and Sri Lanka, cutting the Arabian Sea off from the Bay of Bengal (Fig. 3.26). The mass transport on the seasonal time scale is a balance between meridional transport and the temporary increases and decreases in the mass north of $6.75^{\circ} \mathrm{N}$, which peak at $8 \mathrm{~Sv}$ southward in June to 7.5 Sv northward in December. The differences between runs F and FD are slight. Lee and Marotzke [1998] found a similar (but stronger) baroclinic transport driven by the seasonally-reversing winds, which in their model was very quickly compensated by a barotropic response, obviously missing here. The meridional heat transport peaks at $1.3 \mathrm{PW}$ southward in July and 0.9 PW northward in January, agreeing well with Garternicht and 

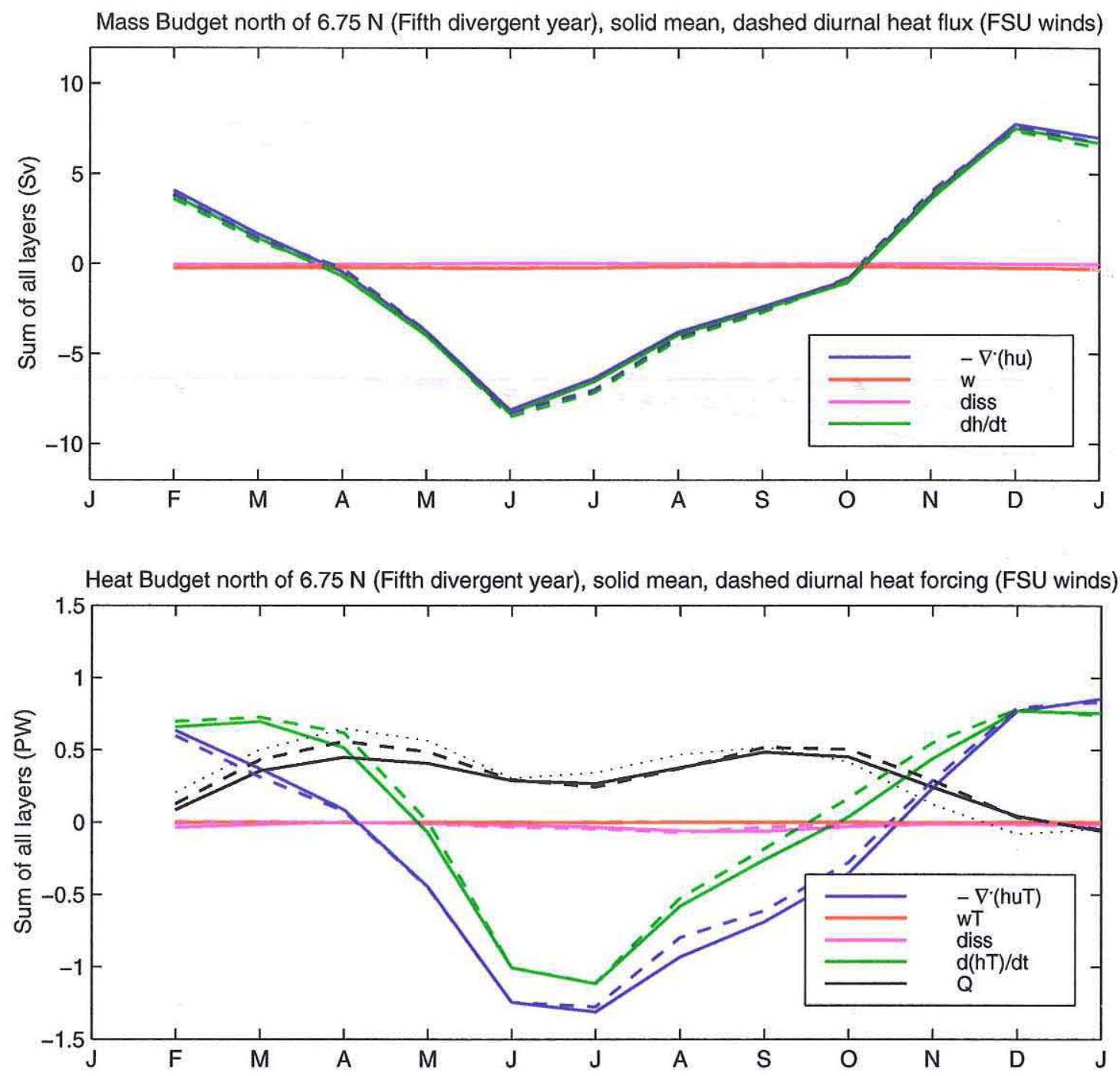

Figure 3.26 Monthly mean terms in the mass and heat budgets of the model, summer over all layers and over the area of the Arabian Sea north of $6.75^{\circ} \mathrm{N}$, from the last year of integration. Solid lines are run F, dashed run FD. For comparison, the dotted black line in the heat budget is the SOC climatology integrated over the Arabian Sea.

Schott [1997] and slightly weaker than Lee and Marotzke [1998]. The net heat flux into the model also varies seasonally, and is stronger, most notably in the intermonsoon seasons, in run FD over run F. The seasonal heat transport is a somewhat weaker southward 
in run FD at the tail end of the SW monsoon, and a little weaker northward during the NE monsoon, leading to the nearly negligible change for the year between runs.

\subsubsection{Summary}

The addition of the diurnal cycle in the surface heat flux changed the model fields and integrated mass and heat transports more on the seasonal time scales than in the annual mean. There were some significant differences in the annual mean, however. The diurnal cycle drove additional exchange between the surface layers and deeper layers, generally reducing sea surface temperatures, and increasing the net surface heat flux into the ocean.

These differences were driven locally by the addition of the diurnal cycle to the surface forcing, but some major and unexpected changes appeared in the interaction of local forcing with changed remote wave forcing. One of the largest signals was the lack of cooling in run FD in the broad swath centered just north of the equator during the NE monsoon, which was due ultimately to a change in the westward propagation of a minimum in mixed layer depth from the previous SW monsoon. The amplitude of the vertically alternating currents, and thus the layer depth disturbances, in this Rossby wave packet were reduced through the additional vertical momentum exchange driven by the diurnal cycling.

Outside of the equatorial region, the net meridional mass and heat transports in the model were changed mildly by the addition of the diurnal cycle, but the vertical exchange between layers was quite different. The diurnal cycle also brought additional heat input into the basin by increasing the net surface heat flux. The sum of these terms yielded a stronger imbalance in the heat budget and stronger heat gains on an annual basis. In the equatorial region, the diurnal cycling modified the appearance of shallow meridional rolls in both the mass and heat transports. 


\subsection{ECMWF wind-forced solution}

The model solutions discussed in Section 3.3 and Section 3.4 were both forced with the FSU monthly mean wind climatology. In addition to the large diurnal cycle observed at the Arabian Sea buoy, there was considerable variability in the wind field, on time scales varying from the diurnal and synoptic, to the seasonal time scales that are captured in a monthly climatology.

This section reports on the differences in a model solution that is forced with a monthly mean realistic wind forcing compared to a solution forced with a 6-hour wind analysis. In order to compare the solutions to the observations at the Arabian Sea buoy site, winds from 1994-1995 are used. Lee et al. [2000], using SOC climatological winds, demonstrated that wind-driven Ekman pumping during the 1995 SW monsoon was fairly typical when compared to a 15 year climatology, with differences generally within one standard deviation, and rarely exceeding two. The additional energy available for mixing contained in the high-frequency winds is expected to drive additional vertical mixing in the mean. Their time resolution will also modify the time evolution of mixing and advective transport. Since mixing is an irreversible process, changes to the dynamic and thermodynamic evolution of the model can be expected.

Previous work [Weller et al., 1998] showed a good correspondence between moored observations of the winds in the Arabian Sea and wind stresses and the ECMWF analysis. This analysis (which did not include the buoy data as part of its source data) is able to capture much of the temporal variability (Fig. 3.27) observed at the buoy. During the NE monsoon, synoptic-scale variability is well-captured, though a very strong event in the middle of October is not captured. This squall, associated with the only significant rainfall of the yearlong moored record, was likely of too small a scale to be captured in the $1.125^{\circ}$ horizontal resolution of the ECMWF analysis. A "false start" to the SW monsoon in May is also captured in the analysis, as are the synoptic to month-long variations in the wind stress during the entire SW monsoon. 


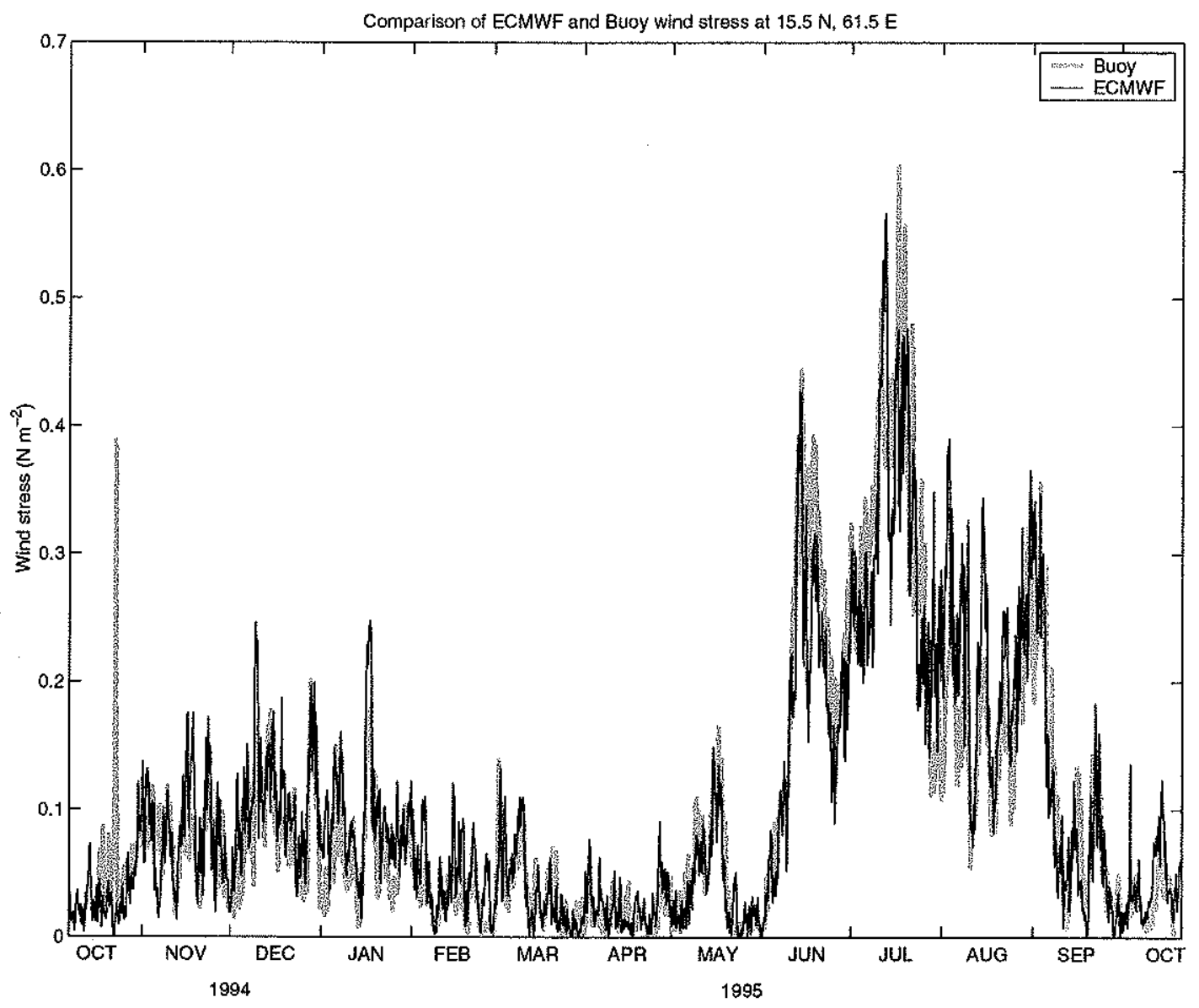

Figure 3.27 Buoy (gray) and ECMWF (black) wind stresses at 6 hour resolution, from the Arabian Sea buoy site $\left(61.5^{\circ} \mathrm{E}, 15.5^{\circ} \mathrm{N}\right)$ during 1994 and 1995.

A comparison of ECMWF snapshots across the basin during the SW monsoon (Fig. 3.28 bottom two panels) shows that the Findlater Jet, in large part, is a construct of the averaged wind fields. The actual winds during the SW monsoon are quite variable in magnitude on short time scales, though the directions are fairly consistent. The strongest wind stresses are always found in close vicinity to the Somali coast.

I begin with an examination of the differences between the original run forced with the FSU climatologies (Run F), and a run driven by monthly mean ECMWF winds from 1994-95 (Run E). The focus then turns to the differences between the monthly mean ECMWF run and a run forced by the fully-resolved six hour ECMWF winds (Run EH). 

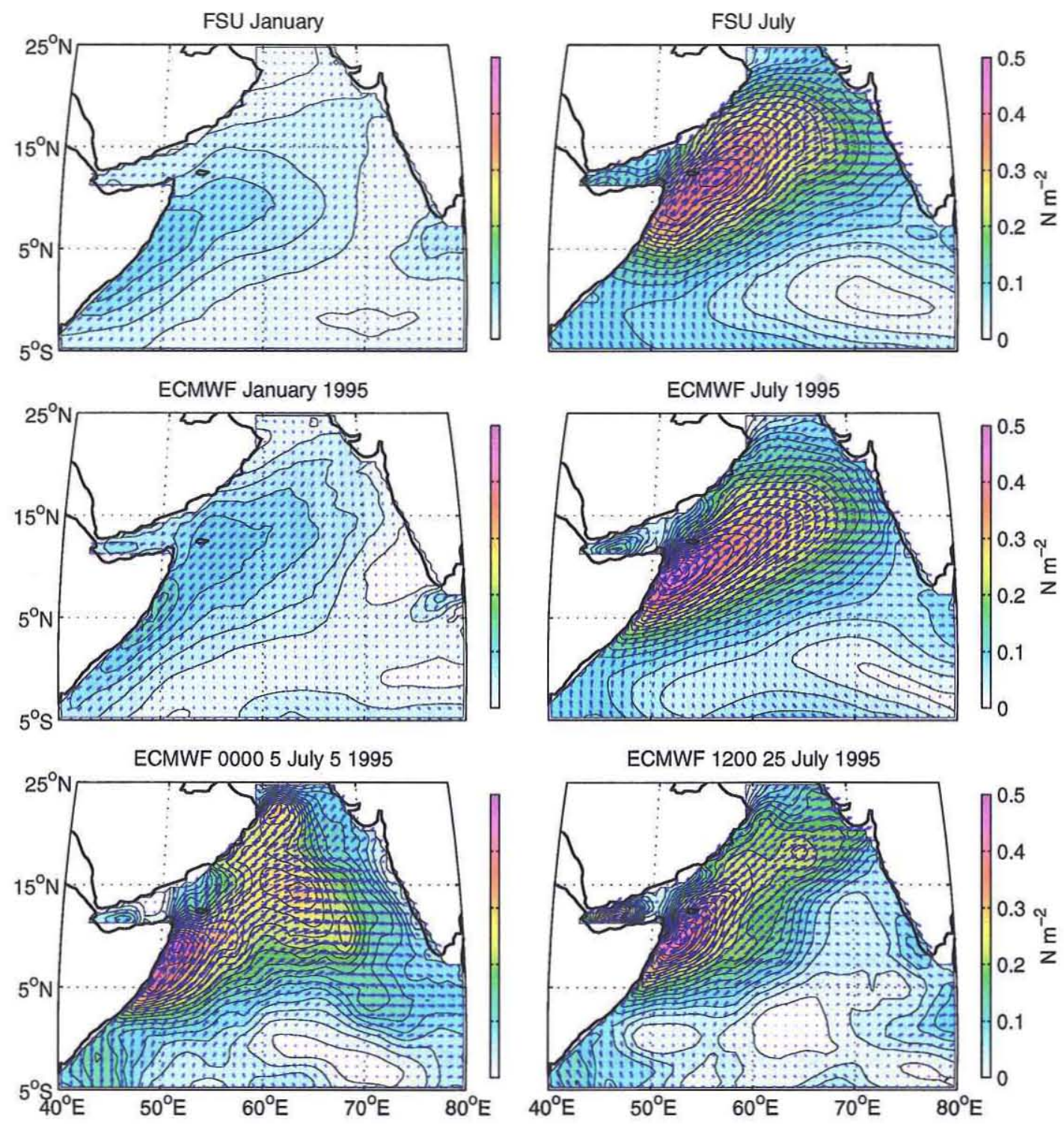

Figure 3.28 An overview of the wind forcing products used on the model. The top two panels are the January and July FSU wind stresses used in runs F and FD. The middle two panels are the January and July 1995 ECMWF wind stresses used in runs E, EH, and EHD. The bottom two panels are two snapshots of the ECMWF wind stress during July 1995, and demonstrate some of the variability in the wind fields. 


\subsubsection{Differences introduced by the wind climatologies}

There are some notable differences between the FSU climatological winds and the ECMWF mean winds (Fig. 3.28). Gradients in the ECMWF wind stress are sharper, and there is more horizontal structure, particularly during the NE monsoon. This difference probably comes from the fact that the FSU wind climatology is an average over 26 years, while the ECMWF analysis comes from the specific year of 1994-95. Another source of the difference is the higher spatial resolution $\left(1.125^{\circ}\right.$ vs. $\left.2^{\circ}\right)$ of the ECMWF fields. The most conspicuous difference during the SW monsoon is that the strongest wind stresses in the ECMWF winds are very close to the Somali coast, while the maximum winds in the FSU climatology are farther offshore, east of Socotra.

In July, the difference between the model solutions forced by the monthly mean FSU winds (run F) and the monthly mean ECMWF winds (run E) are directly connected to the difference in the forcing. The deepest mixed layers are closer to shore in run $\mathrm{E}$, just south and east of the strongest winds (compare Fig. 3.29 with Fig. 3.5). The region of upwelling is broader, though the peak strength is reduced, off the Somali coast, and the strength of the upwelling along the Arabian coast is reduced, due to the slightly weaker winds in run $\mathrm{E}$ vs. run $\mathrm{F}$. As a consequence, the sea surface temperatures along the Arabian coast are warmer in run $\mathrm{E}$, and while the temperatures reach similar values off the coast of Somalia, the shape of the cold wedge north of the SG is modified. The heat flux into the regions of upwelling along the western coasts is likewise reduced. The upwelling off the southwestern coast of India is similar in both model runs. The Somali current is stronger in run $\mathrm{E}$, with peak speeds just over $3 \mathrm{~m} \mathrm{sec}^{-1}$, and the offshore turn of the Southern Gyre is slightly farther south. The Great Whirl, the retroflection of the Somali current that occurs about $9^{\circ} \mathrm{N}$, is weakly present in run $\mathrm{E}$, an improvement over its absence in run $\mathrm{F}$. The strong eastward flows just north of the equator are reduced in strength in run $\mathrm{E}$, except for a region east of $70^{\circ} \mathrm{E}$, which in run $\mathrm{E}$ is associated with a strong gradient in layer depth. Layer 3 circulations are similar in both model runs, though 


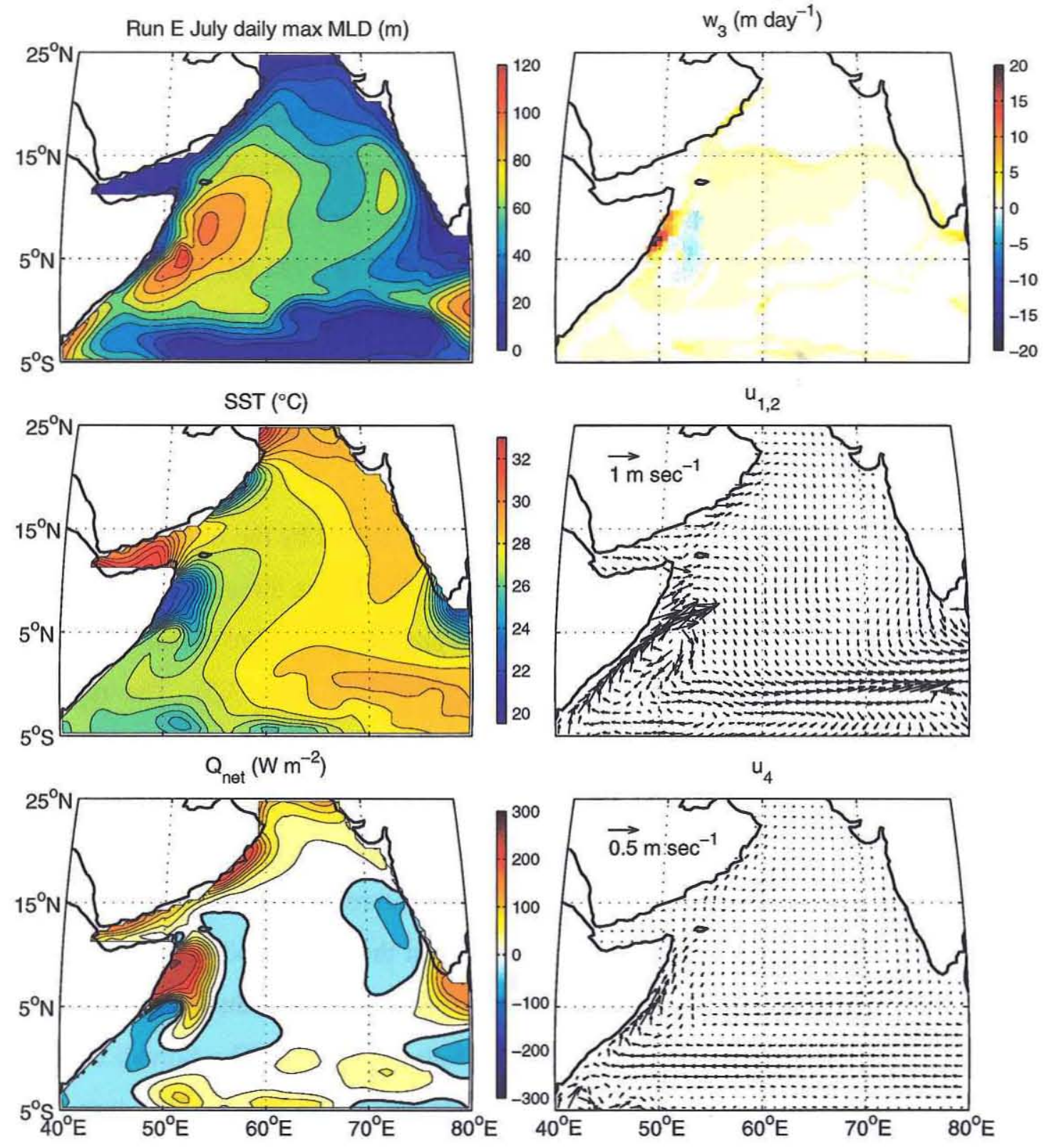

Figure 3.29 July Run E. As in Fig. 3.5, except for July Run E.

there is a significant northward current along the Arabian coastline in E, not present in run F. The structure of layer 4 circulations are similar, but weaker in run $\mathrm{E}$.

In January, the mixed layer depth structures are similar, though the maximum depth in run E occurs farther north (compare Fig. 3.30 with Fig. 3.5). The spatial gradients in 


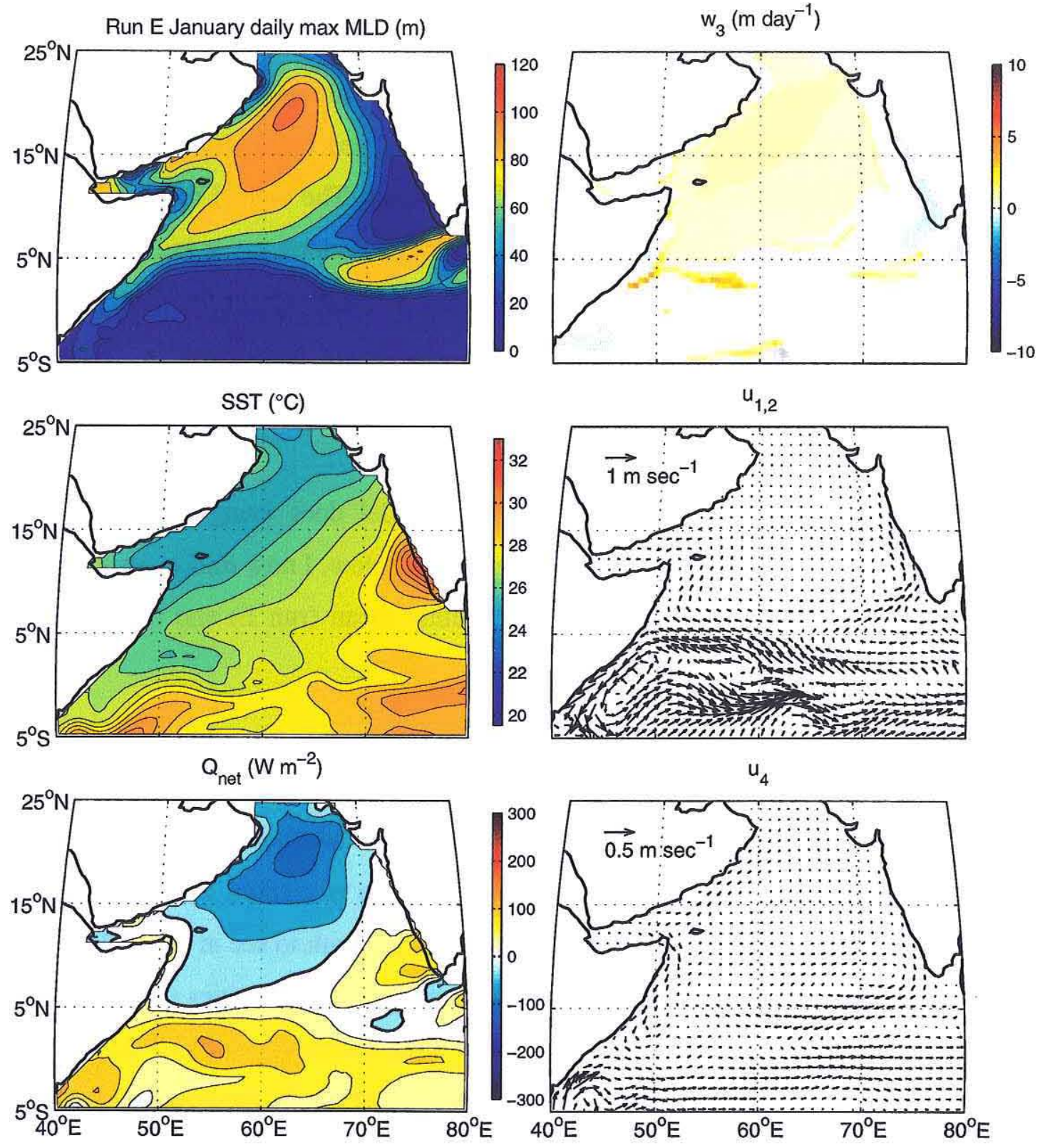

Figure 3.30 January Run E. As in Fig. 3.29 except for January.

run $\mathrm{E}$ are much stronger. The equatorial region of shallow mixed layer is accentuated in run $\mathrm{E}$, but a region of deep mixed layer extending southwest from the southern tip of India is much stronger. Weaker winds off the southwestern coast of India allow for very shallow mixed layers and a net surface heating, leading to raised surface temperatures. 
The zonal band of low SST around $4^{\circ} \mathrm{N}$ is present in both runs, and the circulation is similar in each run, though there is smaller scale structure present in run E.

In the annual mean, run E exhibits a weaker upwelling along the Somali and Arabian coasts, though the upwelling along the Indian coast is of nearly the same strength. Overall the sea surface temperatures are about $0.5^{\circ} \mathrm{C}$ warmer. The annual mean circulations are very similar between each run. Run E surface circulations are a bit stronger, and though there were hints of a separation between the SG and GW in the during the SW monsoon, on average the separation is not clear. The deeper northward flow supplying the upwelling along the Somali and Arabian coasts is shallower, with a larger component in layer 3 .

So the choice of wind product to force the model does bring about significant changes, some of which will be remarked upon further below. I now turn to an analysis of the differences between the run forced with monthly mean (run E) and the run forced with six-hour resolved (run EH) ECMWF winds.

\subsubsection{SW monsoon}

The differences during the SW monsoon driven by the addition of the resolved highfrequency wind are quite strong. The surface circulation is marked by a more distinct Great Whirl north of the Southern Gyre (unfortunately difficult to see in Fig. 3.31), which in run EH has moved southward, with its maximum offshore velocities occurring about $5^{\circ} \mathrm{N}$. The peak velocities in the Somali current have increased to about $3.7 \mathrm{~m} \mathrm{sec}{ }^{-1}$, though since these occur in a region of thinner mixed layer depth, the peak momentum in the Somali current is similar (slightly weaker in run $\mathrm{EH}$ ) in both runs. The equatorial countercurrent is a meandering feature in run $\mathrm{EH}$, and in the eastern portion, where the mixed layer depths vary the most dramatically between model runs (Fig. 3.32), the currents vary quite a bit. Layer 3 velocities are generally stronger in run $\mathrm{EH}$, as the resolved wind stress increases the exchange between layers, with more energy available for turbulent mixing (Section 3.1.2.2). Along the Somali coast, the northward velocities in the 

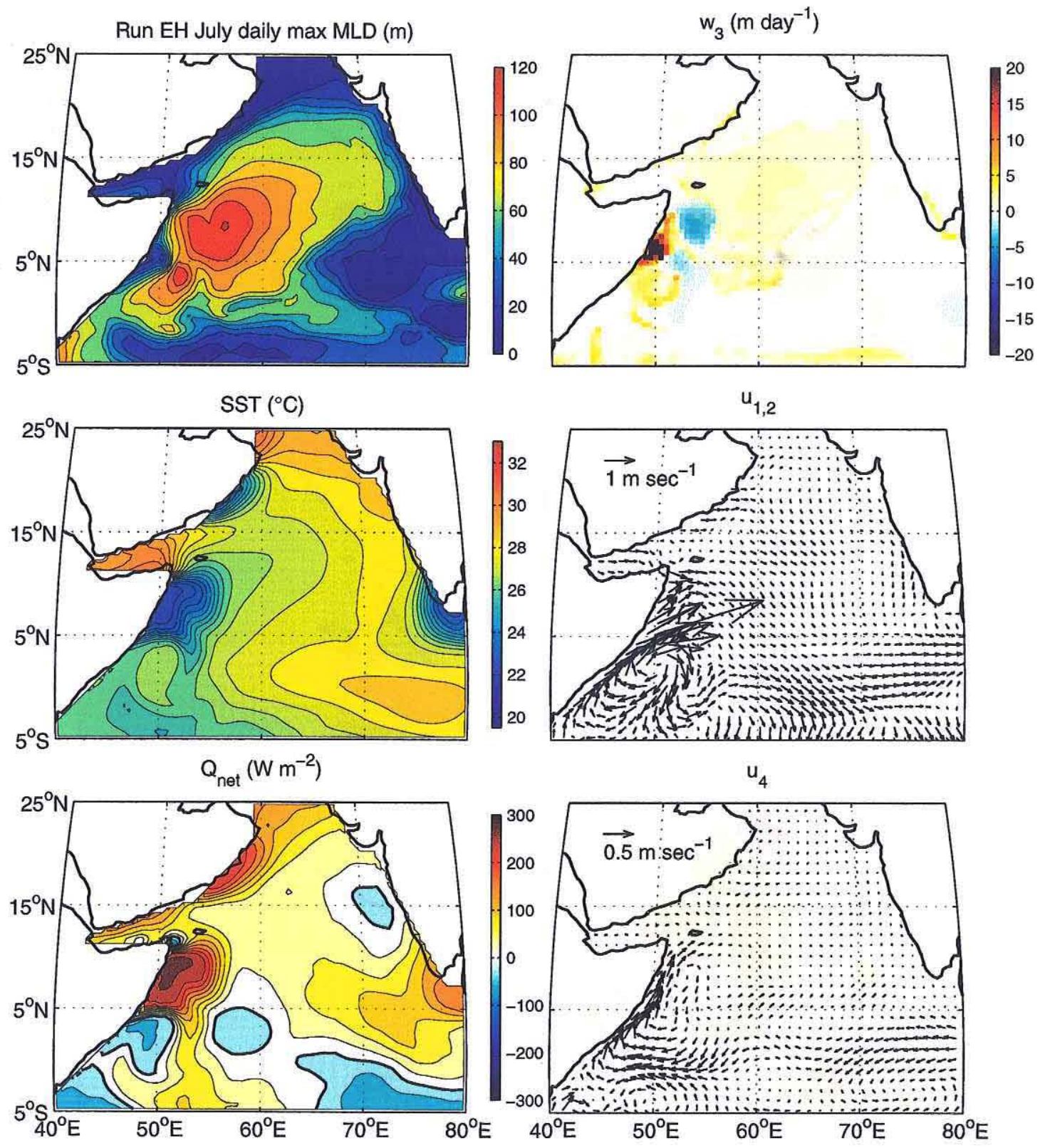

Figure 3.31 July Run EH.As in Fig. 3.29 except for run EH. 

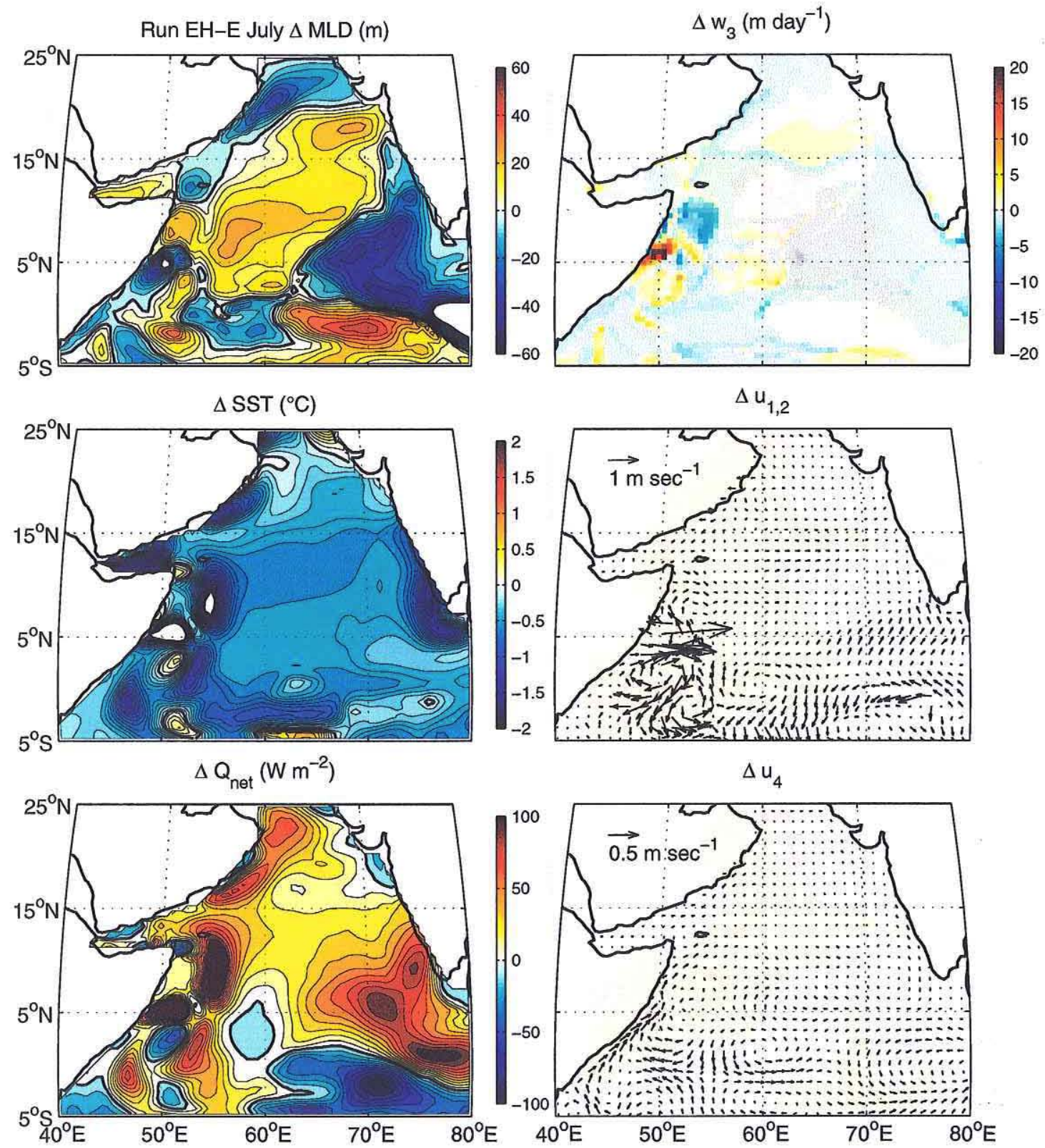

Figure 3.32 July difference run EH - run E. As in Fig. 3.14, except for runs EH and $\mathrm{E}$. 
deepest layer are increased significantly in run $\mathrm{EH}$, which is in turn connected to the shallower layers by a greatly increased and broader upwelling.

Since the mean momentum input from the wind into the surface layer is the same in each run, these changes in the circulation are primarily the result of changed exchanges between layers. The high-frequency winds provide higher turbulent energy available for surface layer entrainment, and the mixed layers in much of the central portion of the basin are $20-50 \mathrm{~m}$ deeper in run $\mathrm{EH}$ (Fig. 3.32). The high-frequency winds also provide a different history of mixing, and in some cases, most notably in the broad region extending southwestward from the southern tip of India, the mixed layers are much shallower in run EH. Shallow mixed layers in the upwelling wedge north of the SG are shifted in run EH with the shifted circulation, and the wedge is broader. The minimum in mixed layer depth seen around $66^{\circ} \mathrm{E}, 10^{\circ} \mathrm{N}$ in run $\mathrm{E}$, associated with the propagation of the previous SW monsoon Indian coastal upwelling, is absent in run EH. And in the equatorial regions, the mixed layers, especially in the eastern portion, are deeper in run $\mathrm{EH}$.

The sea surface temperatures are everywhere cooler in run EH (Fig. 3.32), with temperatures across the broad interior a better match to the Rao climatology (Fig. 3.7). Since run EH is forced by a combination of 1994-95 winds and climatologically-derived surface fluxes, this better agreement is perhaps more by luck than by design. The difference is about $0.5^{\circ} \mathrm{C}$ across the interior, but stronger, commonly exceeding $1^{\circ} \mathrm{C}$ in upwelling regions. The net heat flux across the sea surface is nearly everywhere increased in run $\mathrm{EH}$, in a pattern affected by the changes in upwelling and resulting mixed layer depth more than the changes in SST.

The July monthly mean temperature budget of the surface layer (Fig. 3.33A) reveals that the cooling sea surface temperatures during the month are a result of entrainment cooling (upwelling) and horizontal advection, both away from the upwelling regions and southward across the interior. But the difference between the temperature budget of run $\mathrm{E}$ and EH (Fig. 3.33B) shows that the much cooler sea surface temperature evident during July in run EH are not a result of that month's cooling. The difference in the temperature trend over the month shows a generally weaker cooling in run EH. The difference was 

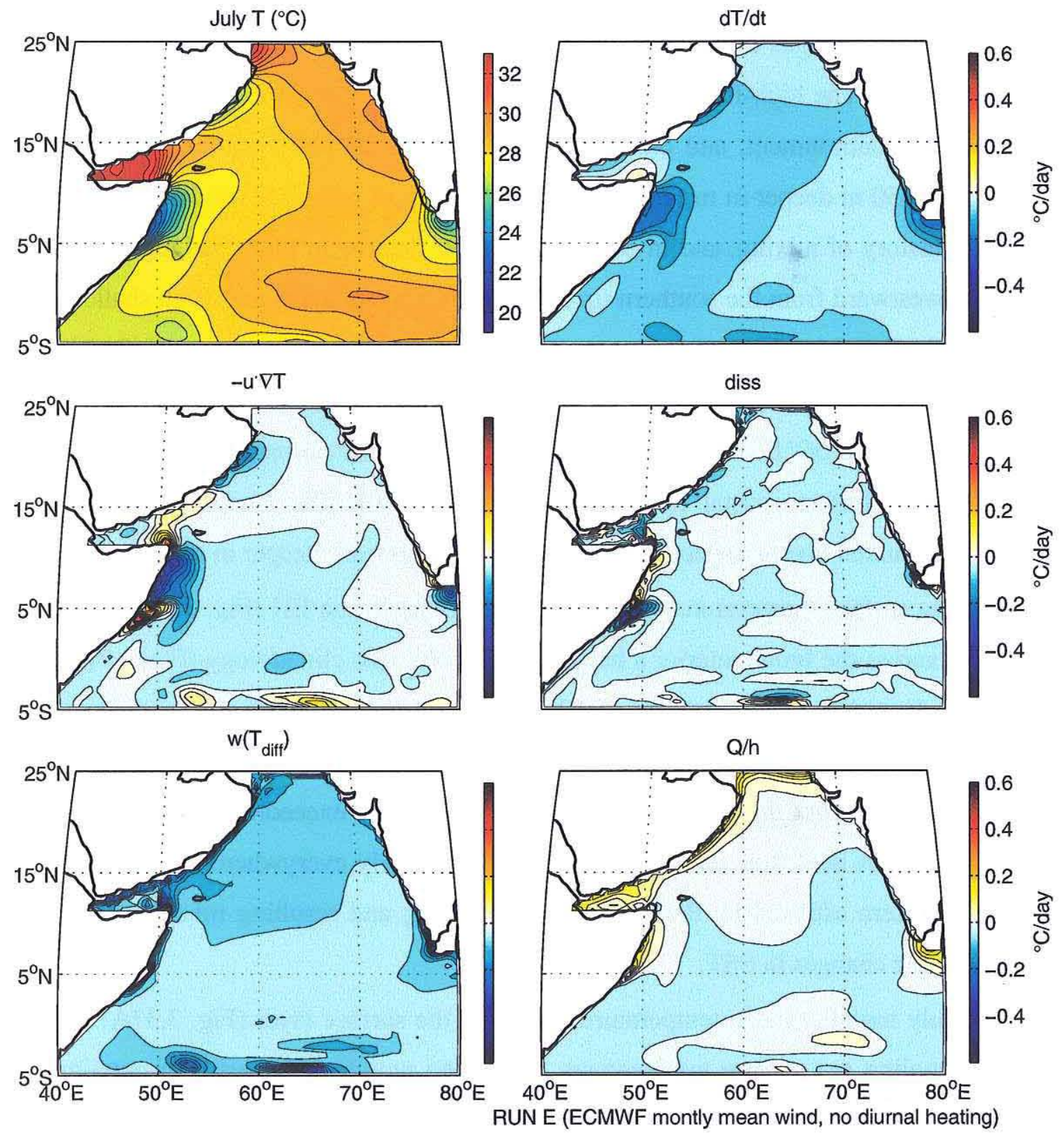

Figure 3.33 A July Run E, terms in the temperature budget. As in Fig. 3.16A except for run $\mathrm{E}$. 

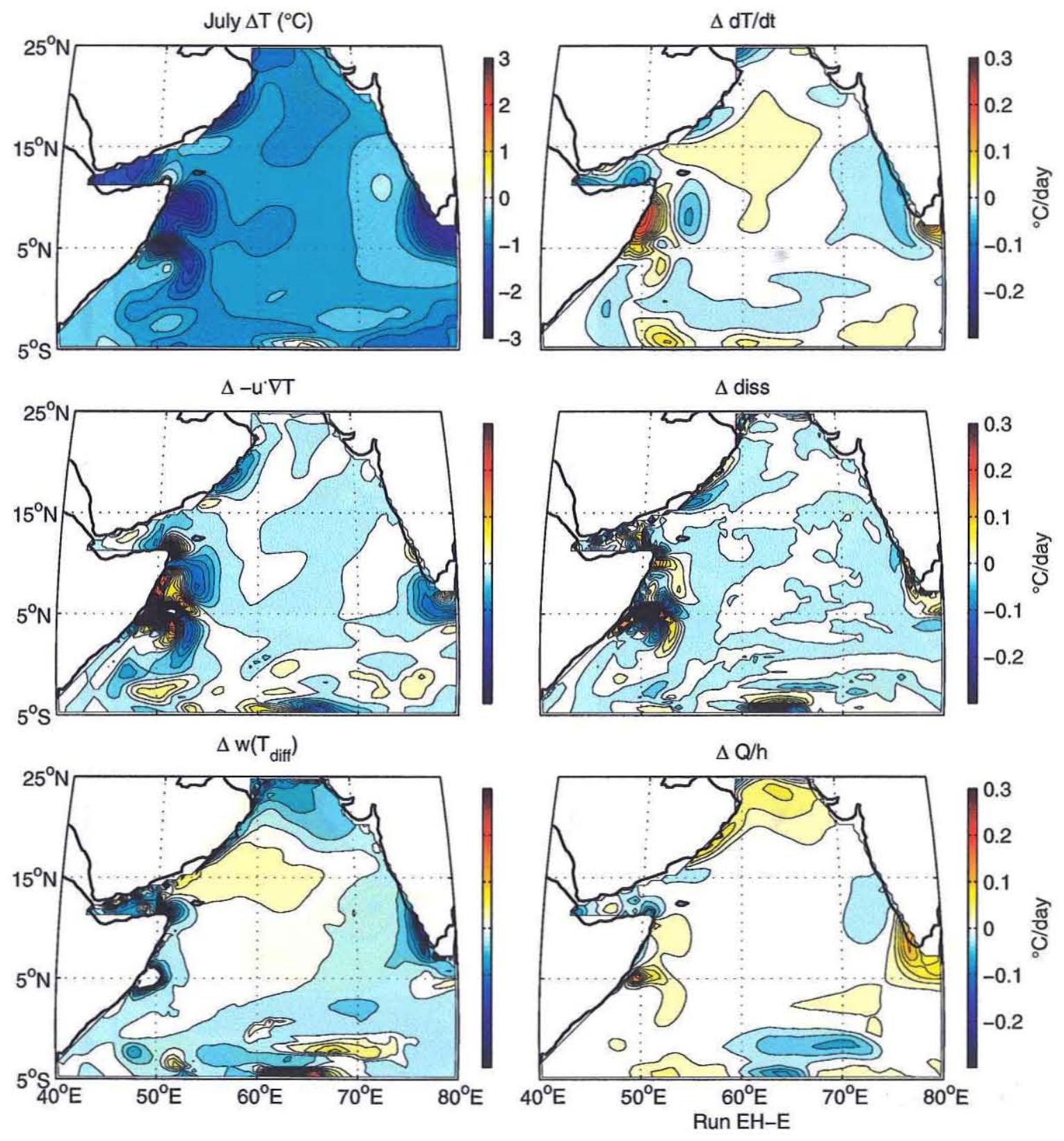

Figure 3.33 B July run EH - run E difference in the terms in the temperature budget of the mixed layer. As in Fig. 3.16B except for runs EH and E. 

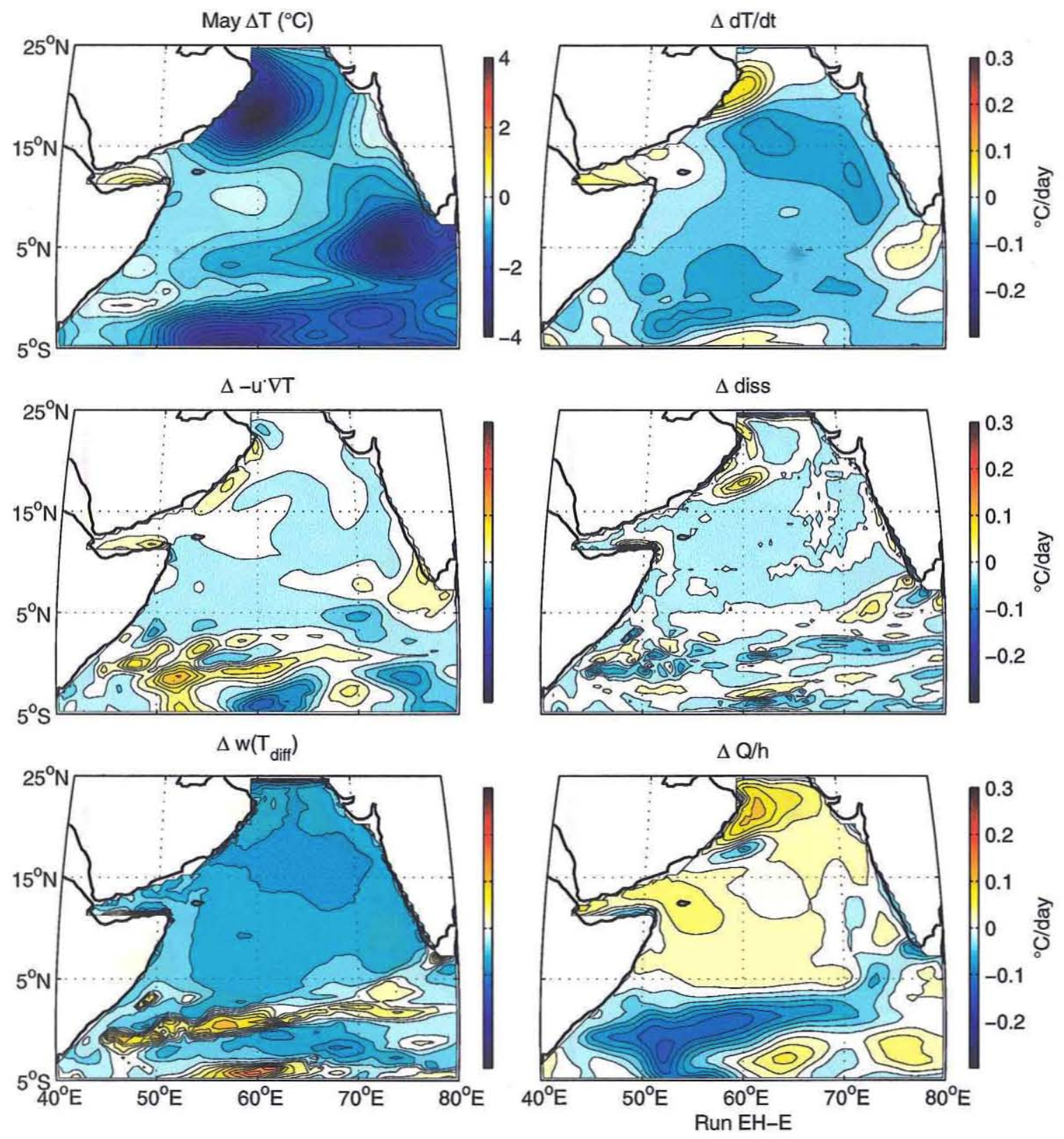

Figure 3.34 May temperature budget. As in Fig. 3.33A except for May. 
created two months earlier in May (Fig. 3.34), where the temperature trend term creates much cooler sea surface temperatures in run EH. The strongest contributing term is the entrainment term, which in run EH is driven by the strong winds of the 'false start' to the monsoon (Fig. 3.27), not captured in the monthly mean ECMWF winds.

\subsubsection{NE monsoon}

In January, perhaps the most striking difference between runs E and EH (Fig. 3.36) is the lack of entrainment out of layer 3 across the interior in run $\mathrm{EH}$ (see $w_{3}$ in Fig. 3.35). January is a different phase in NE monsoon mixed layer deepening in run EH, and the bulk of the deepening has already occurred. The mixed layers north of the equatorial region are shallower, but cooler, with the addition of the high frequency wind. The net surface flux is higher in a broad band extending westward from the western and southern coasts of India. The largest difference in mixed layer depth are the generally deeper mixed layers in equatorial regions in run $\mathrm{EH}$. The high-frequency wind, like the diurnal cycling, appears to keep the region of minimum mixed layer depth which has propagated offshore from the previous SW monsoon somewhat deeper (Fig. 3.37).

Over the entire month, the equatorial region is the region of the biggest temperature differences (Fig. 3.38), with warmer temperatures north of the equator, and cooler temperatures to the south. This is directly reflected in the changed temperature trend for the month. Run E, like run $\mathrm{F}$, has a strong contribution to cooling just north of the equator from upwelling, driven by the monsoon winds over the minimally deep mixed layer. Despite the differences in forcing, the high-frequency winds appear to have a similar effect on the mixed layer depth as the diurnal cycling, keeping the mixed layer in the propagating region somewhat deeper (Fig. 3.37). This greatly reduces the entrainment cooling north of the equator in run $\mathrm{EH}$, since the $\mathrm{NE}$ monsoon winds are acting on a thicker layer depth. The geostrophic currents set up around the region of thin mixed layer depth are also changed, changing the horizontal heat transports. Despite the fact that the difference in cooling in the regions north of the equator is minimal in January, the sea 


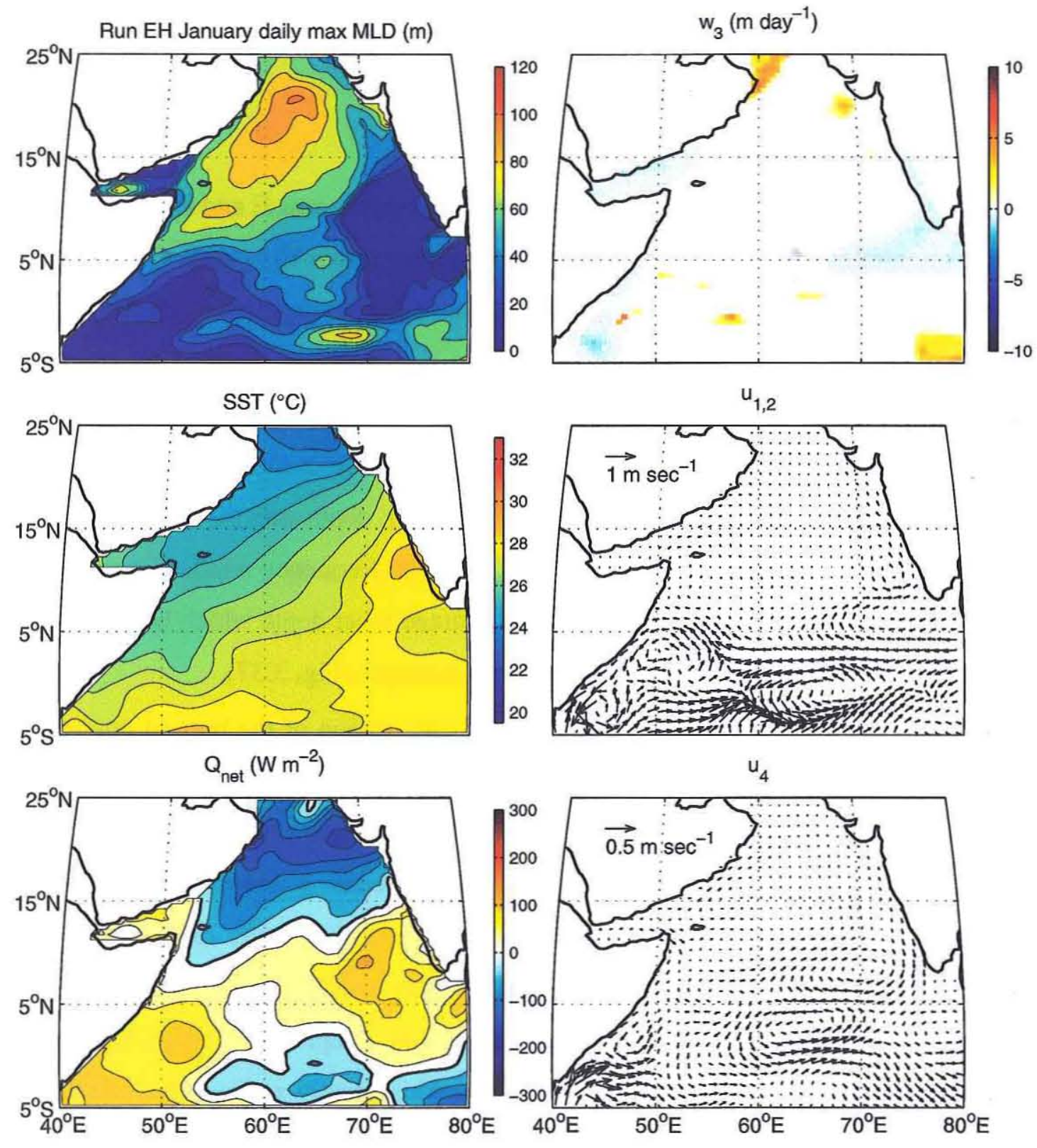

Figure 3.35 January Run EH. As in Fig. 3.30 except for run EH. 


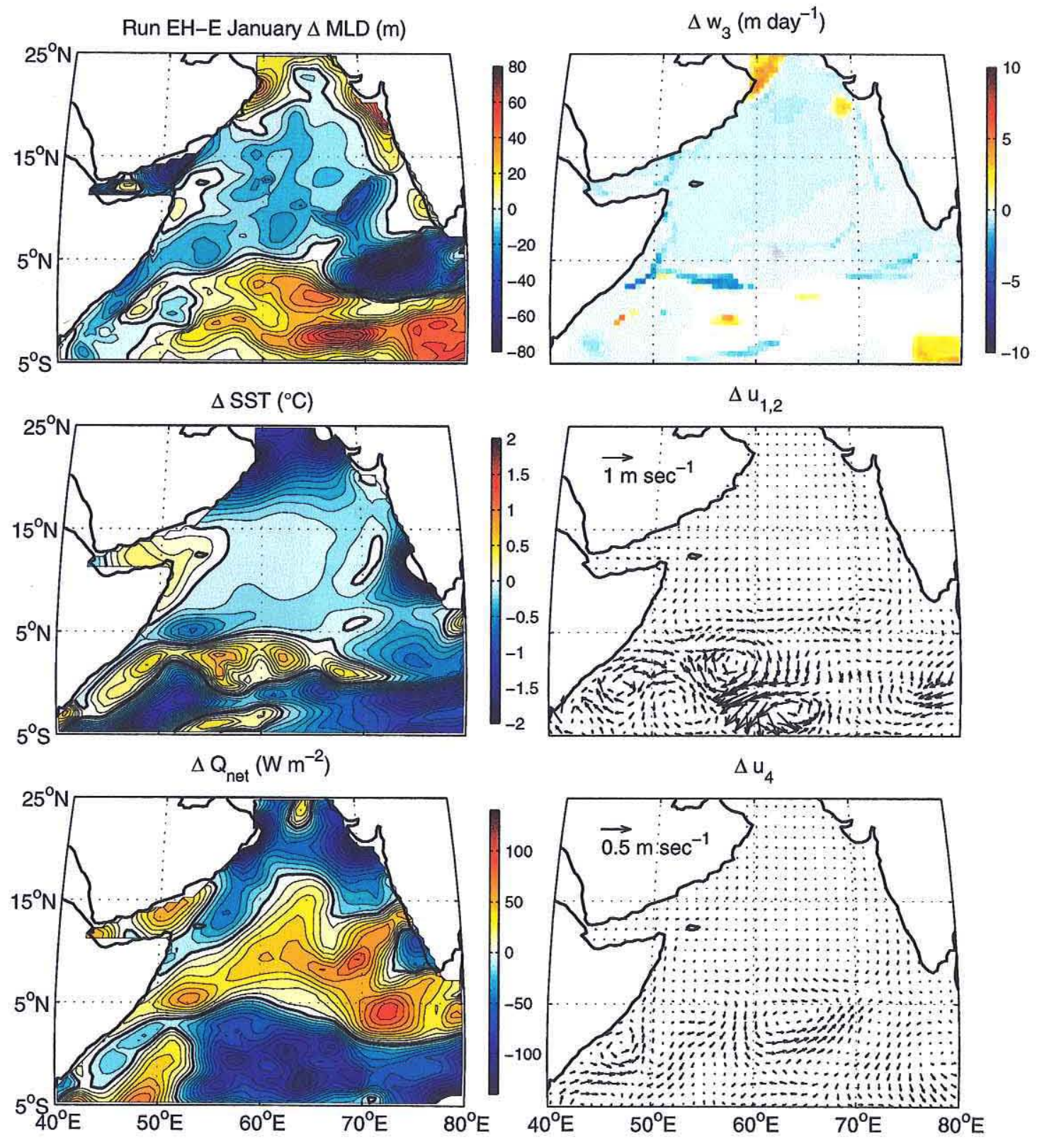

Figure 3.36 January run EH - run E difference. As in Fig. 3.32, except for January. 

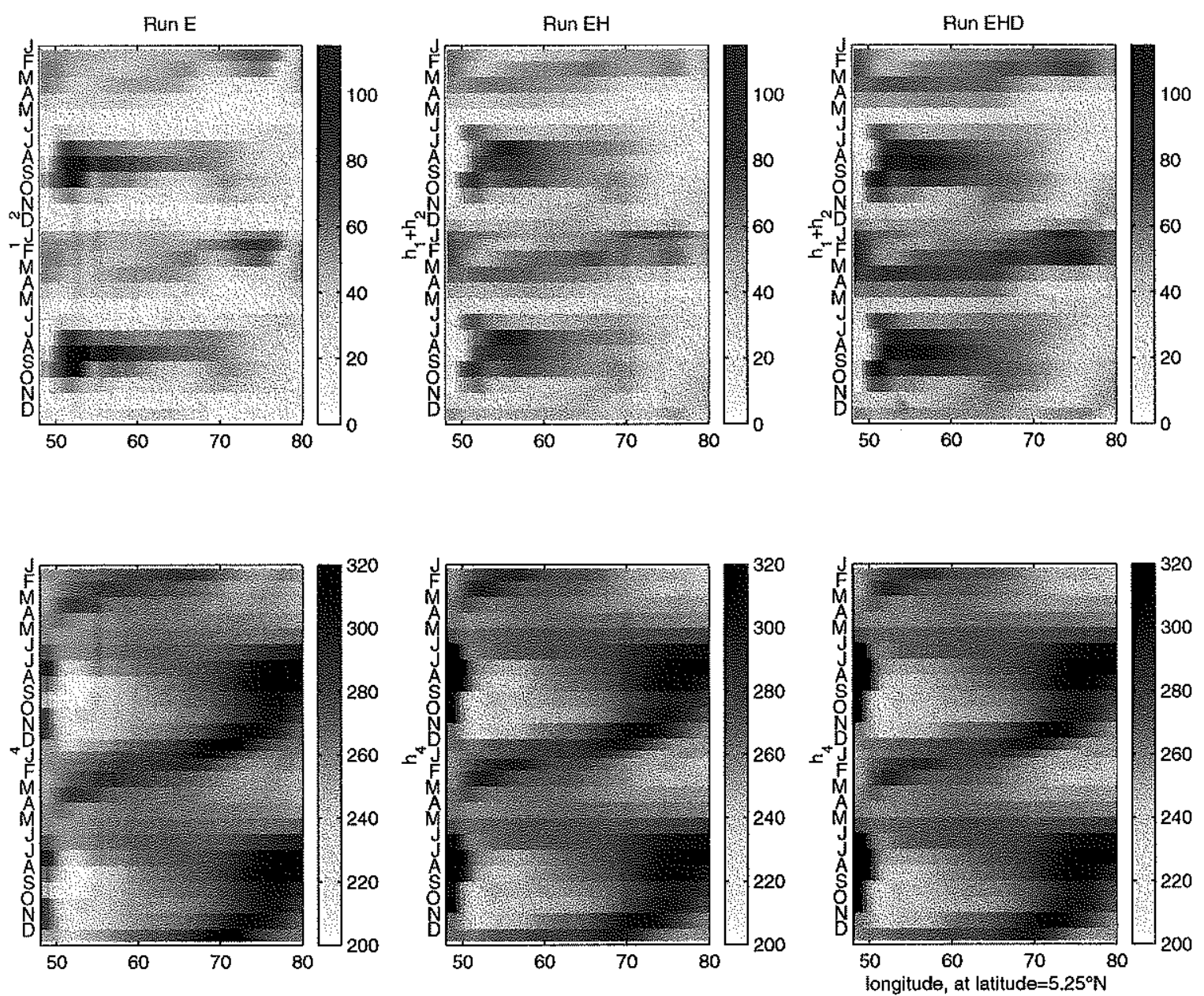

Figure 3.37 Westward propagation of layer depths $h_{1}+h_{2}$ (top) and $h_{4}$ (bottom) in time at the fixed latitude of $5.25^{\circ} \mathrm{N}$, for Runs E, EH, and EHD. The last year of integration is repeated for clarity.

surface temperatures are quite a bit cooler. Like during the SW monsoon, this is due to a changed history of mixing in the previous months.

The overall circulation is similar between the model runs, with the biggest differences coincident with the biggest modeled differences in mixed layer depth and layer depth gradients. The strength of the circulation in lower layers is also increased, indicating increased transfer out of the upper layers. 

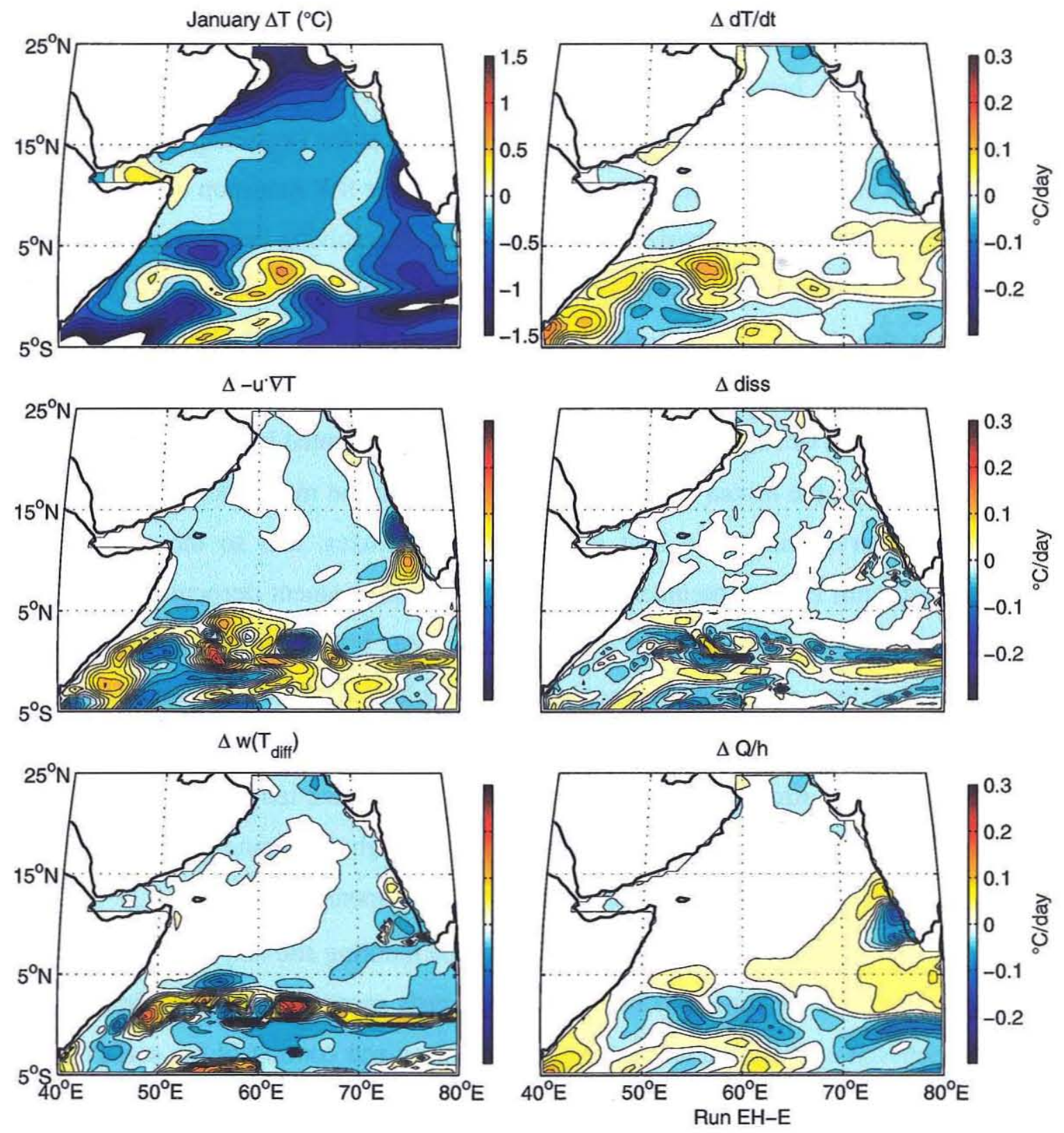

Figure 3.38 January run EH - run E difference in the terms of the temperature budget of the mixed layer. The largest differences come in equatorial regions, where run $\mathrm{E}$ has more entrainment cooling in a band stretching approximately along $3^{\circ} \mathrm{N}$. 


\subsubsection{Buoy site}

There are striking differences in the mixed layer depth evolution at the site of the Arabian Sea moored array (Fig. 3.39 and Fig. 3.40). Run EH, with resolved high-frequency wind events, has a different history of mixed layer deepening and shoaling when compared to run $\mathrm{E}$. The timing of the major deepenings at the beginning of the $\mathrm{SW}$ and NE monsoons are shifted earlier, by one month during the SW monsoon and by 15 days during the NE monsoon, emphasizing the importance of resolving the intraseasonal scale in the wind, which can drive irreversible entrainment into the surface layer. The mixed layer depths also shoal more suddenly in run $\mathrm{EH}$ as the transition into the intermonsoon is made, matching the observations in the NE monsoon. In the SW monsoon, the shoaling observed at the end of July (Fig. 3.1) is only partially represented in the model by a temporary shoaling in the mixed layer depth (Fig. 3.40), but the model does not reproduce the strong observed advective heat and temperature fluxes, and so the mixed layer remains deep until early September. The wind-driven entrainment deepening of the SW monsoon is spread over a longer time period and is a little bit shallower in run EH over E, but still deeper than observed. The seasonal thermocline layer may be too deep in the model, or the parameterization of entrainment-driven deepening may be too strong. Since

the deepening is so strong in the model, the model sea surface temperatures are significantly colder in the early part of the SW monsoon, though the strong horizontal advection in the data closes the gap in the latter part of the SW monsoon.

The temperature budget of the surface layer at the mooring site emphasizes two major differences between the runs. The first is the previously mentioned changed time history of surface-driven entrainment and mixing. The heating and cooling of the surface layer are more episodic in run EH (dashed lines in Fig. 3.41) during the spring intermonsoon and SW monsoon, and the heating and cooling phase associated with the fall intermonsoon and NE monsoon are shifted slightly earlier. The other difference that is noticeable is a growth of the positive/negative balance provided by an increased heat flux term and increased entrainment cooling, similar to what occurred under the influence of diurnal 

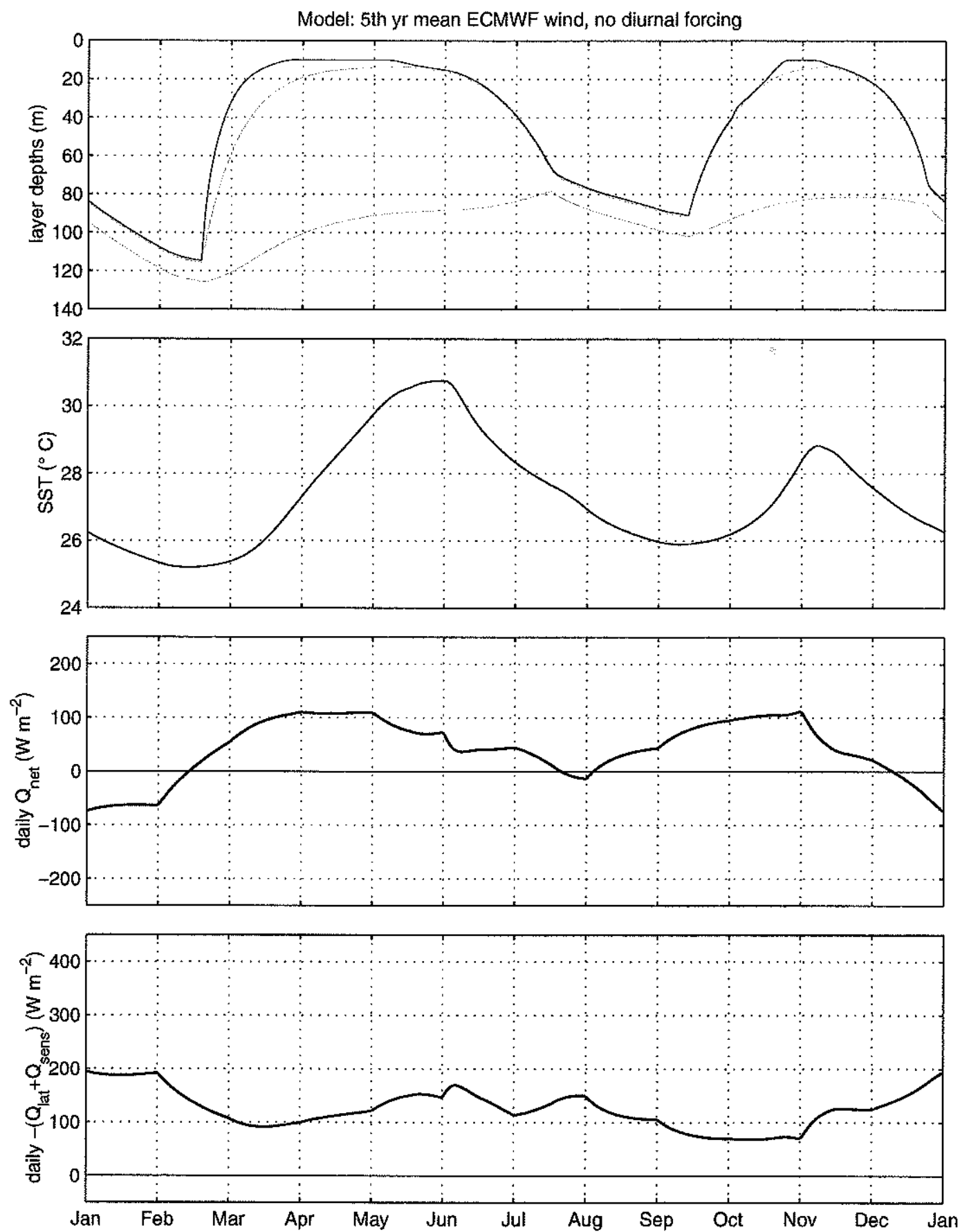

04-Aug-2000/data3/afischer/mcmodel/plot_current current_4panel_m5.m

Figure 3.39 Run E model solution at the mooring site. As in Fig. 3.20, except for run $\mathrm{E}$. 

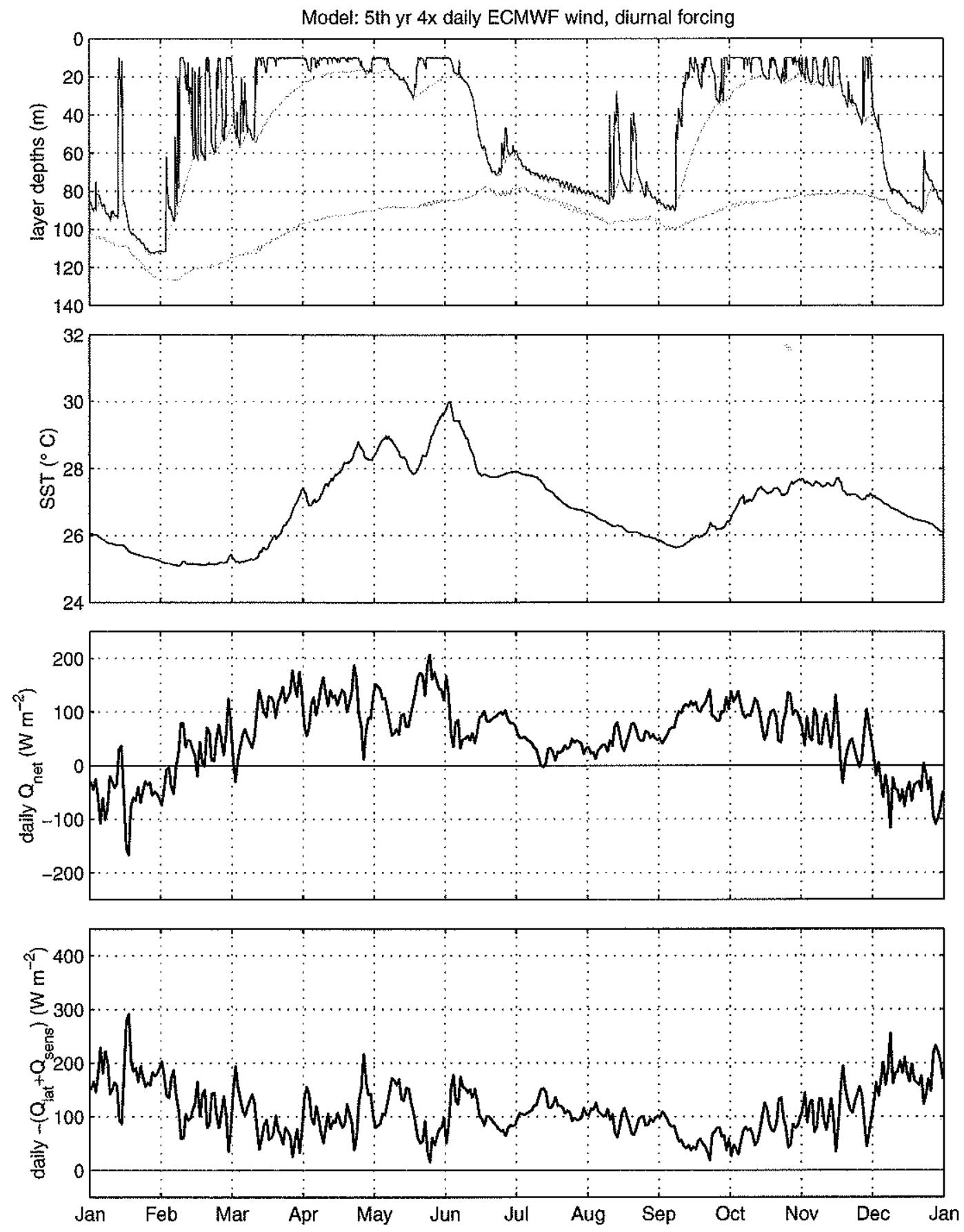

04-Aug-2000/data3/afischer/momodel/plot_current current_4panel_e5.m

Figure 3.40 As in Fig. 3.39, except for run EH. 


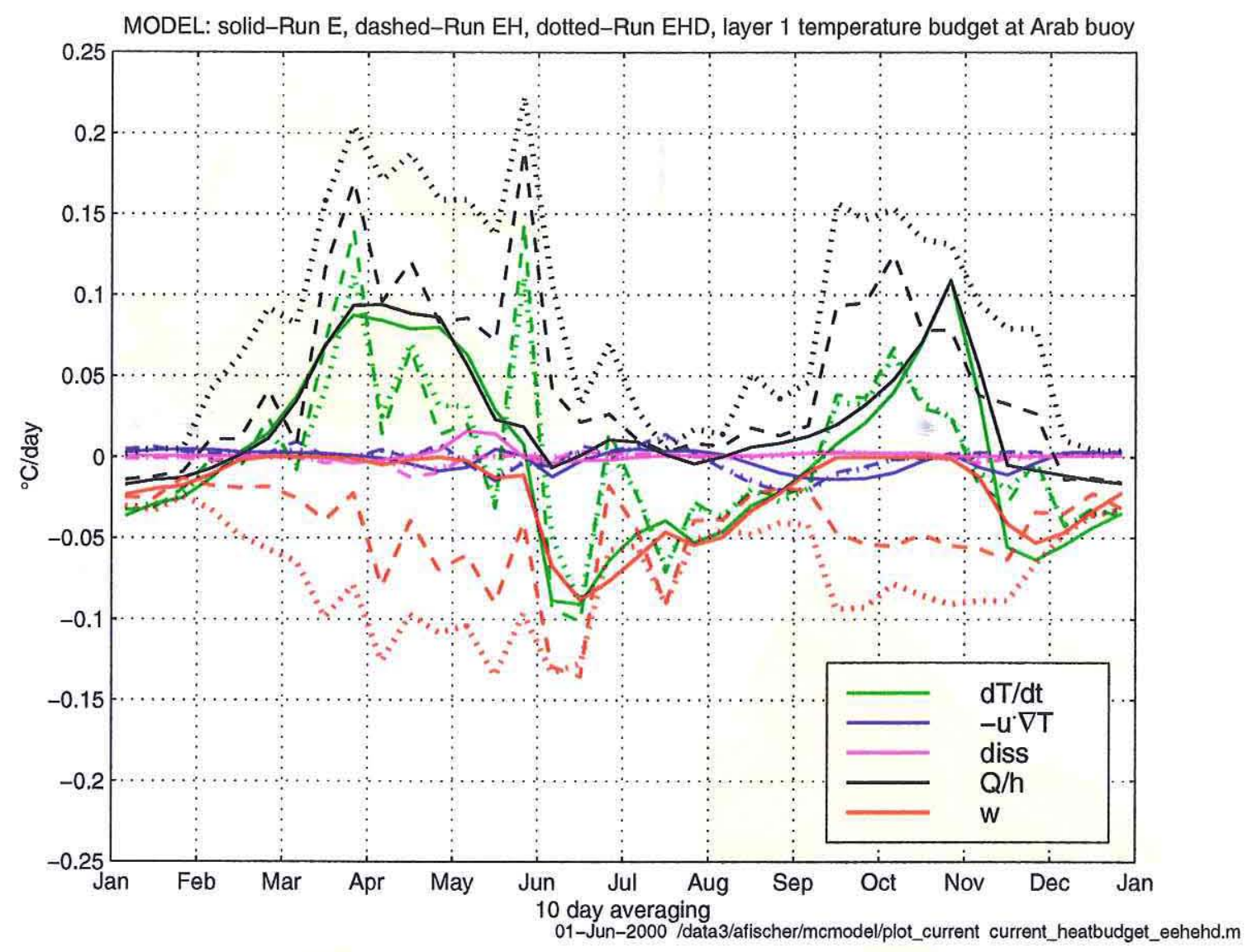

Figure 3.41 Terms in the surface layer temperature budget at the buoy (run E solid, run EH dashed, run EHD dotted). As in Fig. 3.21, except for the ECMWF-forced model runs.

cycling. There is additional exchange between the mixed layer and deeper layers. The mixed layer, particularly in the intermonsoon seasons, is shallower in run $\mathrm{EH}$, leading to a more rapid increase in temperature. There is also a contribution from a generally increased surface heat flux. But the episodic mixing and detrainment events driven by the higher frequency wind increase the exchange with deeper layers, generally balancing this out. 


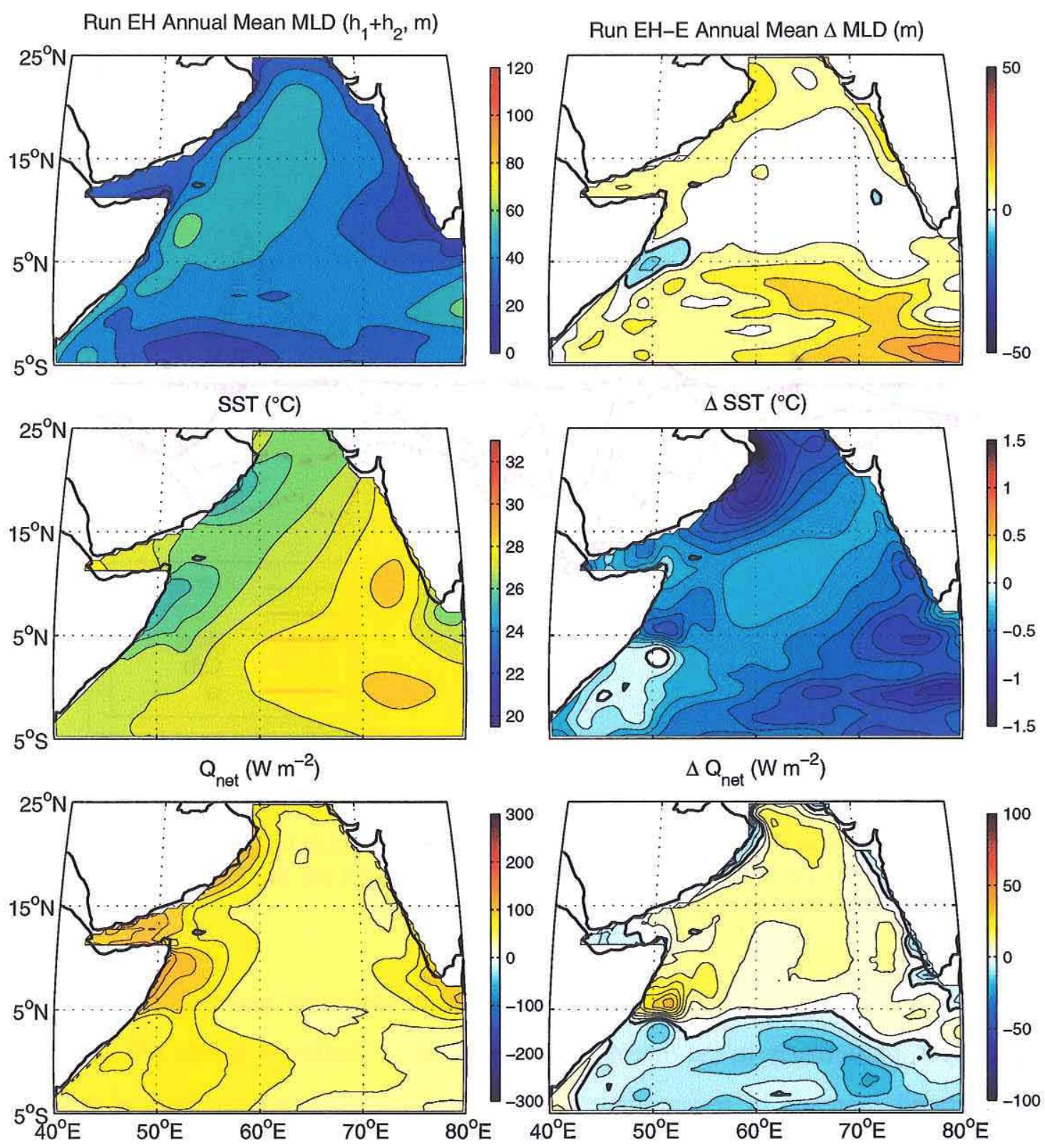

Figure 3.42 Annual mean run $\mathrm{EH}$ (left) and run $\mathrm{EH}$ - run E difference (right) of the thermodynamic variables. As in Fig. 3.22, except for runs $\mathrm{EH}$ and $\mathrm{E}$.

\subsubsection{Annual mean}

The annual mean differences in the model properties (Fig. 3.42) summarize the differences seen in each monsoon. In equatorial regions, the mixed layer is deeper, and the sea 


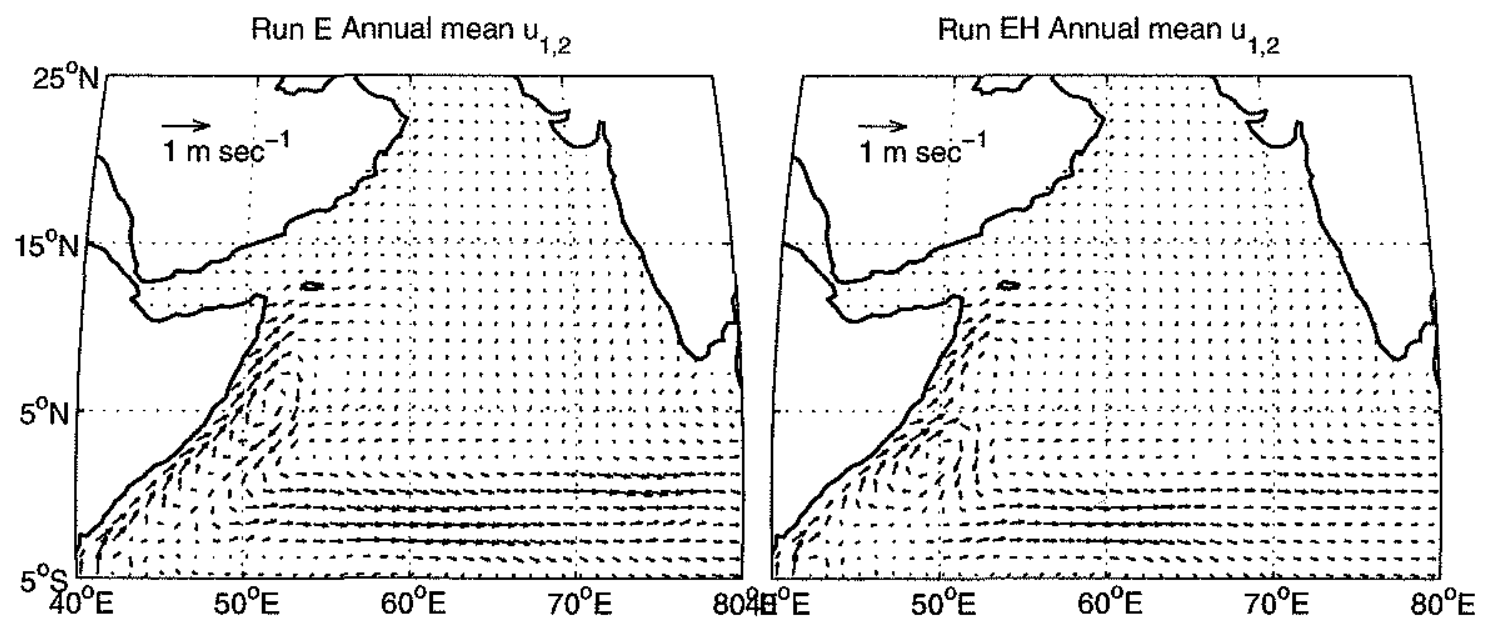

Figure 3.43 Annual mean Run E (left) and Run EH (right) surface layer velocity. The separation of the Great Whirl and the Southern Gyre is dependent on high time resolution of the wind stress field.

surface temperature cooler. The warmer NE monsoon SSTs that appeared in run EH are averaged out in the mean. Over the region of deepest mixed layers formed by the NE and SW monsoons, the mixed layer depths between runs are comparable, though the sea surface temperatures are moderately cooler. Over the entire basin, the mean annual SST in run $\mathrm{EH}$, with the high-frequency wind forcing, is a better match to the climatology (Fig. 3.10 ). There is a slight increase in the net surface heat flux north of $5^{\circ} \mathrm{N}$, and a slight decrease south of it. Both runs $\mathrm{E}\left(0.36 \mathrm{PW}\right.$ gain north of $\left.6.75^{\circ} \mathrm{N}\right)$ and $\mathrm{EH}(0.42 \mathrm{PW})$ have stronger net annual heat fluxes over the Arabian basin than runs F (0.28 PW) or FD (0.32 PW), and are larger than the estimate from the SOC climatology $(0.33 \mathrm{PW})$, although the difference must be discounted by the use of a particular year's wind field, rather than a climatological one.

A remarkable difference in the resulting model circulation is seen in the annual mean upper layer circulation. Run EH has a fully developed double-gyre system in the Somali current, with the Southern Gyre confined to below $5^{\circ} \mathrm{N}$ (centered about $3^{\circ} \mathrm{N}$ ) and the Great Whirl farther north, centered about $9^{\circ} \mathrm{N}$. Run E, in the mean, has only one gyre in the Somali current system. Run EH also has stronger upwelling along the Somali coast, 
though slightly reduced upwelling along the Arabian coast. The reason for this is not entirely clear, but McCreary and Kundu [1988] found that the formation and destruction of gyres in the Somali current system was very sensitive to both the spatial and temporal structure of the wind forcing.

\subsubsection{Meridional mass and heat transport}

The meridional overturning mass and heat transports have a similar structure to those forced by the FSU wind climatology, but the magnitude and details do have differences (compare Fig. 3.23 and Fig. 3.44).

The southward mass transport in the upper layer is reduced in runs $\mathrm{E}$ and $\mathrm{EH}$, peaking at about $4.5 \mathrm{~Sv}$ southward at $5^{\circ} \mathrm{N}$, rather than the $6 \mathrm{~Sv}$ southward found in runs $\mathrm{F}$ and FD. The addition of the high frequency wind does not change the mass transport much north of this point. The cell in the Arabian Sea is of a similar structure, with southward surface flow replaced by upwelling along the coasts (slightly stronger again at the Somali coast over the Arabian) drawn from layer 4, where northward mass transports fill the gap. The equator has a similar shallow double roll, but in this case, it is the southern roll that dominates and crosses the equator, with strong northward transports (peaking at $7 \mathrm{~Sv}$ ) in the upper layers, strong southward flows in layer 3, closed by upwelling to the south and downwelling to the north. The northern cell, which was dominant in run F, is much weaker. The introduction of high-frequency wind forcing makes this weaker northern cell essentially disappear, perhaps because the SG circulation has shifted somewhat southward. It is also likely due to the increased exchange between the surface layers and deeper layers on the intraseasonal time scale, reducing the dynamical independence of the layers. The southern roll remains, and so the cross-equatorial flow is northward at the surface in the mean, now matching the results found in higher vertical resolution modeling studies [Garternicht and Schott, 1997; Lee and Marotzke, 1998; Wacogne and Pacanowski, 1996].

The meridional heat budget is similar in structure to the mass budget, with a weaker southward transport in the upper layers and northward transport in the deeper layers than 

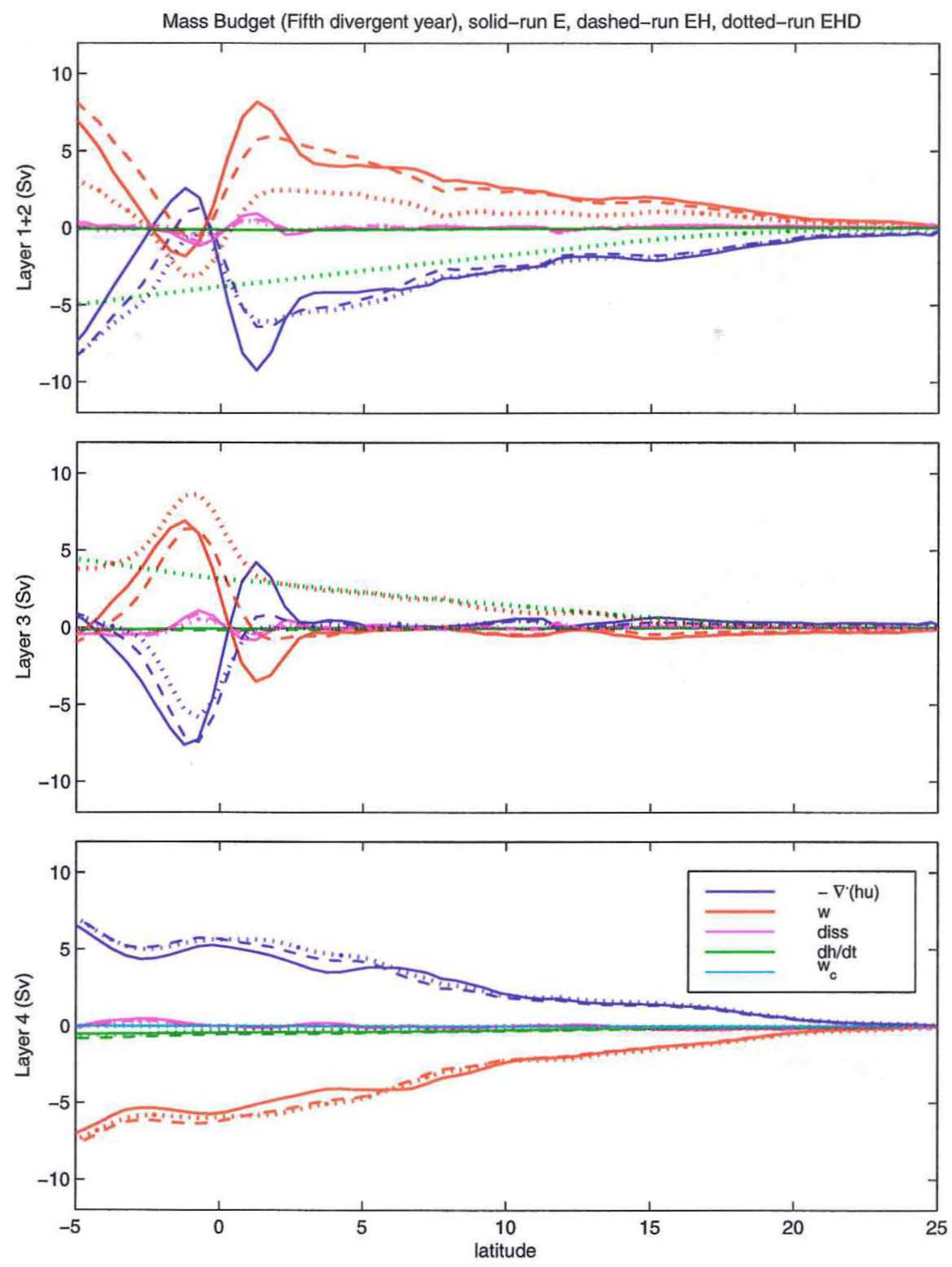

Figure 3.44 Terms in the annual mean mass budget, by layer, for runs E (solid), $\mathrm{EH}$ (dashed), and EHD (dotted). As in Fig. 3.23. 

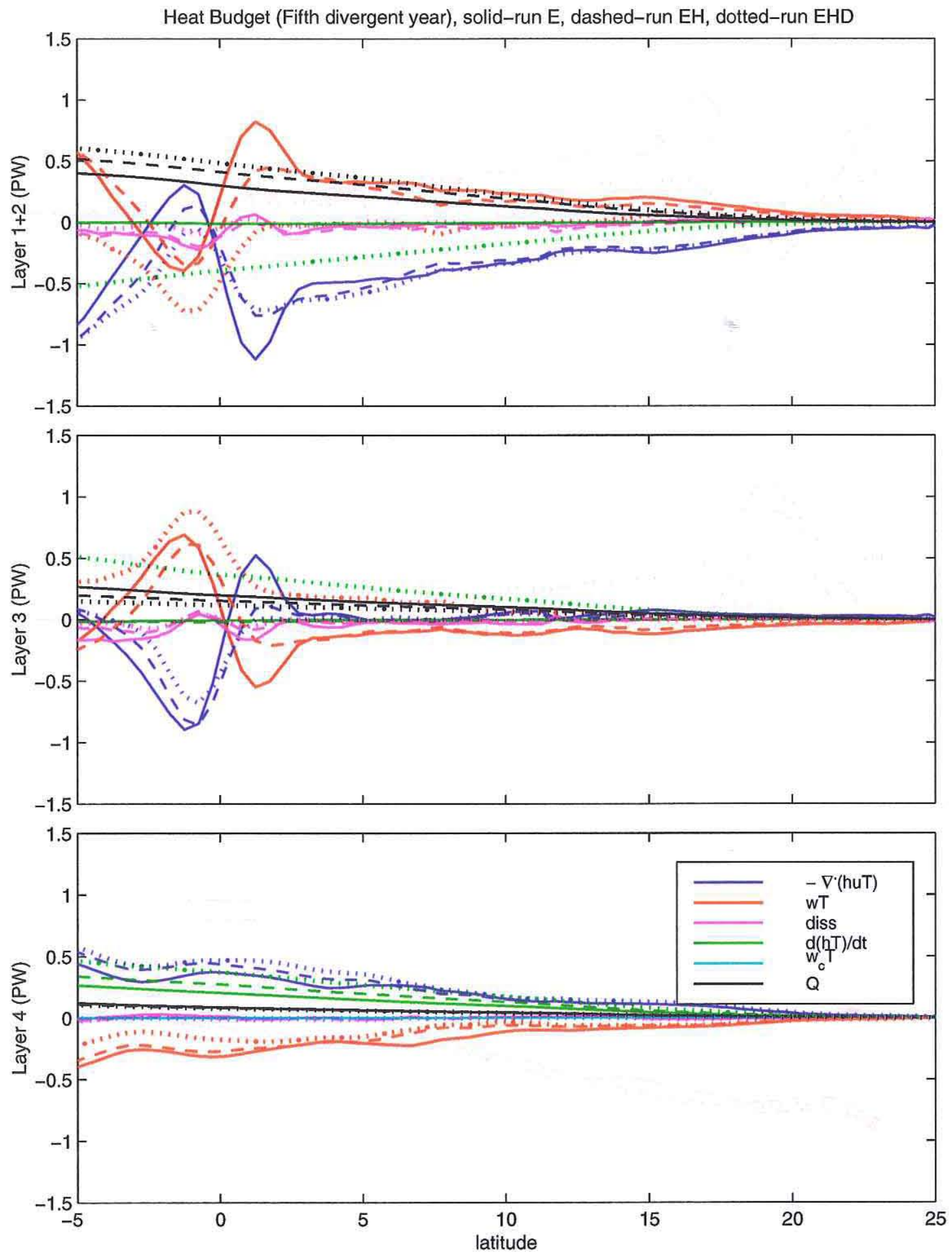

Figure 3.45 Terms in the annual mean heat budget, by layer, for runs $\mathrm{E}$ (solid), EH (dashed), and EHD (dotted). As in Fig. 3.24. 
runs F or FD. The heat flux is increased by the introduction of high-frequency winds. And in the net meridional heat transport summed across all layers of the model (Fig. 3.46), the southward transport of heat by the model circulation does not change much between runs, but is now reduced compared to runs $\mathrm{F}$ and $\mathrm{FD}$, and closer to the low end of estimates from other studies. The net heat flux through the surface, however, is increased in runs $\mathrm{E}$ and $\mathrm{EH}$ over $\mathrm{F}$ and $\mathrm{FD}$, and in run $\mathrm{EH}$ over run $\mathrm{E}$. The resulting net heat gain by the model over all layers is now even stronger, and grows stronger with the high-frequency winds, pulling the model further away from a steady state.

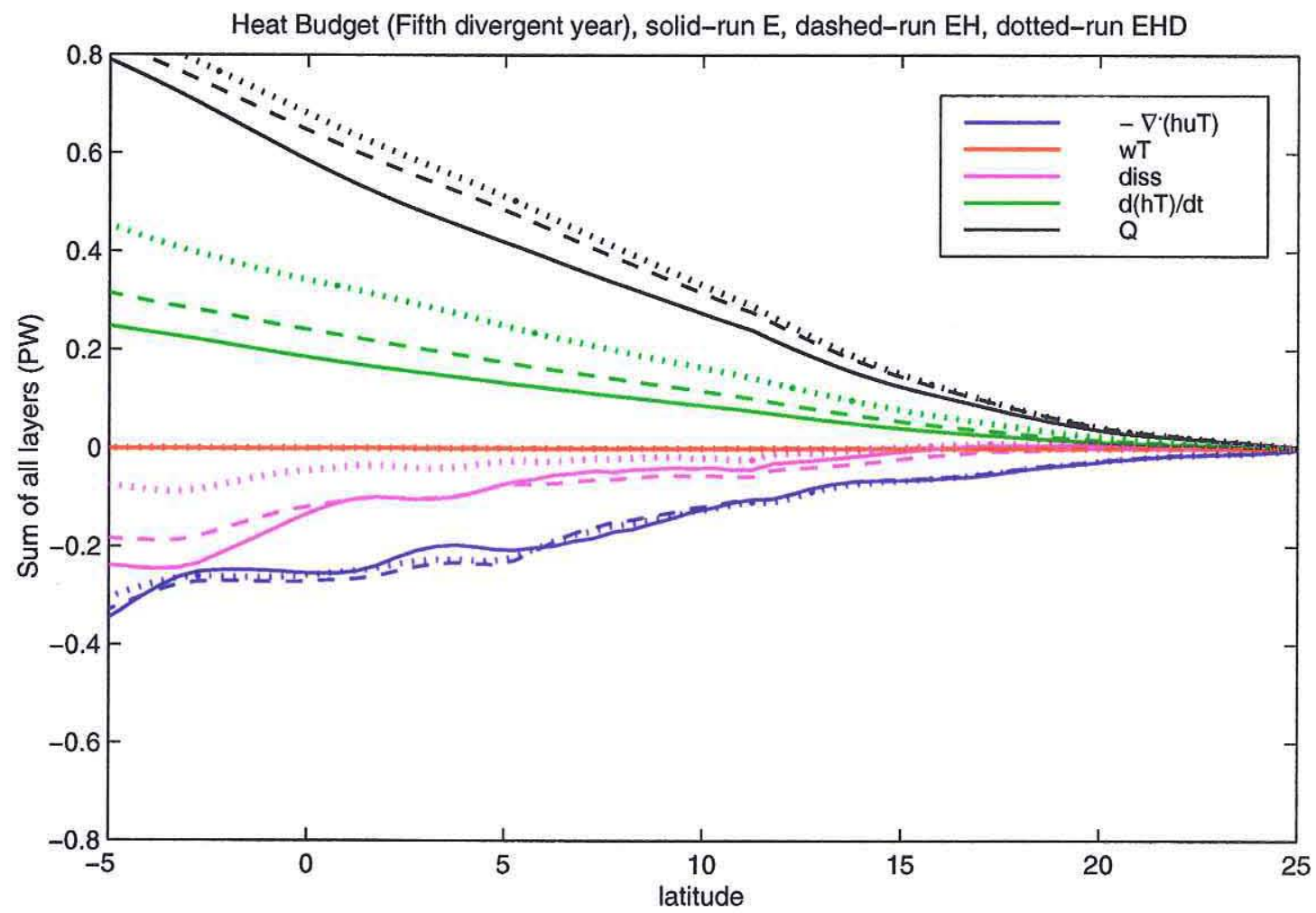

Figure 3.46 Terms in the annual mean heat budget, summed over all layers. As in Fig. 3.25. 


\subsubsection{Summary}

The biggest differences between the model solutions run with mean winds (run E) and high frequency resolved winds (run EH) are due to changes in the timing of mixing events, which generally came earlier in run $\mathrm{EH}$, and to the increased vertical exchange between the surface layers and deeper layers, both on the intraseasonal time scale driven by the high amount of variability in the winds, and driven by the additional mixing due to the resolved winds. While most of these changes were due to this local change in forcing, the increased exchange between layers from the high-frequency wind changed the surface layer depths in propagating, remotely forced features. In ways similar to the changes observed under diurnal forcing, the combination of local forcing on the changed surface layer depths changed predictions of mixed layer depths and surface temperature, particularly in near-equatorial regions.

The high frequency winds improved the Somali current system by resolving the double-gyre Great Whirl/Southern Gyre circulation, though there was no significant difference in the meridional mass or heat transport north of the equatorial region. The additional surface heating brought about by cooler SSTs actually worsened the net heat imbalance in the model, since the southward heat transport of the meridional overturning circulation did not change, while the net input of the surface heat flux increased.

\subsection{High frequency wind and diurnal heating}

The emphasis of this section is what additional effect the diurnal cycle has on top of high frequency wind forcing by adding the diurnal cycle in heat (3.21) to run $\mathrm{EH}$, creating run EHD. The effect of the diurnal cycle added to EH is very similar but muted when compared to its effect on run $\mathrm{F}$ (Section 3.4), since vertical exchanges between layers have already been enhanced by the high frequency wind forcing. 


\subsubsection{Monsoon seasons and annual mean circulation differences}

The addition of diurnal cycling during the SW monsoon tempers the gradients in mixed layer depth across the basin, with somewhat shallower mixed layer depths in the deep bowl in the central Arabian Sea and somewhat deeper mixed layer depths off the coast of India (Fig. 3.48 and Fig. 3.49). The sea surface temperatures are very similar to run EH, with only a slight further reduction in run EHD. The differences in the net surface heat flux are associated with the reduced differences in the mixed layer depth, and are not as strong as in run EH. Entrainment into the upper layer in the central portion of the basin during July is shut off with the addition of the diurnal cycle, though the differences in the circulation patterns change little from run EH.

During the NE monsoon, the central deep mixed layers are slightly deeper with the addition of diurnal cycling (Fig. 3.50 and Fig. 3.51). The changes in SST are minimal from run EH, though there is an increase in the heat loss in the northernmost portion of the Arabian Sea, off the coast of Oman and off the northern coast of India. This additional cooling drives additional tongues of convective entrainment.

In the annual mean (Fig. 3.51), the biggest differences in the thermodynamic fields are that the addition of diurnal cycling deepens the mean daily maximum mixed layer depths, and increases the net heat flux into the model, effects driven by local mixing processes.

\subsubsection{Buoy site}

The addition of diurnal cycling on top of the high-frequency winds at the mooring site increases the realism of the mixed layer depth prediction (compare Fig. 3.1 and Fig. 3.52). The mixed layer depth cycles diurnally, interrupted during the NE monsoon by synoptic variability in the winds, and during the SW monsoon by the strong winds. The daily maximum mixed layer depth is reduced even further over run EH because of the local effect of the diurnal cycling. The sudden shoaling of the mixed layer found in the moored record but missing in the model solution at the end of July is the most glaring 

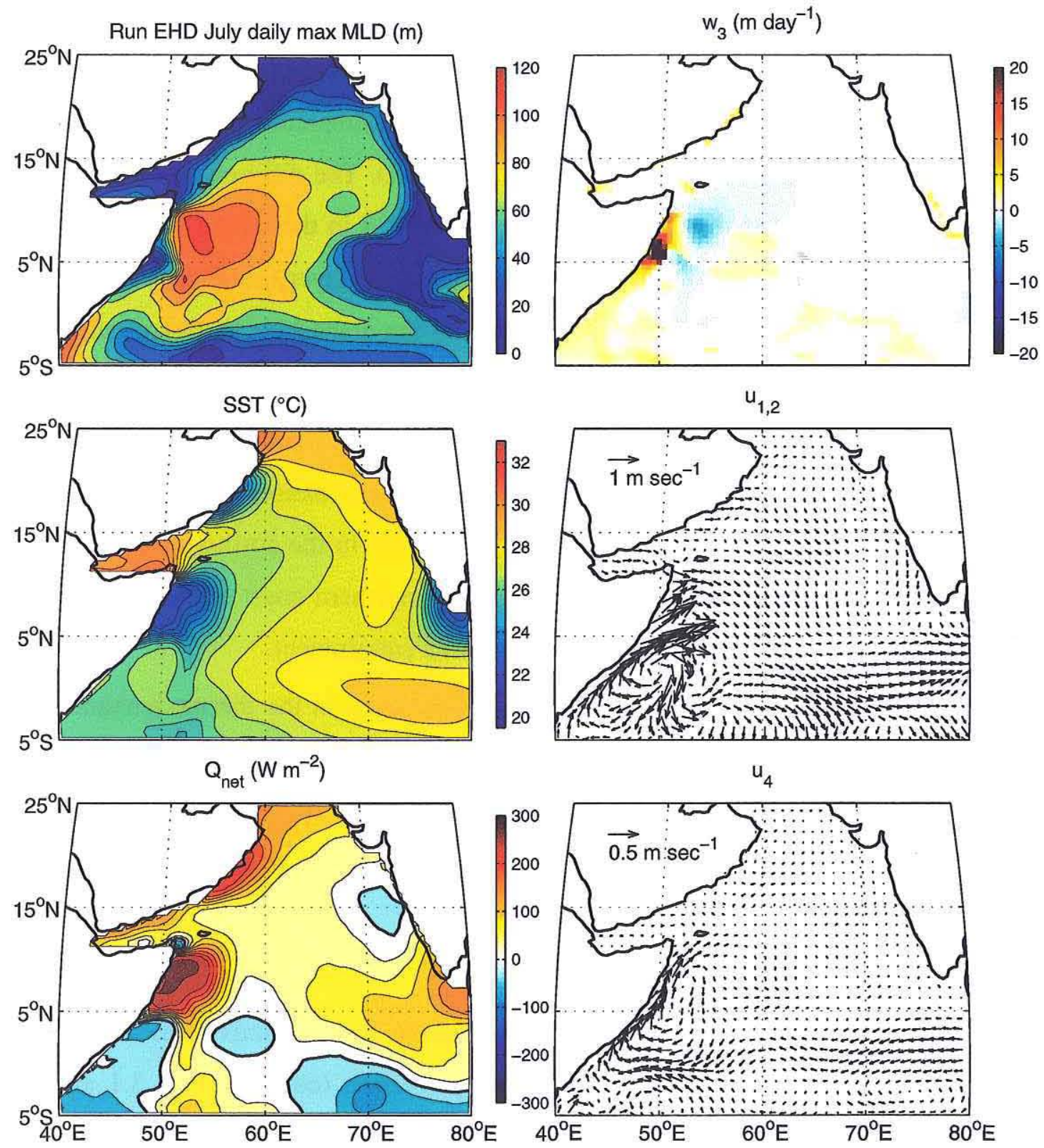

Figure 3.47 July Run EHD. As in Fig. 3.29, except run EHD. 

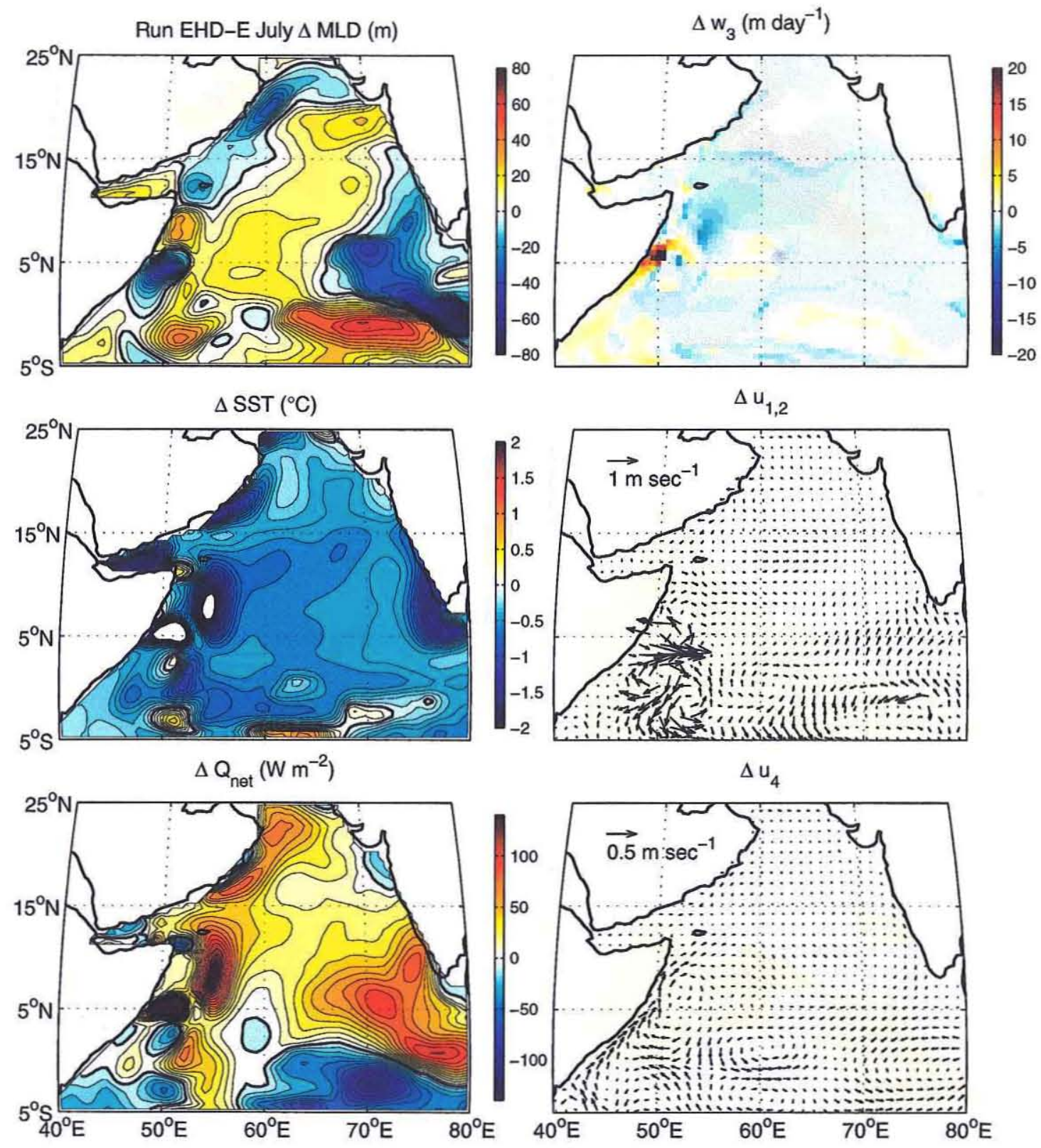

Figure 3.48 July difference run EHD - run E. As in Fig. 3.32, except for runs EHD and $\mathrm{E}$. 

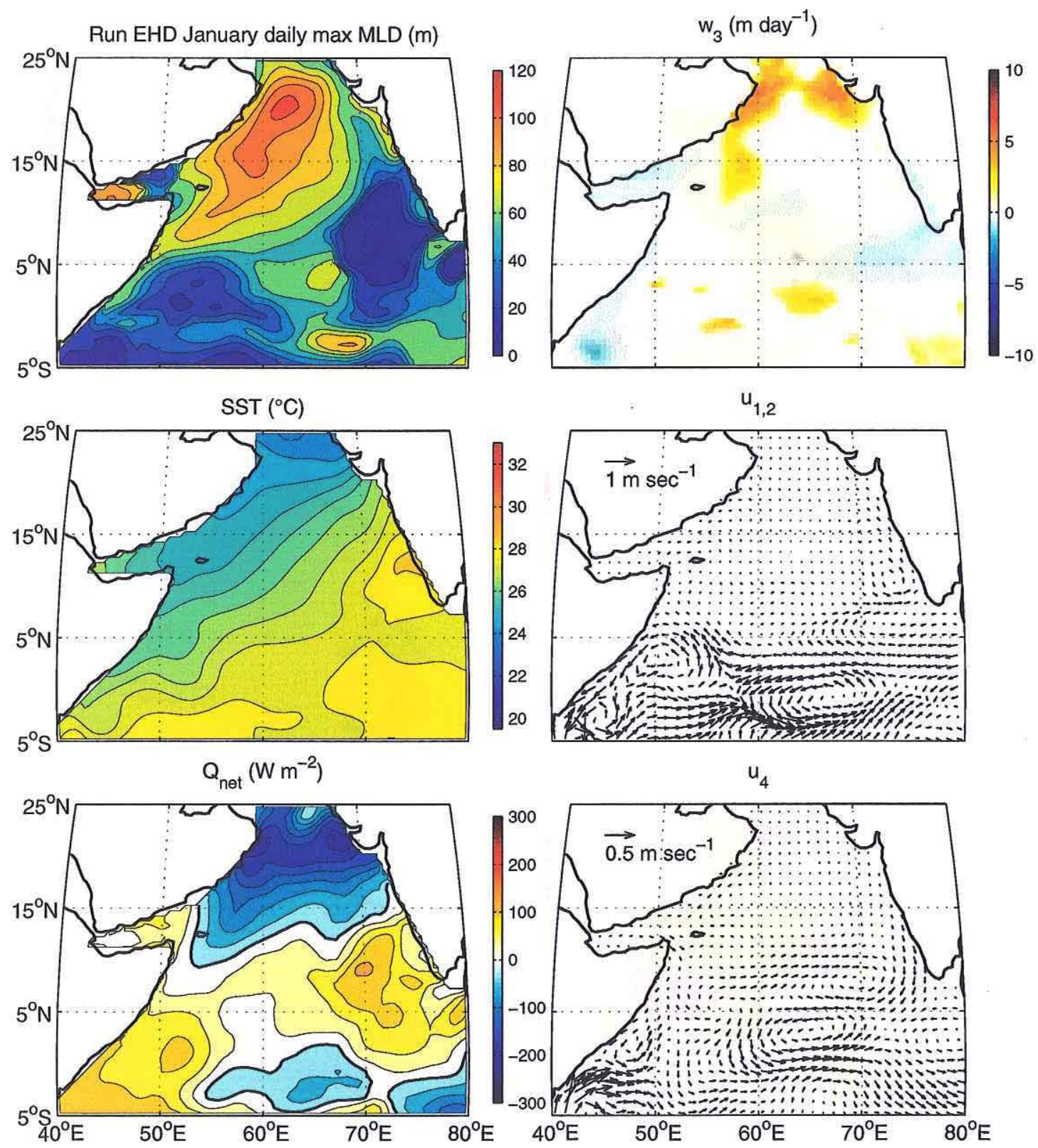

Figure 3.49 January Run EHD. As in Fig. 3.30, except for run EHD. 

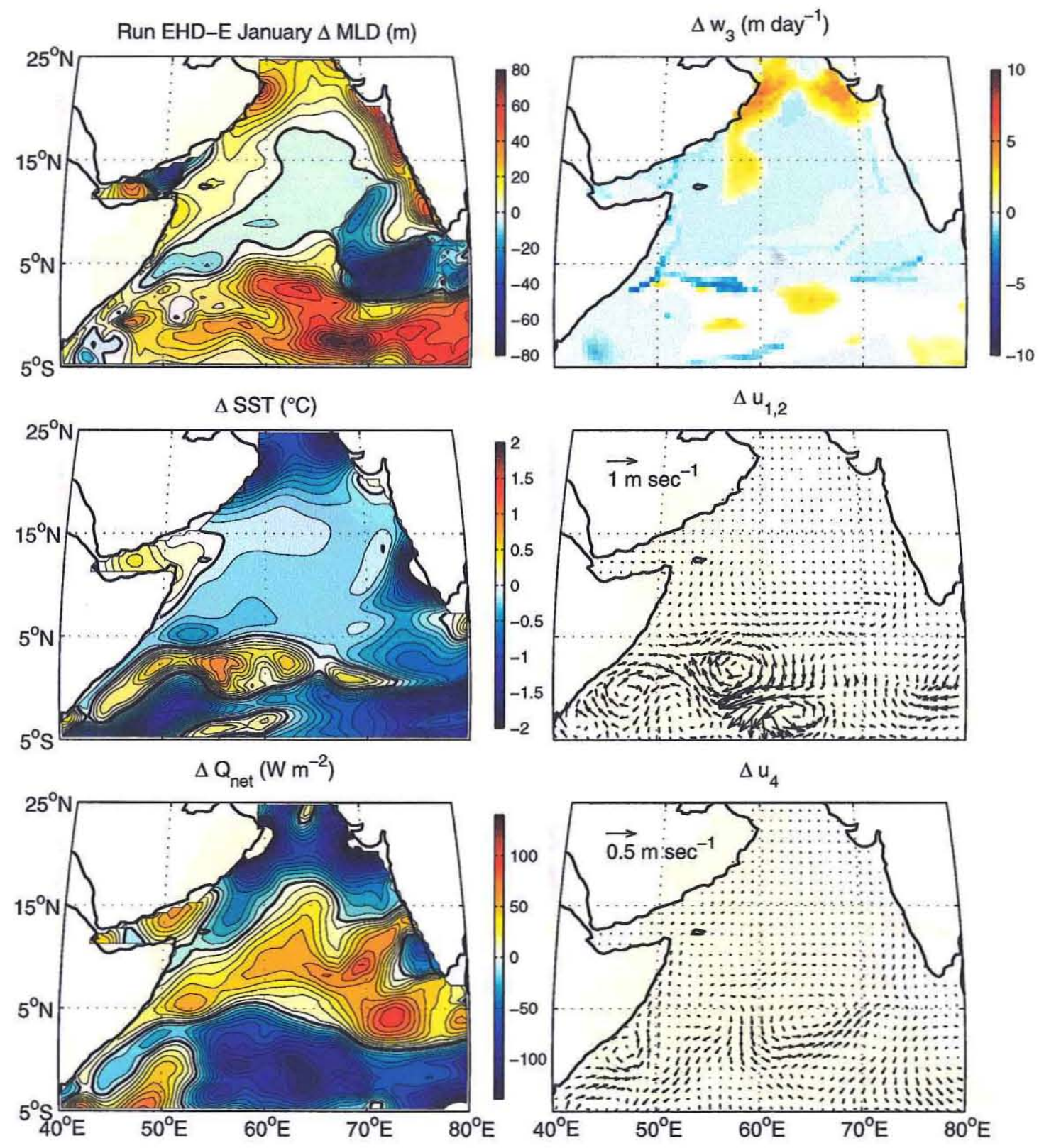

Figure 3.50 January difference run EHD - run E. As in Fig. 3.36, except for runs EHD and E. 


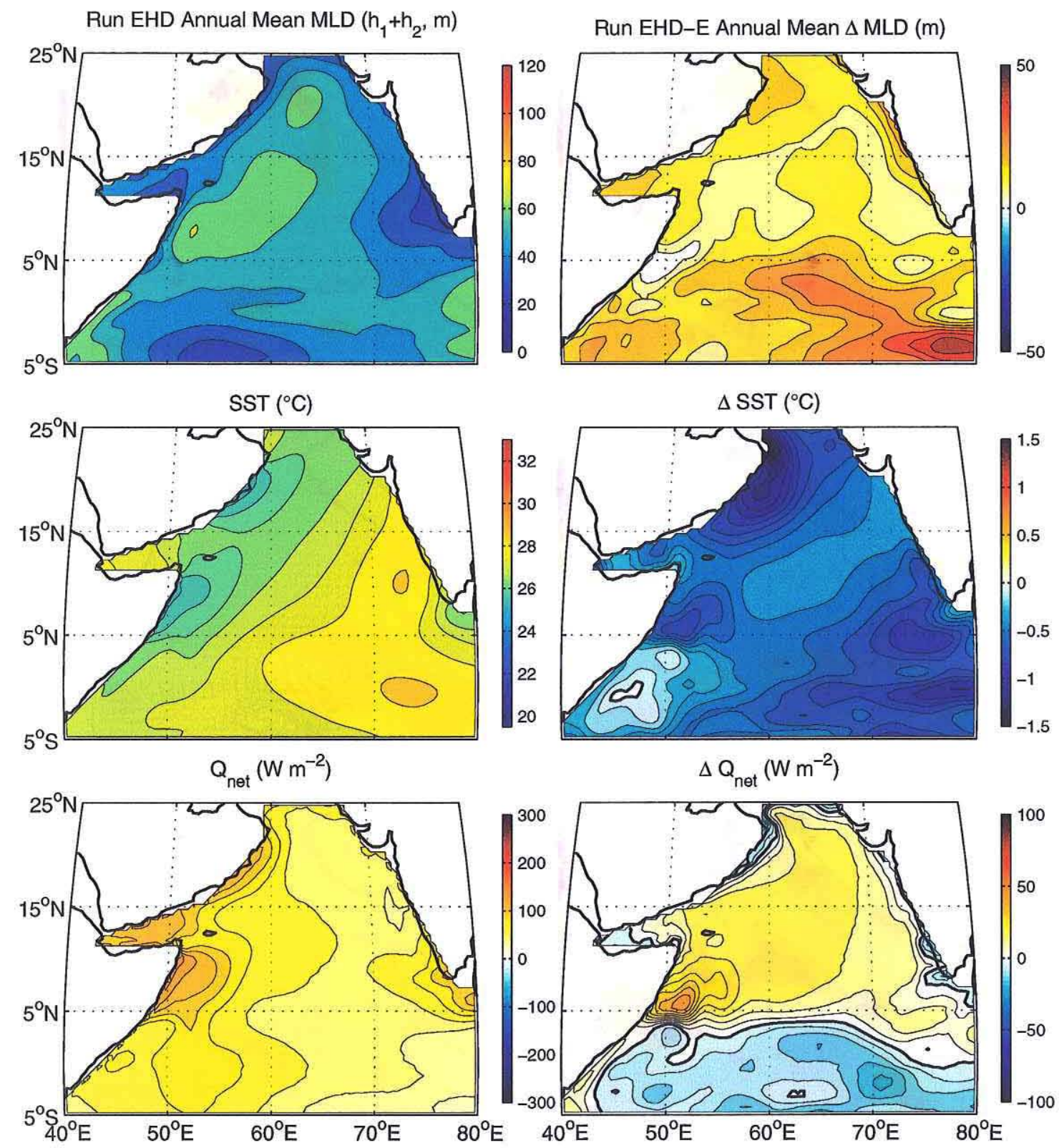

Figure 3.51 Annual mean run EHD (left), difference run EHD - run E (right) thermodynamic variables. As in Fig. 3.42, except for runs EHD and E. 

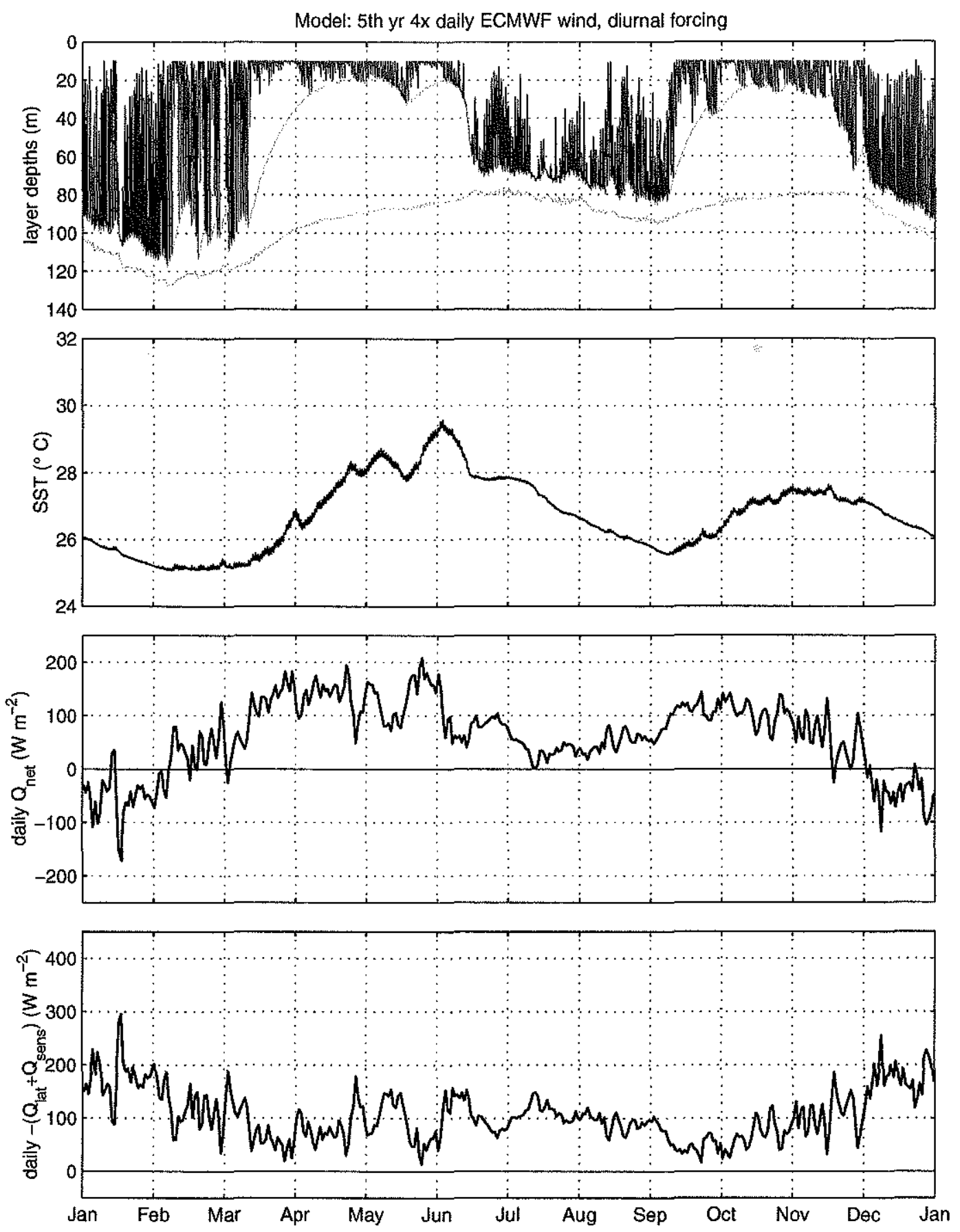

04-Aug-2000/data3/afischer/mcmodel/plot_current current_4panel_ed5.m

Figure 3.52 Run EHD model solution at the mooring site. As in Fig. 3.39 except for run EHD. 
deficiency, since the sharp horizontal heat fluxes off the Arabian coast are not reproduced in the model. The surface layer temperature budget shows virtually no change in the temperature evolution with the addition of the diurnal cycle (dotted lines, Fig. 3.41), though the balance between heating and entrainment is more extreme, for the same reasons as Section 3.4.4.

The surface temperature prediction is lowered during the intermonsoon, and associated with this the surface heat flux is increased during these time periods. This surface temperature evolution in the model driven by higher frequencies does not match the observed temperatures (Fig. 3.1) on the seasonal time scale as well as the model driven by lower frequency forcing (Fig. 3.11 for example). Why is this? Both diurnal and highfrequency forcing work to increase the mixing of temperature and other properties with deeper layers. While there is some evidence that this occurs outside of the model, the model is likely too sensitive to the diurnal cycling (see Chapter 4). Since the deeper layers, which represent a large range of water temperatures with one temperature, are fairly thick, water detrained into them is necessarily represented by the model to have mixed to the mean depth of the layer, too deep. This is a consequence of the low vertical resolution of the model. With mean surface forcing this exchange between layers is less than with diurnal heat and high frequency wind forcing, and so the layer formulation presents less of a problem.

\subsubsection{Meridional mass and heat transport}

The changes to the meridional mass and heat budgets with the addition of the diurnal cycle are familiar from Section 3.4.6. The major difference is the transfer of mass (dotted lines in Fig. 3.44), and so a transfer of heat (dotted lines in Fig. 3.45), from layer 3 to the surface layers. The northern and weaker equatorial roll was damped by the high frequency wind forcing, and so the stronger southern cell remains, transporting surface water northward across the equator.

In the sum of all the layers, the net southward heat transport by the model remains virtually unchanged by the addition of the diurnal cycle. But a mild increase in the net 
surface heat flux and a decrease in heat lost to dissipation (the diurnal cycling appears to smooth gradients in the surface layer depth and temperature fields) yields a significantly stronger heat gain by the model over the Arabian Sea, worsening the imbalance between surface and southward heat transport.

\subsection{Summary and discussion}

High frequency forcing in the form of the diurnal solar heating cycle and high time resolution of wind forcing does create significant differences in predictions of SST and upper layer heat content, as well as changes in the circulation. The biggest changes occur seasonally rather than annually, but there were significant changes in the annual mean predictions of sea surface temperature, mixed layer depth, and current circulation introduced by the high frequency forcing.

The addition of the diurnal cycle locally forced additional exchange between the surface and deeper layers. Physically this is expected, as penetrative nighttime convection and diurnally-modulated velocity shear both act to increase vertical mixing below the mixed layer, and thus modify the mixed layer evolution (Section 3.1.2.3, and further explored in Chapter 4). In the model, however, this additional vertical exchange was driven by an 'accidental parameterization' due to the vertical diurnal movement of the diurnal thermocline-seasonal thermocline layer interface, as neither penetrative convection nor resolved vertical shear are present in the KT parameterization. In addition to reducing SSTs when the surface fluxes were the dominant dynamic, the additional vertical exchange damped the alternating currents associated with coastal-upwelling-generated, propagating mode- 2 Rossby wave packets by mixing momentum vertically. The resulting reduced layer depth disturbances, propagated far westward during the NE monsoon, then interacted with the local surface forcing and wind-driven Ekman divergence, in near-equatorial regions particularly. The addition of the diurnal cycle then served to increase SSTs, as the increased-depth surface layers, driven by the same upwelling-favorable winds, did not cool as dramatically. 
The high-frequency wind forcing, which has additional turbulent energy available for entrainment at the mixed layer base (not an 'accidental parameterization,' but an explicit one), also served to increase the vertical exchanges in the model. When the model dynamics were primarily locally surface-driven, the additional vertical exchange cooled SSTs and increased the surface heat flux, and did this in the annual mean as well. The increased vertical exchanges had a similar effect as the diurnal cycle on the propagation of the coastally-generated Rossby wave packets. The high-frequency winds also yielded a clearer separation of the Southern Gyre and Great Whirl in the model Somali current system.

In addition to effects on the vertical mixing, higher frequency winds have higher wavenumber forcing as well, with potential effects on the circulation. Large et al. [1991] found that high frequency winds (1 day resolution) increased the kinetic energy and excited barotropic waves in a layered quasi-geostrophic (QG) model of the N. Pacific, but that the baroclinic fields and the mean flows had nearly no change from the monthly mean forced model. In a higher resolution QG model of the N. Atlantic with high wavenumber wind forcing, Miliff et al. [1996] found an increase in mean and kinetic energies in the eastern basin, and an improved response due to the resolution of upwelling/downwelling wind stress features on the eastern boundary. So some of the difference with the addition of high frequency wind forcing could be due to these global changes rather than a local increase in vertical mixing, though the baroclinic nature of the model used here makes this less likely.

While the high frequency wind forcing energized the currents, the net transport across latitude lines changed to a much lesser extent, and outside of the tropics there is little change overall. In line with the idea that the meridional heat transport is largely wind driven Garternicht and Schott [1997] found a very good correlation between the zonally averaged wind stress and the meridional heat transport in latitude. Here, the mean zonally averaged wind stress changed only once, between runs F and FD and runs E, EH, and EHD. The meridional heat transports in these runs only changed significantly with the change in the mean wind from FSU to ECMWF forcing. 
Though the expected changes were primarily due to changes in the locally-driven vertical exchange, and many of the changes were associated with this, some of the largest changes were more complicated. They involved changes in coastal upwelling and subsequent wave propagation interacting with local surface forcing, fully dependent on the three dimensions of freedom in the model. Seasonally, the most sensitive regions to the addition of high frequency forcing were the lowest latitudes, particularly the band spanning $5^{\circ} \mathrm{S}$ to $5^{\circ} \mathrm{N}$. Increased variability in the surface forcing, and thus additional vertical exchange, muted the propagating signal of Indian coastal upwelling in the surface layers under both diurnal forcing and high frequency wind forcing.

At the site of the mooring, wind-driven mixing appears to deepen less, and have a slower deepening and recovery time, when forced with the diurnal cycle. When the resolved ECMWF winds were added, the prediction of mixed layer depth by the model at the mooring site was quite good, with the largest differences attributable to the difference between the sharp and sudden horizontal advection observed in the data and the broad, weaker horizontal advection of coastally upwelled water produced by the model.

How large are these changes imposed by the diurnal cycle and high-frequency wind forcing, when compared to changes that might be imposed by uncertainties in the forcing fields themselves? Weller et al. [1998] found climatological and analysis wind stresses up to $30 \%$ stronger or weaker than observed at the moored array during the SW monsoon. Climatological and analysis surface heat fluxes also differed by up to $100 \mathrm{~W} \mathrm{~m}^{-2}$ in the mean over the SW monsoon (the buoy mean was $89.5 \mathrm{~W} \mathrm{~m}^{-2}$ ). The different wind products used in Section 3.3 and Section 3.5 allow an examination of the sensitivity of the model to surface forcing generally. The difference between the FSU July climatological wind stress (used in run F) and the ECMWF July 1995 wind stress (used in run E) are shown in the upper left panel of Fig. 3.53. There are significant differences in the two, likely due to both the difference between the 1995 and climatological winds and different processing algorithms. In the core of the Finlater Jet, ECMWF wind stresses are up to $20 \%$ stronger than the FSU wind stresses, particularly along the Somali coast. Along the Arabian coast, the ECMWF wind stresses are reduced by $40-50 \%$. In equatorial regions, 

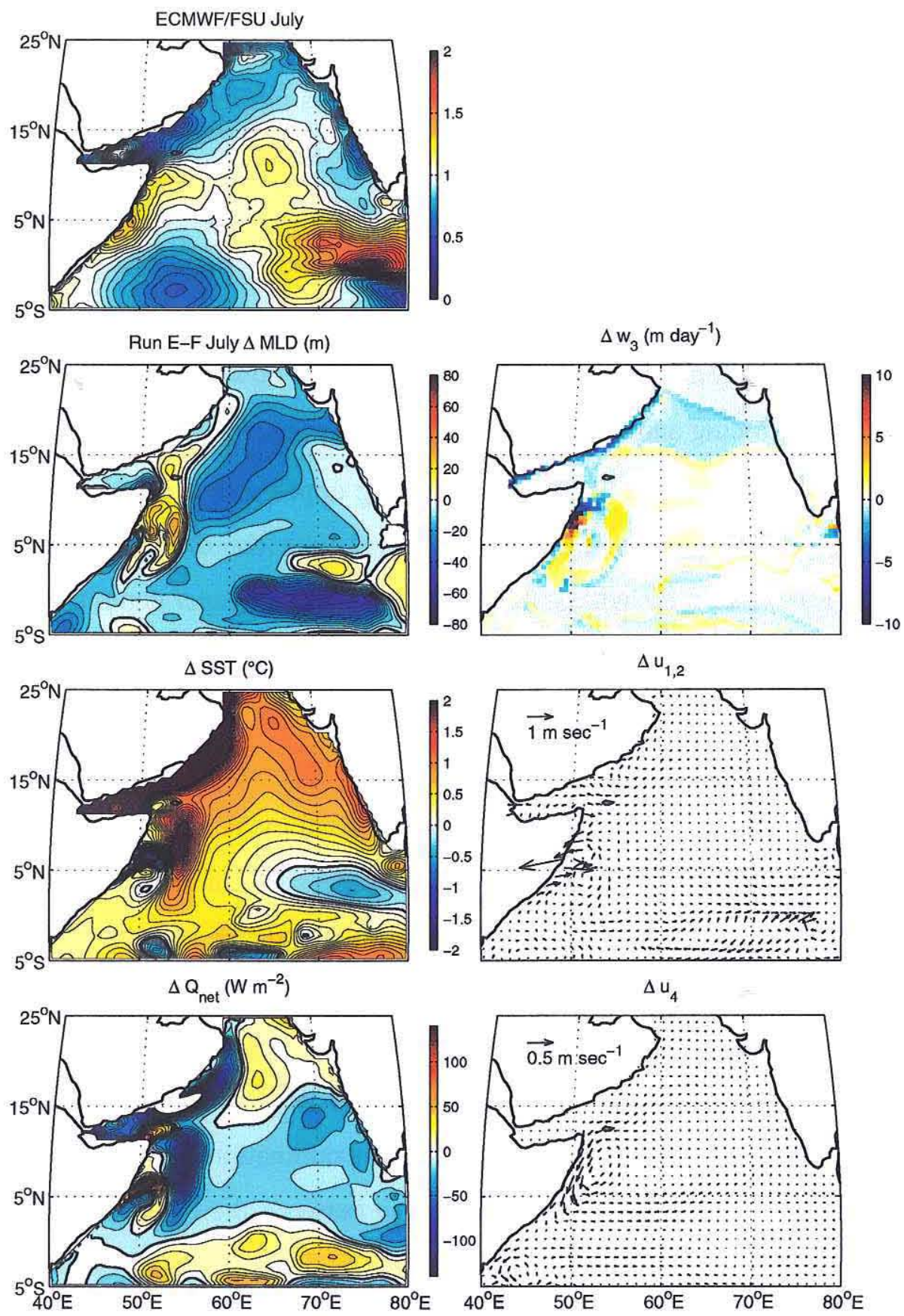

Figure 3.53 An overview of the differences between the model run $\mathrm{E}$ and model run F in July. The top left panel shows the scaled difference in the wind stress magnitude fields (ECMWF July 1995 divided by FSU July climatology, contours every 0.05 , see Fig. 3.28 for the original fields): the ECMWF Findlater Jet is stronger, and more concentrated spatially than the FSU climatology. The rest of the panels are as in Fig. 3.14 and Fig. 3.32. 
there is a dipole pattern in the difference, with ECMWF winds $40 \%$ weaker in the west, and $50-100 \%$ stronger in the east, though the original winds are quite weak (see Fig. 3.28).

Under the Findlater Jet, the increased wind stress in run $\mathrm{E}$ yields a broader region of deeper mixed layers near the Somali coast, with differences up to $25 \mathrm{~m}$ in depth. Across much of the rest of the basin, mixed layers are between 10 and $25 \mathrm{~m}$ shallower in run $\mathrm{E}$, with the largest differences associated with somewhat reduced wind stress forcing in run E. The greatest sensitivity in SST comes along the Arabian coast, where much reduced wind stresses in run $E$ drive much less upwelling. As a consequence, the intense heat losses associated with the upwelling are reduced, and run $E$ has a much weaker heat gain in these regions. These changes in MLD and SST due to the change in wind stress (run EF) are much stronger than the changes introduced by diurnal cycling (see Fig. 3.14), but comparable to the changes introduced by high-frequency winds (see Fig. 3.32).

Despite the peak ECMWF winds being stronger than FSU, the FSU wind stress eastward component over the central $\left(5-15^{\circ} \mathrm{N}\right)$ Arabian Sea is about $7 \%$ stronger than ECMWF in July, a difference that is even more dramatic in other months (60\% in June, $30 \%$ in August). The meridional overturning circulation, driven by southward Ekman flow during the SW monsoon, is likewise stronger, by nearly $35 \%$ in the annual average at $10^{\circ} \mathrm{N}$ (see Fig. 3.23 and Fig. 3.44). The increase in the overturning circulation brought by the change in wind stress forcing is larger than any difference observed either with the addition of the diumal cycle or the addition of high-frequency wind forcing.

Two things can be learned from this analysis of the model sensitivity. The first is that the differences between surface forcing products can be large, and the resulting differences in model solutions are as large or larger than any differences brought by the diurnal cycle or high-frequency wind forcing. Increasing the accuracy of the surface fluxes is thus quite important in our future ability to predict the upper ocean evolution and largescale heat transports. The second is that the changes brought by high-frequency wind forcing are much larger than those brought by the diurnal cycle, and more comparable to the sensitivity of the model to uncertainties in the surface forcing. There is increasing 
availability of both high-frequency wind analyses and data (from scatterometer missions). The results of this work suggest that the use of this high-frequency wind forcing data, or a better parameterization of how high-frequency winds affect vertical mixing processes, are important to prediction of the upper ocean evolution.

Ultimately, how important are these changes? The sea surface temperature and surface heat flux are very important in the prediction of the coupled atmosphere ocean system. The model has a very primitive form of atmospheric coupling, with sensible and latent heat fluxes that are developed based on the freely evolving model sea surface temperature. In a fully coupled model, the changes in SST and in the heat content of the upper ocean that were observed with the addition of higher frequency surface forcing could significantly change model predictions.

In seeking to use a fairly simple model that could be easily interpreted, and run under a number of different surface forcings, there are some limitations introduced that must be noted. One primary limitation is the question of whether the response of the model under diurnal cycling is physically realistic. The increased exchange between surface and deeper layers in the model under diurnal cycling were driven by an 'accidental' parameterization of sub-mixed layer mixing processes due to the model formulation. This question is addressed in the next chapter, which isolates the effect of the diurnal cycling on the vertical mixing and predictions of SST in various one-dimensional upper ocean models with increasing amounts of physical realism.

The levels of horizontal dissipation of momentum and temperature in the model are quite high, perhaps beyond what is strictly necessary for numerical stability. A reduction of this dissipation would increase the nonlinearity of the model, and would certainly affect the changes under the different surface forcings. Whether the increased nonlinearity would create larger changes in the mean is not clear, and certainly warrants further investigation. Perhaps more importantly, the model suffers from an annual mean imbalances in the overall heat budget, with each model solution presented here gaining heat through the year. The meridional overturning circulation forced by the wind is simply not strong enough to carry the strong net heat gain into the ocean southward. Since the addi- 
tion of both the diurnal cycle and high-frequency wind forcing reduced sea surface temperatures by increasing mixing, this imbalance grew as the net surface heat flux over the Arabian basin increased. How the apparent mismatch between the net surface heating and the wind-driven meridional heat transport produced by the model, worsened by both the addition of the diurnal cycle and high-frequency wind forcing, is closed in remains an open question. In the model the existence of the mean meridional overturning circulation is dependent on the entrainment and detrainment processes in and out of deeper layers, and changes to these parameterizations ((3.11), (3.16), and (3.18)) would modify its strength.

The westward propagation of Rossby wave features in the model is slower than the observations presented in Chapter 2. The primary Rossby wave mode excited in the model was mode-2, with currents out of phase in layers 1 and 4 . The moored record, which had some measurements below the thermocline [Fischer, 1997] showed that the velocities associated with the mesoscale eddies were mode-1, with surface-intensified velocities. The observed westward propagation also agreed well with a linear phase speed for mode-1 baroclinic Rossby waves. The small number of vertical degrees of freedom, as well as the reduced gravity formulation with no exchanges with the abyssal ocean, are further limitations of the model used.

The model also lacks any connection with the Pacific, there is no Indonesian Through Flow (ITF). However, a number of studies have shown that the primary influence of the ITF occurs at latitudes south of the ITF (at about $10^{\circ} \mathrm{S}$ ), and particularly along the southwestern boundary of the Indian Ocean domain [McCreary et al., 1993; Murtugudde et al., 1998]. Its absence in the model, for the region I have studied intensely, is then not that problematic.

Despite a number of open question that would prove fruitful avenues for further work, the model results here demonstrate that the diurnal cycle and high frequency (shorter than monthly time scale) winds have significant effects on the evolution of the upper ocean circulation and properties in the Arabian Sea. In this model the high-frequency winds were crucial in the development of the two-gyre Great Whirl/Southern Gyre system of 
the Somali current, and the additional vertical exchange driven by both the diurnal heating and the winds contributed to deeper mixed layer depths and often cooler sea surface temperatures. In equatorial regions, interactions between the surface forcing and remotely propagated features provided some of the largest differences between mean and high-frequency-forced runs. Significant changes in the model-generated surface fluxes and heat content of the upper layers suggest that these differences could be significant in the fully coupled atmospheric-oceanic climate problem. 


\section{Chapter 4}

\section{Sub-mixed layer mixing in one-dimensional upper ocean models}

\subsection{Introduction}

The addition of diurnal variability in the surface heat flux to a regional model of the Arabian Sea and Indian Ocean (Chapter 3) generally acted to increase vertical exchange into the mixed layer and cool sea surface temperatures. In the adaptive heat flux formulation used in that model, the cooler SSTs drove increased heat fluxes. The differences were increased on the seasonal time scale, though changes in the interactions between the locally surface-driven exchange processes and remotely propagated signals sometimes reversed the trend, leading to less upwelling and warmer SSTs with diurnal cycling. In a hint of problems with the model's parameterization of vertical exchange processes, the net exchange between the surface and seasonal thermocline layers did not reach an annual equilibrium. And the increased vertical exchange was dependent on an 'accidental parameterization' of sub-mixed layer exchange, due to the particulars of the model's layer representation of the diurnal thermocline.

My objective in this chapter is to examine more carefully the physical and model processes involved in the increased vertical mixing driven by the diurnal cycle, and to evalu- 
ate how sensitive the results obtained in Chapter 3 are to the particular model physics and parameterizations used, separate from the horizontally non-homogeneous processes that were also acting on the mixed layer.

The approach will be to use three different one-dimensional mixed layer models with varying representations of upper ocean physics, and to force them under idealized conditions and under the typical seasonal cycle in the Arabian Sea. The first model is a 1-D representation of the Kraus-Turner (Kraus and Turner [1967]) physics and vertical layer structure from the 3-D model used in Chapter 3. The second is the Price et al. [1986] (PWP) model, whose use first motivated the investigation in Chapter 3. And the last is the K-profile parameterization (KPP) model of Large et al. [1994]. All have been compared, to some extent, with observations of the mixed layer evolution under the influence of the diurnal cycle. The KPP model, in particular, has been compared to large-eddy simulations (LES) of the diurnal cycle in the equatorial ocean [Large and Gent, 1999]. It was found that the KPP mixing scheme generated daily average turbulent fluxes that compared favorably with the LES results, which in turn, compared favorably with observations of turbulent dissipation rates in the equatorial ocean through the diurnal cycle [Wang et al., 1998]. In addition, the KPP model has greater representation of physical processes than either the PWP or the KT models, and so serves as a sort of touchstone in the comparisons.

The analysis of the model runs will additionally yield insight into what physical (or model) processes are at work in creating the difference between diurnally- and meanforced runs, and how sensitive these differences are to different model formulations.

\subsection{The models}

A slab-type and two fixed-grid models are used, the first to compare with the threedimensional modeling in Chapter 3, and the others because they are widely-cited and used models of the mixed layer, and incorporate more physical processes in their parameterization of the mixing which affects the evolution of the mixed layer. 
All three models account for a penetrative solar flux, using a double exponential profile of absorption,

$$
I(z)=I(0)\left[I_{1} e^{z / \lambda_{1}}+I_{2} e^{z / \lambda_{2}}\right]
$$

where $I$ is the solar insolation, $z=0$ at the surface and is positive upwards, and the subscripts 1 and 2 refer to shortwave and longwave components of the solar radiation. For typical fairly clear, mid-ocean water (Jerlov [1976] type IA), the values used in the models are given by Paulson and Simpson [1977]

$$
\begin{array}{ll}
I_{1}=0.62 & \lambda_{1}=0.6 \mathrm{~m} \\
I_{2}=1-0.62 & \lambda_{2}=20 \mathrm{~m}
\end{array}
$$

In the slab model, the shortwave radiation is parameterized to be entirely absorbed within the first layer, which has a minimum depth of $10 \mathrm{~m}$. The outgoing surface heat fluxes (longwave, latent and sensible) are removed from the surface layer in all three models.

In the experiments described below, each model is initialized with the same initial condition (as close as possible for the low-resolution layered representation), and forced with the same surface forcing. Any difference is then a result of the physical processes as represented by the models.

\subsubsection{McCreary KT layered formulation}

In order to compare directly with the three-dimensional modeling results presented in Chapter 3, a one-dimensional version of the vertical entrainment/detrainment processes in the three-dimensional model was constructed. The mixed layer itself is described by a Kraus-Turner [Kraus and Turner, 1967] parameterization. Below the mixed layer is the diurnal thermocline layer, which carries information about the deep nighttime mixed layer through the daylight hours, when the mixed layer has shoaled due to solar heating. Entrainment out of the seasonal and permanent thermocline layers, below, is forced to keep the layers above from dropping below minimum depths. In the three-dimensional model, entrainment can be forced by Ekman transports which either create divergence 
from the fixed boundary of the coast, or open-ocean divergence and upwelling. Detrainment (subduction) into the lower two layers is parameterized. A full description of the model equations is given in Chapter 3. The sub-mixed layer detrainment and entrainment processes in turn affect the evolution of the mixed layer by mixing properties between the lower layers. In the one-dimensional model, the oceanic velocity structure is irrelevant, since it does not come into play in the Kraus-Turner or other parameterizations, and so momentum need not be calculated.

\subsubsection{PWP model}

The PWP model [Price et al., 1986] is resolved on a fixed-depth high resolution grid, and relies on three fairly simple criterion for all vertical mixing. The first criterion is for static stability $\rho_{z}<0$, which triggers mixing from the surface if violated. Density is calculated from the model temperature (and optionally salinity, neglected here) prediction. This creates a region of entirely uniform properties starting at the surface. The second criterion is a bulk Richardson mixing, which maintains

$$
R_{b}=\frac{g \Delta \rho h}{\rho_{0}(\Delta \bar{u})^{2}}<0.65
$$

for the mixed layer. The $\Delta$ refers to the difference between bottom of the mixed layer and the value immediately below. The final mixing criterion is a gradient Richardson number,

$$
R_{g}=\frac{N^{2}}{\left(\bar{u}_{z}\right)^{2}}<0.25 \text {, }
$$

where $N^{2}$ is the buoyancy frequency $\left(N^{2}=g / \rho_{0} \rho_{z}\right)$ and $\vec{u}$ is the velocity. During the evolution of the model, layers below the mixed layer are partially mixed until the gradient Richardson number criterion is achieved. This creates a smooth transition of temperature below the mixed layer. Since the velocity profile is critical to calculating the gradient Richardson number, the model also calculates and conserves momentum, and requires a 
high-resolution grid ( $0.5 \mathrm{~m}$ vertical resolution is used here) to resolve the small vertical scales over which the velocity shear can lead to instabilities. The addition of the physical process of mixing due to local shear-generated turbulence is the major difference between the PWP and KT models.

\subsubsection{KPP model}

The K-profile parameterization [Large et al., 1994] represents unresolved vertical fluxes through profiles of turbulent dissipation, divided by an oceanic boundary layer depth $h$. For a prognostic variable $x$, the turbulent dissipation is parameterized as

$$
\overline{w^{\prime} x^{\prime}}(z)= \begin{cases}-K_{x}(z)\left(x_{z}-\gamma_{x}\right), & -z \leq h \\ -v_{x}(z) x_{z}, & -z>h\end{cases}
$$

where the profiles $K_{x}$ and $v_{x}$ are eddy coefficients for downgradient turbulent diffusion in the boundary layer and the interior. A nonlocal turbulent transport in the boundary layer is given by $\gamma_{x}$, and is active in convective forcing conditions, acting only on the temperature and salinity (again optional and ignored) fields. The boundary layer depth $h$ can be different from the mixed, or isothermal, layer depth, and is defined as the minimum depth where a bulk Richardson number exceeds a critical value of 0.3 (full details are found in Large et al. [1994]). The profile of diffusivity within the boundary layer, $K_{x}$, is parameterized as the product of a depth-dependent turbulent velocity scale and a vertical shape function, with a matching function to smooth the transition at the boundary $h$. The sub-boundary layer vertical mixing $v_{x}$ is the superposition of local Richardson number instability due to resolved vertical shear (much like the PWP model) and mixing due to unresolved internalwave shear, which has a constant value. The optional double-diffusive mixing is not used here.

The KPP model generates more sub-mixed layer mixing than the PWP model, with the addition of a penetrative convective flux (with $h$ often larger than the mixed layer 
depth), a different profile of local shear-generated mixing, and a background internalwave shear mixing. It can also be run on a much coarser vertical grid than the PWP model, though it will then not resolve the vertical shear structure well. To afford a direct comparison with the PWP model, the KPP model was likewise run on a $0.5 \mathrm{~m}$ vertical resolution grid.

\subsection{The effect of the diurnal cycle under idealized wind and heat forcing}

The surface forcing conditions over the Arabian Sea span a wide variety of conditions. Periods of strong heating accompanied by very strong winds are prevalent during the SW monsoon. Weak to moderate winds and moderate to strong cooling are found during the NE monsoon. Weak winds and strong heating are found during the intermonsoon seasons.

In order to better understand the response of each of the upper ocean models to this wide variety of surface forcing, an idealized experiment spanning this parameter space was devised. Each model was run under a number of different surface forcings in series of twin runs, one model run with a diurnal cycle in the surface flux, one without. In each twin series the net model surface heat flux was identical, as was the constant wind stress forcing. At the end of the model run (two months, to simulate the sustained forcing of the monsoon seasons), the predictions of surface temperature were compared. The initial profile, a constant temperature $30 \mathrm{~m}$ deep mixed layer topping an exponential temperature profile (fitted to the annual mean temperature profile at the moored array), and a close approximation for the layered model, was everywhere the same.

This exploration of parameter space is shown in Fig. 4.1. The horizontal axis represents the daily mean net surface heat flux, the vertical axis the strength of the constant wind forcing. The contours show the difference of the diurnally-forced model SST minus the mean-forced model SST, with each twin model integration in the parameter space marked by a dot. The most striking feature is the large difference in the model responses, 


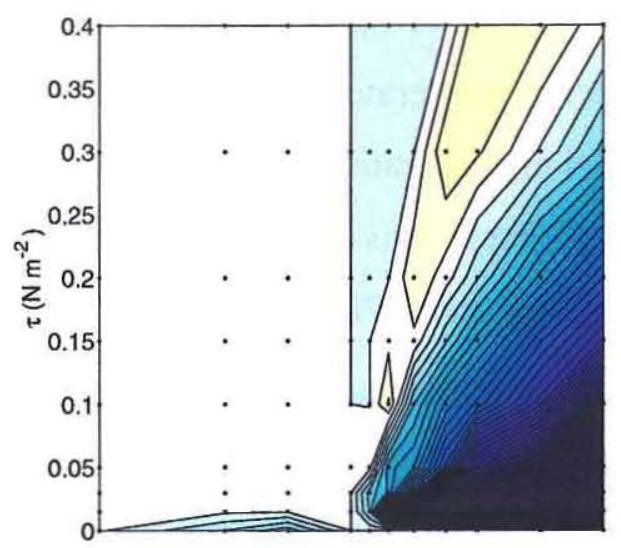

KT

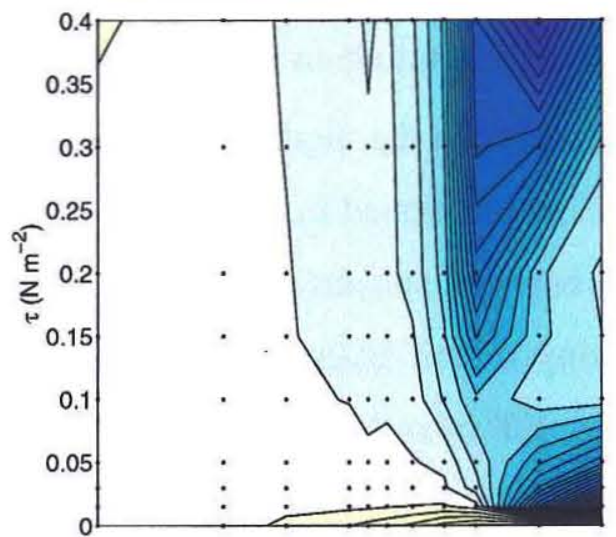

PWP

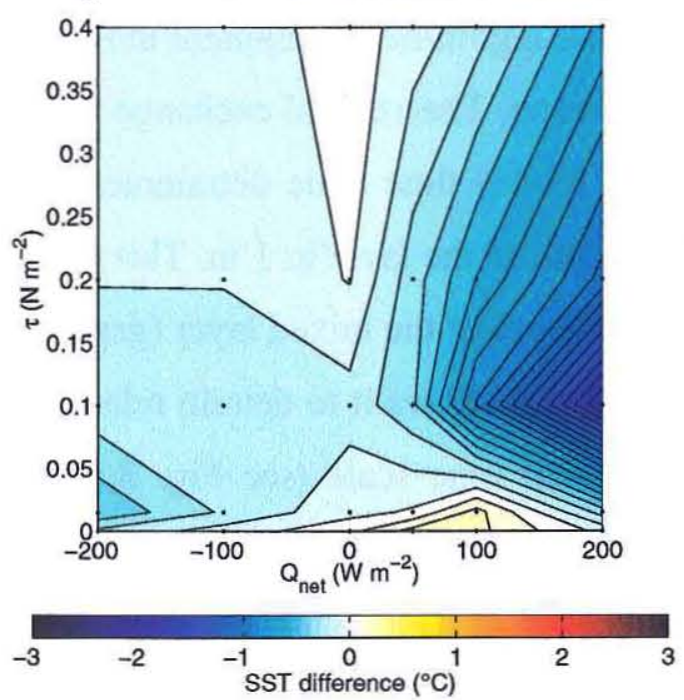

KPP

Figure 4.1 The difference between diurnally-forced and mean-forced model runs, for the one-dimensional version of the McCreary/KT bulk mixed layer model (a), the PWP model (b), and the KPP model (c), for twin experiments run in with constant wind and daily mean heat forcing as indicated. The largest differences, a cooler prediction of SST in the diurnally-forced case, always comes in mean heating conditions. 
with the maximum difference in the KT model coming at high positive heat fluxes and low winds, in the PWP model at moderately positive heat flux and the strongest wind stresses, and in the KPP model at moderate wind stresses and the strongest positive heat fluxes. The magnitude of the differences is also much stronger (more than double) in the KT model as compared to the PWP and KPP models.

One general point in which all three models agree is that the biggest difference due to diurnal cycling in the heat flux comes under the influence of positive (oceanic heating) surface heat fluxes. The difference under heat losses is virtually negligible in the KT and PWP models, and of quite a small magnitude in the KPP model.

What are the mechanisms active in the models that lead to the difference under diurnal cycling? In the KT model, as mentioned in Chapter 3, the difference comes from the formulation of the exchanges between subsurface layers, influenced by the rapid vertical motion of the diurnally varying mixed layer. In brief, the vertical velocity across the mixed layer interface is set by KT mixed layer physics. The diurnal thermocline layer, layer 2, exists below the mixed layer to separate daytime detrained water from the mixed layer from layers below, so that nighttime entrainment into the mixed layer first encounters the previously detrained water. The vertical exchange across the diurnal thermocline layer base is controlled by a 15-day time scale detrainment (see equation (3.16)) and a term limiting the minimum depth of the layer to $1 \mathrm{~m}$. This combination keeps the diurnal thermocline layer close to the depth of the mixed layer (generally achieving its $1 \mathrm{~m}$ minimum height during the night), and allows it to detrain relatively rapidly when the mixed layer shoals on the intraseasonal time scale (see Fig. 3.52). But what this introduces under strong diurnal cycling of the mixed layer depth is a small nightly exchange back and forth with layer 3. During the daytime when the layer 1 depth is minimized, layer 2 detrains slightly, giving up some water to layer 3 . At night when the layer 1 depth is at its maximum, layer 2 is often forced to entrain water from layer 3 to maintain its minimum depth, entraining what it has detrained during the day and perhaps more. But due to the discrete layer formulation, what it has detrained during the day is evenly mixed into layer 3 , and so not exactly what layer 2 entrains again at night. In this way, the diurnal cycling 


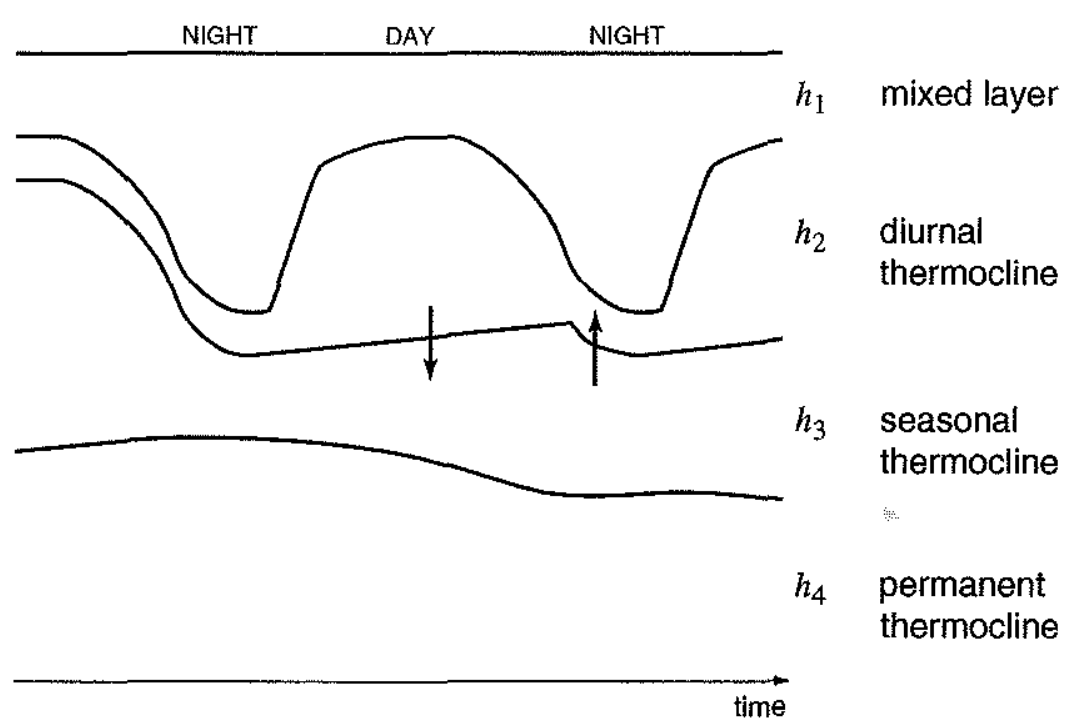

Figure 4.2 Schematic of the exchanges (arrows) forced across the diurnal-seasonal thermocline layer interface by the diurnal cycle in the KT/layered model formulation.

creates small pulses of sub-mixed layer mixing through to the depth of layer 3. It is therefore an artificial and 'accidental' parameterization of sub-mixed layer mixing, not grounded in any physical turbulence processes. McCreary et al. [2000] dubbed this process 'diurnal pumping'.

The PWP model, with fixed vertical layers, does not have such an artificially-driven exchange. The difference introduced by the diurnal cycling and the reason for the increase in vertical mixing is due to the changed vertical current structure brought by the diurnal cycling. With diurnal cycling, momentum input from the wind during the day, when the mixed layer is shallow, is trapped to the depth of the mixed layer. At the onset of convection at night, the momentum is mixed downwards, often quite suddenly to the depth of the previous night's mixed layer. This can provide diurnal pulses of enhanced localized vertical shear, which drive additional episodic vertical mixing. In net cooling conditions, the important mixing criterion is the static stability, which has no dependence on velocity, which is why there is little difference under net cooling conditions. 
The KPP model, with its gradient Richardson number dependent mixing, has a somewhat similar mode of response as the PWP model, though local shear-driven mixing is only one of the mixing mechanisms in the model. Diurnal cycling brings about diurnal changes in the boundary layer depth, and therefore vertical movement in the mixing profile in the model. The net effect is an increase in the sub-mixed layer mixing, which acts to cool the mixed layer. This process is active in net heating or cooling conditions, and accounts for the fact that diurnal cycling in the KPP model appears to cool (slightly) even in net cooling conditions. As in the PWP model, the local shear generation of mixing is only important in net heating conditions.

\subsection{Variations in latitude}

The models in Section 4.3 were run at the latitude of $15.5^{\circ} \mathrm{N}$, although this has no relevance to the physics of the KT model. In the PWP and KPP models, the profile of vertical velocity shear is important in the parameterization of the mixing, and so the latitude, affecting the turning of freely-evolving velocities, has the potential to be important. The inertial period at $15.5^{\circ} \mathrm{N}$ is 44 hours, and at $30^{\circ} \mathrm{N}$ it is in resonance with the diurnal cycle at 24 hours.

To examine whether such a resonance between the diurnal and inertial periods might affect the mixed layer evolution, and whether there is relationship between vertical mixing, the latitude, and diurnal cycling, another series of twin experiments were conducted with the PWP and KPP models, varying just the latitude. A constant wind stress of $\tau=$ $0.2 \mathrm{~N} \mathrm{~m}^{-2}$ and a daily mean net surface heat flux of $Q_{\text {net }}=100 \mathrm{~W} \mathrm{~m}^{-2}$, which produced moderate cooling due to diurnal forcing in both the PWP and KPP models, were used. The initial profile was the same as in the previous experiments, as was the integration time of two months.

The differences under diurnal cycling are shown in Fig. 4.3 and Fig. 4.4. The PWP model is most affected by the resonance at $30^{\circ} \mathrm{N}$, with a difference due to the addition of diurnal cycling of over $2.5^{\circ} \mathrm{C}$ after two months. The nightly pulse of shear delivered to 

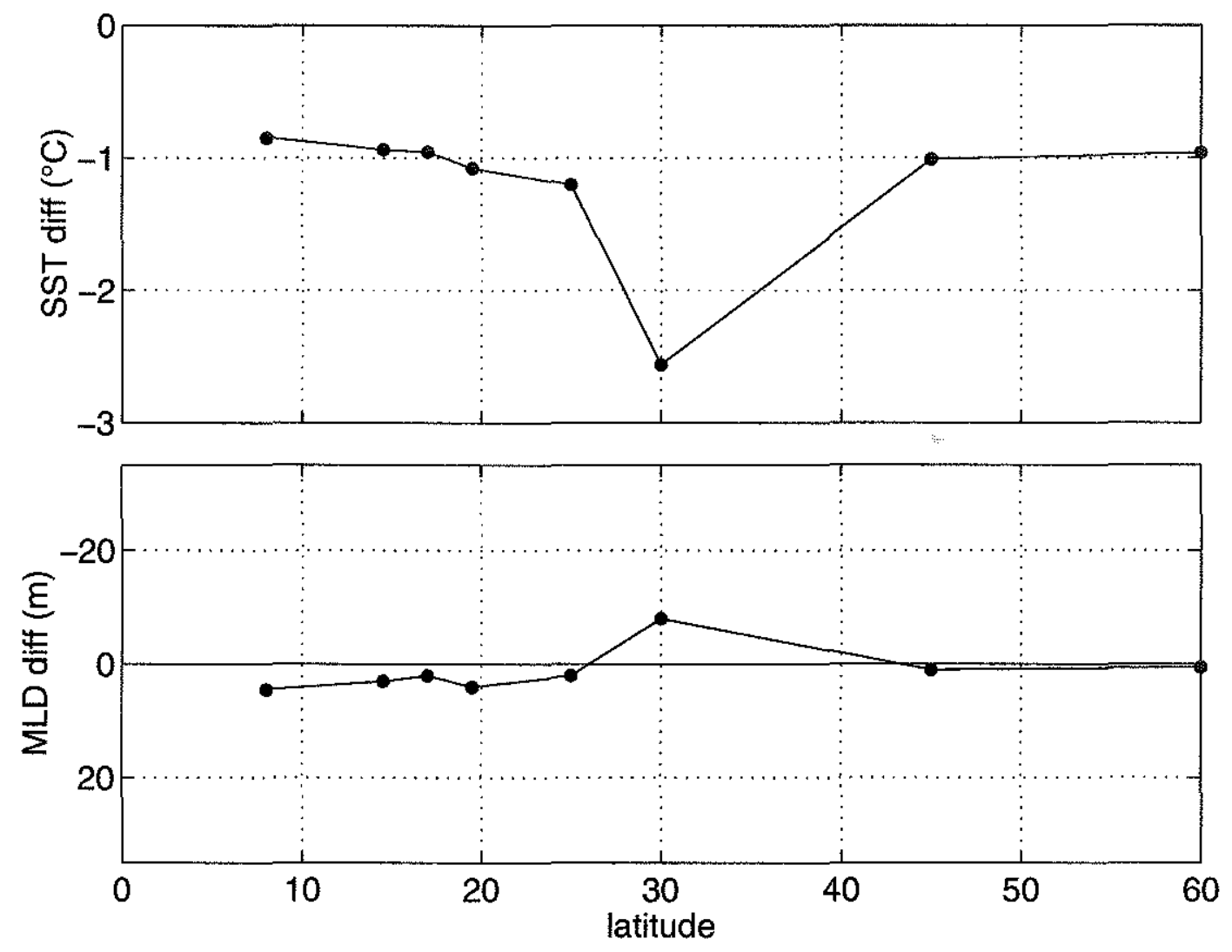

Figure 4.3 The PWP model response with latitude. Difference between diurnallyforced and mean-forced model runs with fixed surface forcing $\tau=0.2 \mathrm{~N} \mathrm{~m}^{-2}$ and a daily mean heat flux of $100 \mathrm{~W} \mathrm{~m}^{-2}$.

the base of the mixed layer greatly increases the mixing underneath the mixed layer, in the region where the gradient Richardson number criterion mixing is most active. Only a very mild effect of the changing inertial period is seen on either side of the resonance point.

The KPP model has a milder response to changing latitude. The largest difference is seen at $30^{\circ} \mathrm{N}$, but the increase in the difference as the latitude approaches on both sides of $30^{\circ} \mathrm{N}$ is broader than what was seen in the PWP model. This reflects the fact that though the KPP model has a similar gradient Richardson number mixing criterion as the PWP model, it does not act over as focused a distance below the mixed layer, and is supplemented by other mixing processes. 

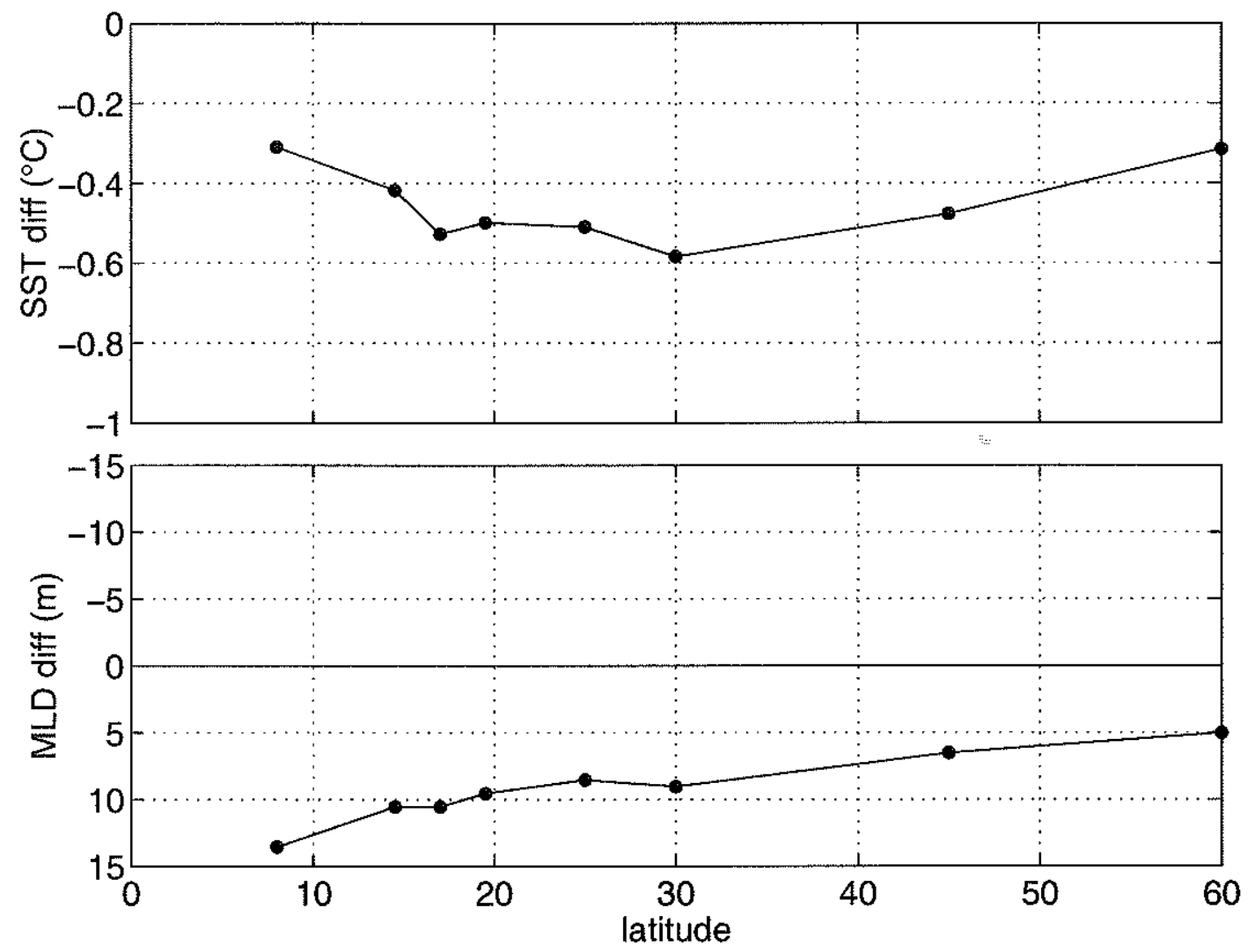

Figure 4.4 The KPP model response with latitude. Difference between diurnallyforced and mean-forced model runs with fixed surface forcing $\tau=0.2 \mathrm{~N} \mathrm{~m}^{-2}$ and a daily mean heat flux of $100 \mathrm{~W} \mathrm{~m}^{-2}$.

\subsection{Seasonal cycle}

The idealized experiments discussed in the two previous sections subjected the models to two sustained months of surface forcing, to get beyond transients in the response. While during the SW monsoon there are two sustained months of fairly strong wind forcing and strong heat forcing, the conditions are not very representative of the true observed oceanic forcing. Will the model results made under idealized conditions hold up in real-world conditions?

The distribution of daily averaged surface forcing observed at the moored array is shown in the same parameter space as Fig. 4.1 in Fig. 4.5. The majority of the forcing 


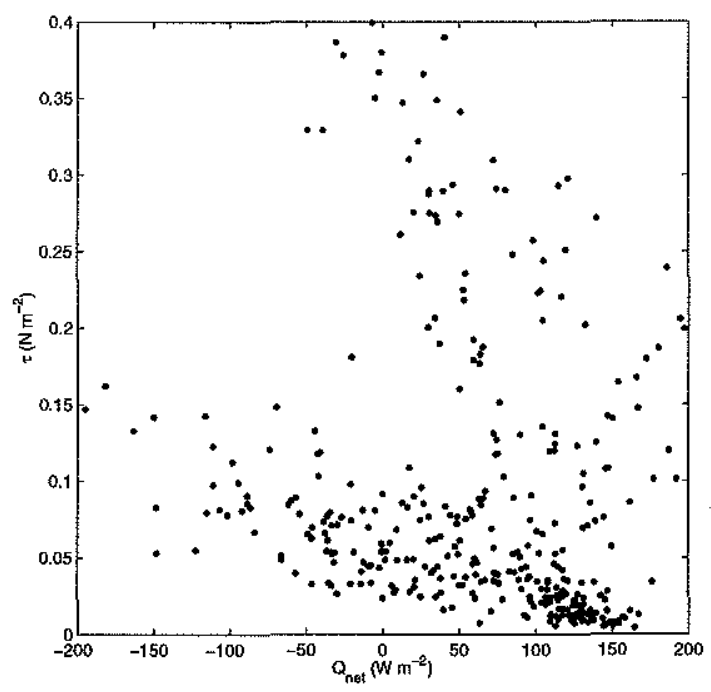

Figure 4.5 The distribution of the daily average surface heat and momentum flux forcing from the Arabian Sea mooring, in the same parameter space as Fig. 4.1. During the NE monsoon there a surface heat loss accompanied by moderately elevated winds. During the SW monsoon there are moderate to strong surface heat gains accompanied by strong wind stresses. And the two intermonsoon seasons contribute significant periods of time with low winds and a strong surface heat gain.

comes during net heating conditions, the exception being during the NE monsoon, when net surface losses are accompanied by mildly elevated wind stresses. The SW monsoon contributes a large scatter of forcing with positive heat fluxes and strong wind stresses, while the intermonsoon seasons contribute a large concentration of days with fairly high surface heat fluxes and low winds. The model responses over this distribution of surface forcing do vary from each other quite a bit (Fig. 4.1).

The experiment with the PWP model in the beginning of Chapter 3 (Section 3.1.2.1) was repeated with the KT and KPP models, and the model integrations are shown in Fig. 4.6 and Fig. 4.7. All of the models suffer from the lack of horizontal advection when compared to the observed SST evolution. In line with expectations from the idealized experiments in Section 4.3, diurnal cycling in the KT model creates a very large difference in the prediction of the SST, with the final SST more than $5^{\circ} \mathrm{C}$ cooler over the base case after the one-year integration. The addition of high frequency wind to the diurnal 


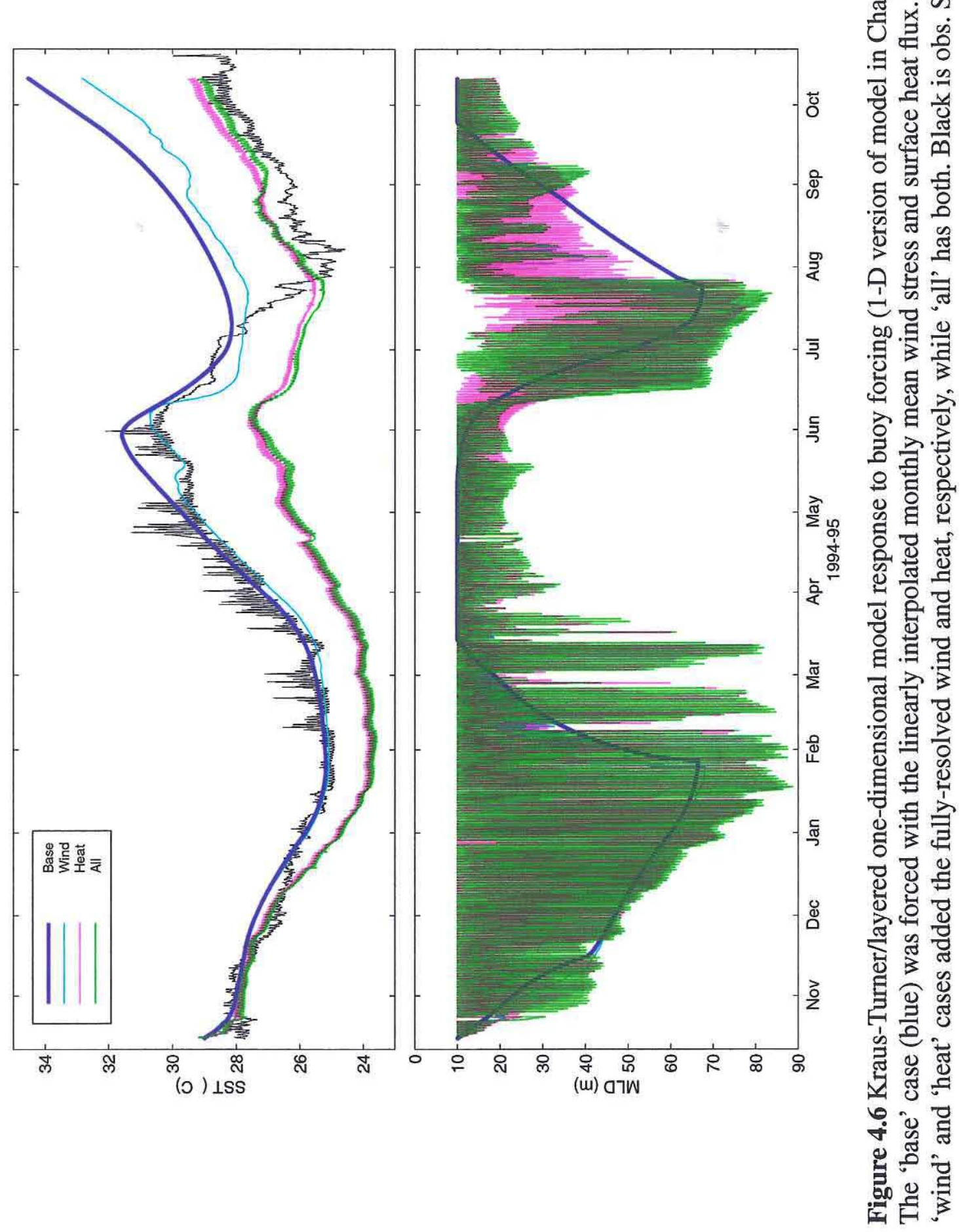



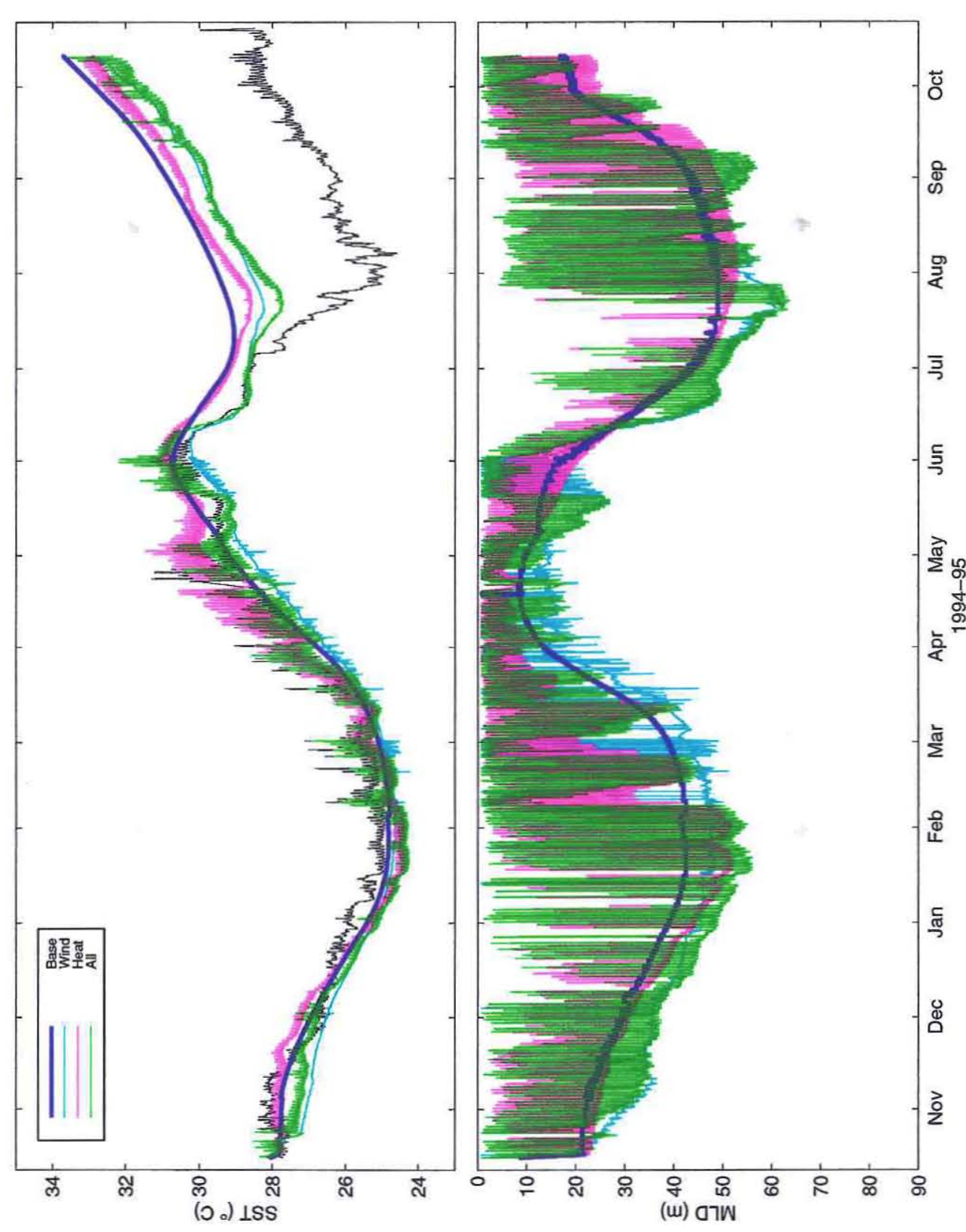

चิ

,

(

क

8

\&

亏 这

.

5

त.

立

눈

ฆ ङ

\&

듀

(

.

की

ì

离 
heat cycle further drops the final SST prediction slightly. The drop induced by the highfrequency wind forcing alone is more in line with that seen in the PWP model (see Fig. 3.2).

The KPP model response in SST under the different surface forcings is reduced in amplitude from the PWP model, but remarkably similar in character, despite the differences seen in Section 4.3. The addition of the fully-resolved heat flux (with diurnal cycling, magenta line in Fig. 4.7) raises the SST prediction during the spring intermonsoon, and reduces it during the $\mathrm{SW}$ monsoon, to about $0.5^{\circ} \mathrm{C}$ cooler than the base case. The addition of just the fully-resolved wind forcing (cyan line) lowers the SST prediction during the spring intermonsoon, and through the SW monsoon, to a final value of just over $1{ }^{\circ} \mathrm{C}$ cooler after the year of integration. The addition of both the high-frequency wind and heat forcing (green line) drops the final SST slightly further, to about $1.3^{\circ} \mathrm{C}$, less than the $1.8^{\circ} \mathrm{C}$ difference seen in the PWP model.

\subsection{Discussion}

The diurnal cycle, in three different models of the mixed layer and upper ocean, causes differences in predictions of the sea surface temperature. This difference is extremely sensitive to the model, and to its parameterizations of the relevant physical processes.

The bulk KT model incorporated into the three-dimensional model used in Chapter 3 is the most sensitive to diurnal forcing, particularly in low-wind, high heating conditions. All of the models showed little influence of the diurnal cycle on SST under net cooling conditions. Ironically the bulk model was constructed with the addition of the diurnal thermocline layer to minimize this 'diurnal pumping' process, and other mixed layer models that depend on a bulk representation of the mixed layer, (including for example Niiler and Kraus [1977], Chen et al. [1994]) will have similar problems when coupled to a layered model. The two models with higher vertical resolution and representations of additional mixing processes were much less sensitive, though they also displayed differ- 
ences due to diurnal cycling under net heating conditions, with significant differences in sensitivity from each other.

While the increase in vertical mixing brought by the diurnal cycle in the KT model was due to an 'accidental parameterization' peculiar to the model formulation, the differences in the PWP and KPP models occurred for more physically convincing reasons. The largest differences were caused by differences in the vertical shear structure of the velocity profiles brought by diurnal cycling, and therefore differences in the generation of turbulence and mixing (as parameterized by the gradient Richardson number mixing). The difference was maximized in both the PWP and KPP models at latitude where the diurnal and inertial periods are in resonance.

The KPP model is typically run at far lower resolutions when incorporated into 3-D models, and it is not clear that this would retain enough resolution of the vertical velocity shear to involve the gradient Richardson number. The response is likely to be dependent on the vertical grid resolution, as is that of the PWP model.

One unfortunate but important lesson from the experiments here is that the changes in the evolution of the 3-D model in Chapter 3 under the influence of the diurnal cycle are overstated, and should not be considered robust. On the positive side, the KT model response to high-frequency wind forcing through a seasonal cycle was similar to the PWP and KPP models, giving some confidence that the results in Chapter 3 pertaining to wind forcing are more robust.

This question of increased vertical exchange below the mixed layer is of importance to the vertical distribution of temperature, but it is particularly crucial in the vertical distribution of quantities with a much sharper vertical gradient across the mixed layer base, typical of surface-depleted nutrients. The mixed layer depth and its time evolution are also important to the response of light-sensitive biological processes. Thus an improved understanding of sub-mixed layer mixing and the diurnal cycle is of particular importance to coupled biological-physical modeling. 


\section{Chapter 5}

\section{Conclusion}

The parts of this thesis are bound together by a very broad question: what processes are important in the upper ocean evolution and response to the monsoon in the Arabian Sea? Such a broad question of course spawned a number of further refining questions and approaches to address them, and two major questions have been tackled here.

The first is: what are the important processes in the upper ocean heat balance, and what breaks it from being one-dimensional?

The Forced Upper Ocean Dynamics experiment yielded the first high-quality record of concurrent atmospheric forcing and upper ocean response from the Arabian Sea during a full monsoonal cycle. The data from the moored array were used to estimate the terms in the upper ocean heat budget. A one-dimensional balance between the heat input of the net surface heat flux and the upper ocean heat content, integrated to a fixed depth, had periods of reasonable balance during the latter part of the NE monsoon, through the spring intermonsoon, and into the early SW monsoon, as well as during the fall intermonsoon. Where this one-dimensional balance broke down, early in the NE monsoon and through the latter part of the SW monsoon, an estimate of the horizontal advective terms in the heat budget showed a rough balance between the temperature trend and the horizontal heat flux. Estimates of the residual vertical velocity were consistent with other 
estimates in the vicinity of mesoscale features, and were much stronger than wind-forced Ekman pumping velocities. During the NE monsoon this horizontal heat flux was confined to below the mixed layer, while during the SW monsoon the mixed layer as well as the upper thermocline were cooled by a horizontal heat flux.

A number of other sources of data were used to help isolate the physical processes responsible for the strong horizontal fluxes observed at the moored array. During the NE monsoon, a linked cyclonic/anticyclonic eddy pair, formed during the previous SW monsoon, passed through the site of the array, dramatically changing the thermocline depth with their passing but having a smaller influence on the sea surface temperature. During the SW monsoon, a filament extending from the Omani coast $600 \mathrm{~km}$ away and captured by altimetry, SST imagery, and a SeaSoar survey, transported recently coastally-upwelled water to the moored array.

Elevated levels of mean eddy kinetic energy (calculated from altimetry) along the Arabian coast, particularly intensified during the SW monsoon, suggest that this observed filament is not an isolated feature, but one that occurs with some regularity, and that offshore transport of coastally-upwelled water in these filaments during the SW monsoon is an important process in the overall heat budget of the Arabian Sea. Also, since the NE monsoon eddies did not bring significant gradients of temperature in the mixed layer, the SST responded mostly to surface-driven entrainment, and a one-dimensional model could predict the SST evolution reasonably well. The filament transport during the SW monsoon, on the other hand, brought significant horizontal fluxes of heat within the mixed layer, and so was very important for SST prediction. Beyond importance in the heat budget, the mesoscale features appeared to have some correlation with biological productivity measured in the vicinity of the moored array.

The second major question addressed was: what is the net effect of high-frequency wind and heat forcing on the vertical structure of the upper ocean, and how does this combine with horizontally non-homogeneous processes in a three-dimensional model?

The record at the moored array included a large amount of high-frequency variability in the surface forcing, and in the oceanic response, with dramatic diurnal cycling in the 
mixed layer depth during the NE monsoon and atmospheric synoptic time scale variability in the wind stress and oceanic response. Inspired by experiments with a one-dimensional model which suggested that both high-frequency wind forcing and the diurnal cycle in heating increased vertical mixing and reduced predictions of SSTs, I used a regional model of the Arabian Sea and Indian Ocean to look at how these one-dimensional effects of the surface forcing would resolve themselves when combined with the horizontal flows in a three-dimensional model. The high frequency wind forcing was expected to increase vertical mixing since more turbulent energy is available over a monthly mean wind. The diurnal cycle was expected to increase vertical mixing below the mixed layer, thus affecting its evolution.

The high-frequency surface forcing did create significant differences in predictions of SST and upper layer heat content, as well as changes in the circulation. The largest amplitude changes took place on seasonal time scales rather than on the annual average. While in many cases the high-frequency forcing did provoke additional vertical mixing and therefore cooler SSTs, during the NE monsoon at low latitudes, the reaction to the local surface forcing combined with changed remotely propagated forcing (damped by the increased vertical mixing) worked to decrease upwelling into the surface layer an yielded warmer SSTs with diurnal cycling.

The changes in vertical exchanges did not change the meridional heat transport, which was carried in the wind-driven circulation. With decreased SSTs, the model developed stronger surface fluxes, and this additional heat built up in the Arabian Sea, as the imbalance between the surface heat gain and the oceanic southward transport grew further.

This work then spawned some other questions: what processes caused the difference due to diurnal cycling? and how sensitive are these differences to the model used?

To answer these questions three different one-dimensional mixed layer models (one being a simplification of the three-dimensional model's Kraus-Turner (KT) mixed layer structure) were run under idealized and typical seasonal conditions for the Arabian Sea, focusing on what effect the diurnal cycle had on vertical mixing and upper ocean predic- 
tions. Each model responded differently, with the KT model the most sensitive to the addition of the diurnal cycle. Each model also responded to the diurnal cycle for somewhat different reasons, with the difference in the KT model driven by an 'accidental' parameterization of the exchange processes between layers. The less sensitive response of the PWP and KPP models was primarily due to changed profiles of vertical velocity with the addition of the diurnal cycle, and thus changed locally shear-driven mixing.

The unfortunate conclusion is that the differences seen in the three-dimensional model under diurnal cycling are overstated. However the KT model representation of the response to high-frequency wind forcing was more in line with the other two models under the seasonal cycle of forcing at the moored array. The differences seen in the threedimensional model due to the high frequency wind, including the increase in vertical exchange and mixing, the clearer formation of the double-gyre SG/GW system, and the reduction in the amplitude of the near-equatorial Indian coastal upwelling propagating Rossby wave, are then more robust than the differences seen under diurnal cycling.

The question of how sub-mixed layer mixing, driven particularly by the diurnal cycle, should be best represented is certainly an open one, and one particularly important to studies of coupled biological-physical processes. It is also clear that many models, which have bulk representations of the mixed layer, are not ready to accept diurnal cycling in the heat flux, since this produces artifacts of mixing that cannot be expected in reality. Even the response of the KPP model, run here at an $0.5 \mathrm{~m}$ vertical resolution but typically run at $5 \mathrm{~m}$ or lower resolution, may be dependent on its vertical resolution to properly capture the shear processes. Would the model remain sensitive to the diurnal cycle at a lower resolution? Is there some simple way to parameterize the effect of the diurnal cycle by increasing vertical mixing in low wind, high heat flux conditions? Or to parameterize the effect of high-frequency wind forcing, which appears to similarly increase the vertical mixing?

There are questions raised as well by the first part of the thesis, involving the role of mesoscale eddies in the upper ocean heat budget. The heat budget was calculated for a moored site in the central Arabian Sea, but how important is the eddy field in transport- 
ing heat in the rest of the basin? Is the offshore transport of upwelled water during the SW monsoon by filaments a significant portion of the basin heat and salt budgets? How strong is this compared to the upwelling and transport associated with the Somali current?

There were suggestions in the altimetry that the filament generation and offshore transport of coastally-upwelled water were dependent on the details of a mesoscale eddy field, which collides with the western boundary, horizontally entraining upwelled water. Because of the appearance of upwelled water during the SW monsoon on the western boundaries of the Arabian Sea, the analogy with the filaments and mesoscale features of the California Current system breaks down to some extent, depending on the origin of the mesoscale features that are found along the Arabian coast. It is possible that these eddies are locally generated from the coastal flow, though the other possibility is that they may have propagated westward from their generation elsewhere. The altimetry showed mildly elevated levels of EKE during the SW monsoon in the central basin, under the Findlater Jet, and traced the formation of the anticyclone eventually forming the southern limb of the observed 1995 filament to the same region. One possibility is that instabilities of accelerations under the Findlater Jet could generate eddies at the onset of the SW monsoon (K. Brink, personal communication). Yet another possibility is that the Socotra Gyre and the Somali Current extension (as I've dubbed it), which appear in the altimetry to be irregularly repeating features, are the generating feature in this region. During the $\mathrm{NE}$ monsoon the eddies moving past the moored array could be traced back to the 1994 SW monsoon, appearing east of the Socotra Gyre in what appeared to be an eastward extension of the Somali coastal current.

The dynamics of this complex system certainly warrant further investigation.

The processes involved in the upper ocean heat budget, and the role of high-frequency forcing in modeling the Arabian Sea response to the monsoon are important in understanding the sea surface temperature and heat content evolution of the Arabian Sea. These processes are important in transporting the annual mean heat gain over the Ara- 
bian Sea and northern Indian Ocean south across the equator, and may have feedbacks to the atmospheric evolution of the monsoons. 


\section{References}

Arnone, R.A., P. Martinolich, J. Kindle, K.H. Brink, and C. Lee, Filament structure along the Oman coast during the 1995 Monsoon, Eos, 77, F382 (abstract), 1996.

Bauer, S., G.L. Hitchcock, and D.B. Olson, Influence of monsoonally-forced Ekman dynamics upon surface layer depth and plankton biomass distribution in the Arabian Sea, Deep-Sea Research, 38 (5), 531-553, 1991.

Brink, K.H., and T.J. Cowles, The Coastal Transition Zone program, Journal of Geophysical Research 96, 14,637-14,647, 1991.

Brink, K., R. Arnone, P. Coble, C. Flagg, B. Jones, J. Kindle, C. Lee, D. Phinney, M. Wood, C. Yentsch, and D. Young, Monsoons boost biological productivity in Arabian Sea, Eos, 27 (13), 168-169, 1998.

Bruce, J.G., J.C. Kindle, L.H. Kantha, J.L. Kerling, and J.F. Bailey, Recent observations and modeling in the Arabian Sea Laccadive High region, Journal of Geophysical Research, 103 (C4), 7593-7600, 1998.

Chen, D., L.M. Rothstein, and A.J. Busalacchi, A hybrid vertical mixing scheme and its application to tropical ocean models, Journal of Physical Oceanography, 24 (10), 2156-2179, 1994.

Chen, D., W.T. Liu, S.E. Zebiak, M.A. Cane, Y. Kushnir, and D. Witter, Sensitivity of the tropical Pacific Ocean simulation to the temporal and spatial resolution of wind forcing, Journal of Geophysical Research, 104 (C5), 11,261-11,271, 1999.

Desai, S.D., and J.M. Wahr, Empirical ocean tide models estimated from TOPEX/Poseidon altimetry, Journal of Geophysical Research, 100, 25,205-25,228, 1995.

Dickey, T., J. Marra, D.E. Sigurdson, R.A. Weller, C.S. Kinkade, S.E. Zedler, J.D. Wiggert, and C. Langdon, Seasonal variability of bio-optical and physical properties in the Arabian Sea: October 1994 - October 1995, Deep-Sea Research II, 45, 20012025, 1998.

Eriksen, C.C., Dahlen, and Shillingford, An upper ocean moored current and density profiler applied to winter conditions near Bermuda, Journal of Geophysical 
Research, 87, 7879-7902, 1982.

Evans, R., and G. Podesta, AVHRR Pathfinder Oceans: Sea Surface Temperature Algorithm Version 4.0, Technical Report, Rosentiel School of Marine and Atmospheric Science, University of Miami, Miami, 1998.

Feng, M., P. Hacker, and R. Lukas, Upper ocean heat and salt balances in response to a westerly wind burst in the western equatorial Pacific during TOGA COARE, Journal of Geophysical Research, 103 (C5), 10,289-10,311, 1998.

Findlater, J., A major low-level air current near the Indian Ocean during the northern summer, Quarterly Journal of the Royal Meteorological Society, 95, 362-380, 1969.

Fischer, A.S., Arabian Sea mixed layer deepening during the monsoon: observations and dynamics, S.M. thesis, MIT/WHOI Joint Program in Oceanography, Cambridge and Woods Hole, MA, 1997.

Fischer, J., F. Schott, and L. Stramma, Currents and transports of the Great Whirl-Socotra Gyre system during the summer monsoon, August 1993, Journal of Geophysical Research, 101 (C2), 3573-3587, 1996.

Flagg, C.N., and H.-S. Kim, Upper ocean currents in the northern Arabian Sea from shipboard ADCP measurements collected during the 1994-1996 U.S. JGOFS and ONR programs, Deep-Sea Research II, 45, 1917-1959, 1998.

Fox, C.A., Estimation of mid-latitude Rossby waves using simple ocean model and Kalman filtering with TOPEX/POSEIDON altimeter data, Ph.D. thesis, University of Colorado, Boulder, CO, 1997.

Garternicht, U., and F. Schott, Heat fluxes of the Indian Ocean from a global eddyresolving model, Journal of Geophysical Research, 102 (C9), 1997.

Grima, N., A. Bentamy, K. Katsaros, Y. Quilfen, P. Delecluse, and C. Levy, Sensitivity of an oceanic general circulation model forced by satellite wind stress fields, Journal of Geophysical Research, 104 (C4), 7967-7989, 1999.

Han, W., Influence of salinity on dynamics, thermodynamics and mixed-layer physics in the Indian Ocean, Ph.D. thesis, Nova Southeastern University, Dania, FL, 1999.

Hastenrath, S., and L. Greischar, The monsoonal heat budget of the hydrosphereatmosphere system in the Indian Ocean sector, Journal of Geophysical Research, 98 (C4), 6869-6881, 1993.

Hendricks, J.R., R.R. Leben, G.H. Born, and C.J. Koblinsky, Empirical orthogonal function analysis of global TOPEX/POSEIDON altimeter data and implications for detection of global sea level rise, Journal of Geophysical Research, 101 (C6), 14,131$14,145,1996$.

Honjo, S., J. Dymond, W. Prell, and V. Ittekkot, Monsoon-controlled export fluxes to the interior of the Arabian Sea, Deep-Sea Research II, 46, 1859-1902, 1999. 
Jerlov, N.G., Marine Optics, 231 pp., Elsevier, 1976.

Josey, S.A., and D. Oakley, On estimating the atmospheric longwave flux at the ocean surface from ship meteorological reports, Journal of Geophysical Research, 102 (C13), 27,961-27,972, 1997.

Josey, S.A., E.C. Kent, and P.K. Taylor, New insights into the ocean heat budget closure problem from analysis of the SOC air-sea flux climatology, Journal of Climate, 12, 2856-2880, 1999.

Keen, T.R., J.C. Kindle, and D.K. Young, The interaction of southwest monsoon upwelling, advection and primary productivity in the northwest Arabian Sea, Journal of Marine Systems, 13, 61-82, 1997.

Knox, R.A., The Indian Ocean: interaction with the monsoon, in Monsoons, edited by J.S. Fein, and P.L. Stephens, pp. 3-32, John Wiley \& Sons, New York, 1987.

Kraus, E.B., and J.S. Turner, A one-dimensional model of the seasonal thermocline, II. The general theory and its consequences, Tellus, 19(1), 99-106, 1967.

Kraus, E.B., and J.A. Businger, Atmosphere-Ocean Interaction, 362 pp., Oxford University Press, New York, 1994.

Large, W.G., W.R. Holland, and J.C. Evans, Quasi-geostrophic ocean response to real wind forcing: the effects of temporal smoothing, Journal of Physical Oceanography, 21, 998-1017, 1991.

Large, W.G., J.C. McWilliams, and S.C. Doney, Oceanic vertical mixing: A review and a model with a nonlocal boundary layer parameterization, Reviews of Geophysics, 32 (4), 363-403, 1994.

Large, W.G., and P.R. Gent, Validation of vertical mixing in an equatorial ocean model using Large Eddy Simulations and observations, Journal of Physical Oceanography, 29, 449-464, 1999.

Lee, C.M., B.H. Jones, K.H. Brink, and A.S. Fischer, The upper ocean response to monsoonal forcing in the Arabian Sea: seasonal and spatial variability, Deep-Sea Research II, 47, 1177-1226, 2000.

Lee, T., and J. Marotzke, Inferring meridional mass and heat transports of the Indian Ocean by fitting a general circulation model to climatological data, Journal of Geophysical Research, 102 (C5), 10,585-10,602, 1997.

Lee, T., and J. Marotzke, Seasonal cycles of meridional overturning and heat transport of the Indian Ocean, Journal of Physical Oceanography, 28 (5), 923-943, 1998.

Legates, D.R., and C.J. Willmott, Mean seasonal and spatial variability in gauge-corrected global precipitation, International Journal of Climatology, 10 (2), 111-127, 1990.

Legler, D.M., I.M. Navon, and J.J. O'Brien, Objective analysis of pseudo-stress over the Indian Ocean using a direct-minimization approach, Monthly Weather Review, 117, 
709-720, 1989.

Lien, R.-C., D.R. Caldwell, M.C. Gregg, and J.N. Moum, Turbulence variability at the equator in the central Pacific at the beginning of the 1991-1993 El Niño, Journal of Geophysical Research, 100 (C4), 6881-6898, 1995.

Liu, W.T., W. Tang, and R. Atlas, Responses of the tropical Pacific to wind forcing as observed by spaceborne sensors and simulated by an ocean general circulation model, Journal of Geophysical Research, 101 (C7), 16,345-16,359, 1996.

Manghnani, V., J.M. Morrison, T.S. Hopkins, and E. Böhm, Advection of upwelled waters in the form of plumes off Oman during the Southwest Monsoon, Deep-Sea Research II, 45, 2027-2052, 1998.

McCreary, J.P., and P.K. Kundu, A numerical investigation of the Somali Current during the Southwest Monsoon, Journal of Marine Research, 46, 25-58, 1988.

McCreary, J.P., and P.K. Kundu, A numerical investigation of Sea Surface Temperature variability in the Arabian Sea, Journal of Geophysical Research, 94 (C11), 16,09716,114, 1989.

McCreary, J.P., P.K. Kundu, and R.L. Molinari, A numerical investigation of dynamics, thermodynamics and mixed-layer processes in the Indian Ocean, Progress in Oceanography, 31, 181-244, 1993.

McCreary, J.P., K.E. Kohler, R.R. Hood, S. Smith, J. Kindle, A.S. Fischer, and R.A. Weller, Influences of diurnal and intraseasonal forcing on mixed-layer and biological variability in the central Arabian Sea, Journal of Geophysical Research, 2000, submitted.

Morales, R.A., E.D. Barton, and K.J. Heywood, Variability of water masses in the western Indian Ocean, Journal of Geophysical Research, 101 (C6), 14,027-14,038, 1996.

Müller, T.J., and G. Siedler, Multi-year current time series in the eastern North Atlantic Ocean, Journal of Marine Research, 50, 63-98, 1992.

Murtugudde, R., A.J. Busalacchi, and J. Beauchamp, Seasonal-to-interannual effects of the Indonesian throughflow on the tropical Indo-Pacific Basin, Journal of Geophysical Research, 103, 21,425-21,441, 1998.

Niiler, P.P., and E.B. Kraus, One-dimensional models of the upper ocean, in Modelling and Prediction of the Upper Layers of the Ocean, edited by E.B. Kraus, pp. 143-177, Pergamon Press, 1977.

Palmer, T.N., and D.A. Mansfield, Response of two atmospheric general circulation models to sea-surface temperature anomalies in the tropical east and west Pacific, Nature, 310, 483-488, 1984.

Paulson, C.A., and J.J. Simpson, Irradiance measurements in the upper ocean, Journal of Physical Oceanography, 7, 952-956, 1977. 